\title{
EFFECT OF SHORT-TERM ESTROGEN DEPLETION ON COMPACT BONE MICRODENSITOMETRY IN THE EWE
}

\author{
A Thesis \\ presented to \\ the Faculty of California Polytechnic State University, \\ San Luis Obispo
}

\author{
In Partial Fulfillment \\ of the Requirements for the Degree \\ Master of Science in Biomedical Engineering
}

by

Cailyn Bugbee

November 2012 
(C) 2012

Cailyn Bugbee

ALL RIGHTS RESERVED 


\section{COMMITTEE MEMBERSHIP}

TITLE:

AUTHOR:

DATE SUBMITTED:

COMMITTEE CHAIR:

COMMITTEE MEMBER:

COMMITTEE MEMBER: Dr. Clifford Les

Cailyn Bugbee

November 2012
Effect of Short-Term Estrogen Depletion on Compact Bone Microdensitometry in the Ewe

Dr. Scott Hazelwood

Dr. Lanny Griffin 


\title{
ABSTRACT \\ EFFECT OF SHORT-TERM ESTROGEN DEPLETION ON COMPACT BONE MICRODENSITOMETRY IN THE EWE
}

\author{
Cailyn Bugbee
}

Osteoporosis affects the human skeleton through the direct effects of the disease on the function and structure of bone. Individuals who are affected by osteoporosis may be subject to serious fractures and it is estimated that annually approximately 1.5 million fractures can be attributed to this disease [1]. The disease is categorized as the direct side effect of increased bone porosity and bone loss and is directly linked to estrogen deprivation [2]. Animal models are often used to make initial conclusions about the effects of the disease or pharmacological treatments. In this study, sheep were chosen as a representative animal model due to their similar metabolic characteristics to that of a human. Like most animals, the ovine does not undergo a natural menopause and an ovariectomy was necessary to replicate the condition. The study objective was to quantify compact bone density present in ovine at three months post ovariectomy.

The study included 112 ovine separated into different treatment groups. The treatment groups were separated into 4 groups of 28 based on season of surgery: autumn, winter, spring, and summer. Each seasonal group was further divided into 2 groups of 14; the first group underwent an ovariectomy; and the second group underwent a sham surgery, in which the ovaries were visualized and handled but left in the abdomen. One group was sacrificed 3 months post operatively and the other group was sacrificed at 12 months post operatively. This study specifically looks at ewe sacrificed at 3 months. The radius from each sheep was cut into the anatomical sectors: cranial, caudal, craniolateral, craniomedial, caudomedial, and caudolateral. Each anatomical sector was turned into a 
microradiograph for analysis. Densitometry was performed to determine the density of each specimen using the estimated thickness of aluminum (ETA) as the key. Statistical analysis assessed the resulting data to understand the effects of treatment, season of sacrifice, season of surgery, and anatomical sector by comparing both mean ETA and standard deviation ETA to understand changes in bone density.

The results revealed significant differences between the ovariectomy and sham groups as well as variation within season of surgery and season of sacrifice in both groups. Anatomical sector showed no significant variation. The differences in the thickness of aluminum seen in the sheep that underwent a sham operation can be attributed to the presence of estrogen. The sheep that underwent an ovariectomy showed differences in the estimated thickness of aluminum that can be attributed to other seasonal characteristics including the influence of Vitamin D. The results and conclusions within this study can be used to influence bone material characteristics and bone loss test protocols in future osteoporosis and estrogen depletion studies.

Keywords: Estrogen Depletion, Bone Remodeling, Osteoporosis, Ovariectomy, OVX, Ewe 


\section{ACKNOWLEDGEMENTS}

I would like to thank Dr. Scott Hazelwood for giving me the opportunity to work and learn in his lab. Through this opportunity I have been able to learn and develop my skills. The project has allowed me to better understand what I would like to pursue post college as a career path. I would like to thank Dr. Clifford Les for providing me with the opportunity to complete this project. Your feedback and guidance have been helpful, without it I would not have finished in such a timely manner. I would also like to thank Erica Wong and Joe Calcagno for the assistance in the preliminary research and the initial development of the study. Thank you Erica for training me on the initial procedures. Finally, I would like to thank my friends and family for helping me through the whole process.

This project was supported by NIH-NIAMS AR 47434. 


\section{TABLE OF CONTENTS}

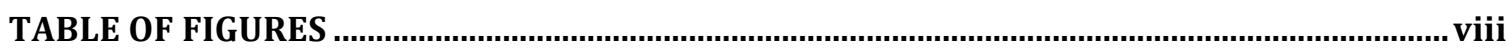

TABLE OF TABLES

1. INTRODUCTION

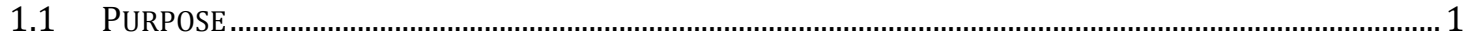

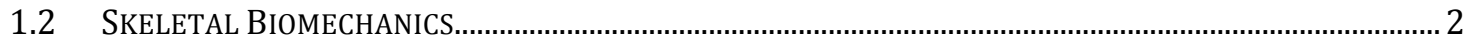

1.2.1 General Structure and Composition ………................................................................................ 2

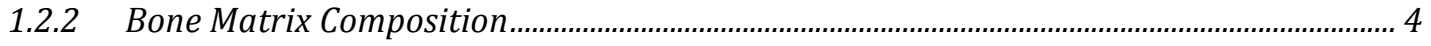

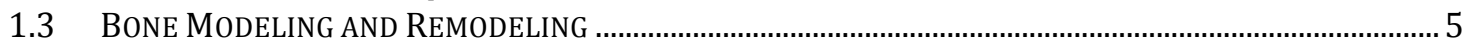

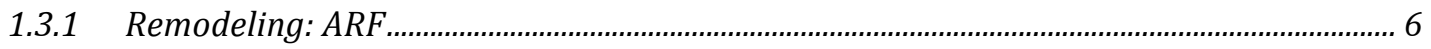

1.3.2 Cellular Events in Remodeling ............................................................................................... 7

1.3.3 Quantitative Analysis of Bone Remodeling ........................................................................ 9

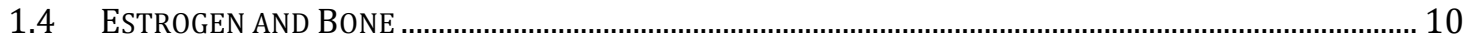

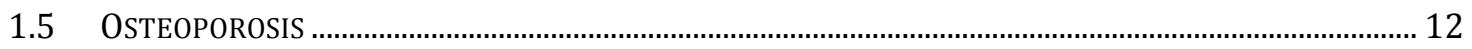

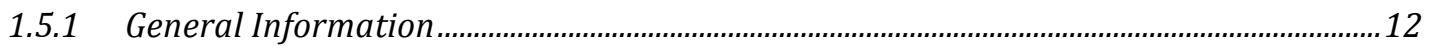

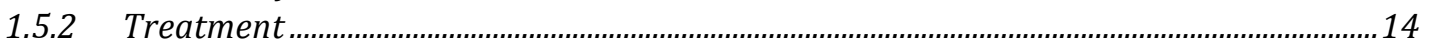

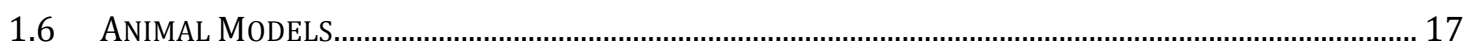

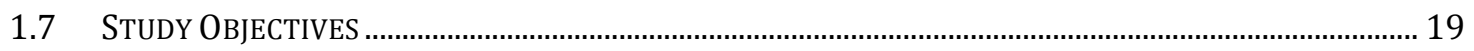

2. MATERIALS AND METHODS

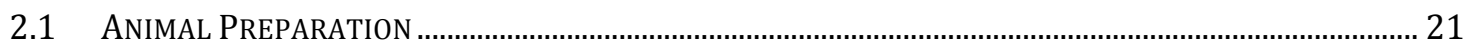

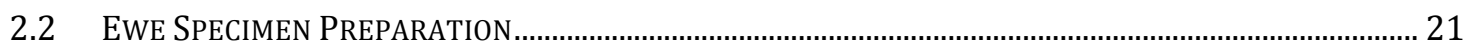

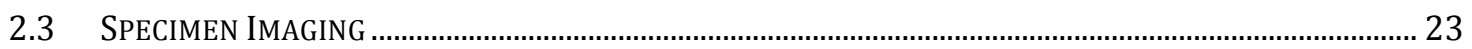

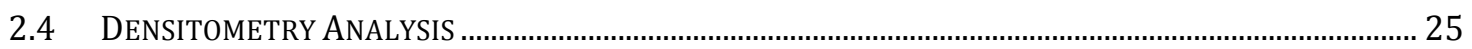

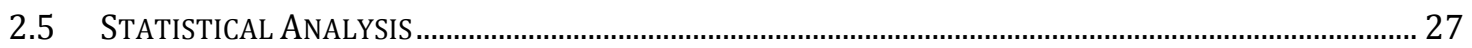

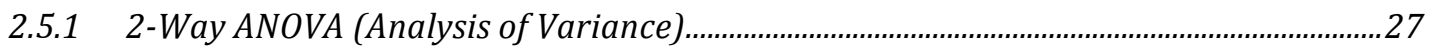

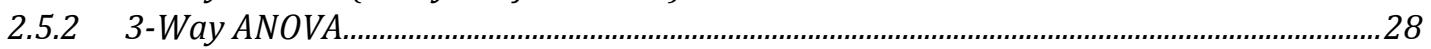

2.5.3 Frequency Distributions..............................................................................................................29

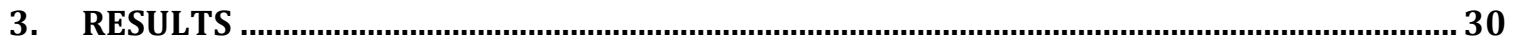

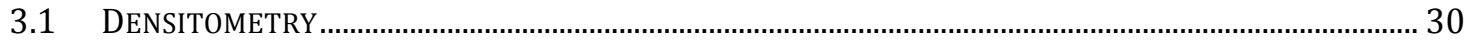

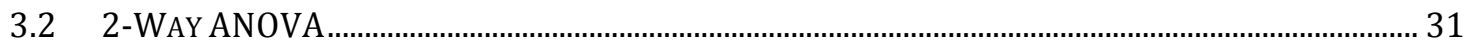

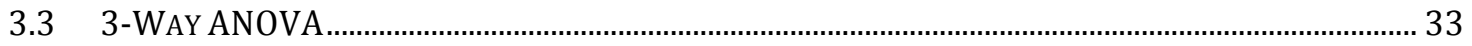

3.3.1 3-Way ANOVA: Season of Sacrifice ………....................................................................

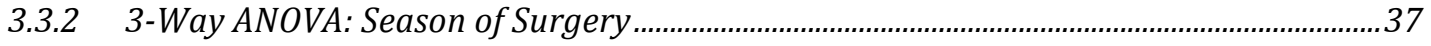

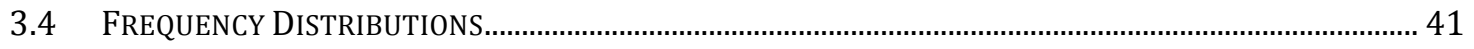

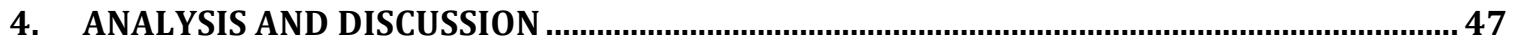

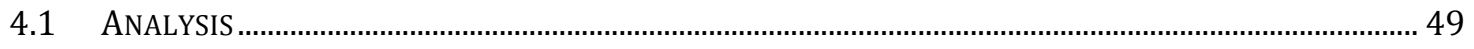

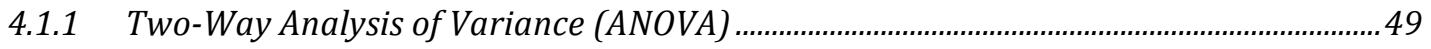

4.1.2 Three-Way ANOVA Sheep Reproductive Response Analysis ..................................................49

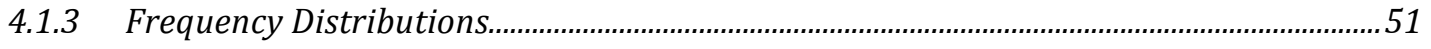

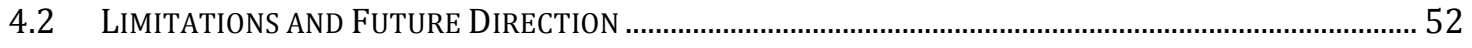

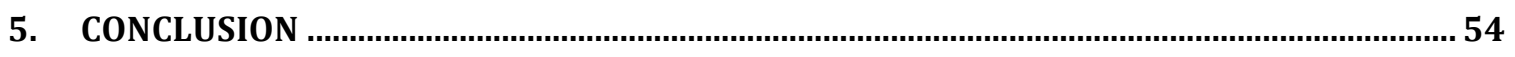

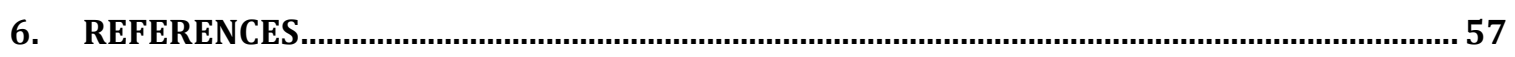

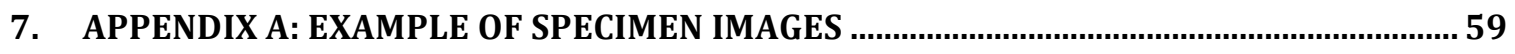

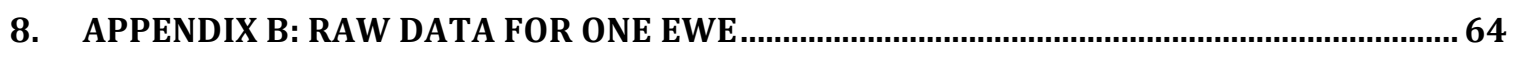

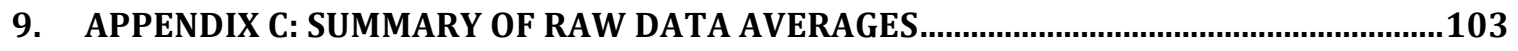




\section{TABLE OF FIGURES}

Figure 1 Key structures characteristic of an adult human long bone [5]........................ 3

Figure 2 The remodeling process in a adult human bone [9] ........................................ 6

Figure 3 The stages of bone remodeling, including the development of osteoclasts and osteoblasts. Factors listed in red are factors that have been confirmed or are being researched in clinical studies. Factors in green are potential factors

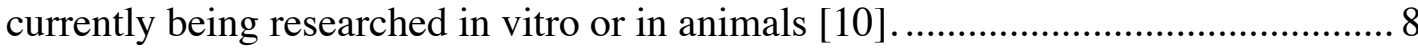

Figure 4 A breakdown of how estrogen influences the different types of bone cells $[8]$.

Figure 5 Left: An X-Ray of a healthy woman's pelvis [19], Right: An X-Ray of a woman diagnosed with osteoporosis post menopause [20]. Note the decrease in density in the bone from left to right.....

Figure 6 Average total hip bone mineral density levels at different ages. The graph is separated into normal, low, and osteoporotic levels demonstrated through shading [21].

Figure 7 A typical path a physian may take in patients in menopause or post menopause to determine the most appropriate course of action to prevent further decrease in BMD [21].

Figure 8 Fracture rates per 1000 people/year in elderly women. The dark bar demonstrates women treated with vitamin $\mathrm{D}$ and calcium and the light bar demonstrates women treated with a placebo [22].

Figure 9 Anatomical separation of the radius and ulna. The cranial sector is located in the upper right and the lateral sectors are located in the top left side of the figure [29].

Figure 10: Microradiograph setup. Ewe 1 is on the left and ewe 2 is on the right. Sectors begin at the top with cranial and end with the caudolateral section.

Figure 11: The break down of an anatomical sector imaged at 40x from a previous study [29]. Each of the 4 quadrants were imaged at 100x and analyzed in the current study

Figure 12: The stepwedge for ewe 93, an example of the aluminum stepwedge, showing the increase thickness. From left to right, top to bottom, the stepwedge demonstrates an increase from $0.0 \mathrm{~mm}$ to $0.02 \mathrm{~mm}, 0.04 \mathrm{~mm}, 0.06 \mathrm{~mm}$, $0.08 \mathrm{~mm}, 0.1 \mathrm{~mm}, 0.12 \mathrm{~mm}$ and $0.14 \mathrm{~mm}$.

Figure 13. A frequency curve distribution, which includes all ETA values for sheep sacrificed at 3 months, including OVX and control. The $\mathrm{x}$ axis contains bins 120 , additionally displaying the range of each bin. The mean of each bin can be seen in the table below the graph.

Figure 14. A frequency curve distribution including ETA values separated into OVX and control ewes, for ewes sacrificed at 3 months. The mean of each bin for OVX and control groups can be seen in the table below the graph. The bin distribution is equal to that seen in Figure 13.

Figure 15. A frequency distribution of the count of ETA in each bin group in each anatomical sector for all ewes sacrificed at 3 months. The mean of each bin can be seen in the table below the graph. The bin distribution is equal to that seen in Figure 13. 
Figure 16. Count of ETA for craniomedial sector separated by control and sham ewe, for ewe sacrificed at 3 months. The table below the graph shows the mean of each bin. The bin distribution is equal to that seen in Figure 13.

Figure 17. Count of ETA for cranial sector separated by control and sham ewe, for ewe sacrificed at 3 months. The table below the graph shows the mean of each bin. The bin distribution is equal to that seen in Figure 13 ................................. 44

Figure 18. Count of ETA for craniolateral sector separated by control and sham ewe, for ewe sacrificed at 3 months. The table below the graph shows the mean of each bin. The bin distribution is equal to that seen in Figure 13.

Figure 19. Count of ETA for caudomedial sector separated by control and sham ewe, for ewe sacrificed at 3 months. The table below the graph shows the mean of each bin. The bin distribution is equal to that seen in Figure 13.

Figure 20. Count of ETA for caudal sector separated by control and sham ewe, for ewe sacrificed at 3 months. The table below the graph shows the mean of each bin. The bin distribution is equal to that seen in Figure 13 ................................ 46

Figure 21. Count of ETA for caudolateral sector separated by control and sham ewe, for ewe sacrificed at 3 months. The table below the graph shows the mean of each bin. The bin distribution is equal to that seen in Figure 13 


\section{TABLE OF TABLES}

Table 1 Densitometry values (ETA) for sheep sacrificed at 3 months

Table 2 2-Way ANOVA statistical analysis results for the ewe sacrificed 3 months

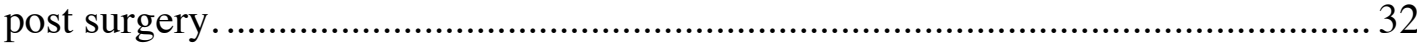

Table 3 Summary of Fisher LSD comparisons for the 2-Way ANOVA analysis of season within the control group of sheep sacrificed at 3 months .............................. 33

Table 4 3-Way ANOVA results, including season of sacrifice. Analysis performed at significance level of .05 .

Table 5 Summary of post hoc Fisher LSD Analysis for data containing season of sacrifice. Data table has been separated by mean ETA and standard deviation ETA

Table 6 3-Way ANOVA results based on season of surgery for the animals sacrificed at 3 months. Analysis was performed at significance level of .05 .......... 38

Table 7 Summary of post hoc Fisher LSD Analysis for data including season of surgery. Data table has been separated by mean ETA and standard deviation ETA. 


\section{INTRODUCTION}

\subsection{Purpose}

Osteoporosis greatly affects elderly postmenopausal women, and often men. The disease is categorized as the direct side effect of increased bone porosity and bone loss. Slowly osteoporosis has shown an even larger financial cost to society due to the increased life expectancy that comes with improved medical technology and research [2]. As the average life expectancy of women and men increases, the treatment of osteoporosis produces an increased cost to society due to medical costs. This cost totals approximately $\$ 5-10$ billion in healthcare with the potential to increase to an annual cost of $\$ 60$ billion in 30 years [1]. Individuals who are affected by osteoporosis may be subject to serious fractures, annually approximately 1.5 million fractures may be attributed to the disease [1]. From these fractures come further detriments to the body induced by the side effects of the fractures, including death, due to immobility causing blood clots. In elderly patients, the mortality rate 1 year after a hip fracture can be between $14.7 \%$ and $24.3 \%$ [3].

The condition itself was first understood in the mid 1940's but has only recently been well characterized when methods for accurate bone mass measurements were developed in the 1970's, but is still not well understood [1]. Research has been done in human epidemiology studies producing probabilities of lifetime risk of fracture as high as $16 \%$ for a 50 year old woman [1]. By studying the condition in the ovine with induced osteopenia and osteoporosis characteristics, knowledge of osteoporosis can be applied to the human condition. In this study, sheep have undergone an ovariectomy to induce estrogen depletion to further understand this condition. The goal is to differentiate bone 
architectural changes known to be characteristic of estrogen depletion from material changes that are independent of changes in porosity. This knowledge could aid in the development of possible treatments or prevention measures of osteoporosis.

\subsection{Skeletal Biomechanics}

Osteoporosis affects the skeleton through the direct effect of the disease on the function and structure of bone. The human skeleton includes 206 bones, each of which is composed of a similar structure. The human skeleton provides the protection and framework necessary to support the human body.

\subsubsection{General Structure and Composition}

The human skeletal system is a functional unit within the human body that provides support, protection, movement, electrolyte balance, acid-base balance, calcium storage, and blood formation. The system is composed of bone, cartilage, ligaments and tendons, each with its own specialized purpose to support the basic structure of the body. Bone acts as the basic structure of the human body, providing support, protection, bone marrow production and mineral storage, among other functions [4]. Cartilage acts as a separating cushion within diarthrodial joints preventing bone-to-bone contact and to provide nearly frictionless motion for our joints. Ligaments connect bone to bone and tendons act to connect muscle to bone. Ligaments and tendons allow for movement of the body and also prevent unwanted movement of the joints. Bone is composed of osseous tissue. Osseous tissue is the calcified tissue that provides bone with its hard structure and allows it to support the human frame [4].

There are several different types of bones in the human body: long bones, short bones, flat bones, and irregular bones. Examples of long bones include the tibia, femur, 
and phalanges, short bones include the capitate and talus, flat bones include the scapula and sternum, and irregular bones include vertebra and sphenoid. Long bones, including the femur, are generally longer than they are wide. They act as levers for which the ligaments and tendons are able to apply forces allowing the body to move as intended. The shape of the humerus, as seen in Figure 1, can be broken down into two specific areas, the epiphysis and diaphysis. The epiphysis is located at either end of the bone and provides a larger amount of surface area for ligaments and tendons to attach. The diaphysis is located down the shaft of the bone between the epiphyses. The epiphysis and diaphysis are separated by the epiphyseal line, the location of prenatal, postnatal, and adolescent growth, commonly known as the growth plate [4].

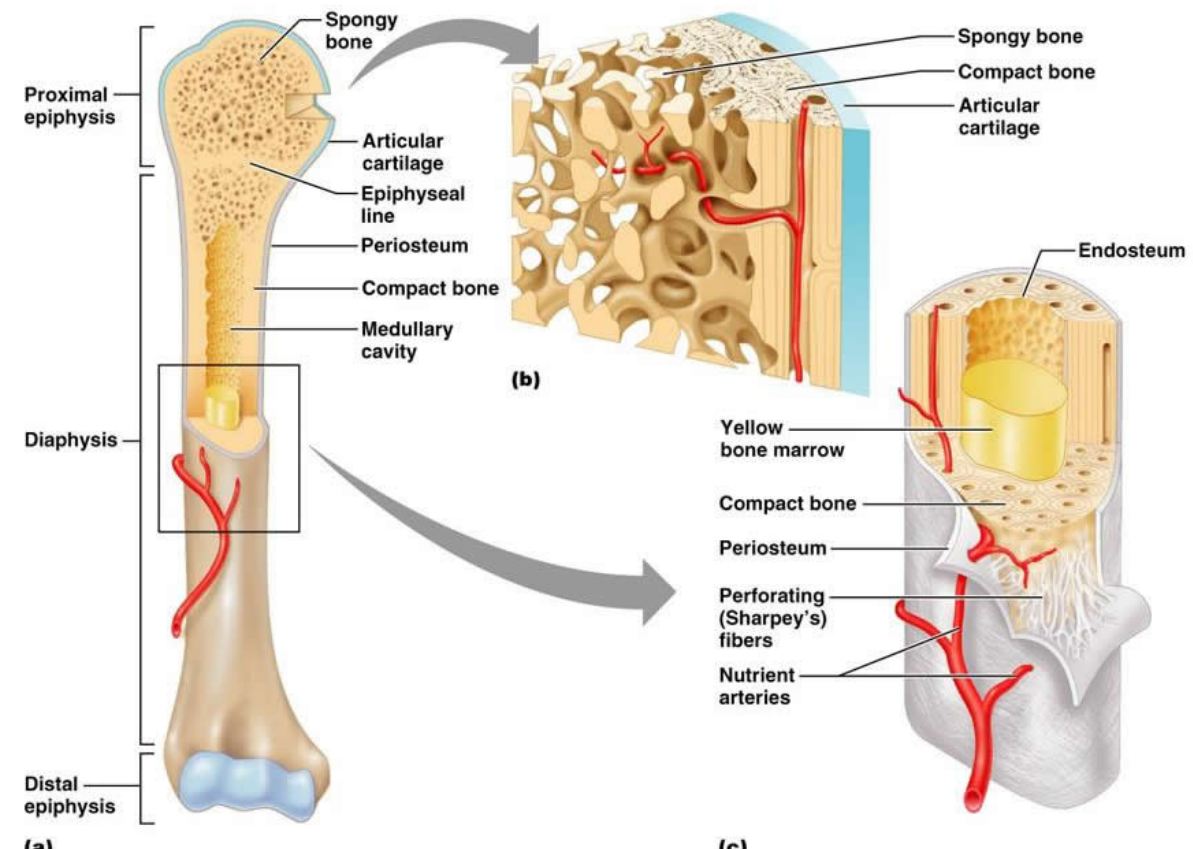

Figure 1 Key structures characteristic of an adult human long bone [5].

All bones include two basic types of bone: compact and cancellous (spongy) bone. Compact bone is composed of dense osseous tissue, providing strength in the bone [6]. Generally, the compact tissue is located throughout the diaphysis of the bone with a 
porosity of approximately 5\%-10\%, Figure 1 [6]. Cancellous bone is composed of osseous tissue that is more porous, approximately 75\%-95\% [6]. This tissue is often located at the ends of the bone in the epiphyses and houses bone marrow and provides a large surface area ideal for ion exchange. The outside surface of bone is covered by the periosteum, the outer layer of which is composed of collagen (protein) and an inner osteogenic layer, the location of bone forming cells. The inner surface of bone is lined with the endosteum [4]. Each layer of bone is important to the growth and maintenance of bone structure.

\subsubsection{Bone Matrix Composition}

The bone matrix is a composite of both organic and inorganic materials. The organic components include collagen and other various proteins, acting as the fibers. The inorganic material is composed of mostly calcium hydroxyapatite [4]. Collagen plays a critical role in the function and structure of bone tissue. In total there are 28 types of collagen currently discovered, type I being the most prominent. In addition to collagen, the organic portion of the bone matrix is composed of noncollagenous matrix proteins (NCP's), including osteocalcin. The NCP's can be used to measure bone formation and collagen can be used to measure bone resorption through their presence in urine or serum. Another NCP found in the bone matrix is fibronectin, accumulating at the initial sites of osteogenesis, the initial stages of bone formation and resorption [7]. These larger proteins found within the bone matrix can be measured and used in the diagnosis and treatment of osteoporosis.

Within the bone matrix there are five main types of bone cells. These cell types include: osteogenic (osteoprogenitor) cells, osteoblasts, osteocytes, osteoclasts, and bone 
lining cells. Osteogenic cells are stem cells developed from embryonic mesenchymal cells and hematopoietic progenitor cells. These are the basic cells that have the opportunity to develop into most other types of bone cells. Osteogenic cells are located in the endostium just below the periosteum and in bone marrow. Osteoblasts are boneforming cells, created to synthesize the unmineralized bone matrix. Generally the cells are cuboidal and are seen as a monolayer below the endosteum making a sheet. Osteocytes are former osteoblasts remaining in the bone matrix after mineral deposition. They are located in lacunae and are connected by canaliculi. Osteocytes help maintain the appropriate balance of bone density and blood concentrations of calcium and phosphate. The cells are able to act as strain sensors to regulate bone remodeling [4]. In addition to maintaining bone density, the cells sense developing microcracks and respond to hormonal changes, including changes in estrogen levels [8]. Osteoclasts are bonedissolving cells. These cells are much larger than the three previous cell types, and are often multi-nucleated. Bone lining cells are osteoblasts that have become inactive. They function as a barrier along the bone surface and maintain communication with osteocytes. They also have receptors for the parathyroid hormones and estrogen [6]. These five types of cells work together to perform the processes of bone formation and resorption.

\subsection{Bone Modeling and Remodeling}

During normal service, bone constantly undergoes microcracking, which needs to be repaired to prevent serious fracture. If microcracks are not repaired, the bone will continue to crack and the microcracks have the potential to develop into full fractures. Bone remodeling is the process through which these microcracks are repaired. Remodeling is similar to bone modeling with a few significant differences. In bone 
modeling, osteoclast and osteoblast cells are working in different areas and certain cells are active in specific locations, while in remodeling the osteoclasts and osteoblasts are working together as a single unit. During modeling, changes in bone size and shape are often apparent while the opposite is seen in remodeling, size and shape are not affected [6]. At the location of the damage, microcracks in bone, bone cells work together to first remove and then replace the damaged tissue, Figure 2. This process has a specific beginning and ending as opposed to bone modeling, which continues for an extended period of time. After the initiation of the process, the osteoclasts work to remove the damaged bone to prepare for bone replacement by the osteoblasts [6].

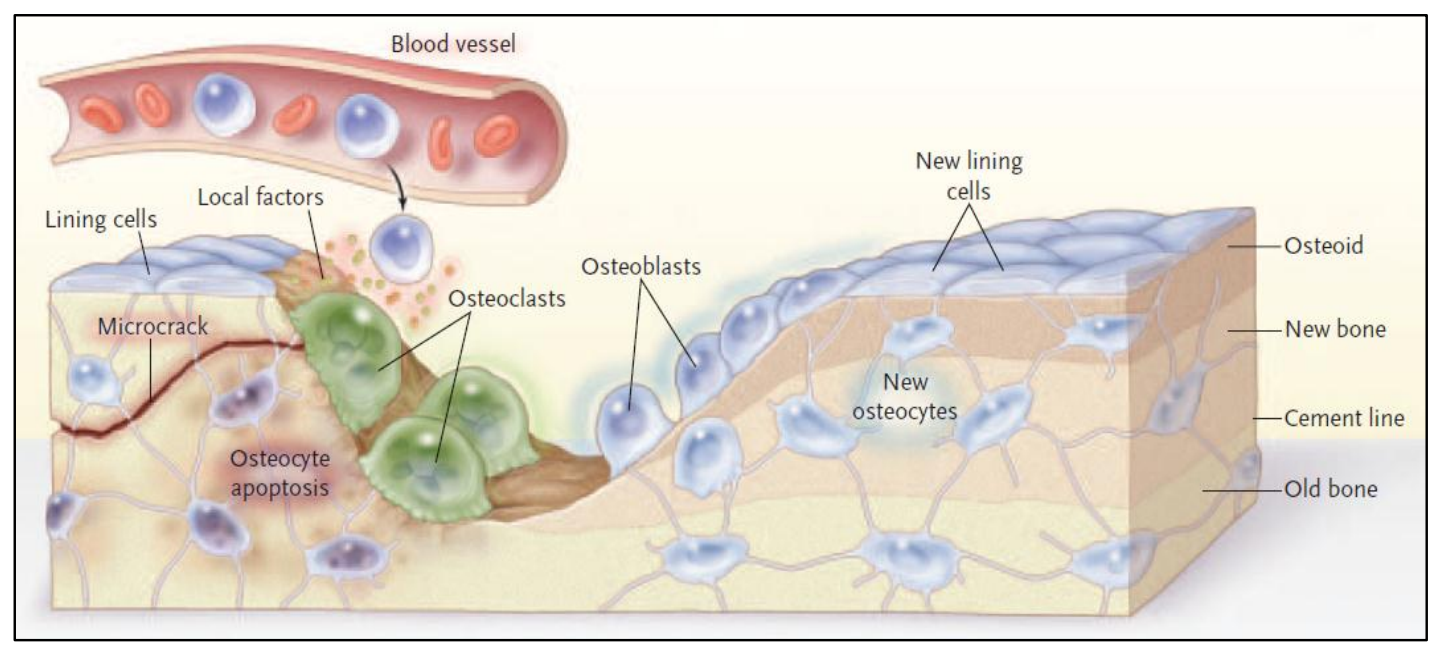

Figure 2 The remodeling process in a adult human bone [9].

\subsubsection{Remodeling: ARF}

Diving deeper into the bone remodeling process gives view to the basic multicellular unit (BMU). A BMU is composed of teams of osteoclasts and osteoblasts working together to replace damaged tissue, in situations of intense stress, as well as respond to hormonal changes including estrogen depletion. The cycle of a BMU is based on three basic stages: activation, resorption, and formation, abbreviated ARF [6]. 
During activation, the process is initiated by a mechanical or chemical signal [6]. The signal is believed to be one of the many different hormones in the body, including estrogen. This signal brings about the formation of osteoclasts through the fusion of monocytes, which then begin to remove bone. Second in the process is resorption; the osteoclasts continue to resorb bone in preparation for new bone to be formed. The resorption process creates a ditch on the surface or a tunnel through the matrix of bone. The osteoclast cells move at approximately $40 \mathrm{um}$ per day and the process takes approximately three weeks to reach the maximum resorbed depth or diameter. Following resorption, formation begins. During formation osteoblasts are differentiated from mesenchymal cells and are dispersed to form new tissue. The formation process as a whole is a much slower process than resorption; the process takes approximately 3 months [6].

\subsubsection{Cellular Events in Remodeling}

Through the stages of ARF, certain cellular processes are initiated and maintained through cellular migration, mitosis, and differentiation. The cellular processes are controlled and maintained through hormones or chemicals, including estrogen [6]. Specific cellular pathways can be seen in Figure 3 . 


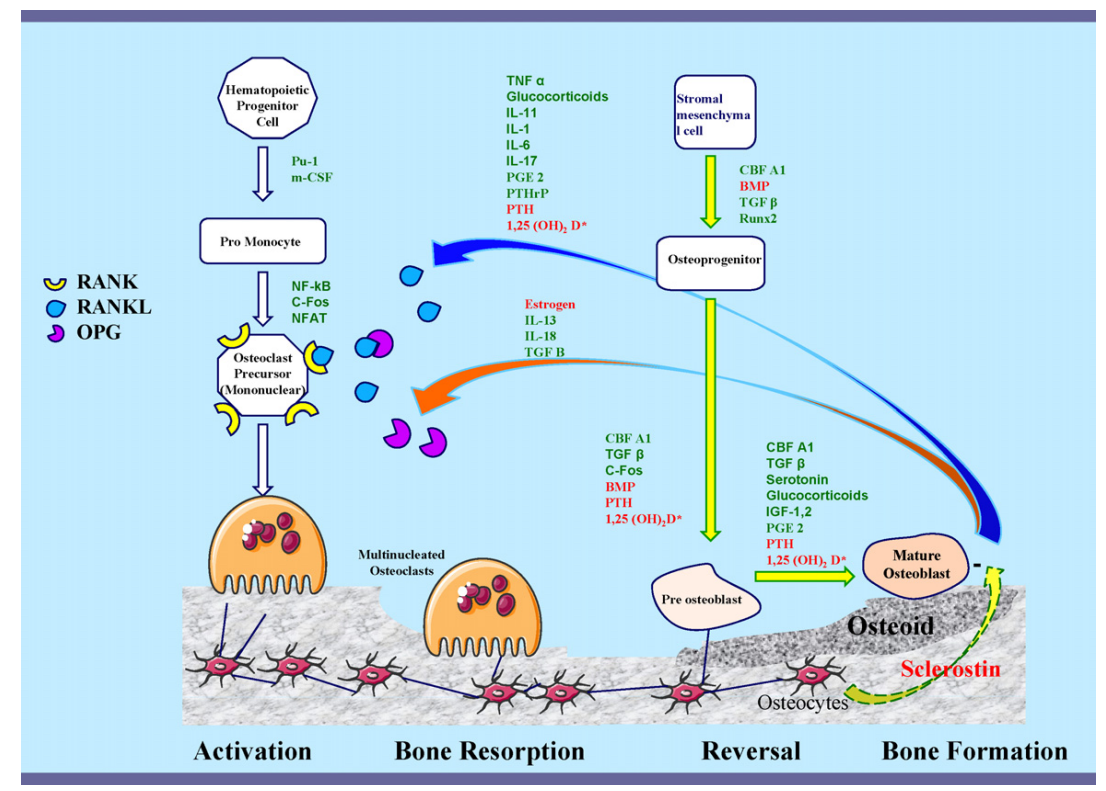

Figure 3 The stages of bone remodeling, including the development of osteoclasts and osteoblasts. Factors listed in red are factors that have been confirmed or are being researched in clinical studies. Factors in green are potential factors currently being researched in vitro or in animals [10].

Each step through the ARF process is initiated by several factors [10]. There are three known forms of communication between osteoclasts (resorption) and osteoblasts (formation) that initiate the resorption and formation processes. The first is through direct contact. Direct contact allows ligands to bind to receptors within the membranes of the cells to initiate the cell signaling process, specific ligands include the receptor activator of nuclear factor kappa-B (RANK) and the receptor activator of nuclear factor kappa-B ligand (RANKL). RANKL is a cytokine that functions as a key factor in osteoclast activation and differentiation. RANK is the membrane protein expressed on the surface of osteoclasts. Upon binding of RANK to RANKL, the osteoclast initiates resorption [11]. The second is through the formation of gap junctions. Through the gap junctions, small water soluble molecules are passed between the two types of cells [12]. The gap junctions are composed of 6 proteins and are able to pass small molecules up to $1 \mathrm{kDa}$ between osteoblasts, or between osteoblasts and osteocytes. Not much is known 
about the factors passed through these channels, but the communication between cells has been proven to be an important component of resorption [13]. The third method is through diffusible paracrine factors, including growth factors, cytokines, chemokines, and additional small molecules, including estrogen [12].

Living osteocytes secrete the transforming growth factor $\beta$ (TGF- $\beta$ ), which is known to inhibit osteoclastogenesis and resorption by osteoclasts [14]. It is also known that estrogen, a hormone, prevents osteocyte apoptosis. With normal levels of estrogen, bones continue to follow the typical bone remodeling process, maintaining homeostasis with appropriate levels of resorption and formation. However during estrogen deprivation, as present in menopause, the total amount of osteocyte apoptosis is increased, which leads to an increase in active osteoclasts. Estrogen increases the levels of TGF- $\beta$, a transforming growth factor that acts as an inhibitor of resorption by the osteoclasts [14]. If estrogen levels are not at normal healthy levels, this process demonstrates an increase in bone resorption while formation remains constant. It is already known, the resorption process is a much quicker process than bone formation [6].

\subsubsection{Quantitative Analysis of Bone Remodeling}

In past years, the study of bone remodeling has used conventional techniques to gather information. By being forced to rely on histological analysis to provide an accurate assessment of bone remodeling, methods of using architectural and cellular patterns have been used to identify resorption and remodeling [15]. These methods can also be used to identify the bone microarchitecture.

Frost was one of the first to demonstrate in bone how histologic sections could be analyzed to quantify the characteristics of bone remodeling, serving as the foundation to 
future studies [6]. This process was first used on the human rib and since then has been used on other human and other animal models. In this process, a model is labeled twice with tetracycline or another fluorochrome stain to show mineralizing bone, the first given 7-14 days before the second label. The stain is used to determine bone remodeling characteristics and is best observed under epiflourescent light [6].

Bone density can be quantified in several different ways through invasive and non-invasive procedures. A specific procedure to measure bone mineral density (BMD) to quantify density is through a micro-computed tomography $(\mu \mathrm{CT})$. A $\mu \mathrm{CT}$ has the ability to generate high-resolution images of cortical and cancellous bone in both human and animal models. Other options in addition to a $\mu \mathrm{CT}$ include dual energy X-ray absorptiometry (DXA) and quantitative computed tomography (QCT) [16]. More invasive options include microradiography; a cross sectional representation of the specimen is ground to approximately $100 \mu \mathrm{m}$ thick, a microradiograph is taken and subsequently imaged, and then further micro-densitometry analysis performed using computer software.

\subsection{Estrogen and Bone}

Estrogen has been directly linked to bone metabolism both in women and men through many in depth studies [8]. A common treatment in post-menopausal women is the replacement of the estrogen hormone in several different forms. With estrogen replacement treatments, a reduction in the basic serum markers present during bone resorption can be noted [8]. The results of these treatments also show lower cell counts of osteoclasts and osteoblasts. The low counts of osteoclasts depends on the number of hematopoietic osteoclast progenitors, and the activity of osteoblast progenitors, in 
addition to the activities of those cells and their ability to support bone resorption and formation [17]. A lower level of osteoclasts supports the conclusion that estrogen treatments reduce the amount of resorption occurring in the bone. This helps to maintain the homeostasis between resorption and formation, by allowing the amount of resorption and formation to better represent levels seen in healthy individuals.

Similar to menopause, an oophorectomy leads to an increase in the total number of osteoclasts. By removing the ovaries, a large producer of estrogen, estrogen levels within the body are significantly decreased. This leads to an increase in bone resorption and an increase in bone formation. The cycle time required for bone formation is longer than the cycle time of resorption, but because the resorption cycle time is shorter it dominates when estrogen levels are lower, leading to a net decrease in bone density [8]. Although it is known estrogen depletion leads to a decrease in bone mineral density (BMD), additional research needs to be conducted to understand exactly how and why estrogen inhibits bone resorption and in turn is a large factor in the regulation of formation. It is believed osteocytes are the initial target of estrogen treatments. Estrogen directly influences osteoblasts, osteoclasts, and osteocytes; osteocytes being the regulators of bone homeostasis, Figure 4. Estrogen causes osteocytes to inhibit the activation of bone remodeling. The hormone causes osteoblasts to also undergo a reduction in several mechanisms regulating the maintenance of bone formation. Estrogen influences osteoclasts to cause a reduction in bone resorption. Individually each of these cells also depend on each other to regulate different aspects of bone remodeling [8]. Currently many research groups are conducting studies to better understand the effects of estrogen on its ability to decrease bone resorption and the activation of bone remodeling. 


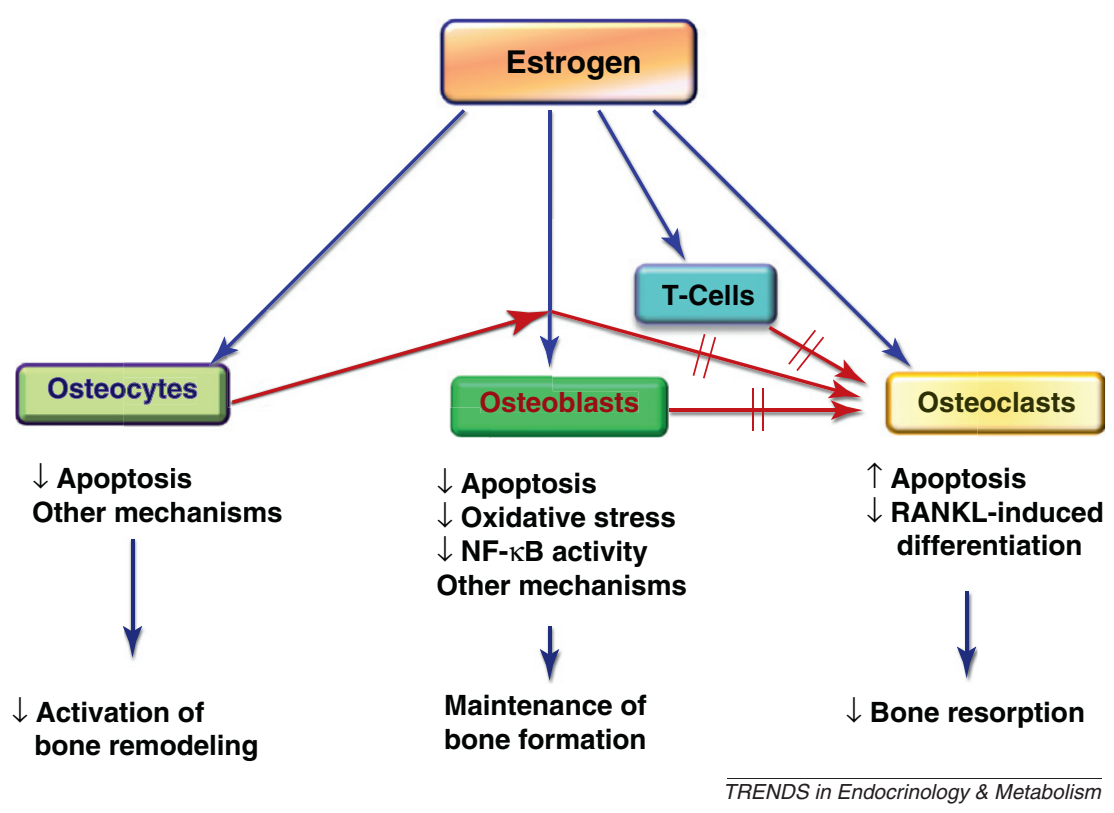

Figure $4 \mathrm{~A}$ breakdown of how estrogen influences the different types of bone cells [8].

\subsection{Osteoporosis}

\subsubsection{General Information}

Osteoporosis is a systemic condition characterized by a low bone mineral density (BMD). Low levels of BMD can be the result of a micro-architectural deterioration of bone tissue or a defect in mineralization. These symptoms are associated with bone fragility and a severely increased fracture risk [18]. The condition occurs in postmenopausal women, and often in the elderly. In people over the age of 55, 1 in 2 women will have a severe fracture due to low bone density and 1 in 4 men will have an equivalent fracture [18]. Not only may individuals diagnosed with the condition endure fractures, but the fractures can lead to other debilitating conditions including blood clots due to immobility caused by the fracture. Although the initial fracture may not be serious, the condition can lead to much more serious conditions. 


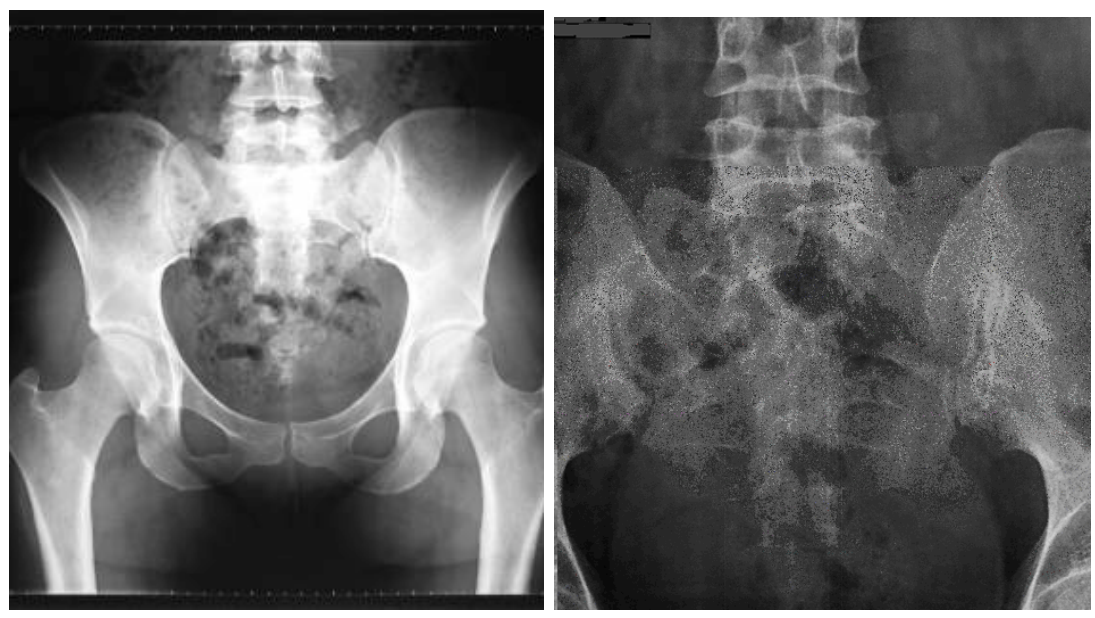

Figure 5 Left: An X-Ray of a healthy woman's pelvis [19], Right: An X-Ray of a woman diagnosed with osteoporosis post menopause [20]. Note the decrease in density in the bone from left to right.

Bone mineral density peaks when an individual is in their 30's, declines in women as menopause approaches, and the decline accelerates immediately post menopause. In total, following menopause approximately one third of peak BMD is lost, Figure 5. If the decline in BMD is not treated, the likelihood of developing osteoporosis increases significantly. With low BMD, fracture can be caused by minimal impact, such as bumping into a table, or a short trip and fall [21]. Osteoporosis is defined as a BMD less than or equal to 2.5 standard deviations below the mean BMD for adults age 25-30 [22]. If an individual has a BMD that is within 1 and 2.5 standard deviations below the mean BMD of a healthy adult age 25-30, they are diagnosed with osteopenia, a precursor to osteoporosis. The T-score is a value used by physicians to compare an individual's bone density to the optimal bone density based on age and gender which is used in diagnosis [21]. The T-scores is compared to the fracture risk and BMD in Figure 6. As the total BMD decreases below the mean, the fracture risk increases at a T-score below 2.5. 


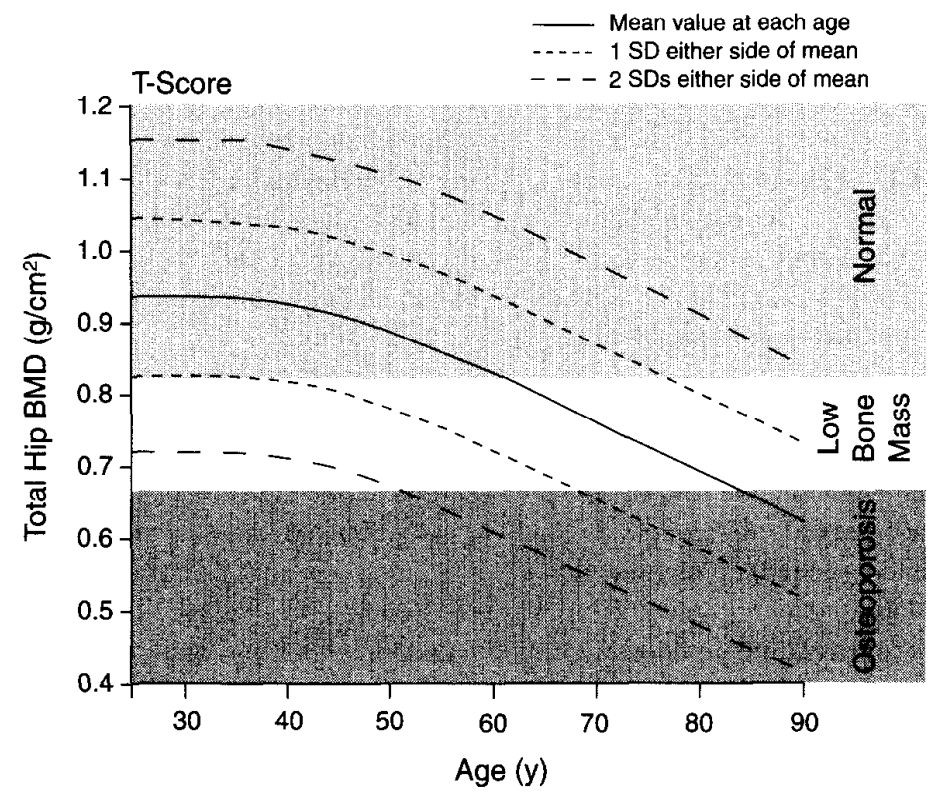

Figure 6 Average total hip bone mineral density levels at different ages. The graph is separated into normal, low, and osteoporotic levels demonstrated through shading [21].

\subsubsection{Treatment}

When treating osteoporosis the main goal is to reduce the threat of death and injury by reducing the risk of a serious fracture, as it is not possible to cure the condition. The goal is to identify patients who will be at an increased risk based on the levels of BMD before they reach a T-score at an osteopenic or osteoporotic level. Postmenopausal women are already at an increased risk due to estrogen depletion [21].

Fracture risk can be grouped into three categories based on the levels of risk and required treatment: low, moderate and high. Those with higher BMD and T-score levels are considered to be low risk and will not require present treatment because the bone mineral density is near normal levels. Those with a lower BMD as compared to the mean will be considered to have moderate or high risk. To treat those with moderate risk, a physician should consider clinical risks to determine if there is a need for treatment or if the individual is at an increased risk for future fractures, such as participation in a contact 
sport or old age. Those who are considered to have a high risk for injury should be considered for pharmacologic treatment. This group of individuals have approximately a $20 \%$ probability of sustaining a major fracture in the next 10 years [23]. Physicians must consider both BMD and physical risk factors when assigning a patient to a particular group. Often the algorithm in Figure 7 is used by physicians to determine an appropriate treatment for the at-risk patient.

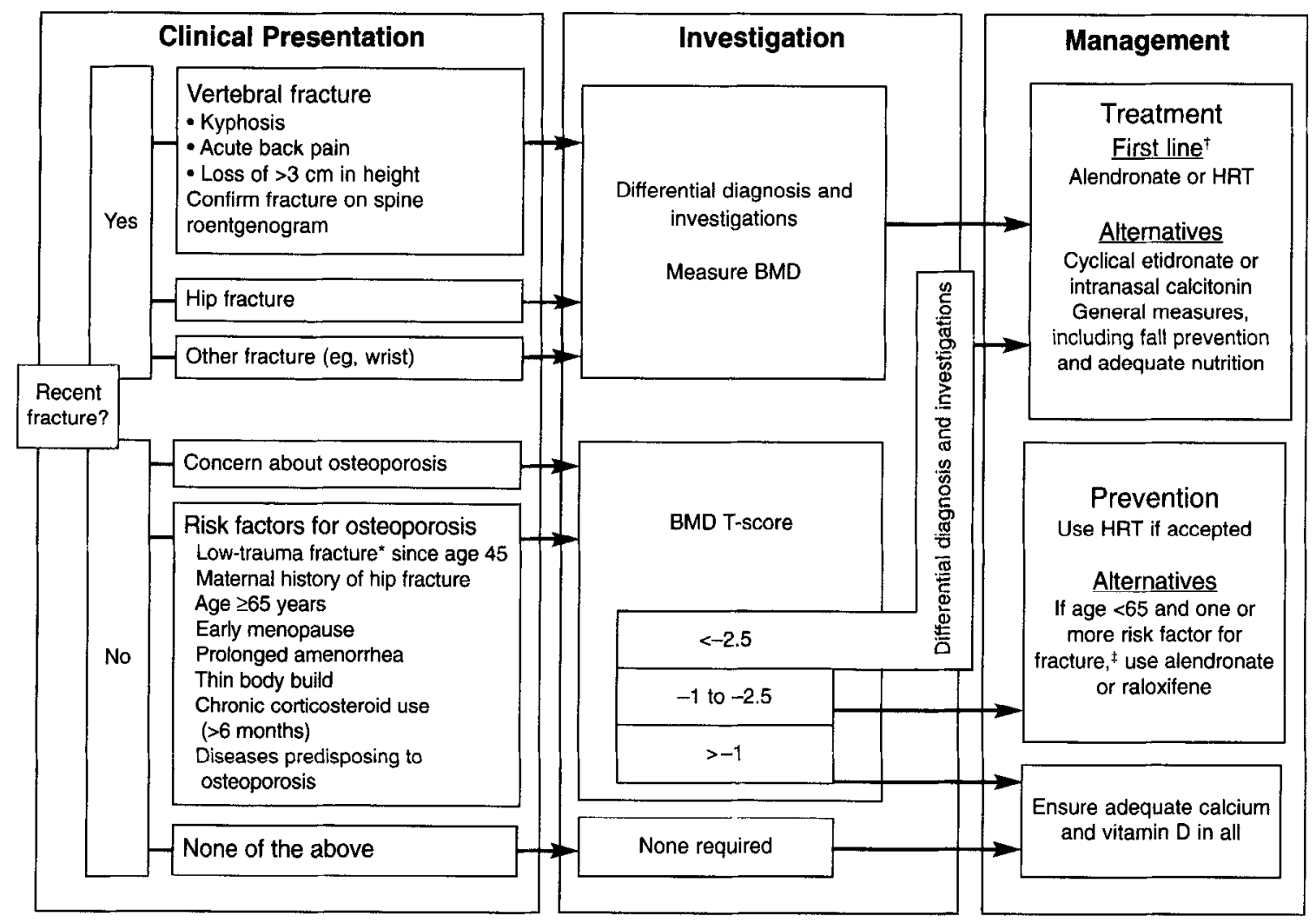

Figure 7 A typical path a physian may take in patients in menopause or post menopause to determine the most appropriate course of action to prevent further decrease in BMD [21].

Many patients are asymptomatic until they get their first fracture, with the exception of vertebral fractures. However there are several adequate ways to aid in prevention, before a patient is even at risk. An adequate intake of vitamin D and calcium has been proven to improve the T-score, along with a general awareness for their own 
overall health, Figure 8 [21]. There are also several pharamacologic methods of intervention including estrogen and progesterone treatments, selective estrogen-receptor modulation, and several additional therapies. Estrogen and progesterone treatments are only approved for prevention of osteoporosis in women with post-menopausal symptoms [22]. This treatment also has the benefit of minimizing hot flashes, a common symptom of menopause, however it also has the potential to be carcinogenic. Another treatment option is a selective estrogen - receptor modulator (SERM). SERM's are able to bind to the estrogen receptor and produce an alternative action within the cell. These are able to mimic the effect of estrogen without the likelihood of bad side effects, acting in the same fashion as estrogen and reducing the activation of osteoclasts. An example of a SERM is Raloxifene. This however also has poor side effects; it has the potential to increase the chance of blood clots, which could lead to heart attack or stroke. Additional treatment options are available, including bisphosphonates, which are the most common [22], [24].

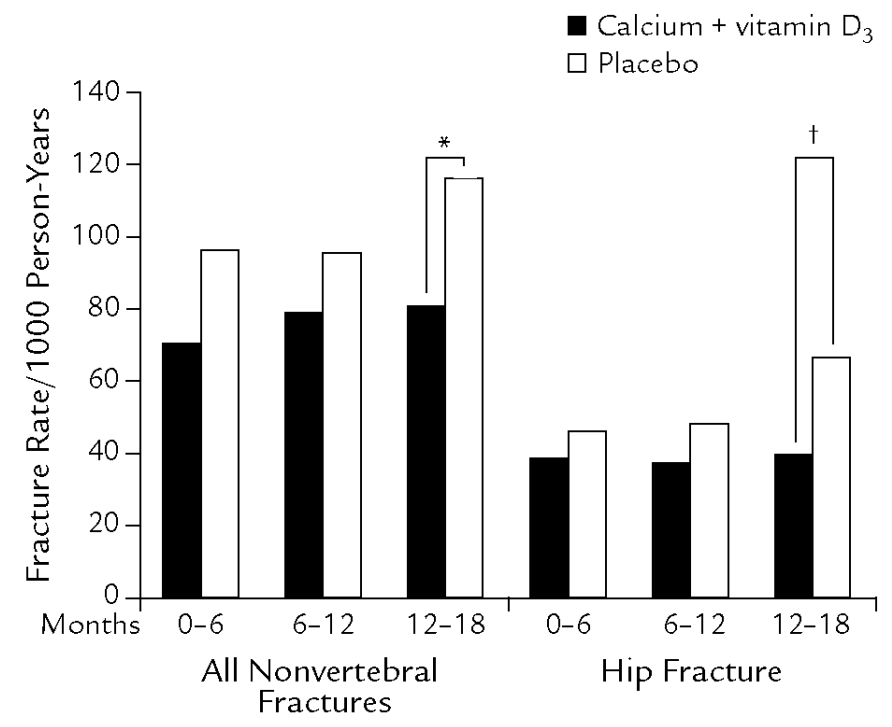

Figure 8 Fracture rates per 1000 people/year in elderly women. The dark bar demonstrates women treated with vitamin $D$ and calcium and the light bar demonstrates women treated with a placebo [22]. 


\subsection{Animal Models}

As with any study in the medical field, animals are often used to make initial conclusions about the effects of a disease or pharmological treatments. The studies are used to isolate a specific treatment and perform statistical analysis to eventually provide results to lead to further research or drugs to help humans who are affected by the condition [25]. In this specific study, an animal model is needed to understand how estrogen depletion affects the basic model. This understanding can then be applied to human treatments and aid in the understanding of osteoporosis in humans.

There are many animal models available to choose from when studying estrogen and osteoporosis, however from previous studies, ovine are one of the better models for a study requiring a large number of samples conducted over a long term period [26]. Other possible animal models include minipigs, ferrets, guinea pigs, rats, rabbits, primates, dogs, and cats, each with its own unique benefits and detriments. Similar studies have used ovariectomized rats as a consistent model for osteoporosis [25]. For 12 months after an ovarectomy, rats cancellous bone mimics post menopausal bone in women. However, after the 12-month period rats tend to show higher values of BMD, bone area, and bone weight as compared to average human values. Also an absence of impaired osteoblast function during the late stages of estrogen deficiency is present in rats, a phenomenon not present in humans [25]. Based on these conclusions, a rat model was determined to be too inconsistent to fit the needs of the study. For the study, an animal model with bone and metabolic characteristics similar to humans as well as being able to fulfill the time length requirement of the study was required.

In this study, skeletally mature ovine were chosen as the animal model. Most 
importantly, the metabolic rate of an ovine is similar to humans, based on $\mathrm{O}_{2}$ consumption per gram body weight, in sheep the metabolic rate is .22 and in humans it is .21 [27]. Ovine are also docile, compliant, and there is not a significant emotional attachment from humans, as there is with dogs and cats. From a chemical perspective, the regulation of hormones is similar to that of women [25]. Additionally their bone composition is similar to humans, composed of a woven and lamellar bone structure, with the presence of haversian remodeling [26]. During a study, if necessary it is also possible to take blood and urine samples to determine levels of relevant proteins or identifying factors. From a financial perspective, they are affordable and are available in large quantities [25]. Despite the benefits, there are some limitations of using mature sheep as a model. Sheep do not have a clear-cut menopause period characterized by accelerated bone loss and decrease in BMD as is present in women around the age of 50. The completion of an ovariectomy in ovine is required to mimic menopause and induce osteopenia, post ovariectomy ovine have similar estrogen and bone mineral density levels to women. On a chemical level, an ovine's phosphorous metabolism is different, and the excretion of phosphate in urine is lower than humans [26]. Despite the limitations, based on their characteristics, they are one of the best animal models for this type of study.

When using ovine as an animal model for this type of study, it is important to maintain appropriate vitamin D and calcium levels. To achieve the appropriate vitamin D levels, animals must be exposed to sunlight. The amount of sunlight an animal is exposed to is dependent on the season, daytime length, and amount of time in the sun, essentially UV exposure. Several studies have provided evidence that seasonal variation affects BMD of the animal [25]. This is one of the factors studied in the analysis of this 
study.

\subsection{Study Objectives}

The purpose of this study was to quantify compact bone density present in sheep at 3 months post ovariectomy. Measurements were taken from cortical bone in the radius. Analysis was completed for each sheep to consider the impact of treatment, season of surgery, season of sacrifice, and sector to the mean equivalent thickness of aluminum (ETA). The thickness of aluminum was used to represent the bone density of the animal specimen in density measurements. Aluminum has a similar atomic number to hydroxyapatite, making it an effective way to measure bone density [28]. Anatomical sector is defined as the different anatomical sections of the bone: craniomedial, cranial, cranolateral, caudomedial, caudal, and caudolateral.

Previous research has provided conclusions based upon the study of skeletally mature sheep after undergoing an ovariectomy. Research has been published to provide a connection between bone remodeling and season [25]. This study is a continuation of a previous study looking at the density based on sector and season [28]. Based on the results of the previous study, [28], it is expected the current study will provide insight into the expected differences in density between sector, season, and treatment. There has been little research looking further into bone material density with respect to the interaction between season of sacrifice and the anatomical location within the bone. It is expected that there will be a significant interaction between the season and anatomical location, and additionally there will be a difference in the results of the ovine that underwent an ovariectomy and those who underwent a sham operation. The results of this study will aid in opening the door to additional research by expanding the definition 
of the animal model, and by looking at changes in the anatomic distribution of the parameters in the OVX group as compared to the control. 


\section{MATERIALS AND METHODS}

\subsection{Animal Preparation}

As part of a larger study approved by the Colorado State University Animal Care and Use Committee, this study utilized 112 female ewes. The ewes were commercial culls purchased at auction in southern and eastern Colorado at the beginning of the study. Each was greater than 5 years old and was kept at Colorado State University, Ft. Collins, Colorado. The surgeries were performed at the College of Veterinary Medicine and Biomedical Sciences at Colorado State University. They were kept in dry lots at $41^{\circ}$ latitude and $1,500 \mathrm{~m}$ above sea level and fed a grass-alfalfa mixture. The 112 ovine were separated into different treatment groups. Initially, they were separated into 4 groups of 28 based on season of surgery: autumn, winter, spring, and summer. Each seasonal group was further divided into 2 groups of 14; the first group underwent an ovariectomy (OVX) and the second group a sham surgery, in which the ovaries were visualized and handled but left in the abdomen. The summer group had their surgeries performed in August, autumn in November, winter in February, and spring in May. Post surgeries, the groups of 14 were further separated into groups of 7 ewes. One group was sacrificed 3 months postoperatively and the other group was sacrificed at 12 months postoperatively.

\subsection{Ewe Specimen Preparation}

Once sacrificed using an intravenous overdose of a barbiturate anesthesia, both the right and left radius and ulna were removed from each ewe. In sheep the radius and ulna are functionally fused early in life and all samples used in this study were from the radius. The bones were removed and stored in a saline soaked towel and kept at $-20^{\circ}$ Celsius. The samples were transferred and prepared for analysis at Henry Ford Hospital. 
From the left radius, the epiphyses were removed with a band saw (Model 5212, Hobart Corporation, Troy, $\mathrm{OH}$ ) to leave only $50 \mathrm{~mm}$ of the diaphysis in the long bones. The diaphysis was further cut using the Exakt cutting-grinding system (Exakt Corporation, Oklahoma City, OK). The radius was divided into 6 sectors including cranial, caudal, craniolateral, craniomedial, caudomedial, and caudolateral; the sections can be seen in Figure 9. Up to 25 beams were cut from each left radius with the dimensions $1.75 \times 1.75 \times 19 \mathrm{~mm}$; a single beam from each sector was chosen at random to act as a representative sample from each location. Non-destructive dynamic mechanical testing was performed on each of the beams. After testing, an $8 \mathrm{~mm}$ section was cut for drying and ashing to determine the bulk density. A $150 \mu \mathrm{m}$ thick section was also cut from the beam to be used in histomorphometric analysis. The remaining portion of the beam was frozen for analysis at a later date.

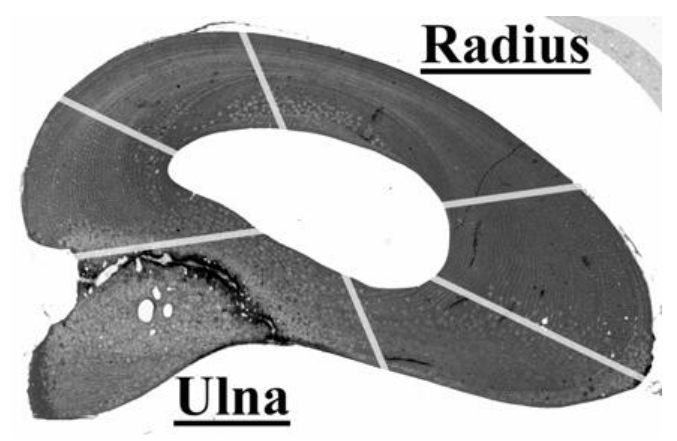

Figure 9 Anatomical separation of the radius and ulna. The cranial sector is located in the upper right and the lateral sectors are located in the top left side of the figure [29].

The $150 \mu \mathrm{m}$ sections were further ground by hand, using fine grit sand paper, to a thickness of $100 \mu \mathrm{m}$. Microradiographs of each $100 \mu \mathrm{m}$ section were taken using 2506AGHD 2.5x2.5x0.06 High Definition Photo Emulsion Plates and an HP Cabinet Faxitron (HTA Enterprises, Microtome Technology Product, San Jose, CA). This process was performed at $25 \mathrm{kV}$ for 20 minutes at $3 \mathrm{~mA}$. The location of each sector on 
each the microradiograph can be seen in Figure 10. Each plate contains all 6 sectors for 2 separate ewes in addition to a Reynolds Aluminum Foil stepwedge down the center. Aluminum was used to determine the density of the bone based on the similarities in the atomic number of aluminum and hydroxyapatite [28]. Using the Reynolds Aluminum Foil stepwedge, it was possible to determine the density of each specimen by comparing the intensity of the aluminum foil stepwedge to the image intensity of the bone specimen. The stepwedge was created by layering $.02 \mathrm{~mm}$ pieces of aluminum foil on top of each other to create steps with a known value, seen down the center of Figure 10.

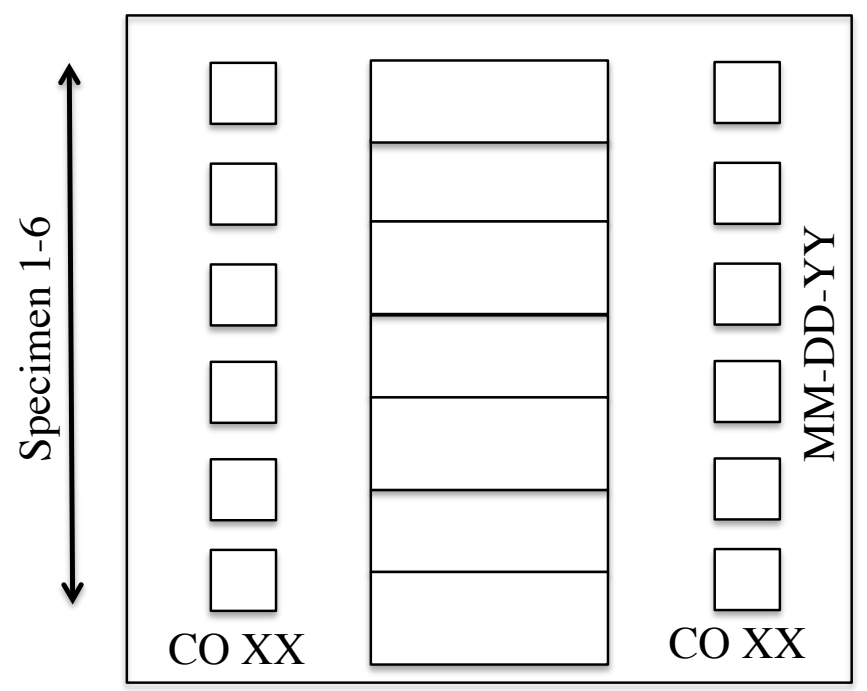

Figure 10: Microradiograph setup. Ewe 1 is on the left and ewe 2 is on the right. Sectors begin at the top with cranial and end with the caudolateral section.

\subsection{Specimen Imaging}

The samples prepared at Henry Ford Hospital were sent to Cal Poly where they were imaged at 100x using an Olympus BX-41 Microscope and an attached Retiga EXi Q color camera (QImaging, Surrey, BC, Canada). Each anatomical sector on the microradiograph was imaged at 100x using the attached camera, QCapture Pro (QImaging). In this study, all ewes sacrificed at 3 months and ewes that underwent a 
sham surgery sacrificed at 12 months were imaged. Bone samples of ewes who underwent an ovariectomy and were sacrificed at 12 months were imaged in a previous study [28].

During the imaging process, the appropriate light intensity was selected to be used for all of the 6 sectors and remained constant between each sector. When viewed through the microscope, the sample must be bright enough to be visible, however not so intense the bone characteristics were not visible. It was important to ensure each bone specimen was visible both through the microscope as well as through the imaging camera and software. When imaging the specimens, each anatomical sector was broken into 4 quadrants: northeast, northwest, southeast, and southwest. Each quadrant was imaged individually at 100x. An example of the quadrant breakdown is seen in Figure 11. In total, this includes 24 separate images per ewe.

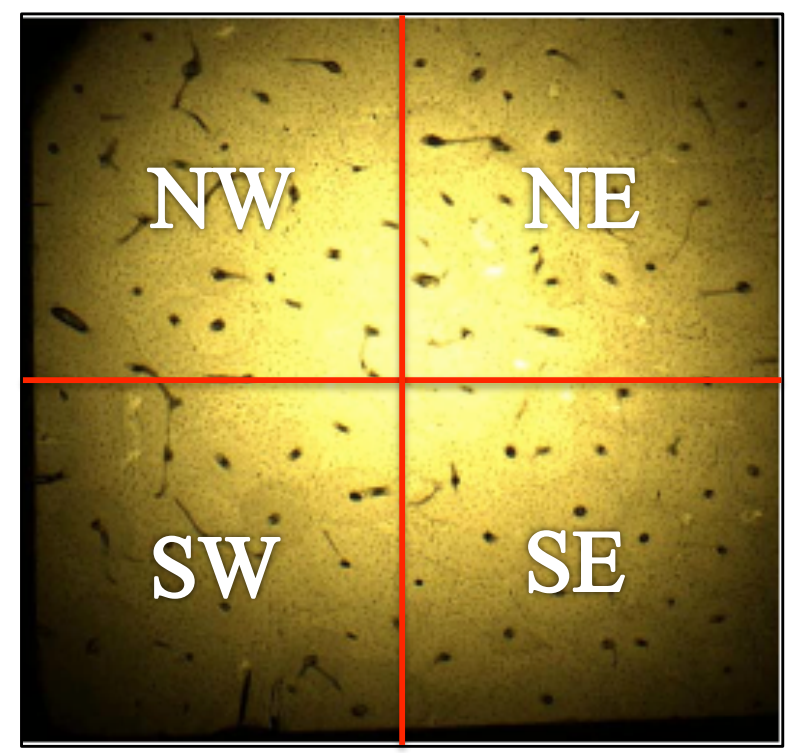

Figure 11: The break down of an anatomical sector imaged at 40x from a previous study [29]. Each of the 4 quadrants were imaged at 100x and analyzed in the current study.

Using the same intensity as the bone specimens, the aluminum stepwedge was 
imaged at a 40x magnification with the camera and saved. The aluminum stepwedge is composed of 9 steps of different aluminum layers, including a blank microradiograph with a zero thickness image, beginning with $0.0 \mathrm{~mm}$ of aluminum increasing by $0.02 \mathrm{~mm}$ with each step, for a total of 8 steps, Figure 12. Each step was only imaged a single time.

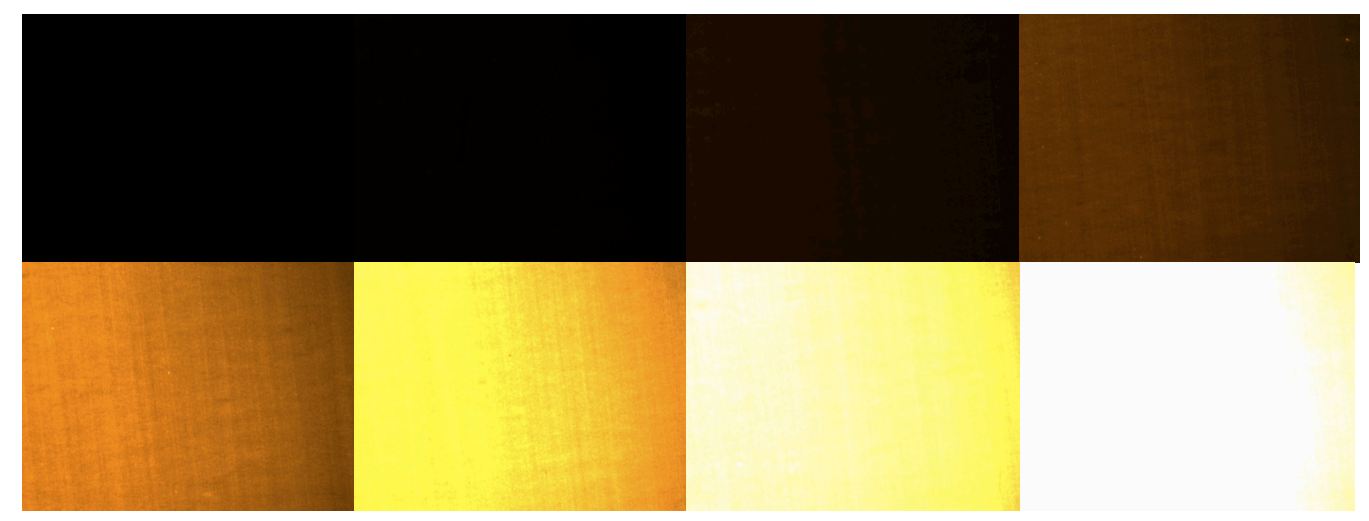

Figure 12: The stepwedge for ewe 93, an example of the aluminum stepwedge, showing the increase thickness. From left to right, top to bottom, the stepwedge demonstrates an increase from $0.0 \mathrm{~mm}$ to $0.02 \mathrm{~mm}, 0.04 \mathrm{~mm}, 0.06 \mathrm{~mm}, 0.08 \mathrm{~mm}, 0.1 \mathrm{~mm}, 0.12 \mathrm{~mm}$ and $0.14 \mathrm{~mm}$.

\subsection{Densitometry Analysis}

To quantify bone density, the intensity of each bone specimen was compared to the intensity of its corresponding aluminum stepwedge. Each image, including both sectors and stepwedges were loaded into ImageJ (Wayne Rashband (NIH)) and analyzed. Using this software tool, it was possible to produce a numerical pixel value corresponding to the intensity. Aluminum is often used because it is repeatable in its makeup and X-ray attenuation properties. It is a consistent standard to which a bone section of known thickness can be compared, therefore it is possible to calculate a density for each specific bone specimen. The numerical values for each specimen can be compared to the numerical values of the aluminum stepwedge, thereby producing a density value. Typically thicker more dense materials appear lighter, while thinner less dense materials appear darker. 
Each step in the stepwedge, correlates with a thickness increase of $0.02 \mathrm{~mm}$.

Using the histogram feature in Image (Wayne Rashband (NIH)), it was possible to create a table of data, which includes the number of pixels at every pixel density from 0 to 255 . The mean pixel intensity was determined for each level in the step wedge to serve as the key. By graphing the aluminum thickness and the mean pixel intensity it is possible to produce a 4-parameter sigmoid curve (Equation 1) in Sigma Plot 11.0 (Systat Software, Inc.). In the equation $1, \mathrm{y}_{0}$ represents the maximum asymptote, a represents the difference between the maximum and minimum asymptotes, and $\left(\mathrm{x}-\mathrm{x}_{0}\right) / \mathrm{b}$ represents the steepness of the curve. The results of the 4-parameter sigmoid curve provide the key parameters necessary to determine the equivalent thickness of aluminum (ETA) of each pixel to determine the density of each bone sample, based on the stepwedge created using aluminum. The distribution of the pixel counts was used to determine the ETA of each specimen using the parameters of the stepwedge, using the Stepwedge Template and the Quantitative Densitometry Template. Based on the distribution of the stepwedge pixels, it is necessary to use the complex curve to achieve an accurate fit while also making the fewest assumptions.

$$
y=y_{0}+\frac{a}{1+e^{-\left(\frac{x-x_{0}}{b}\right)}}
$$

With the parameters determined by the sigmoid curve, it was possible to determine the ETA of each specimen. In equation 1, the ETA value is represented as the $\mathrm{x}$ variable. Again, the histogram feature in ImageJ (Wayne Rashband (NIH)) was used to determine the density in each quadrant of a given specimen. From the histogram, the pixel count at each pixel density was converted to ETA using the parameters calculated from the corresponding stepwedge, and pixel count is represented as the y value. Also 
included in this calculation was the porosity of each sector to represent the proportion of pixels in the image representing non bone pixels [28]. The porosity was determined in a previous study by counting all points that were not considered bone and dividing that number by 144 , the number of possible points. Beginning with the lowest ETA pixel values, the ETA data values were deleted until the value represented 1 minus the porosity. These values were determined for each sample and their corresponding stepwedge [28].

\subsection{Statistical Analysis}

The densitometry results for the ewe sacrificed 3 months post-operatively were analyzed using Microsoft Excel Version 14.2.5 (Microsoft Corporation) and Sigma Plot 11.0 (Systat Software, Inc.). The images and data collected for the group of ewe sacrificed 12 months post-operatively were saved and will be analyzed in a future study as indicated in Future Work, Section 4.2. A statistical analysis was performed to look for significance in the main effects and interactions between the treatment, season of surgery, season of sacrifice, and anatomical sector comparing the data groups mean ETA and standard deviation of ETA, ETA chosen to represent bone density in the samples and standard deviation used to determine the differences in the variation in ETA in the comparisons.

\subsubsection{2-Way ANOVA (Analysis of Variance)}

Initially the statistical software Sigma Plot 11.0 (Systat Software, Inc.) was used to perform a 2-way ANOVA. The 2-way ANOVA was used to compare the effects of season of sacrifice and sector considering mean ETA and standard deviation in the ETA for ewes who underwent a sham surgery. This analysis allowed for the creation of a baseline to allow further comparison of the effects of season of surgery and sector. These 
results had the potential to show normal differences in densitometry from sector to sector in healthy animals. The pairwise comparisons in the 2-way ANOVA were performed using a post-hoc Fisher Least Significant Difference (LSD) test.

When performing a 2-way ANOVA, it was necessary to make assumptions required for a 2-way ANOVA. These assumptions include equal variance and normality. If these assumptions are met, the strength of the comparisons produced by the ANOVA analysis increases.

\subsubsection{3-Way ANOVA}

Using Sigma Plot 11.0 (Systat Software, Inc.), 4 separate 3-way ANOVA analyses were performed.

1. Season of sacrifice, sector, and treatment with mean ETA

2. Season of sacrifice, sector, and treatment with standard deviation ETA

3. Season of surgery, sector, and treatment with mean ETA

4. Season of surgery, sector, and treatment with standard deviation ETA

The comparison of the data with respect to season of sacrifice and season of surgery had the potential to show differences as well as interactions. Expected differences could be due to the remodeling which occurred during the 3 months between surgery and sacrifice. The pairwise comparisons in the 3 way ANOVAe were made using post-hoc Fisher LSD tests.

Equal variance was checked through the statistical software or through a plot of residuals vs. predicted values. In this plot, the spread of the data should be regular; a large or small spread signifies a violation of equal variance. Normality of the data can be checked through a normal plot of the data. In this graph the data should follow a normal 
Gaussian curve. In this specific study, the normality of each combination of groups was also examined.

\subsubsection{Frequency Distributions}

In addition to the ANOVA analysis performed on the data, a Gaussian distribution was developed from the raw data to check for the degree of normality. Using the data output from ImageJ (Wayne Rashband (NIH)), the bone pixel values and ETAs were graphed to create frequency curves. The frequency distributions were created by graphing the ETA on the x-axis and pixel frequency on the y-axis. The ETA values were grouped into 20 bins of equal size and the following graphs were created.

1. Graph of all data: all sectors and all sheep

2. Graph of OVX and Sham: 2 separate curves

3. Graph of all Sectors: single graph with 6 separate curves: OVX and control

4. Graph of each Sector: 6 separate graphs, 2 curves per graph: OVX and control Based on the distribution of the graphs, it was also possible to determine how the ETA values were distributed by pixel value based on the sector and treatment. The location of the bulk of the ETA and corresponding pixel count described the density of the specific sector and treatment as a whole. When the graphs were analyzed it was important to look at the differences and similarities between the sector and treatment as seen in the curves. 


\section{RESULTS}

\subsection{Densitometry}

The study was designed to examine the effect of treatment, season of surgery, season of sacrifice, and anatomical sector on sector mean ETA. Using the statistical techniques described in Section 2, the interactions were analyzed through 2-way ANOVAs and several 3-way ANOVAs using Sigma Plot 11.0 (Systat Software, Inc.). The tests performed include:

\section{2-Way ANOVA}

- Sector, Season of Sacrifice, mean ETA

- Sector, Season of Sacrifice, standard deviation ETA

\section{3-Way ANOVA}

- Sector, Treatment, Season of Sacrifice, mean ETA

- Sector, Treatment, Season of Sacrifice, standard deviation ETA

- Sector, Treatment, Season of Surgery, mean ETA

- Sector, Treatment, Season of Surgery, standard deviation ETA

Constant values determined from the 4-parameter sigmoid curve calculated the mean ETA for each. The mean ETA was determined through a pixel count based on the intensity. The mean ETA was determined for all ewe sacrificed at 3 months for OVX and sham, as well as, the sham surgery group sacrificed at 12 months. The mean ETA for ewe sacrificed at 12 months with an ovariectomy was determined in a previous study [28]. In this study, statistical analysis was performed only to compare sheep sacrificed at 3 months.

The data prior to the statistical analysis, as seen in Table 1, shows a calculated value of the mean ETA for each group before any possible interactions have been determined. Based on these calculated values, variation is noted in the mean ETA with respect to treatment, season of surgery or sacrifice, and anatomical sector. 
Table 1 Densitometry values (ETA) for sheep sacrificed at 3 months

\begin{tabular}{|l|c|l|}
\hline \multicolumn{3}{|c|}{ Densitometry (ETA) (mm) } \\
\hline Group & Mean & Standard Deviation \\
\hline OVX & 0.054 & 0.022 \\
\hline Sham & 0.071 & 0.026 \\
\hline \multicolumn{3}{|c|}{ Season of surgery } \\
\hline Autumn & 0.076 & 0.027 \\
\hline Winter & 0.055 & 0.021 \\
\hline Spring & 0.073 & 0.014 \\
\hline Summer & 0.044 & 0.023 \\
\hline \multicolumn{3}{|c|}{ Season of Sacrifice } \\
\hline Autumn & 0.044 & 0.023 \\
\hline Winter & 0.076 & 0.023 \\
\hline Spring & 0.055 & 0.021 \\
\hline Summer & 0.074 & 0.014 \\
\hline \multicolumn{3}{|c|}{ Anatomical Sector } \\
\hline Craniomedial & 0.066 & 0.025 \\
\hline Cranial & 0.062 & 0.025 \\
\hline Cranolateral & 0.063 & 0.026 \\
\hline Caudomedial & 0.062 & 0.025 \\
\hline Caudal & 0.059 & 0.023 \\
\hline Caudolateral & 0.063 & 0.027 \\
\hline
\end{tabular}

\subsection{2-Way ANOVA}

The 2-way ANOVA analysis, using Sigma Plot 11.0 (Systat Software, Inc.) compared sector and season of sacrifice to both mean ETA and standard deviation ETA for the sham treatment group. The results of this statistical test established the baseline to show the statistical differences and interactions in a sheep with normal mean and standard deviation ETA levels.

The 2-way ANOVA examining the effects of sector and season of sacrifice on mean ETA provided similar results to 2 way ANOVA comparing sector, season of sacrifice and standard deviation ETA, Table 2. The result of the analyses led to the 
conclusion that there is no demonstrable significant difference in mean ETA or standard deviation ETA in the interaction between sector and season of sacrifice. However, there is evidence of a difference in the mean ETA as well as the standard deviation ETA within the different seasons of sacrifice. Essentially within the control group, the sector does not affect the mean/standard deviation ETA.

Table 2 2-Way ANOVA statistical analysis results for the ewe sacrificed 3 months post surgery.

\begin{tabular}{|l|r|r|l|}
\hline \multicolumn{4}{|c|}{ 2-Way ANOVA: Mean ETA } \\
\hline Parameter & F Value & P Value & Significance \\
\hline Sector & 0.192 & 0.956 & No \\
\hline Season of Sacrifice & 18.873 & $<0.001$ & Yes \\
\hline Sector x Season of Sacrifice & 0.102 & 1.00 & No \\
\hline \multicolumn{4}{|c|}{ 2 -Way ANOVA: Standard Deviation ETA } \\
\hline Parameter & F Value & P Value & Significance \\
\hline Sector & 0.958 & 0.446 & No \\
\hline Season of Sacrifice & 6.437 & $<0.001$ & Yes \\
\hline Sector $x$ Season of Sacrifice & 0.31 & 0.310 & No \\
\hline
\end{tabular}

To evaluate the seasonal effects, it is necessary to look further into the results using a post-hoc Fisher LSD analysis to determine the differences in ETA. The analysis comparing the seasonal ETAs can be seen in Table 3. The statistical analysis of the mean ETA shows the following results, $($ spring $=$ fall $) \neq($ winter $=$ summer $)$, where $\neq$ demonstrates significant statistical difference and $=$ demonstrates no significant difference. The mean ETA of spring and fall are similar and the mean ETA of winter and summer are similar. The analysis comparing the standard deviation ETA present (winter $=$ fall $\neq$ spring $=$ summer. The standard deviation of winter and fall are similar but both different from spring and similar to summer. These comparisons between mean and standard deviation ETA are the basic differences in season for a healthy sheep. 
Table 3 Summary of Fisher LSD comparisons for the 2-Way ANOVA analysis of season within the control group of sheep sacrificed at 3 months.

\begin{tabular}{|l|r|l|}
\hline \multicolumn{3}{|c|}{ Fisher LSD: Mean ETA \& Season of Sacrifice } \\
\hline Sacrifice Season within Control & P Value & Difference \\
\hline Comparison & $<0.001$ & Yes \\
\hline Summer vs. Fall & $<0.001$ & Yes \\
\hline Summer vs. Spring & 0.238 & No \\
\hline Summer vs. Winter & $<0.001$ & Yes \\
\hline Winter vs. Fall & $<0.001$ & Yes \\
\hline Winter vs. Spring & 0.68 & No \\
\hline Spring vs. Fall & \\
\hline \multicolumn{3}{|c|}{ Fisher LSD: SD ETA \& Season of Sacrifice } \\
\hline \multicolumn{2}{|c|}{} \\
\hline Sacrifice Season within Control & P Value & Difference \\
\hline Comparison & $<0.001$ & Yes \\
\hline Winter vs. Spring & $<0.001$ & Yes \\
\hline Winter vs. Summer & 0.066 & No \\
\hline Wnter vs. Fall & 0.03 & Yes \\
\hline Fall vs. Spring & 0.117 & No \\
\hline Fall vs. Summer & 0.498 & No \\
\hline Summer vs. Spring & \\
\hline
\end{tabular}

\subsection{3-Way ANOVA}

Two groups of 3-way ANOVA analyses were performed using Sigma Plot 11.0 (Systat Software, Inc.): the first to compare the different factors by mean ETA; and the second by standard deviation ETA.

\subsubsection{3-Way ANOVA: Season of Sacrifice}

Two 3-way ANOVA analyses were performed using Sigma Plot 11.0 (Systat Software, Inc.): the first to analyze the effects of sector, treatment, and season of sacrifice on the dependent variable mean ETA; and the second to analyze the effects of sector, treatment, and season of sacrifice on the dependent variable standard deviation ETA.

The comparison of sector, treatment, and sacrifice season, using the mean ETA as 
the dependent data variable provided the following results. The 3 way interaction, sector*treatment* season of sacrifice, did not produce a statistically significant interaction, Table 4. The analysis compared interactions between sector and treatment, sector and season of sacrifice, and treatment and season of sacrifice. The treatment and season of sacrifice interaction showed statistical significance. Based on the significant interactions and p-values, it was concluded there is no significant difference between sectors when comparing mean ETA. The same results were observed when comparing standard deviation ETA. In OVX and control animals the variation in the density of the bone material in the radius is similar between anatomical sectors, for animals sacrificed 3 months post ovariectomy.

Table 4 3-Way ANOVA results, including season of sacrifice. Analysis performed at significance level of .05 .

\begin{tabular}{|l|r|r|l|}
\hline \multicolumn{4}{|c|}{ 3-Way ANOVA: Mean ETA \& Season of Sacrifice } \\
\hline Parameter & F Value & P Value & Significance \\
\hline Sector & 0.779 & 0.551 & No \\
\hline Treatment & 45.122 & $<0.001$ & Yes \\
\hline Season of Sacrifice & 46.557 & $<0.001$ & Yes \\
\hline Sector x Treatment & 0.463 & 0.803 & No \\
\hline Sector x Season of Sacrifice & 0.549 & 0.911 & No \\
\hline Treatment x Season of Sacrifice & 12.57 & $<0.001$ & Yes \\
\hline Sector x Treatment x Season of Sacrifice & 0.262 & 0.998 & No \\
\hline \multicolumn{3}{|c|}{ 3-Way ANOVA: SD ETA \& Season of Sacrifice } \\
\hline Parameter & F Value & P Value & Significance \\
\hline Sector & 0.783 & 0.563 & No \\
\hline Treatment & 0.715 & 0.398 & No \\
\hline Season of Sacrifice & 11.939 & $<0.001$ & Yes \\
\hline Sector x Treatment & 0.248 & 0.941 & No \\
\hline Sector x Season of Sacrifice & 0.247 & 0.998 & No \\
\hline Treatment x Season of Sacrifice & 4.648 & 0.003 & Yes \\
\hline Sector x Treatment x Season of Sacrifice & 0.33 & 0.992 & No \\
\hline
\end{tabular}


To evaluate the seasonal interactions, it is necessary to look further into the results using a post-hoc Fisher LSD analysis to determine the differences in ETA. The analysis to determine the differences in mean ETA was completed for the significant interactions, Table 5. In the group of ewe who underwent an ovariectomy the following interactions were observed for mean ETA, fall $\neq($ spring $=$ summer $=$ winter $)$. Thus, fall shows a difference in mean ETA from any other season and spring, summer, and winter are not demonstrably different from each other. In the control group, differences were assessed for mean ETA, spring $\neq$ summer $\neq($ winter $=$ fall $)$. Thus, spring and summer show a significant difference from any other season, and winter and fall are not statistically different.

The same interactions seen with season of sacrifice were observed in the comparisons between sector, treatment, and season of sacrifice using the dependent variable standard deviation ETA, Table 4. The standard deviation ETA analysis produced different Fisher LSD results than those seen using mean ETA, Table 5. Based on the Fisher LSD analysis using standard deviation ETA for the OVX treatment group, fall $\neq(($ winter $\neq$ spring $)=$ summer $)$. The standard deviation ETA of fall is significantly different than all other seasons and the standard deviation ETA of winter and spring are different but are both similar to summer. Within the control group, differences were assessed for the standard deviation ETA, fall $=(\operatorname{spring} \neq($ winter $=$ summer $))$. Fall is similar to all other seasons. 
Table 5 Summary of post hoc Fisher LSD Analysis for data containing season of sacrifice. Data table has been separated by mean ETA and standard deviation ETA.

\begin{tabular}{|c|c|c|}
\hline \multicolumn{3}{|c|}{ Fisher LSD: Mean ETA \& Season of Sacrifice } \\
\hline \multicolumn{3}{|c|}{ Sacrifice Season within OVX } \\
\hline Comparison & P Value & Difference \\
\hline Winter vs. Fall & $<0.001$ & Yes \\
\hline Winter vs. Summer & 0.139 & No \\
\hline Winter vs. Spring & 0.713 & No \\
\hline Spring vs. Fall & $<0.001$ & Yes \\
\hline Spring vs. Summer & 0.26 & No \\
\hline Summer vs. Fall & 0.005 & Yes \\
\hline \multicolumn{3}{|c|}{ Sacrifice Season within Control } \\
\hline Comparison & P Value & Difference \\
\hline Spring vs. Fall & $<0.001$ & Yes \\
\hline Spring vs. Winter & $<0.001$ & Yes \\
\hline Spring vs. Summer & 0.017 & Yes \\
\hline Summer vs. Fall & $<0.001$ & Yes \\
\hline Summer vs. Winter & $<0.001$ & Yes \\
\hline Winter vs. Fall & 0.314 & No \\
\hline \multicolumn{3}{|c|}{ Fisher LSD: Standard Deviation ETA \& Season of Sacrifice } \\
\hline \multicolumn{3}{|c|}{ Sacrifice Season within OVX } \\
\hline Comparison & P Value & Difference \\
\hline Fall vs. Winter & $<0.001$ & Yes \\
\hline Fall vs. Summer & $<0.001$ & Yes \\
\hline Fall vs. Spring & $<0.001$ & Yes \\
\hline Spring vs. Winter & 0.016 & Yes \\
\hline Spring vs. Summer & 0.064 & No \\
\hline Summer vs. Winter & 0.633 & No \\
\hline \multicolumn{3}{|c|}{ Sacrifice Season within Control } \\
\hline Comparison & P Value & Difference \\
\hline Spring vs. Summer & 0.004 & Yes \\
\hline Spring vs. Winter & 0.016 & Yes \\
\hline Spring vs. Fall & 0.100 & No \\
\hline Fall vs. Summer & 0.211 & No \\
\hline Fall vs. Winter & 0.434 & No \\
\hline Winter vs. Summer & 0.639 & No \\
\hline
\end{tabular}




\subsubsection{3-Way ANOVA: Season of Surgery}

Two 3-way ANOVA's were also performed using Sigma Plot 11.0 (Systat

Software, Inc.) to analyze the impact of the sector, treatment, and season of surgery with the dependent data variables mean ETA for the first analysis and standard deviation ETA in the second analysis.

The analysis results comparing sector, treatment, and season of surgery based on mean ETA are provided in Table 6 . The tested interaction between sector, treatment, and season of surgery showed no significant interaction. The ANOVA further compared interactions between sector and treatment, sector and season of surgery, and treatment and season of surgery. The results of the ANOVA led to the conclusion that there is a significant interaction between treatment and season of surgery. The main effects of sector do not show a significant impact on mean ETA. The significant results of the interactions comparing standard deviation ETA are the same as those comparing mean ETA, Table 6. 
Table 6 3-Way ANOVA results based on season of surgery for the animals sacrificed at 3 months. Analysis was performed at significance level of $\mathbf{0 5}$.

\begin{tabular}{|l|r|r|l|}
\hline \multicolumn{4}{|c|}{ 3-Way ANOVA: Mean ETA \& Season of Surgery } \\
\hline Parameter & F Value & P Value & Significance \\
\hline Sector & 0.779 & 0.551 & No \\
\hline Treatment & 45.122 & $<0.001$ & Yes \\
\hline Season of Surgery & 46.557 & $<0.001$ & Yes \\
\hline Sector $x$ Treatment & 0.463 & 0.803 & No \\
\hline Sector $x$ Season of Surgery & 0.549 & 0.911 & No \\
\hline Treatment x Season of Surgery & 12.57 & $<0.001$ & Yes \\
\hline Sector x Treatment x Season of Surgery & 0.262 & 0.998 & No \\
\hline \multicolumn{3}{|c|}{ 3-Way ANOVA: Standard Deviation ETA \& Season of Surgery } \\
\hline Parameter & F Value & P Value & Significance \\
\hline Sector & 0.783 & 0.563 & No \\
\hline Treatment & 0.715 & 0.398 & No \\
\hline Season of Surgery & 11.939 & $<0.001$ & Yes \\
\hline Sector $x$ Treatment & 0.248 & 0.941 & No \\
\hline Sector $x$ Season of Surgery & 0.247 & 0.998 & No \\
\hline Treatment x Season of Surgery & 4.648 & 0.003 & Yes \\
\hline Sector x Treatment x Season of Surgery & 0.33 & 0.992 & No \\
\hline
\end{tabular}

Based on the analysis comparing mean ETA, the interactions between the significant factors, the results of this post hoc Fisher LSD analysis are seen in Table 7. Ewe who underwent an ovariectomy showed differences in mean ETA, summer $\neq$ (fall $=$ spring $=$ winter $)$. The mean ETA sheep ovariectomized during the summer is significantly different than those who had the surgery in fall, spring, or winter, who have similar mean ETA values. The control group showed differences in mean ETA as well, winter $\neq$ spring $\neq$ (fall $=$ summer $)$. The mean ETA in winter and spring were significantly different than the mean ETA in fall and summer, which showed similar results. These differences are different from those seen with season of sacrifice as a variable. 
The differences in the post hoc Fisher LSD analysis based on standard deviation ETA are seen in Table 7. Significant differences in standard deviation ETA in ewes who underwent an ovariectomy were evident, summer $\neq(($ fall $\neq$ winter $)=$ spring $)$. The standard deviation ETA within summer is different from all other seasons. In ewes who underwent a sham operation, the Fisher analysis of standard deviation ETA demonstrated that summer $=(($ fall $=$ spring $) \neq$ winter $)$. Fall and spring show similar standard deviations in ETA, as does summer with all other seasons. Winter appears to show significantly different results from fall and spring. The evident differences within treatment based on season of surgery are different than those seen based on season of sacrifice. 
Table 7 Summary of post hoc Fisher LSD Analysis for data including season of surgery. Data table has been separated by mean ETA and standard deviation ETA.

\begin{tabular}{|c|c|c|}
\hline \multicolumn{3}{|c|}{ Fisher LSD: Mean ETA \& Season of Surgery } \\
\hline \multicolumn{3}{|c|}{ Season of Surgery within OVX } \\
\hline Comparison & P Value & Difference \\
\hline Fall vs. Summer & $<0.001$ & Yes \\
\hline Fall vs. Spring & 0.139 & No \\
\hline Fall vs. Winter & 0.713 & No \\
\hline Winter vs. Summer & $<0.001$ & Yes \\
\hline Winter vs. Spring & 0.26 & No \\
\hline Spring vs. Summer & 0.005 & Yes \\
\hline \multicolumn{3}{|c|}{ Season of Surgery within Control } \\
\hline Comparison & P Value & Difference \\
\hline Winter vs. Summer & $<0.001$ & Yes \\
\hline Winter vs. Fall & $<0.001$ & Yes \\
\hline Winter vs. Spring & 0.017 & Yes \\
\hline Spring vs. Summer & $<0.001$ & Yes \\
\hline Spring vs. Fall & $<0.001$ & Yes \\
\hline Fall vs. Summer & 0.314 & No \\
\hline \multicolumn{3}{|c|}{ Fisher LSD: Standard Deviation ETA \& Season of Surgery } \\
\hline \multicolumn{3}{|c|}{ Season of Surgery within OVX } \\
\hline Comparison & P Value & Difference \\
\hline Summer vs. Fall & $<0.001$ & Yes \\
\hline Summer vs. Spring & $<0.001$ & Yes \\
\hline Summer vs. Winter & $<0.001$ & Yes \\
\hline Winter vs. Fall & 0.016 & Yes \\
\hline Winter vs. Spring & 0.064 & No \\
\hline Spring vs. Fall & 0.633 & No \\
\hline \multicolumn{3}{|c|}{ Season of Surgery within Control } \\
\hline Comparison & P Value & Difference \\
\hline Winter vs. Spring & 0.004 & Yes \\
\hline Winter vs. Fall & 0.016 & Yes \\
\hline Winter vs. Summer & 0.1 & No \\
\hline Summer vs. Spring & 0.211 & No \\
\hline Summer vs. Fall & 0.434 & No \\
\hline Fall vs. Spring & 0.639 & No \\
\hline
\end{tabular}




\subsection{Frequency Distributions}

Frequency distributions of each group of treatments were analyzed to better understand the distribution of the data. The ETA for all groups at each bone pixel was separated into 20 equal bins and graphed, Figure 13. The ETA was separated into OVX and sham surgery ETA values and graphed showing a count of the ETA values present in each of 20 bins, Figure 14. ETA was segregated by anatomical sector and graphed in 20 bins, Figure 15. The figure includes all 6 anatomical sectors on the same graph. Once the similarities in anatomical sector were seen, each sector was separated by OVX and sham ewe and graphed, Figure 16 - Figure 21.

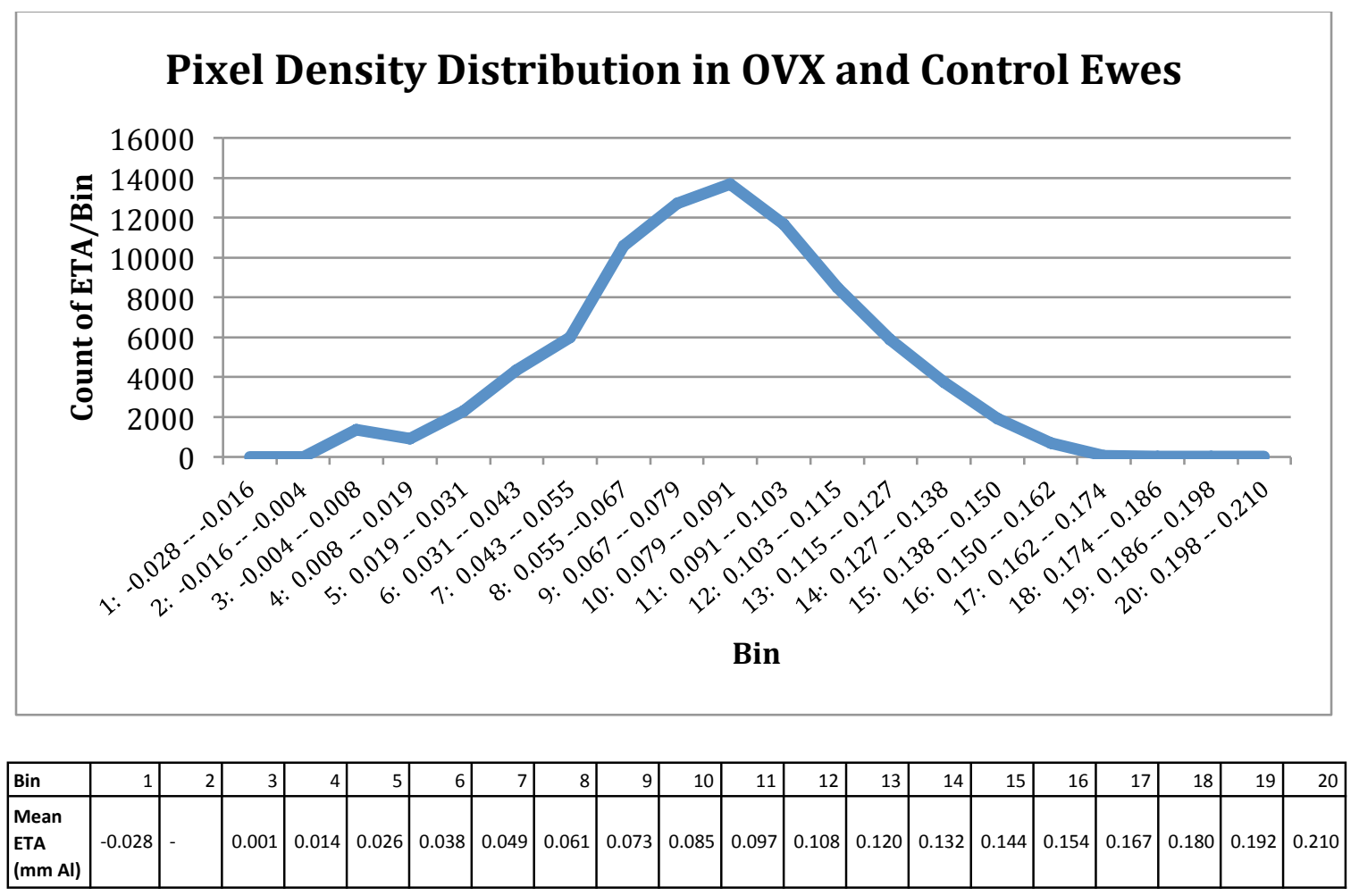

Figure 13. A frequency curve distribution, which includes all ETA values for sheep sacrificed at 3 months, including OVX and control. The $x$ axis contains bins 1-20, additionally displaying the range of each bin. The mean of each bin can be seen in the table below the graph. 


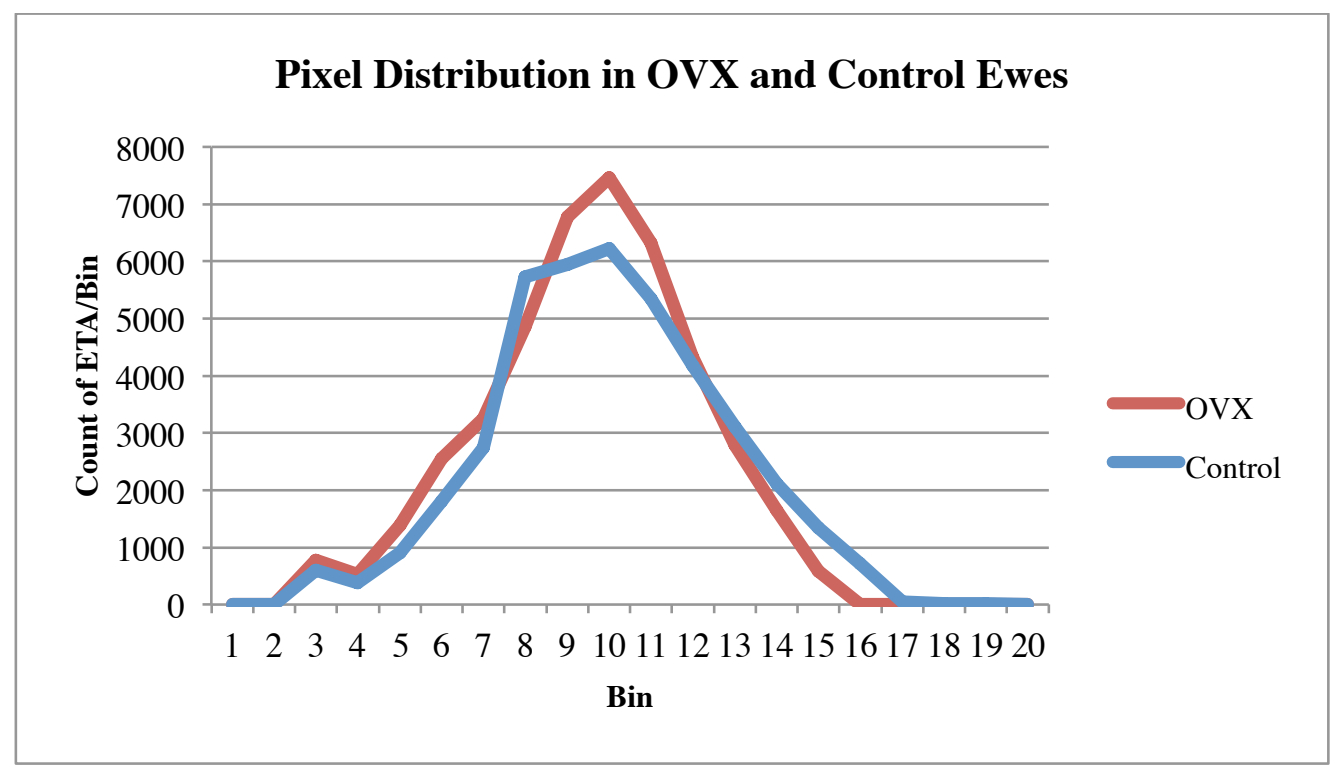

\begin{tabular}{|l|r|r|r|r|r|r|r|r|r|r|r|r|r|r|r|r|r|r|r|r|r|}
\hline Bin & 1 & 2 & 3 & 4 & 5 & 6 & 7 & 8 & 9 & 10 & 11 & 12 & 13 & 14 & 15 & 16 & 17 & 18 & 19 & 20 \\
\hline $\begin{array}{l}\text { OVX: Mean } \\
\text { ETA (mm Al) }\end{array}$ & -- & -- & 0.001 & 0.014 & 0.026 & 0.038 & 0.050 & 0.062 & 0.073 & 0.085 & 0.096 & 0.108 & 0.120 & 0.132 & 0.142 & -- & -- & -- & - & -- \\
\hline $\begin{array}{l}\text { Control: } \\
\begin{array}{l}\text { Mean ETA } \\
\text { (mm Al) }\end{array}\end{array}$ & -0.028 & -- & 0.001 & 0.014 & 0.026 & 0.038 & 0.049 & 0.061 & 0.074 & 0.085 & 0.097 & 0.108 & 0.120 & 0.132 & 0.144 & 0.154 & 0.167 & 0.180 & 0.192 & 0.210 \\
\hline
\end{tabular}

Figure 14. A frequency curve distribution including ETA values separated into OVX and control ewes, for ewes sacrificed at 3 months. The mean of each bin for OVX and control groups can be seen in the table below the graph. The bin distribution is equal to that seen in Figure 13. 


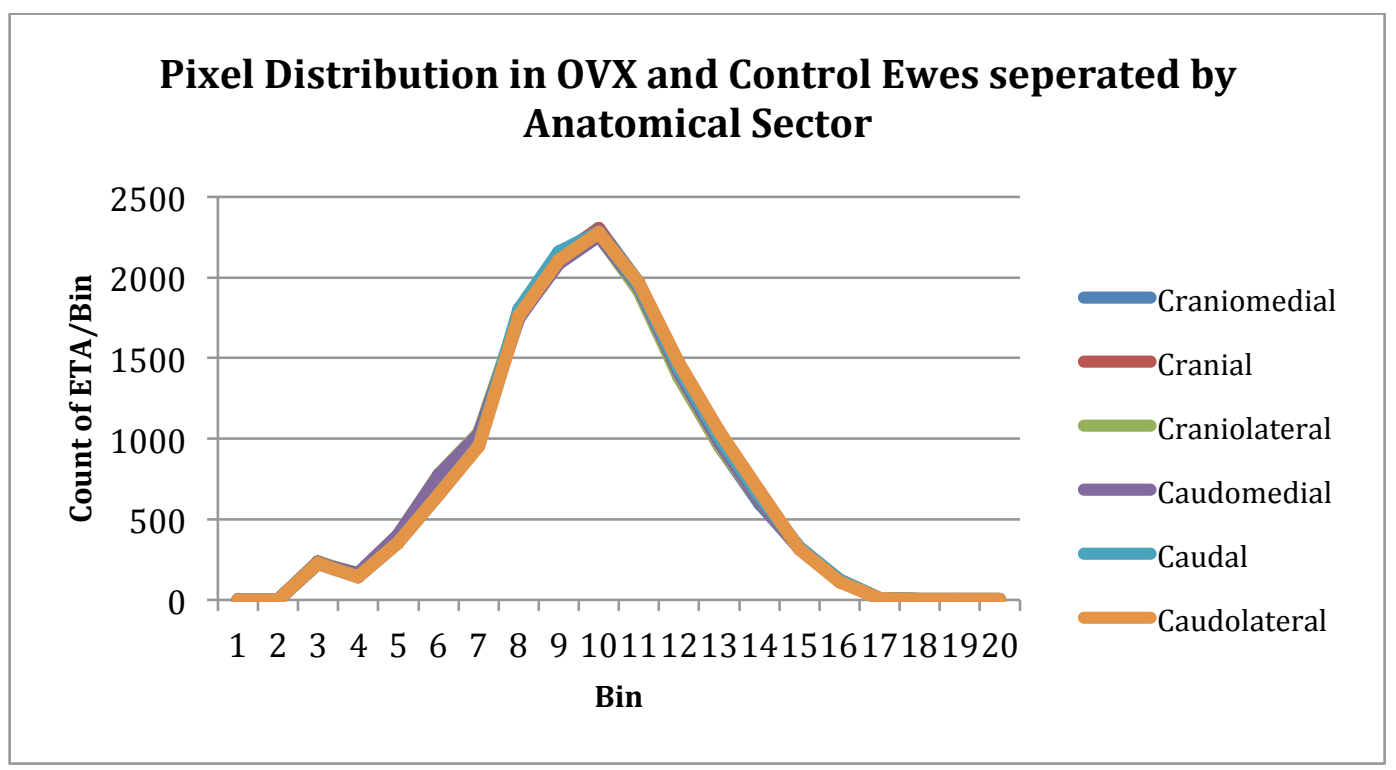

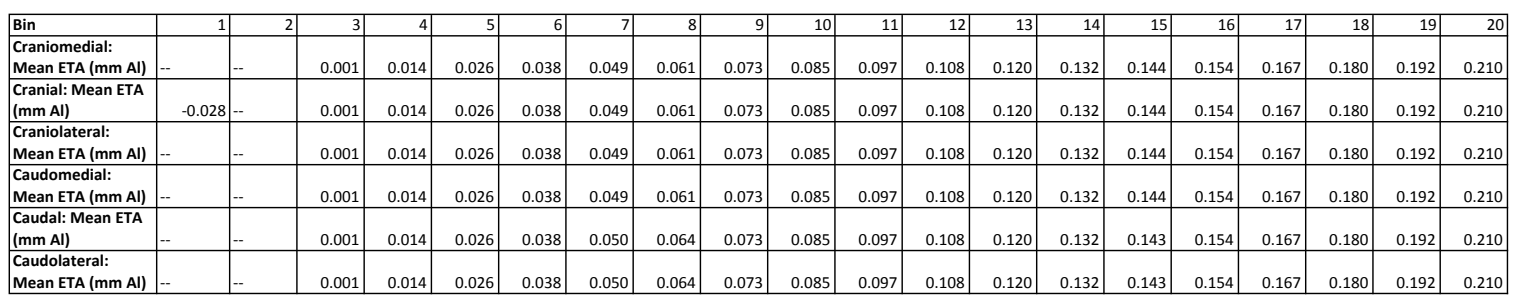

Figure 15. A frequency distribution of the count of ETA in each bin group in each anatomical sector for all ewes sacrificed at 3 months. The mean of each bin can be seen in the table below the graph.

The bin distribution is equal to that seen in Figure 13. 


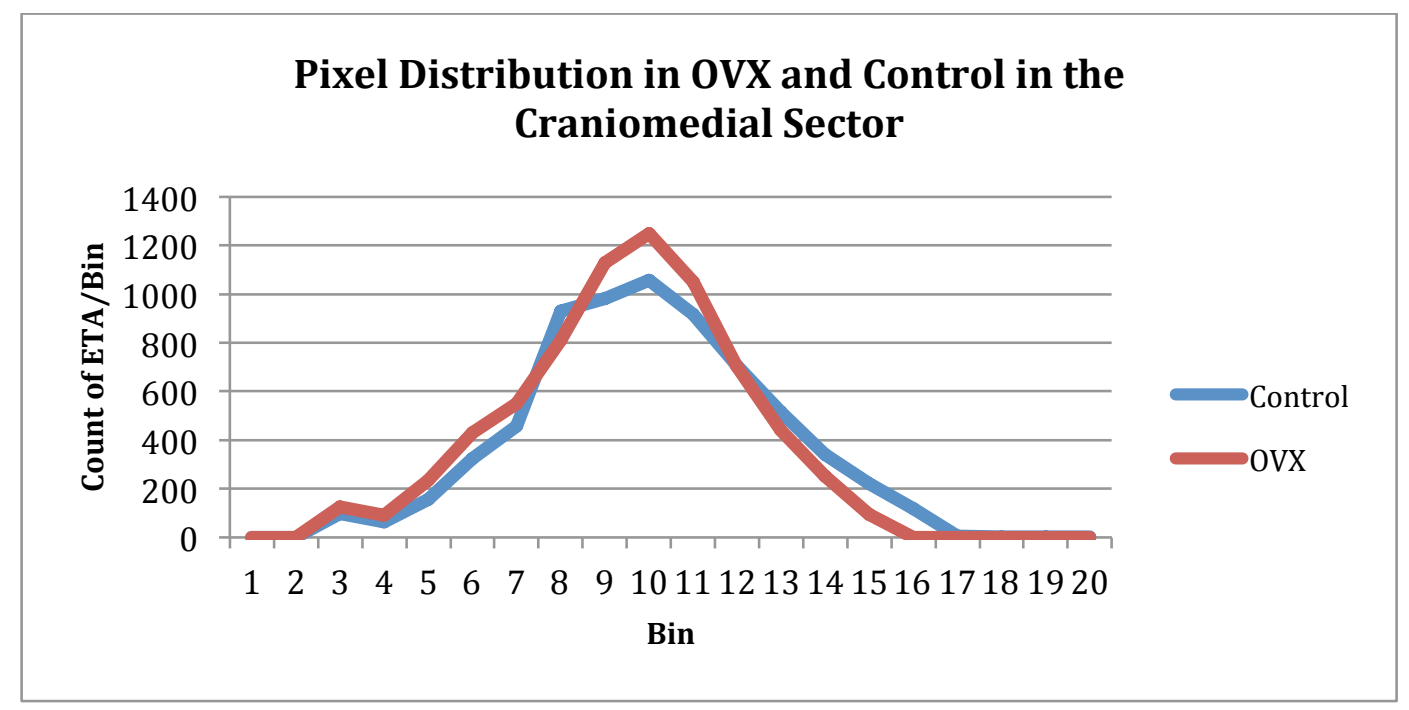

\begin{tabular}{|c|c|c|c|c|c|c|c|c|c|c|c|c|c|c|c|c|c|c|c|c|}
\hline Bin & 1 & 2 & 3 & 4 & 5 & 6 & 7 & 8 & 9 & 10 & 11 & 12 & 13 & 14 & 15 & 16 & 17 & 18 & 19 & 20 \\
\hline $\begin{array}{l}\text { Craniomedial (Control): } \\
\text { Mean ETA (mm Al) }\end{array}$ & - & - & 0.001 & 0.014 & 0.026 & 0.038 & 0.049 & 0.061 & 0.073 & 0.085 & 0.097 & 0.108 & 0.120 & 0.132 & 0.144 & 0.154 & 0.167 & 0.180 & 0.192 & 0.210 \\
\hline $\begin{array}{l}\text { Craniomedial (OVX): } \\
\text { Mean ETA (mm Al) }\end{array}$ & - & - & 0.001 & 0.014 & 0.026 & 0.038 & 0.050 & 0.062 & 0.073 & 0.085 & 0.096 & 0.108 & 0.120 & 0.132 & 0.142 & - & - & - & - & - \\
\hline
\end{tabular}

Figure 16. Count of ETA for craniomedial sector separated by control and sham ewe, for ewe sacrificed at 3 months. The table below the graph shows the mean of each bin. The bin distribution is equal to that seen in Figure 13.

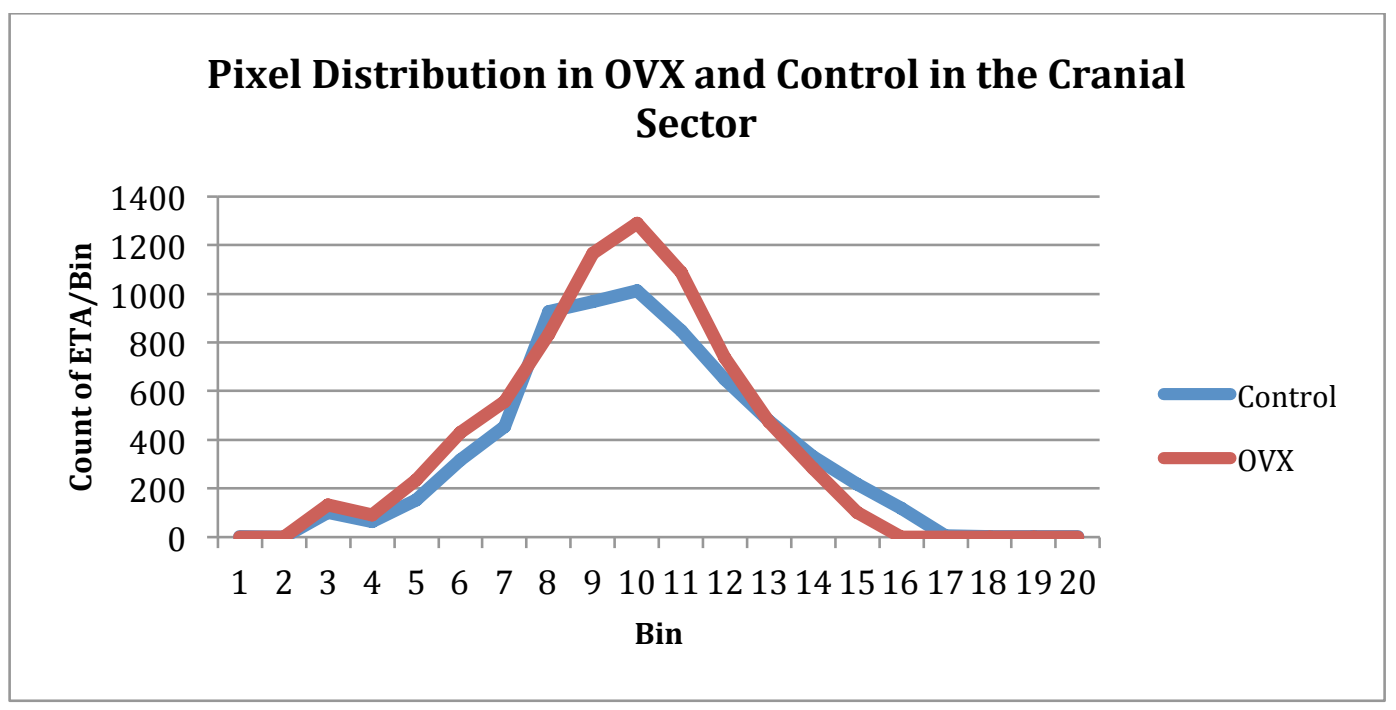

\begin{tabular}{|l|r|r|r|r|r|r|r|r|r|r|r|r|r|r|r|r|r|r|r|r|}
\hline Bin & 1 & 2 & 3 & 4 & 5 & 6 & 7 & 8 & 9 & 10 & 11 & 12 & 13 & 14 & 15 & 16 & 17 & 18 & 19 & 20 \\
\hline $\begin{array}{l}\text { Cranial (Control): Mean } \\
\text { ETA (mm Al) }\end{array}$ & -0.028 & - & 0.001 & 0.014 & 0.026 & 0.038 & 0.049 & 0.061 & 0.073 & 0.085 & 0.097 & 0.108 & 0.120 & 0.132 & 0.144 & 0.154 & 0.167 & 0.180 & 0.192 & 0.210 \\
\hline $\begin{array}{l}\text { Cranial (OVX): Mean ETA } \\
\text { (mm Al) }\end{array}$ & - & - & 0.001 & 0.014 & 0.026 & 0.038 & 0.050 & 0.062 & 0.073 & 0.085 & 0.096 & 0.108 & 0.120 & 0.132 & 0.142 & - & - & - & - & - \\
\hline
\end{tabular}

Figure 17. Count of ETA for cranial sector separated by control and sham ewe, for ewe sacrificed at 3 months. The table below the graph shows the mean of each bin. The bin distribution is equal to that seen in Figure 13. 


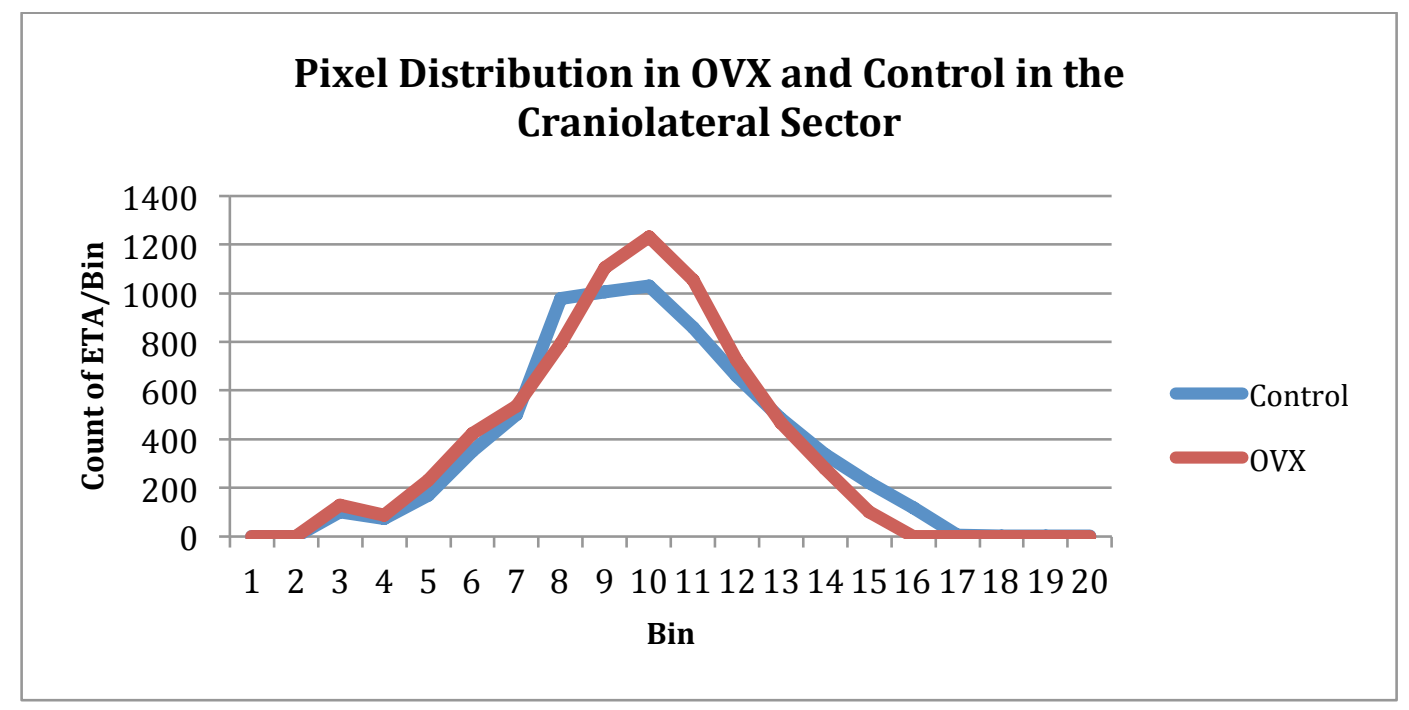

\begin{tabular}{|l|r|r|r|r|r|r|r|r|r|r|r|r|r|r|r|r|r|r|r|r|}
\hline Bin & 1 & 2 & 3 & 4 & 5 & 6 & 7 & 8 & 9 & 10 & 11 & 12 & 13 & 14 & 15 & 16 & 17 & 18 & 19 & 20 \\
\hline $\begin{array}{l}\text { Craniolateral (Control): } \\
\text { Mean ETA (mm Al) }\end{array}$ & - & - & $7 \mathrm{E}-04$ & 0.014 & 0.026 & 0.038 & 0.049 & 0.061 & 0.073 & 0.085 & 0.097 & 0.108 & 0.12 & 0.132 & 0.144 & 0.154 & 0.167 & 0.18 & 0.192 & 0.21 \\
\hline $\begin{array}{l}\text { Craniolateral (OVX): } \\
\text { Mean ETA (mm Al) }\end{array}$ & - & - & $7 \mathrm{E}-04$ & 0.014 & 0.026 & 0.038 & 0.05 & 0.062 & 0.073 & 0.085 & 0.096 & 0.108 & 0.12 & 0.132 & 0.142 & - & - & - & - & - \\
\hline
\end{tabular}

Figure 18. Count of ETA for craniolateral sector separated by control and sham ewe, for ewe sacrificed at 3 months. The table below the graph shows the mean of each bin. The bin distribution is equal to that seen in Figure 13.

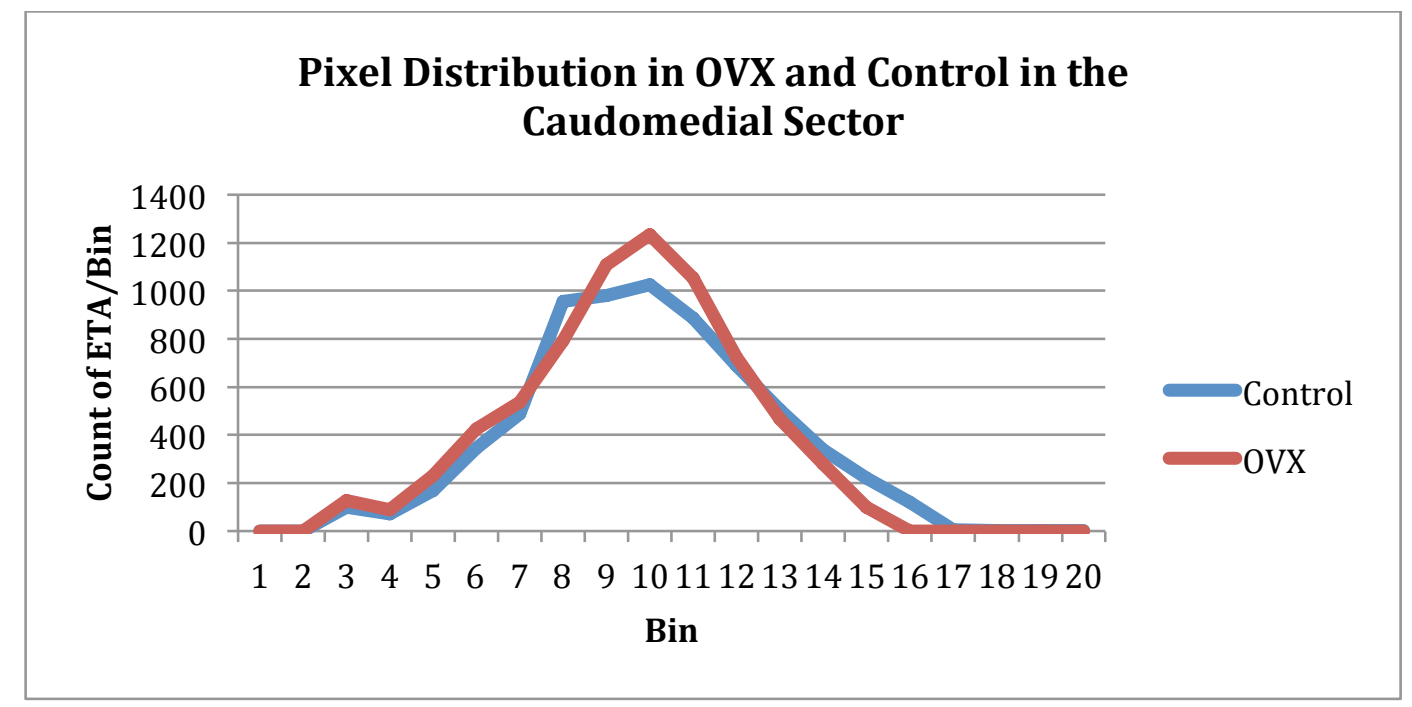

\begin{tabular}{|l|r|r|r|r|r|r|r|r|r|r|r|r|r|r|r|r|r|r|r|r|}
\hline Bin & 1 & 2 & 3 & 4 & 5 & 6 & 7 & 8 & 9 & 10 & 11 & 12 & 13 & 14 & 15 & 16 & 17 & 18 & 19 & 20 \\
\hline $\begin{array}{l}\text { Caudomediall (Control): } \\
\text { Mean ETA (mm Al) }\end{array}$ & - & - & $7 \mathrm{E}-04$ & 0.014 & 0.026 & 0.038 & 0.049 & 0.061 & 0.073 & 0.085 & 0.097 & 0.108 & 0.12 & 0.132 & 0.144 & 0.154 & 0.167 & 0.18 & 0.192 & 0.21 \\
\hline $\begin{array}{l}\text { Caudomedial (OVX): } \\
\text { Mean ETA (mm Al) }\end{array}$ & - & - & $7 \mathrm{~m}-04$ & 0.014 & 0.026 & 0.038 & 0.05 & 0.062 & 0.073 & 0.085 & 0.096 & 0.108 & 0.12 & 0.132 & 0.142 & - & - & - & - & - \\
\hline
\end{tabular}

Figure 19. Count of ETA for caudomedial sector separated by control and sham ewe, for ewe sacrificed at 3 months. The table below the graph shows the mean of each bin. The bin distribution is equal to that seen in Figure 13. 


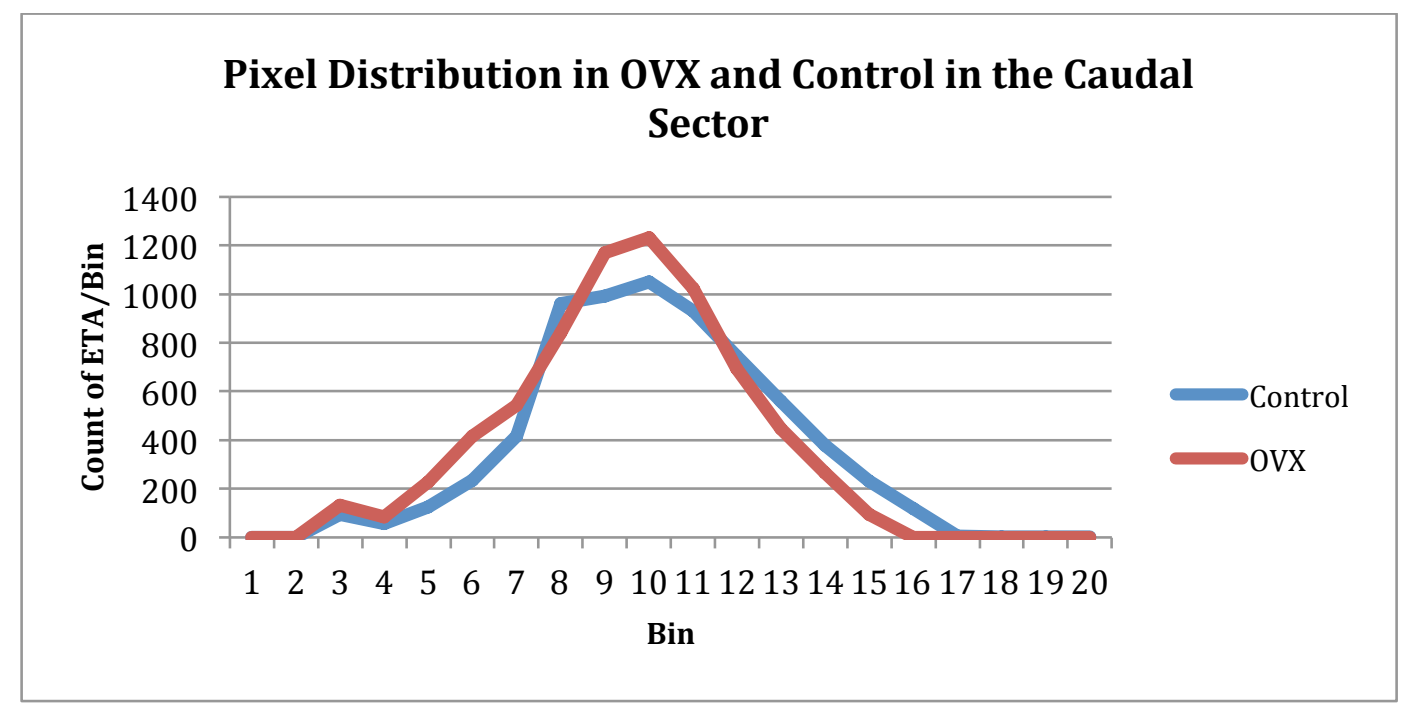

\begin{tabular}{|c|c|c|c|c|c|c|c|c|c|c|c|c|c|c|c|c|c|c|c|c|}
\hline Bin & 1 & 2 & 3 & 4 & 5 & 6 & 7 & 8 & 9 & 10 & 11 & 12 & 13 & 14 & 15 & 16 & 17 & 18 & 19 & 20 \\
\hline $\begin{array}{l}\text { Caudal (Control): Mean } \\
\text { ETA (mm Al) }\end{array}$ & - & - & $6 \mathrm{E}-04$ & 0.014 & 0.026 & 0.038 & 0.05 & 0.061 & 0.073 & 0.085 & 0.097 & 0.108 & 0.12 & 0.132 & 0.144 & 0.154 & 0.167 & 0.18 & 0.192 & 0.21 \\
\hline $\begin{array}{l}\text { Caudal (OVX): Mean ETA } \\
\text { (mm Al) }\end{array}$ & - & - & $7 E-04$ & 0.014 & 0.026 & 0.038 & 0.05 & 0.062 & 0.073 & 0.085 & 0.096 & 0.108 & 0.12 & 0.132 & 0.142 & - & - & - & - & - \\
\hline
\end{tabular}

Figure 20. Count of ETA for caudal sector separated by control and sham ewe, for ewe sacrificed at 3 months. The table below the graph shows the mean of each bin. The bin distribution is equal to that seen in Figure 13.

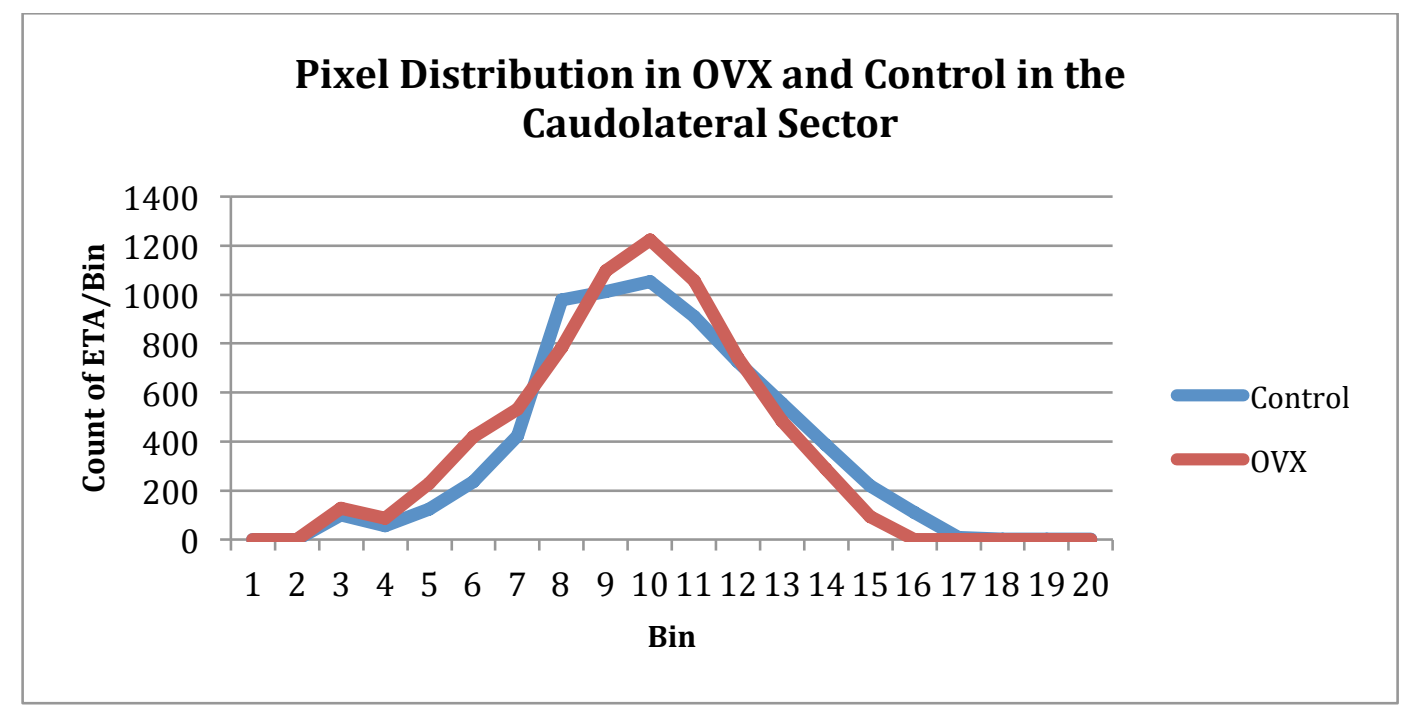

\begin{tabular}{|l|r|r|r|r|r|r|r|r|r|r|r|r|r|r|r|r|r|r|r|r|}
\hline Bin & 1 & 2 & 3 & 4 & 5 & 6 & 7 & 8 & 9 & 10 & 11 & 12 & 13 & 14 & 15 & 16 & 17 & 18 & 19 & 20 \\
\hline $\begin{array}{l}\text { Caudolateral (Control): } \\
\text { Mean ETA (mm Al) }\end{array}$ & - & - & $6 \mathrm{E}-04$ & 0.014 & 0.026 & 0.038 & 0.05 & 0.061 & 0.073 & 0.085 & 0.097 & 0.108 & 0.12 & 0.132 & 0.144 & 0.154 & 0.167 & 0.18 & 0.192 & 0.21 \\
\hline $\begin{array}{l}\text { Caudolateral (OVX): Mean } \\
\text { ETA (mm Al) }\end{array}$ & - & - & $7 \mathrm{E}-04$ & 0.014 & 0.026 & 0.038 & 0.05 & 0.062 & 0.073 & 0.085 & 0.096 & 0.108 & 0.12 & 0.132 & 0.142 & - & - & - & - & - \\
\hline
\end{tabular}

Figure 21. Count of ETA for caudolateral sector separated by control and sham ewe, for ewe sacrificed at 3 months. The table below the graph shows the mean of each bin. The bin distribution is equal to that seen in Figure 13. 


\section{ANALYSIS AND DISCUSSION}

Individuals who have been diagnosed with osteoporosis are considered to have a low bone mineral density causing bone fragility and an increased risk of bone fracture [18]. The condition has become a financial detriment to society, costing $\$ 5-\$ 10$ billion in healthcare annually [2]. Many of the dollars are spent treating patients with fractures and related health conditions caused by the decreased bone mass. The disease is often diagnosed using a Dual energy X-ray absorptiometer. If the bone density levels fall within the range of osteoporosis then the patient is diagnosed with the disease [30]. When diagnosed with osteoporosis early, several preventative treatments are possible [23]. Patients can be treated with pharmacological treatments including bisphosphonates, estrogen/progesterone or SERM's [24], [22]. The objective of treatments is to reduce the impact of decreased bone mineral density on daily activities.

In this study, low bone density levels were evaluated in sheep that had a depletion of estrogen due to the removal of their ovaries. The result is induced estrogen depletion, which simulates a change in the bone material. Factors in the study included treatment, season of surgery, season of sacrifice, and anatomical sector. Variation in bone density data was evaluated comparing mean and standard deviation ETA. The mean ETA values represent the average amount of bone material present and the standard deviation ETA represents the variation within the amount of bone material. By understanding the variation within mean ETA for each group, it is possible to ascertain conclusions about how BMD shows variation with different levels of estrogen.

Sheep are an effective animal model to be used in the study of osteoporosis because of the characteristics similar to those in humans. The metabolic rate of a sheep is 
similar to that in a human [27]. Also, the regulation of hormones is similar to that in an adult woman [26]. When induced with estrogen depletion, sheep demonstrate a decrease in bone mineral density as well as bone loss. These are important similarities between humans and sheep to understand in the study, in addition to the docile nature of the animal.

In addition to the basic characteristic responses to estrogen depletion it is necessary to understand the reproductive response cycle in sheep. It is known that reproductive responses in sheep can differ based on several factors including season. Reproductive responses to shorter days are mediated by melatonin secreted by the pineal gland during the night. It has been proven that injections of melatonin into sheep with a removed pineal gland can stimulate the effect of shorter days, generally winter, and inhibit the effects of long days, generally the summer. During the day lengths of a typical breeding season, a marked rise in melatonin can be seen. Based on this knowledge, the capacity of estradiol to inhibit the frequency of the luteinizing hormone (LH) changes with season [31]. When LH is present estrus cycles are triggered. In sheep, the reproductive cycle in non-pregnant ewe consists of two distinct rhythms. The first consists of a regular estrus cycle, which extends from 16-17 days. The second is the anestrus cycle, during which no menstrual cycle occurs. The anestrus cycle is only present in ewes raised in a temperate climate. Estrogen has the greatest influence from mid November to late January, a winter estrus cycle [32]. The anestrus cycle generally occurs during spring, summer, and fall, from May to September [33]. Through this study, it was possible to better understand how these cycles affect the density of ovine bone from the various statistical analyses performed. 


\subsection{Analysis}

\subsubsection{Two-Way Analysis of Variance (ANOVA)}

The Two-Way ANOVA established a baseline in the control group to understand what results to expect under natural conditions. In a normal healthy sheep, the differences in mean and standard deviation ETA should be expected between the seasons of sacrifice, showing a variation in the remodeling process. The significance in the variation in mean and standard deviation ETA between seasons is assumed to be due to the variation in the estrus and anestrus cycles. Variations in the cycles cause deeper changes within the remodeling cycle, which is controlled heavily by estrogen, a chemical signal which initiates the activation, resorption, and formation (ARF) process of bone remodeling [6]. Based on the differences between average mean ETA in each season, the largest mean ETA is seen during winter. During winter, the sheep is likely in the period of estrus during which estrogen has the highest effect, promoting the ARF process which increases BMD through the regulation of the resorption phase [32], [8]. The control group of sheep sacrificed at 3 months was used as a baseline for the analysis comparison.

\subsubsection{Three-Way ANOVA Sheep Reproductive Response Analysis}

\subsubsection{Three-Way ANOVA: Season of Sacrifice}

The results of the 3-way ANOVA showed specific results demonstrating differences between the OVX and control ewes. The results showed a significant interaction between treatment and season of sacrifice, and an insignificant difference in anatomical sector, both for mean ETA and standard deviation ETA. The post surgery control group continued with a normal reproductive cycle; the OVX group's reproductive 
cycle was no longer present. With estrogen depletion, the estrus cycle is minimized and possibly eliminated causing the sheep to remain in the anestrus cycle. Theoretically estrogen depletion should cause the OVX group to remain at similar mean ETA levels throughout the year, however this is not the case in this study.

The results of the Fisher LSD analysis of the OVX group show fall mean ETA values being significantly different from all other seasons, while the mean ETA of spring, summer, and winter are similar. In typical osteoporosis treatment, increased intake of Vitamin D has been shown to maintain or increase bone mineral density [21]. Previous studies have begun to understand the effect of vitamin D on rats induced with osteopenia. It is believed that vitamin $\mathrm{D}$ stimulates bone formation through the regulation of bone resorption, being the driver of the formation of bone-resorbing osteoclasts acting in a similar fashion to estrogen [34]. Additionally, vitamin D alone is a driver of bone formation [34]. If vitamin $\mathrm{D}$ does in fact mimic the actions of estrogen during the remodeling cycle, longer days during the summer would promote bone formation increasing bone density, the results of which could be seen during the fall months, bone formation generally takes 3 months [6]. Although vitamin D is not as significant as estrogen in the bone remodeling process, with estrogen depleted in the OVX group similar results are seen when looking at the treatments when comparing standard deviation, the group with a surgery performed in the summer is identified as having the greatest influence on variation in ETA.

\subsubsection{3 way ANOVA: Season of Surgery}

The results of the 3-way ANOVA season of surgery are the same as those seen in the 3-way ANOVA based on season of sacrifice, because the sheep have only been 
through one remodeling cycle. Based on the Fisher LSD analysis, OVX ewes with surgeries performed in the summer months had a mean ETA significantly different from the mean ETA in any other month. The mean ETA values of all other months were similar. The higher mean ETA values seen in summer demonstrate an increased BMD. The increased BMD is potentially due to the additional vitamin D present in the sheep with a surgery performed during the summer. Vitamin D has the potential to mimic the effects of estrogen during the bone remodeling process [34]. Estrogen has been proven to decrease the activation of the resorption process, thus increasing bone density [8]. Within the control group of ewes, the healthy estrus cycle was present causing significant variation between seasons in mean ETA values. The affects of vitamin D are not as significant as those of estrogen in bone remodeling.

\subsubsection{Frequency Distributions}

Frequency distributions were developed to better understand the variation of ETA data in the control and OVX groups. Five different groupings of the data were graphed using the same bin groupings. The bins were created by determining the maximum and minimum mean ETA value and then dividing the range into 20 equal bins producing a count of the ETA values in each bin. The mean of the ETA values in each bin was then calculated. The most prominent variations were noticed in the Pixel Density Distribution in OVX and Control Ewes graph, Figure 14 and the graphs of Pixel Distribution in OVX and Control in each anatomical sector, Figure 19-Figure 21. The Pixel Distribution in OVX and Control Ewe separated by Sector, Figure 14 demonstrates the similarities between the ETA in each anatomical sector.

The peaks of the OVX curve appear to be approximately $15 \%$ taller than the 
control curve, displaying kurtosis. Within both the Pixel Density Distribution in OVX and Control Ewes and Pixel Distribution in OVX and Control in each anatomical sector, similar curves are seen in all of the graphs. The difference in the overall shape of the control curve shows a more even distribution than the OVX curve. Because of estrogen depletion, there is less variation in the bone density between seasons and more of the ewes are situated at a bone density in the middle.

\subsection{Limitations and Future Direction}

Within the design of the study there were specific limitations, including both those with a biological origin and those with a technical origin. Included in this list is the purchase cohort effect. When purchased at auction the sheep were already skeletally mature. Because they were already skeletally mature the sheep had already gone through several complete reproductive cycles which had the potential to affect the results. The previous reproductive cycles are not accounted for in this study. Also there were potential problems with the setup of the microradiographs. These problems included but were not limited to specific sectors appearing washed out under the microscope, some sectors were dense while others were not, and specific sectors were not visible despite the brightest lighting options. Each of the bone sections were in the range of 95-106 microns thick. If a bone sample was at the upper allowed thickness level, the viewing of this more dense sample was more problematic.

When imaging the microradiographs, a future possibility is to treat the images as grey-scale rather than using the full color capabilities of the camera. This could potentially improve visibility of the specimens, by eliminating the effect of the color temperature of the microscope and how the color changes with the rheostat setting. 
Potential future directions of study include further analysis of the sheep sacrificed at 12 months that were imaged as part of this study. Statistical analysis similar to what was completed in this study should be completed using the data from the sheep sacrificed at 12 months. The results of the 12-month statistical analysis could then be compared to the results of this study. Additionally the frequency distributions could be further analyzed using a Kolmogorov-Smirnov analysis to better understand the differences between the individual curves present on each distribution. 


\section{CONCLUSION}

The ovariectomized adult ewe was chosen as the economical animal model of choice used in the study to better understand the effects of estrogen depletion in bone. The sheep are an effective model for the study of osteoporosis because they have a metabolic rate similar to that in a human, a similar bone structure, and their docile nature allows for an easy study set up. There are specific limitations that were necessary to take into account, including the need for an ovariectomy to produce accelerated bone loss and a decrease in BMD to simulate osteoporosis caused by estrogen depletion. Sheep do not have a clear-cut menopause period and require the ovariectomy to mimic what is understood in humans. The goal of the study was to better understand the effects of estrogen depletion through the quantification of compact bone density in the ewe at different stages post ovariectomy.

The study separated the 112 ewes into different treatment groups based on season, treatment, and time of sacrifice. First the ovine were separated into groups based on season of surgery: fall, winter, spring, and summer. They were then further grouped into treatments: OVX and sham surgery (control). Post surgery, the groups were then sacrificed at either 3 or 12 months. Only the group sacrificed at 3 months were analyzed in this portion of the study. After sacrifice, the right and left radius and ulna were sent to Henry Ford Hospital for analysis. There the left radius was removed, cut, and ground to a thickness of $100 \mu \mathrm{m}$ for microradiograph imaging. When cut, the left radius was separated into 6 anatomical sectors to be used for analysis. The microradiographs contained all 6 anatomical sectors as well as an aluminum stepwedge that was used as the key. Each ewe sacrificed at 3 months and 12 months were imaged and densitometry 
analysis was completed on those sacrificed at 3 months. Statistical analysis was performed to understand the similarities and differences between treatment, anatomical sector variation, season of sacrifice, and season of surgery.

The densitometry analysis required the collection of images of each anatomical sector for all sheep as well as images of the corresponding key. When collecting the images it was important to maintain the same light intensity between anatomical sector and the corresponding stepwedge. Based on the light intensity, it was possible to produce a numerical pixel value from 0 to 255 . The distribution of the pixel counts was used to determine the equivalent thickness of aluminum (ETA) of each specimen using the parameters of the stepwedge. The unique ETA values of each specimen were used in further analysis to determine the differences between treatment, sector, season of sacrifice, and season of surgery.

The results of the densitometry analysis showed differences and similarities in compact bone density between treatment, sector, season of sacrifice, and season of surgery. Overall, there were significant differences between the sham surgery group (control) and the OVX group, due to the estrogen depletion caused by the ovariectomy. By removing estrogen control from the ewes, the normal reproductive cycle is eliminated causing the compact bone remodeling process to be altered. Within each sector, there also was a difference between the control and OVX groups. Differences were seen within the period of estrus during which estrogen has the most influence. The significance in treatment shows the difference in bone mineral density between a healthy adult and one affected by osteoporosis. The differences in cortical bone remodeling seen within season of sacrifice and season of surgery show the significance of potential non- 
hormonal effects such as vitamin D and other factors. Based on the results seen within the ovariectomized groups, the groups do not remain at similar mean ETA values throughout the year, potentially due to non-hormonal effects. Vitamin D is believed to stimulate bone formation in a similar fashion to estrogen by driving the ARF process. The variance seen could potentially be due to the longer days with increased sunlight exposure seen during the summer months.

The similarities and differences concluded in this study show the variation in bone density between a healthy animal and one affected by estrogen depletion. The conclusions of this study are important to take into account when developing new protocols to study the effects of estrogen depletion and its effect on the remodeling cycle and bone density. The effect of each factor considered in the analysis, including treatment, anatomical sector, season of surgery, and season of sacrifice, had different effects on the ewes. To better develop the results of this study it is necessary to better understand the hormonal effects on bone density and the reproductive cycle. The results of this study show varying levels of bone density within all significant factors, indicating that an ovariectomy, the season of sacrifice, and the season of surgery do have an effect on bone density. Variation in anatomical sector is minimal in the ovine model, based on the results of this study the bone density of each anatomical sector is similar. 


\section{REFERENCES}

1. Riggs, B.L. and L.J. Melton Iii, The worldwide problem of osteoporosis: Insights afforded by epidemiology. Bone, 1995. 17(5, Supplement 1): p. S505-S511.

2. Arens, D., et al., Seasonal changes in bone metabolism in sheep. The Veterinary Journal, 2007. 174(3): p. 585-591.

3. Kim, S.-M., et al., Prediction of survival, second fracture, and functional recovery following the first hip fracture surgery in elderly patients. Bone, 2012. 50(6): p. 1343-1350.

4. Saladin, K.S., Anatomy \& Physiology: The Unity of Form and Function. 5th ed, ed. M.H.H. Education2010, New York: McGraw Hill Higher Education.

5. Skeletal Cartilages. Chapter 6: Bones and Skeleal Tissue [cited 2012 Sept. 3, 2012].

6. R. Bruce Martin, D.B.B., Neil A. Sharkey, Skeletal Tissue Mechanics2004, New York: Springer.

7. Young, M.F., Bone matrix proteins: their function, regulation, and relationship to osteoporosis. Osteoporosis International, 2003. 14(0): p. 35-42.

8. Khosla, S., M.J. Oursler, and D.G. Monroe, Estrogen and the skeleton. Trends in Endocrinology \&amp; Metabolism, (0).

9. Seeman, E.a.P.D.D., Bone quality--the material and structural basis of bone strength and fragility. N Engl J Med, 2006. 354(21): p. 2250-2261.

10. Gallagher, J.C. and A.J. Sai, Molecular biology of bone remodeling: Implications for new therapeutic targets for osteoporosis. Maturitas, 2010. 65(4): p. 301-307.

11. Pivonka, P., et al., Theoretical investigation of the role of the $R A N K, \ddot{A} i R A N K L, \ddot{A} i O P G$ system in bone remodeling. Journal of Theoretical Biology, 2010. 262(2): p. 306-316.

12. Matsuo, K. and N. Irie, Osteoclast, Äiosteoblast communication. Archives of Biochemistry and Biophysics, 2008. 473(2): p. 201-209.

13. Ransj $\sqrt{ } \partial$, M., J. Sahli, and A. Lie, Expression of connexin $43 \mathrm{mRNA}$ in microisolated murine osteoclasts and regulation of bone resorption in vitro by gap junction inhibitors. Biochemical and Biophysical Research Communications, 2003. 303(4): p. 1179-1185.

14. Henriksen, K., et al., Local communication on and within bone controls bone remodeling. Bone, 2009. 44(6): p. 1026-1033.

15. S. R. Buchman, D.G.S., R.W. Goulet, S.A. Goldstein, Use of microcomputed tomography scanning as a new technique for the evaluation of membranous bone. The Journal of craniofacial surgery, 1998. 9(1): p. 48-54.

16. Nazarian, A., et al., Quantitative micro-computed tomography: A non-invasive method to assess equivalent bone mineral density. Bone, 2008. 43(2): p. 302-311.

17. Jilka, R.L., Cytokines, bone remodeling, and estrogen deficiency: a 1998 update. Bone, 1998. 23(2): p. 75-81.

18. Lane, J.M., A.C. Serota, and B. Raphael, Osteoporosis: Differences and Similarities in Male and Female Patients. Orthopedic Clinics of North America, 2006. 37(4): p. 601-609. 
19. Talbot, N. Vaginal Prolabse Post-Menopause. Women's Health 2011; Available from: http://suite101.com/article/vaginal-prolapse-post-menopause-a366041.

20. Stress Fracture Sacrum -Case Discussion. Summer's Radiology Site 2011 [cited 2012; Available from: http://sumerdoc.blogspot.com/2011/06/stress-fracturesacrum-case-discussion.html.

21. Meunier, P.J., et al., Diagnosis and management of osteoporosis in postmenopausal women: Clinical guidelines. Clinical Therapeutics, 1999. 21(6): p. 1025-1044.

22. Epstein, S., Update of current therapeutic options for the treatment of postmenopausal osteoporosis. Clinical Therapeutics, 2006. 28(2): p. 151-173.

23. Lentle, B., et al., Osteoporosis Canada 2010 Guidelines for the Assessment of Fracture Risk. Canadian Association of Radiologists Journal, 2011. 62(4): p. 243250.

24. Laroche, M., Treatment of Osteoporosis: All the Questions We Still Cannot Answer. The American Journal of Medicine, 2008. 121(9): p. 744-747.

25. Turner, A.S., Seasonal changes in bone metabolism in sheep: Further characterization of an animal model for human osteoporosis. The Veterinary Journal, 2007. 174(3): p. 460-461.

26. Turner, A.S., ANIMAL MODELS OF OSTEOPOROSIS - NECESSITY AND LIMITATIONS. Cells \& Materials, 2001. 1: p. 66-81.

27. Newton, B.I., et al., The Ovariectomized Sheep as a Model for Human Bone Loss. Journal of Comparative Pathology, 2004. 130(4): p. 323-326.

28. Wong, E., Effects of Ovariectomy, Seasonal Changes, and Anatomical Position on the Compact Bone Remodeling as seen in the Adult Ovine Model, in Biomedical Engineering2012, Cal Poly: San Luis Obispo. p. 93.

29. Calcagno, J., Seasonal and Anatomical Variation in Compact Bone Remodeling in the Adult Sheep, in Biomedical Engineering2011, Cal Poly: San Luis Obispo.

30. Baylink, D.J., D.D. Strong, and S. Mohan, The diagnosis and treatment of osteoporosis: future prospects. Molecular Medicine Today, 1999. 5(3): p. 133140.

31. Bittman, E.L. and F.J. Karsch, Nightly duration of pineal melatonin secretion determines the reproductive response to inhibitory day length in the ewe. Biology of Reproduction, 1984.30(3): p. 585-593.

32. Bartlewski, P.M., T.E. Baby, and J.L. Giffin, Reproductive cycles in sheep. Animal Reproduction Science, 2011. 124(3, Äì): p. 259-268.

33. Arendt, J., A. Symons, and C. Laud, Pineal function in the sheep: evidence for a possible mechanism mediating seasonal reproductive activity. Cellular and Molecular Life Sciences, 1981. 37(6): p. 584-586.

34. Ikeda, K. and E. Ogata, Modulation of bone remodeling by active vitamin D: its role in the treatment of osteoporosis. Mechanisms of Ageing and Development, 2000. 116(2, Ӓì): p. 103-111. 


\section{APPENDIX A: EXAMPLE OF SPECIMEN IMAGES}

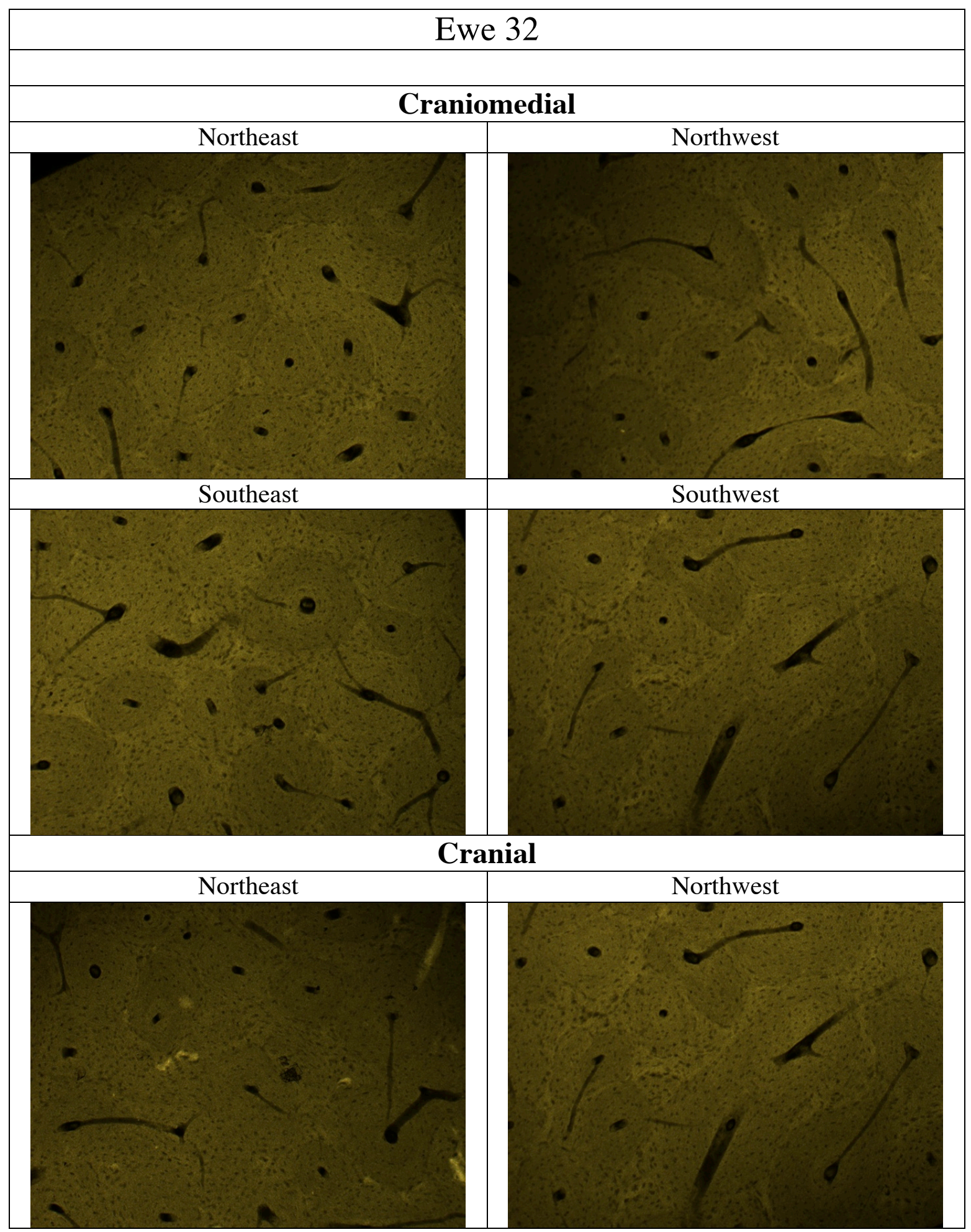




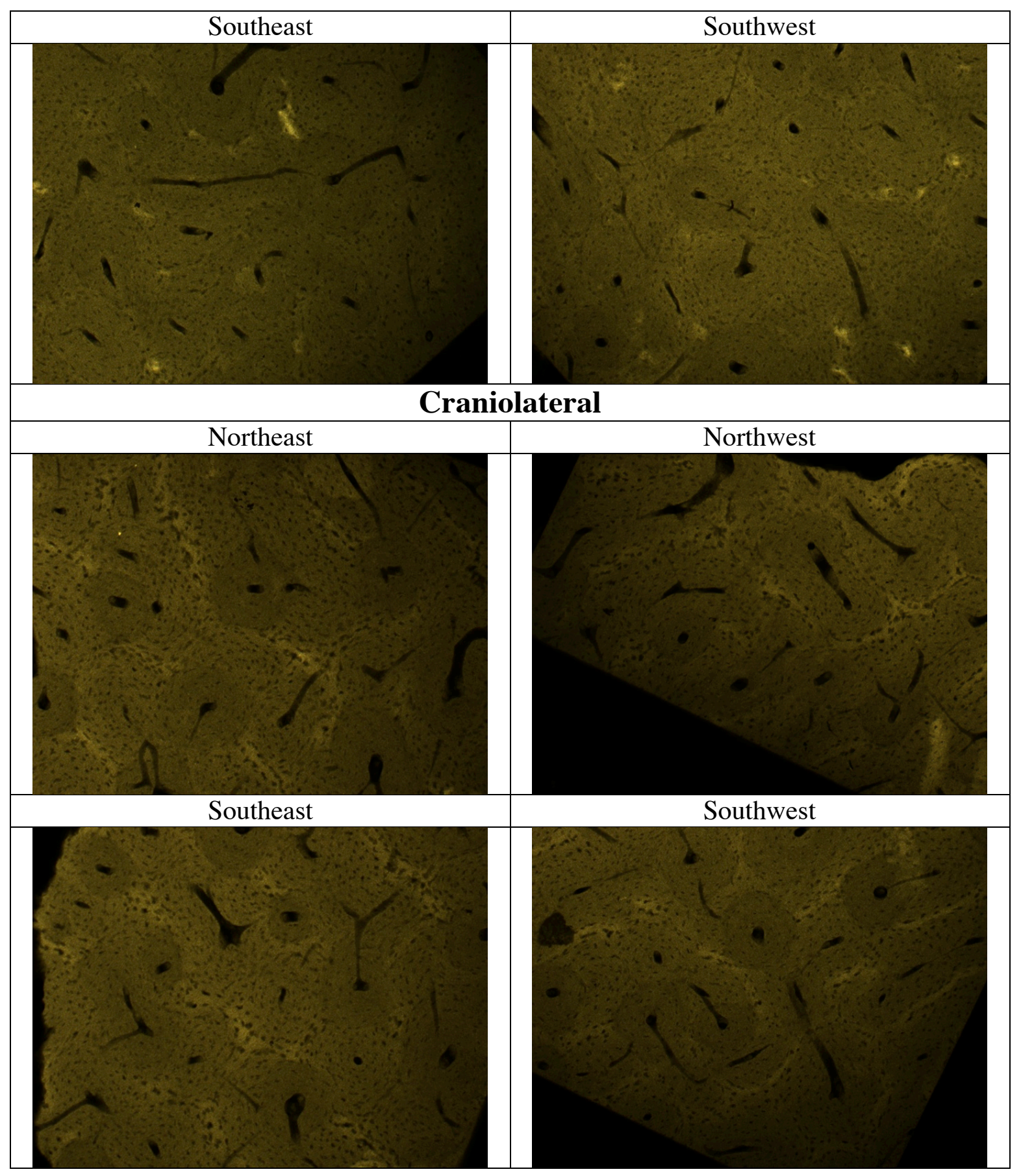




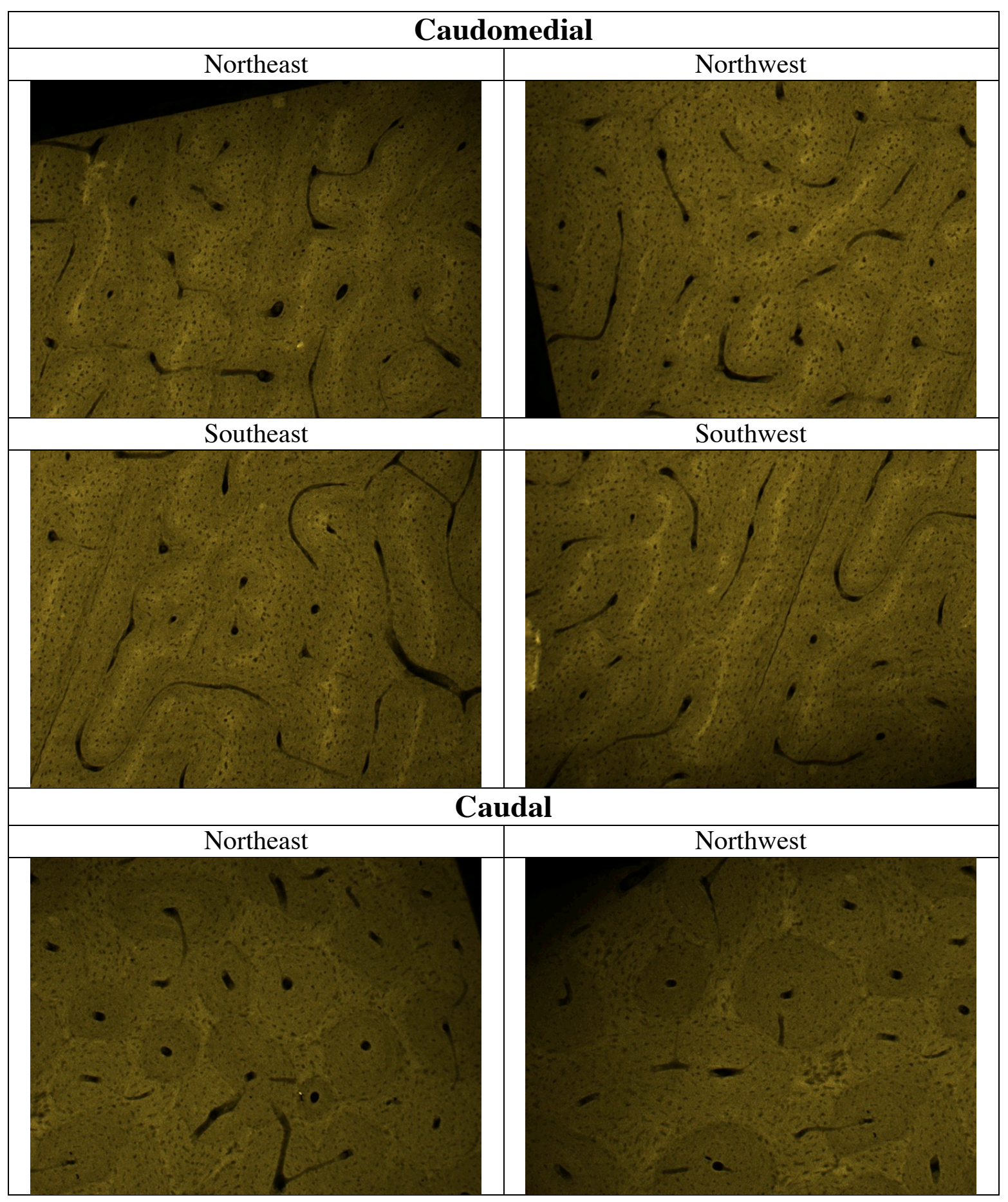




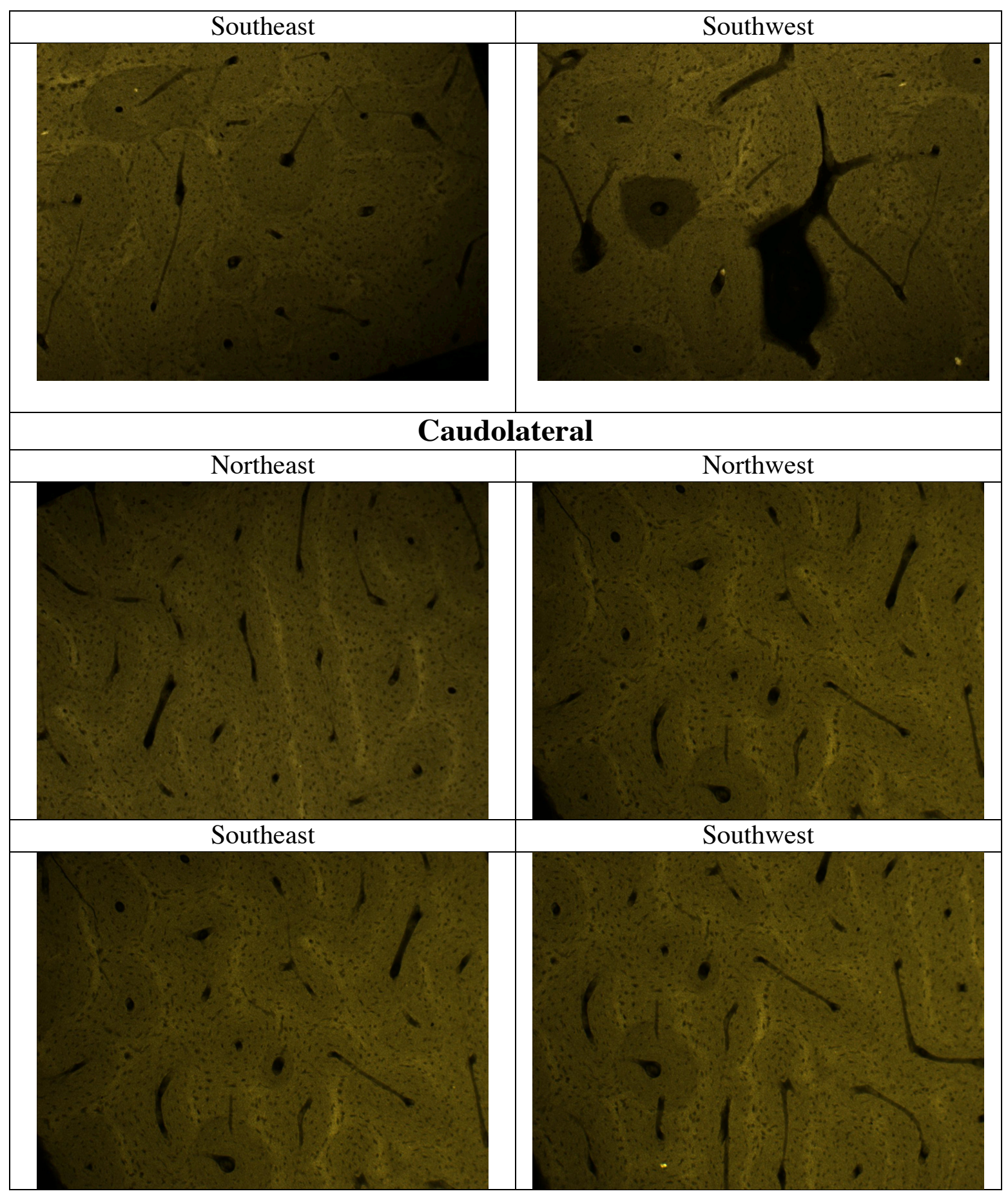




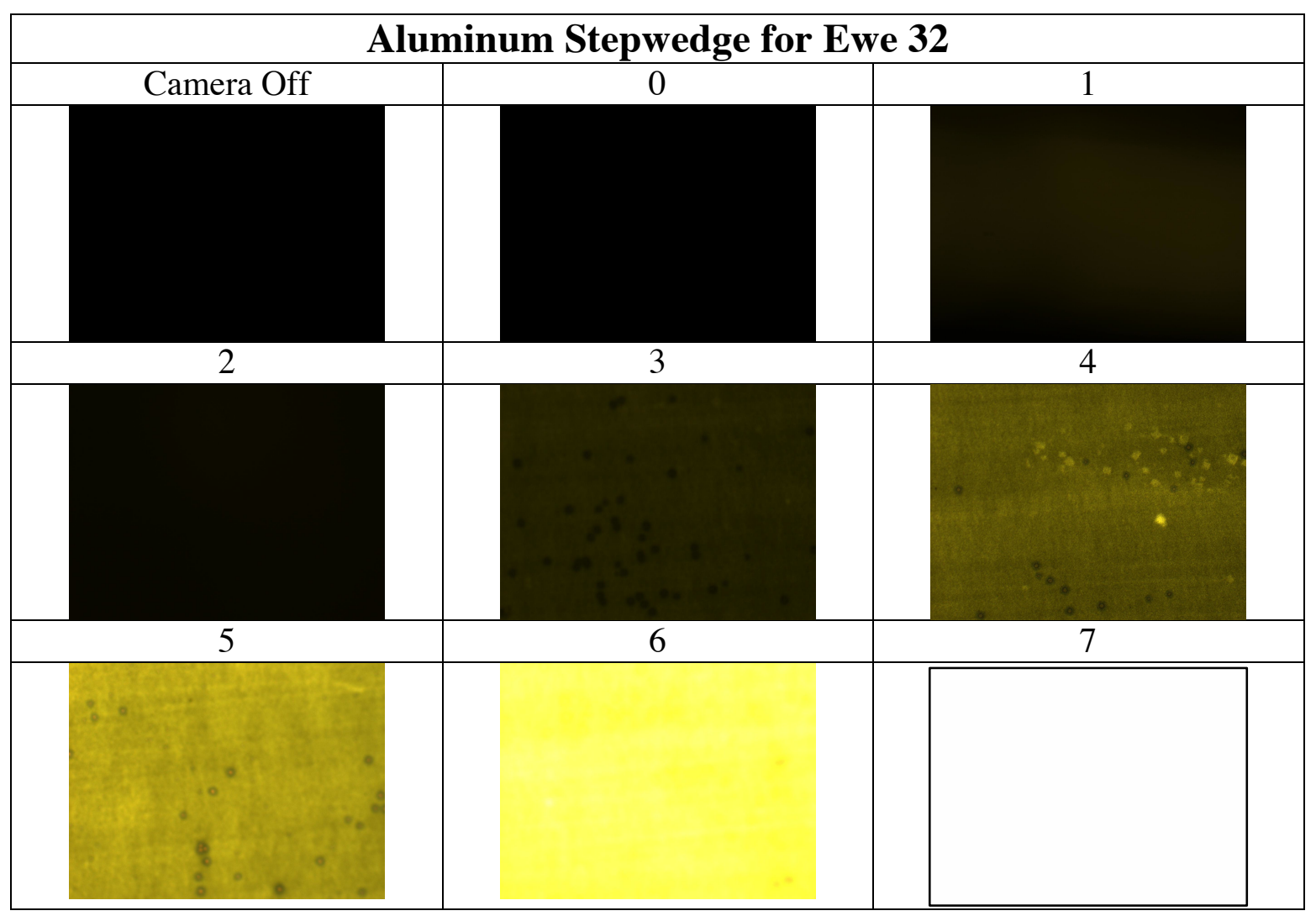




\section{APPENDIX B: RAW DATA FOR 1 EWE}

\begin{tabular}{|l|l|}
\hline \multicolumn{2}{|l|}{ Key for Sector in Raw Data } \\
\hline 1 & Craniomedial \\
\hline 2 & Cranial \\
\hline 3 & Craniolateral \\
\hline 4 & Caudomedial \\
\hline 5 & Caudal \\
\hline 6 & Caudolateral \\
\hline
\end{tabular}

\begin{tabular}{|c|c|c|c|c|c|c|c|}
\hline $\begin{array}{l}\text { Sheep } \\
\text { Eartag }\end{array}$ & Sector & $\begin{array}{l}\text { ETA } \\
(\mathrm{mm})\end{array}$ & $\begin{array}{l}\text { Bone } \\
\text { Pixels }\end{array}$ & $\begin{array}{l}\text { Sacrifice } \\
\text { Season }\end{array}$ & Treatment & $\begin{array}{l}\text { Season of } \\
\text { surgery }\end{array}$ & $\begin{array}{l}\text { Time } \\
\text { (months) }\end{array}$ \\
\hline 32 & 1 & 0.0059 & 0 & Winter & ovx & Autumn & 3 \\
\hline 32 & 1 & 0.0114 & 0 & Winter & ovx & Autumn & 3 \\
\hline 32 & 1 & 0.0158 & 0 & Winter & ovx & Autumn & 3 \\
\hline 32 & 1 & 0.0196 & 0 & Winter & ovx & Autumn & 3 \\
\hline 32 & 1 & 0.0228 & 0 & Winter & ovx & Autumn & 3 \\
\hline 32 & 1 & 0.0257 & 0 & Winter & ovx & Autumn & 3 \\
\hline 32 & 1 & 0.0283 & 0 & Winter & ovx & Autumn & 3 \\
\hline 32 & 1 & 0.0306 & 0 & Winter & ovx & Autumn & 3 \\
\hline 32 & 1 & 0.0327 & 0 & Winter & ovx & Autumn & 3 \\
\hline 32 & 1 & 0.0347 & 0 & Winter & ovx & Autumn & 3 \\
\hline 32 & 1 & 0.0365 & 0 & Winter & ovx & Autumn & 3 \\
\hline 32 & 1 & 0.0382 & 0 & Winter & ovx & Autumn & 3 \\
\hline 32 & 1 & 0.0398 & 0 & Winter & ovx & Autumn & 3 \\
\hline 32 & 1 & 0.0413 & 0 & Winter & ovx & Autumn & 3 \\
\hline 32 & 1 & 0.0427 & 0 & Winter & ovx & Autumn & 3 \\
\hline 32 & 1 & 0.0441 & 0 & Winter & ovx & Autumn & 3 \\
\hline 32 & 1 & 0.0454 & 0 & Winter & ovx & Autumn & 3 \\
\hline 32 & 1 & 0.0466 & 0 & Winter & ovx & Autumn & 3 \\
\hline 32 & 1 & 0.0478 & 0 & Winter & ovx & Autumn & 3 \\
\hline 32 & 1 & 0.0489 & 0 & Winter & ovx & Autumn & 3 \\
\hline 32 & 1 & 0.0500 & 0 & Winter & ovx & Autumn & 3 \\
\hline 32 & 1 & 0.0510 & 0 & Winter & ovx & Autumn & 3 \\
\hline 32 & 1 & 0.0520 & 36605 & Winter & ovx & Autumn & 3 \\
\hline 32 & 1 & 0.0530 & 43953 & Winter & ovx & Autumn & 3 \\
\hline 32 & 1 & 0.0539 & 45526 & Winter & ovx & Autumn & 3 \\
\hline 32 & 1 & 0.0548 & 50590 & Winter & ovx & Autumn & 3 \\
\hline 32 & 1 & 0.0557 & 49640 & Winter & ovx & Autumn & 3 \\
\hline 32 & 1 & 0.0566 & 52279 & Winter & ovx & Autumn & 3 \\
\hline 32 & 1 & 0.0574 & 52760 & Winter & ovx & Autumn & 3 \\
\hline
\end{tabular}




\begin{tabular}{|c|c|c|c|c|c|c|c|}
\hline $\begin{array}{l}\text { Sheep } \\
\text { Eartag }\end{array}$ & Sector & $\begin{array}{l}\text { ETA } \\
(\mathrm{mm})\end{array}$ & $\begin{array}{l}\text { Bone } \\
\text { Pixels } \\
\end{array}$ & $\begin{array}{l}\text { Sacrifice } \\
\text { Season }\end{array}$ & Treatment & $\begin{array}{l}\text { Season of } \\
\text { surgery }\end{array}$ & $\begin{array}{l}\text { Time } \\
\text { (months) }\end{array}$ \\
\hline 32 & 1 & 0.0582 & 53690 & Winter & ovx & Autumn & 3 \\
\hline 32 & 1 & 0.0590 & 58309 & Winter & ovx & Autumn & 3 \\
\hline 32 & 1 & 0.0597 & 61116 & Winter & ovx & Autumn & 3 \\
\hline 32 & 1 & 0.0605 & 66335 & Winter & ovx & Autumn & 3 \\
\hline 32 & 1 & 0.0612 & 75162 & Winter & ovx & Autumn & 3 \\
\hline 32 & 1 & 0.0619 & 80769 & Winter & ovx & Autumn & 3 \\
\hline 32 & 1 & 0.0626 & 88839 & Winter & ovx & Autumn & 3 \\
\hline 32 & 1 & 0.0633 & 91475 & Winter & ovx & Autumn & 3 \\
\hline 32 & 1 & 0.0640 & 99996 & Winter & ovx & Autumn & 3 \\
\hline 32 & 1 & 0.0646 & 105409 & Winter & ovx & Autumn & 3 \\
\hline 32 & 1 & 0.0652 & 109374 & Winter & ovx & Autumn & 3 \\
\hline 32 & 1 & 0.0659 & 117971 & Winter & ovx & Autumn & 3 \\
\hline 32 & 1 & 0.0665 & 125427 & Winter & ovx & Autumn & 3 \\
\hline 32 & 1 & 0.0671 & 131714 & Winter & ovx & Autumn & 3 \\
\hline 32 & 1 & 0.0677 & 136761 & Winter & ovx & Autumn & 3 \\
\hline 32 & 1 & 0.0683 & 140128 & Winter & ovx & Autumn & 3 \\
\hline 32 & 1 & 0.0688 & 142909 & Winter & ovx & Autumn & 3 \\
\hline 32 & 1 & 0.0694 & 147827 & Winter & ovx & Autumn & 3 \\
\hline 32 & 1 & 0.0699 & 151210 & Winter & ovx & Autumn & 3 \\
\hline 32 & 1 & 0.0705 & 155333 & Winter & ovx & Autumn & 3 \\
\hline 32 & 1 & 0.0710 & 159183 & Winter & ovx & Autumn & 3 \\
\hline 32 & 1 & 0.0716 & 163141 & Winter & ovx & Autumn & 3 \\
\hline 32 & 1 & 0.0721 & 166740 & Winter & ovx & Autumn & 3 \\
\hline 32 & 1 & 0.0726 & 168995 & Winter & ovx & Autumn & 3 \\
\hline 32 & 1 & 0.0731 & 170999 & Winter & ovx & Autumn & 3 \\
\hline 32 & 1 & 0.0736 & 172816 & Winter & ovx & Autumn & 3 \\
\hline 32 & 1 & 0.0741 & 174558 & Winter & ovx & Autumn & 3 \\
\hline 32 & 1 & 0.0746 & 175523 & Winter & ovx & Autumn & 3 \\
\hline 32 & 1 & 0.0751 & 174292 & Winter & ovx & Autumn & 3 \\
\hline 32 & 1 & 0.0755 & 171566 & Winter & ovx & Autumn & 3 \\
\hline 32 & 1 & 0.0760 & 166433 & Winter & ovx & Autumn & 3 \\
\hline 32 & 1 & 0.0765 & 158849 & Winter & ovx & Autumn & 3 \\
\hline 32 & 1 & 0.0769 & 149370 & Winter & ovx & Autumn & 3 \\
\hline 32 & 1 & 0.0774 & 138358 & Winter & ovx & Autumn & 3 \\
\hline 32 & 1 & 0.0778 & 126473 & Winter & ovx & Autumn & 3 \\
\hline 32 & 1 & 0.0783 & 114066 & Winter & ovx & Autumn & 3 \\
\hline 32 & 1 & 0.0787 & 100428 & Winter & ovx & Autumn & 3 \\
\hline 32 & 1 & 0.0791 & 87559 & Winter & ovx & Autumn & 3 \\
\hline 32 & 1 & 0.0796 & 75068 & Winter & ovx & Autumn & 3 \\
\hline 32 & 1 & 0.0800 & 63045 & Winter & ovx & Autumn & 3 \\
\hline
\end{tabular}




\begin{tabular}{|c|c|c|c|c|c|c|c|}
\hline $\begin{array}{l}\text { Sheep } \\
\text { Eartag }\end{array}$ & Sector & $\begin{array}{l}\text { ETA } \\
(\mathbf{m m})\end{array}$ & $\begin{array}{l}\text { Bone } \\
\text { Pixels } \\
\end{array}$ & $\begin{array}{l}\text { Sacrifice } \\
\text { Season }\end{array}$ & Treatment & $\begin{array}{l}\text { Season of } \\
\text { surgery }\end{array}$ & $\begin{array}{l}\text { Time } \\
\text { (months) }\end{array}$ \\
\hline 32 & 1 & 0.0804 & 52507 & Winter & ovx & Autumn & 3 \\
\hline 32 & 1 & 0.0808 & 43583 & Winter & ovx & Autumn & 3 \\
\hline 32 & 1 & 0.0812 & 35223 & Winter & ovx & Autumn & 3 \\
\hline 32 & 1 & 0.0816 & 28610 & Winter & ovx & Autumn & 3 \\
\hline 32 & 1 & 0.0820 & 22520 & Winter & ovx & Autumn & 3 \\
\hline 32 & 1 & 0.0824 & 18073 & Winter & ovx & Autumn & 3 \\
\hline 32 & 1 & 0.0828 & 14105 & Winter & ovx & Autumn & 3 \\
\hline 32 & 1 & 0.0832 & 10953 & Winter & ovx & Autumn & 3 \\
\hline 32 & 1 & 0.0836 & 8345 & Winter & ovx & Autumn & 3 \\
\hline 32 & 1 & 0.0840 & 6261 & Winter & ovx & Autumn & 3 \\
\hline 32 & 1 & 0.0844 & 4831 & Winter & ovx & Autumn & 3 \\
\hline 32 & 1 & 0.0848 & 3509 & Winter & ovx & Autumn & 3 \\
\hline 32 & 1 & 0.0852 & 2625 & Winter & ovx & Autumn & 3 \\
\hline 32 & 1 & 0.0855 & 1890 & Winter & ovx & Autumn & 3 \\
\hline 32 & 1 & 0.0859 & 1342 & Winter & ovx & Autumn & 3 \\
\hline 32 & 1 & 0.0863 & 995 & Winter & ovx & Autumn & 3 \\
\hline 32 & 1 & 0.0867 & 687 & Winter & ovx & Autumn & 3 \\
\hline 32 & 1 & 0.0870 & 455 & Winter & ovx & Autumn & 3 \\
\hline 32 & 1 & 0.0874 & 336 & Winter & ovx & Autumn & 3 \\
\hline 32 & 1 & 0.0878 & 272 & Winter & ovx & Autumn & 3 \\
\hline 32 & 1 & 0.0881 & 168 & Winter & ovx & Autumn & 3 \\
\hline 32 & 1 & 0.0885 & 114 & Winter & ovx & Autumn & 3 \\
\hline 32 & 1 & 0.0888 & 84 & Winter & ovx & Autumn & 3 \\
\hline 32 & 1 & 0.0892 & 61 & Winter & ovx & Autumn & 3 \\
\hline 32 & 1 & 0.0895 & 47 & Winter & ovx & Autumn & 3 \\
\hline 32 & 1 & 0.0899 & 42 & Winter & ovx & Autumn & 3 \\
\hline 32 & 1 & 0.0902 & 25 & Winter & ovx & Autumn & 3 \\
\hline 32 & 1 & 0.0906 & 25 & Winter & ovx & Autumn & 3 \\
\hline 32 & 1 & 0.0909 & 15 & Winter & ovx & Autumn & 3 \\
\hline 32 & 1 & 0.0913 & 15 & Winter & ovx & Autumn & 3 \\
\hline 32 & 1 & 0.0916 & 8 & Winter & ovx & Autumn & 3 \\
\hline 32 & 1 & 0.0919 & 3 & Winter & ovx & Autumn & 3 \\
\hline 32 & 1 & 0.0923 & 1 & Winter & ovx & Autumn & 3 \\
\hline 32 & 1 & 0.0926 & 1 & Winter & ovx & Autumn & 3 \\
\hline 32 & 1 & 0.0930 & 1 & Winter & ovx & Autumn & 3 \\
\hline 32 & 1 & 0.0933 & 0 & Winter & ovx & Autumn & 3 \\
\hline 32 & 1 & 0.0936 & 1 & Winter & ovx & Autumn & 3 \\
\hline 32 & 1 & 0.0939 & 0 & Winter & ovx & Autumn & 3 \\
\hline 32 & 1 & 0.0943 & 0 & Winter & ovx & Autumn & 3 \\
\hline 32 & 1 & 0.0946 & 0 & Winter & ovx & Autumn & 3 \\
\hline
\end{tabular}




\begin{tabular}{|c|c|c|c|c|c|c|c|}
\hline $\begin{array}{l}\text { Sheep } \\
\text { Eartag }\end{array}$ & Sector & $\begin{array}{l}\text { ETA } \\
(\mathbf{m m})\end{array}$ & $\begin{array}{l}\text { Bone } \\
\text { Pixels }\end{array}$ & $\begin{array}{l}\text { Sacrifice } \\
\text { Season }\end{array}$ & Treatment & $\begin{array}{l}\text { Season of } \\
\text { surgery }\end{array}$ & $\begin{array}{l}\text { Time } \\
\text { (months) }\end{array}$ \\
\hline 32 & 1 & 0.0949 & 0 & Winter & ovx & Autumn & 3 \\
\hline 32 & 1 & 0.0953 & 0 & Winter & ovx & Autumn & 3 \\
\hline 32 & 1 & 0.0956 & 0 & Winter & ovx & Autumn & 3 \\
\hline 32 & 1 & 0.0959 & 0 & Winter & ovx & Autumn & 3 \\
\hline 32 & 1 & 0.0962 & 0 & Winter & ovx & Autumn & 3 \\
\hline 32 & 1 & 0.0965 & 0 & Winter & ovx & Autumn & 3 \\
\hline 32 & 1 & 0.0969 & 0 & Winter & ovx & Autumn & 3 \\
\hline 32 & 1 & 0.0972 & 0 & Winter & ovx & Autumn & 3 \\
\hline 32 & 1 & 0.0975 & 0 & Winter & ovx & Autumn & 3 \\
\hline 32 & 1 & 0.0978 & 0 & Winter & ovx & Autumn & 3 \\
\hline 32 & 1 & 0.0981 & 0 & Winter & ovx & Autumn & 3 \\
\hline 32 & 1 & 0.0984 & 0 & Winter & ovx & Autumn & 3 \\
\hline 32 & 1 & 0.0988 & 0 & Winter & ovx & Autumn & 3 \\
\hline 32 & 1 & 0.0991 & 0 & Winter & ovx & Autumn & 3 \\
\hline 32 & 1 & 0.0994 & 0 & Winter & ovx & Autumn & 3 \\
\hline 32 & 1 & 0.0997 & 0 & Winter & ovx & Autumn & 3 \\
\hline 32 & 1 & 0.1000 & 0 & Winter & ovx & Autumn & 3 \\
\hline 32 & 1 & 0.1003 & 0 & Winter & ovx & Autumn & 3 \\
\hline 32 & 1 & 0.1006 & 0 & Winter & ovx & Autumn & 3 \\
\hline 32 & 1 & 0.1009 & 0 & Winter & ovx & Autumn & 3 \\
\hline 32 & 1 & 0.1012 & 0 & Winter & ovx & Autumn & 3 \\
\hline 32 & 1 & 0.1015 & 0 & Winter & ovx & Autumn & 3 \\
\hline 32 & 1 & 0.1018 & 0 & Winter & ovx & Autumn & 3 \\
\hline 32 & 1 & 0.1022 & 0 & Winter & ovx & Autumn & 3 \\
\hline 32 & 1 & 0.1025 & 0 & Winter & ovx & Autumn & 3 \\
\hline 32 & 1 & 0.1028 & 0 & Winter & ovx & Autumn & 3 \\
\hline 32 & 1 & 0.1031 & 0 & Winter & ovx & Autumn & 3 \\
\hline 32 & 1 & 0.1034 & 0 & Winter & ovx & Autumn & 3 \\
\hline 32 & 1 & 0.1037 & 0 & Winter & ovx & Autumn & 3 \\
\hline 32 & 1 & 0.1040 & 0 & Winter & ovx & Autumn & 3 \\
\hline 32 & 1 & 0.1043 & 0 & Winter & ovx & Autumn & 3 \\
\hline 32 & 1 & 0.1046 & 0 & Winter & ovx & Autumn & 3 \\
\hline 32 & 1 & 0.1049 & 0 & Winter & ovx & Autumn & 3 \\
\hline 32 & 1 & 0.1052 & 0 & Winter & ovx & Autumn & 3 \\
\hline 32 & 1 & 0.1055 & 0 & Winter & ovx & Autumn & 3 \\
\hline 32 & 1 & 0.1058 & 0 & Winter & ovx & Autumn & 3 \\
\hline 32 & 1 & 0.1061 & 0 & Winter & ovx & Autumn & 3 \\
\hline 32 & 1 & 0.1064 & 0 & Winter & ovx & Autumn & 3 \\
\hline 32 & 1 & 0.1067 & 0 & Winter & ovx & Autumn & 3 \\
\hline 32 & 1 & 0.1070 & 0 & Winter & ovx & Autumn & 3 \\
\hline
\end{tabular}




\begin{tabular}{|c|c|c|c|c|c|c|c|}
\hline $\begin{array}{l}\text { Sheep } \\
\text { Eartag }\end{array}$ & Sector & $\begin{array}{l}\text { ETA } \\
(\mathbf{m m})\end{array}$ & $\begin{array}{l}\text { Bone } \\
\text { Pixels } \\
\end{array}$ & $\begin{array}{l}\text { Sacrifice } \\
\text { Season }\end{array}$ & Treatment & $\begin{array}{l}\text { Season of } \\
\text { surgery }\end{array}$ & $\begin{array}{l}\text { Time } \\
\text { (months) }\end{array}$ \\
\hline 32 & 1 & 0.1073 & 0 & Winter & ovx & Autumn & 3 \\
\hline 32 & 1 & 0.1076 & 0 & Winter & ovx & Autumn & 3 \\
\hline 32 & 1 & 0.1079 & 0 & Winter & ovx & Autumn & 3 \\
\hline 32 & 1 & 0.1082 & 0 & Winter & ovx & Autumn & 3 \\
\hline 32 & 1 & 0.1085 & 0 & Winter & ovx & Autumn & 3 \\
\hline 32 & 1 & 0.1088 & 0 & Winter & ovx & Autumn & 3 \\
\hline 32 & 1 & 0.1091 & 0 & Winter & ovx & Autumn & 3 \\
\hline 32 & 1 & 0.1094 & 0 & Winter & ovx & Autumn & 3 \\
\hline 32 & 1 & 0.1097 & 0 & Winter & ovx & Autumn & 3 \\
\hline 32 & 1 & 0.1100 & 0 & Winter & ovx & Autumn & 3 \\
\hline 32 & 1 & 0.1103 & 0 & Winter & ovx & Autumn & 3 \\
\hline 32 & 1 & 0.1106 & 0 & Winter & ovx & Autumn & 3 \\
\hline 32 & 1 & 0.1109 & 0 & Winter & ovx & Autumn & 3 \\
\hline 32 & 1 & 0.1112 & 0 & Winter & ovx & Autumn & 3 \\
\hline 32 & 1 & 0.1115 & 0 & Winter & ovx & Autumn & 3 \\
\hline 32 & 1 & 0.1118 & 0 & Winter & ovx & Autumn & 3 \\
\hline 32 & 1 & 0.1122 & 0 & Winter & ovx & Autumn & 3 \\
\hline 32 & 1 & 0.1125 & 0 & Winter & ovx & Autumn & 3 \\
\hline 32 & 1 & 0.1128 & 0 & Winter & ovx & Autumn & 3 \\
\hline 32 & 1 & 0.1131 & 0 & Winter & ovx & Autumn & 3 \\
\hline 32 & 1 & 0.1134 & 0 & Winter & ovx & Autumn & 3 \\
\hline 32 & 1 & 0.1137 & 0 & Winter & ovx & Autumn & 3 \\
\hline 32 & 1 & 0.1140 & 0 & Winter & ovx & Autumn & 3 \\
\hline 32 & 1 & 0.1143 & 0 & Winter & ovx & Autumn & 3 \\
\hline 32 & 1 & 0.1146 & 0 & Winter & ovx & Autumn & 3 \\
\hline 32 & 1 & 0.1149 & 0 & Winter & ovx & Autumn & 3 \\
\hline 32 & 1 & 0.1152 & 0 & Winter & ovx & Autumn & 3 \\
\hline 32 & 1 & 0.1155 & 0 & Winter & ovx & Autumn & 3 \\
\hline 32 & 1 & 0.1158 & 0 & Winter & ovx & Autumn & 3 \\
\hline 32 & 1 & 0.1161 & 0 & Winter & ovx & Autumn & 3 \\
\hline 32 & 1 & 0.1165 & 0 & Winter & ovx & Autumn & 3 \\
\hline 32 & 1 & 0.1168 & 0 & Winter & ovx & Autumn & 3 \\
\hline 32 & 1 & 0.1171 & 0 & Winter & ovx & Autumn & 3 \\
\hline 32 & 1 & 0.1174 & 0 & Winter & ovx & Autumn & 3 \\
\hline 32 & 1 & 0.1177 & 0 & Winter & ovx & Autumn & 3 \\
\hline 32 & 1 & 0.1180 & 0 & Winter & ovx & Autumn & 3 \\
\hline 32 & 1 & 0.1183 & 0 & Winter & ovx & Autumn & 3 \\
\hline 32 & 1 & 0.1187 & 0 & Winter & ovx & Autumn & 3 \\
\hline 32 & 1 & 0.1190 & 0 & Winter & ovx & Autumn & 3 \\
\hline 32 & 1 & 0.1193 & 0 & Winter & ovx & Autumn & 3 \\
\hline
\end{tabular}




\begin{tabular}{|c|c|c|c|c|c|c|c|}
\hline $\begin{array}{l}\text { Sheep } \\
\text { Eartag }\end{array}$ & Sector & $\begin{array}{l}\text { ETA } \\
(\mathbf{m m})\end{array}$ & $\begin{array}{l}\text { Bone } \\
\text { Pixels } \\
\end{array}$ & $\begin{array}{l}\text { Sacrifice } \\
\text { Season }\end{array}$ & Treatment & $\begin{array}{l}\text { Season of } \\
\text { surgery }\end{array}$ & $\begin{array}{l}\text { Time } \\
\text { (months) }\end{array}$ \\
\hline 32 & 1 & 0.1196 & 0 & Winter & ovx & Autumn & 3 \\
\hline 32 & 1 & 0.1199 & 0 & Winter & ovx & Autumn & 3 \\
\hline 32 & 1 & 0.1203 & 0 & Winter & ovx & Autumn & 3 \\
\hline 32 & 1 & 0.1206 & 0 & Winter & ovx & Autumn & 3 \\
\hline 32 & 1 & 0.1209 & 0 & Winter & ovx & Autumn & 3 \\
\hline 32 & 1 & 0.1212 & 0 & Winter & ovx & Autumn & 3 \\
\hline 32 & 1 & 0.1216 & 0 & Winter & ovx & Autumn & 3 \\
\hline 32 & 1 & 0.1219 & 0 & Winter & ovx & Autumn & 3 \\
\hline 32 & 1 & 0.1222 & 0 & Winter & ovx & Autumn & 3 \\
\hline 32 & 1 & 0.1226 & 0 & Winter & ovx & Autumn & 3 \\
\hline 32 & 1 & 0.1229 & 0 & Winter & ovx & Autumn & 3 \\
\hline 32 & 1 & 0.1232 & 0 & Winter & ovx & Autumn & 3 \\
\hline 32 & 1 & 0.1236 & 0 & Winter & ovx & Autumn & 3 \\
\hline 32 & 1 & 0.1239 & 0 & Winter & ovx & Autumn & 3 \\
\hline 32 & 1 & 0.1243 & 0 & Winter & ovx & Autumn & 3 \\
\hline 32 & 1 & 0.1246 & 0 & Winter & ovx & Autumn & 3 \\
\hline 32 & 1 & 0.1249 & 0 & Winter & ovx & Autumn & 3 \\
\hline 32 & 1 & 0.1253 & 0 & Winter & ovx & Autumn & 3 \\
\hline 32 & 1 & 0.1256 & 0 & Winter & ovx & Autumn & 3 \\
\hline 32 & 1 & 0.1260 & 0 & Winter & ovx & Autumn & 3 \\
\hline 32 & 1 & 0.1263 & 0 & Winter & ovx & Autumn & 3 \\
\hline 32 & 1 & 0.1267 & 0 & Winter & ovx & Autumn & 3 \\
\hline 32 & 1 & 0.1270 & 0 & Winter & ovx & Autumn & 3 \\
\hline 32 & 1 & 0.1274 & 0 & Winter & ovx & Autumn & 3 \\
\hline 32 & 1 & 0.1278 & 0 & Winter & ovx & Autumn & 3 \\
\hline 32 & 1 & 0.1281 & 0 & Winter & ovx & Autumn & 3 \\
\hline 32 & 1 & 0.1285 & 0 & Winter & ovx & Autumn & 3 \\
\hline 32 & 1 & 0.1288 & 0 & Winter & ovx & Autumn & 3 \\
\hline 32 & 1 & 0.1292 & 0 & Winter & ovx & Autumn & 3 \\
\hline 32 & 1 & 0.1296 & 0 & Winter & ovx & Autumn & 3 \\
\hline 32 & 1 & 0.1300 & 0 & Winter & ovx & Autumn & 3 \\
\hline 32 & 1 & 0.1303 & 0 & Winter & ovx & Autumn & 3 \\
\hline 32 & 1 & 0.1307 & 0 & Winter & ovx & Autumn & 3 \\
\hline 32 & 1 & 0.1311 & 0 & Winter & ovx & Autumn & 3 \\
\hline 32 & 1 & 0.1315 & 0 & Winter & ovx & Autumn & 3 \\
\hline 32 & 1 & 0.1319 & 0 & Winter & ovx & Autumn & 3 \\
\hline 32 & 1 & 0.1323 & 0 & Winter & ovx & Autumn & 3 \\
\hline 32 & 1 & 0.1327 & 0 & Winter & ovx & Autumn & 3 \\
\hline 32 & 1 & 0.1331 & 0 & Winter & ovx & Autumn & 3 \\
\hline 32 & 1 & 0.1335 & 0 & Winter & ovx & Autumn & 3 \\
\hline
\end{tabular}




\begin{tabular}{|c|c|c|c|c|c|c|c|}
\hline $\begin{array}{l}\text { Sheep } \\
\text { Eartag }\end{array}$ & Sector & $\begin{array}{l}\text { ETA } \\
(\mathbf{m m})\end{array}$ & $\begin{array}{l}\text { Bone } \\
\text { Pixels }\end{array}$ & $\begin{array}{l}\text { Sacrifice } \\
\text { Season }\end{array}$ & Treatment & $\begin{array}{l}\text { Season of } \\
\text { surgery }\end{array}$ & $\begin{array}{l}\text { Time } \\
\text { (months) }\end{array}$ \\
\hline 32 & 1 & 0.1339 & 0 & Winter & ovx & Autumn & 3 \\
\hline 32 & 1 & 0.1343 & 0 & Winter & ovx & Autumn & 3 \\
\hline 32 & 1 & 0.1347 & 0 & Winter & ovx & Autumn & 3 \\
\hline 32 & 1 & 0.1351 & 0 & Winter & ovx & Autumn & 3 \\
\hline 32 & 1 & 0.1355 & 0 & Winter & ovx & Autumn & 3 \\
\hline 32 & 1 & 0.1359 & 0 & Winter & ovx & Autumn & 3 \\
\hline 32 & 1 & 0.1364 & 0 & Winter & ovx & Autumn & 3 \\
\hline 32 & 1 & 0.1368 & 0 & Winter & ovx & Autumn & 3 \\
\hline 32 & 1 & 0.1372 & 0 & Winter & ovx & Autumn & 3 \\
\hline 32 & 1 & 0.1377 & 0 & Winter & ovx & Autumn & 3 \\
\hline 32 & 1 & 0.1381 & 0 & Winter & ovx & Autumn & 3 \\
\hline 32 & 1 & 0.1386 & 0 & Winter & ovx & Autumn & 3 \\
\hline 32 & 1 & 0.1390 & 0 & Winter & ovx & Autumn & 3 \\
\hline 32 & 1 & 0.1395 & 0 & Winter & ovx & Autumn & 3 \\
\hline 32 & 1 & 0.1400 & 0 & Winter & ovx & Autumn & 3 \\
\hline 32 & 1 & 0.1404 & 0 & Winter & ovx & Autumn & 3 \\
\hline 32 & 1 & 0.1409 & 0 & Winter & ovx & Autumn & 3 \\
\hline 32 & 1 & 0.1414 & 0 & Winter & ovx & Autumn & 3 \\
\hline 32 & 1 & 0.1419 & 0 & Winter & ovx & Autumn & 3 \\
\hline 32 & 1 & 0.1424 & 0 & Winter & ovx & Autumn & 3 \\
\hline 32 & 1 & 0.1429 & 0 & Winter & ovx & Autumn & 3 \\
\hline 32 & 1 & 0.1434 & 0 & Winter & ovx & Autumn & 3 \\
\hline 32 & 1 & 0.1439 & 0 & Winter & ovx & Autumn & 3 \\
\hline 32 & 1 & 0.1444 & 0 & Winter & ovx & Autumn & 3 \\
\hline 32 & 1 & 0.1450 & 0 & Winter & ovx & Autumn & 3 \\
\hline 32 & 1 & 0.1455 & 0 & Winter & ovx & Autumn & 3 \\
\hline 32 & 1 & 0.1461 & 0 & Winter & ovx & Autumn & 3 \\
\hline 32 & 2 & 0.0059 & 0 & Winter & ovx & Autumn & 3 \\
\hline 32 & 2 & 0.0114 & 0 & Winter & ovx & Autumn & 3 \\
\hline 32 & 2 & 0.0158 & 0 & Winter & ovx & Autumn & 3 \\
\hline 32 & 2 & 0.0196 & 0 & Winter & ovx & Autumn & 3 \\
\hline 32 & 2 & 0.0228 & 0 & Winter & ovx & Autumn & 3 \\
\hline 32 & 2 & 0.0257 & 0 & Winter & ovx & Autumn & 3 \\
\hline 32 & 2 & 0.0283 & 0 & Winter & ovx & Autumn & 3 \\
\hline 32 & 2 & 0.0306 & 0 & Winter & ovx & Autumn & 3 \\
\hline 32 & 2 & 0.0327 & 0 & Winter & ovx & Autumn & 3 \\
\hline 32 & 2 & 0.0347 & 0 & Winter & ovx & Autumn & 3 \\
\hline 32 & 2 & 0.0365 & 0 & Winter & ovx & Autumn & 3 \\
\hline 32 & 2 & 0.0382 & 0 & Winter & ovx & Autumn & 3 \\
\hline 32 & 2 & 0.0398 & 0 & Winter & ovx & Autumn & 3 \\
\hline
\end{tabular}




\begin{tabular}{|c|c|c|c|c|c|c|c|}
\hline $\begin{array}{l}\text { Sheep } \\
\text { Eartag }\end{array}$ & Sector & $\begin{array}{l}\text { ETA } \\
(\mathbf{m m})\end{array}$ & $\begin{array}{l}\text { Bone } \\
\text { Pixels }\end{array}$ & $\begin{array}{l}\text { Sacrifice } \\
\text { Season }\end{array}$ & Treatment & $\begin{array}{l}\text { Season of } \\
\text { surgery }\end{array}$ & $\begin{array}{l}\text { Time } \\
\text { (months) }\end{array}$ \\
\hline 32 & 2 & 0.0413 & 0 & Winter & ovx & Autumn & 3 \\
\hline 32 & 2 & 0.0427 & 0 & Winter & ovx & Autumn & 3 \\
\hline 32 & 2 & 0.0441 & 0 & Winter & ovx & Autumn & 3 \\
\hline 32 & 2 & 0.0454 & 0 & Winter & ovx & Autumn & 3 \\
\hline 32 & 2 & 0.0466 & 0 & Winter & ovx & Autumn & 3 \\
\hline 32 & 2 & 0.0478 & 0 & Winter & ovx & Autumn & 3 \\
\hline 32 & 2 & 0.0489 & 0 & Winter & ovx & Autumn & 3 \\
\hline 32 & 2 & 0.0500 & 0 & Winter & ovx & Autumn & 3 \\
\hline 32 & 2 & 0.0510 & 43776 & Winter & ovx & Autumn & 3 \\
\hline 32 & 2 & 0.0520 & 47878 & Winter & ovx & Autumn & 3 \\
\hline 32 & 2 & 0.0530 & 53877 & Winter & ovx & Autumn & 3 \\
\hline 32 & 2 & 0.0539 & 54445 & Winter & ovx & Autumn & 3 \\
\hline 32 & 2 & 0.0548 & 59516 & Winter & ovx & Autumn & 3 \\
\hline 32 & 2 & 0.0557 & 62366 & Winter & ovx & Autumn & 3 \\
\hline 32 & 2 & 0.0566 & 69420 & Winter & ovx & Autumn & 3 \\
\hline 32 & 2 & 0.0574 & 72570 & Winter & ovx & Autumn & 3 \\
\hline 32 & 2 & 0.0582 & 75266 & Winter & ovx & Autumn & 3 \\
\hline 32 & 2 & 0.0590 & 86090 & Winter & ovx & Autumn & 3 \\
\hline 32 & 2 & 0.0597 & 90366 & Winter & ovx & Autumn & 3 \\
\hline 32 & 2 & 0.0605 & 98363 & Winter & ovx & Autumn & 3 \\
\hline 32 & 2 & 0.0612 & 112444 & Winter & ovx & Autumn & 3 \\
\hline 32 & 2 & 0.0619 & 120660 & Winter & ovx & Autumn & 3 \\
\hline 32 & 2 & 0.0626 & 134333 & Winter & ovx & Autumn & 3 \\
\hline 32 & 2 & 0.0633 & 138827 & Winter & ovx & Autumn & 3 \\
\hline 32 & 2 & 0.0640 & 151884 & Winter & ovx & Autumn & 3 \\
\hline 32 & 2 & 0.0646 & 156699 & Winter & ovx & Autumn & 3 \\
\hline 32 & 2 & 0.0652 & 159532 & Winter & ovx & Autumn & 3 \\
\hline 32 & 2 & 0.0659 & 165972 & Winter & ovx & Autumn & 3 \\
\hline 32 & 2 & 0.0665 & 168947 & Winter & ovx & Autumn & 3 \\
\hline 32 & 2 & 0.0671 & 171208 & Winter & ovx & Autumn & 3 \\
\hline 32 & 2 & 0.0677 & 174940 & Winter & ovx & Autumn & 3 \\
\hline 32 & 2 & 0.0683 & 175783 & Winter & ovx & Autumn & 3 \\
\hline 32 & 2 & 0.0688 & 177807 & Winter & ovx & Autumn & 3 \\
\hline 32 & 2 & 0.0694 & 179887 & Winter & ovx & Autumn & 3 \\
\hline 32 & 2 & 0.0699 & 180337 & Winter & ovx & Autumn & 3 \\
\hline 32 & 2 & 0.0705 & 181045 & Winter & ovx & Autumn & 3 \\
\hline 32 & 2 & 0.0710 & 180236 & Winter & ovx & Autumn & 3 \\
\hline 32 & 2 & 0.0716 & 178333 & Winter & ovx & Autumn & 3 \\
\hline 32 & 2 & 0.0721 & 172225 & Winter & ovx & Autumn & 3 \\
\hline 32 & 2 & 0.0726 & 166587 & Winter & ovx & Autumn & 3 \\
\hline
\end{tabular}




\begin{tabular}{|c|c|c|c|c|c|c|c|}
\hline $\begin{array}{l}\text { Sheep } \\
\text { Eartag }\end{array}$ & Sector & $\begin{array}{l}\text { ETA } \\
(\mathrm{mm})\end{array}$ & $\begin{array}{l}\text { Bone } \\
\text { Pixels } \\
\end{array}$ & $\begin{array}{l}\text { Sacrifice } \\
\text { Season }\end{array}$ & Treatment & $\begin{array}{l}\text { Season of } \\
\text { surgery }\end{array}$ & $\begin{array}{l}\text { Time } \\
\text { (months) }\end{array}$ \\
\hline 32 & 2 & 0.0731 & 158556 & Winter & ovx & Autumn & 3 \\
\hline 32 & 2 & 0.0736 & 149976 & Winter & ovx & Autumn & 3 \\
\hline 32 & 2 & 0.0741 & 139515 & Winter & ovx & Autumn & 3 \\
\hline 32 & 2 & 0.0746 & 129632 & Winter & ovx & Autumn & 3 \\
\hline 32 & 2 & 0.0751 & 119984 & Winter & ovx & Autumn & 3 \\
\hline 32 & 2 & 0.0755 & 109347 & Winter & ovx & Autumn & 3 \\
\hline 32 & 2 & 0.0760 & 97866 & Winter & ovx & Autumn & 3 \\
\hline 32 & 2 & 0.0765 & 87293 & Winter & ovx & Autumn & 3 \\
\hline 32 & 2 & 0.0769 & 76240 & Winter & ovx & Autumn & 3 \\
\hline 32 & 2 & 0.0774 & 65933 & Winter & ovx & Autumn & 3 \\
\hline 32 & 2 & 0.0778 & 57082 & Winter & ovx & Autumn & 3 \\
\hline 32 & 2 & 0.0783 & 48460 & Winter & ovx & Autumn & 3 \\
\hline 32 & 2 & 0.0787 & 40008 & Winter & ovx & Autumn & 3 \\
\hline 32 & 2 & 0.0791 & 33270 & Winter & ovx & Autumn & 3 \\
\hline 32 & 2 & 0.0796 & 27530 & Winter & ovx & Autumn & 3 \\
\hline 32 & 2 & 0.0800 & 21813 & Winter & ovx & Autumn & 3 \\
\hline 32 & 2 & 0.0804 & 17441 & Winter & ovx & Autumn & 3 \\
\hline 32 & 2 & 0.0808 & 13856 & Winter & ovx & Autumn & 3 \\
\hline 32 & 2 & 0.0812 & 10792 & Winter & ovx & Autumn & 3 \\
\hline 32 & 2 & 0.0816 & 8444 & Winter & ovx & Autumn & 3 \\
\hline 32 & 2 & 0.0820 & 6518 & Winter & ovx & Autumn & 3 \\
\hline 32 & 2 & 0.0824 & 5133 & Winter & ovx & Autumn & 3 \\
\hline 32 & 2 & 0.0828 & 4094 & Winter & ovx & Autumn & 3 \\
\hline 32 & 2 & 0.0832 & 3231 & Winter & ovx & Autumn & 3 \\
\hline 32 & 2 & 0.0836 & 2495 & Winter & ovx & Autumn & 3 \\
\hline 32 & 2 & 0.0840 & 2028 & Winter & ovx & Autumn & 3 \\
\hline 32 & 2 & 0.0844 & 1659 & Winter & ovx & Autumn & 3 \\
\hline 32 & 2 & 0.0848 & 1267 & Winter & ovx & Autumn & 3 \\
\hline 32 & 2 & 0.0852 & 1081 & Winter & ovx & Autumn & 3 \\
\hline 32 & 2 & 0.0855 & 865 & Winter & ovx & Autumn & 3 \\
\hline 32 & 2 & 0.0859 & 803 & Winter & ovx & Autumn & 3 \\
\hline 32 & 2 & 0.0863 & 655 & Winter & ovx & Autumn & 3 \\
\hline 32 & 2 & 0.0867 & 643 & Winter & ovx & Autumn & 3 \\
\hline 32 & 2 & 0.0870 & 525 & Winter & ovx & Autumn & 3 \\
\hline 32 & 2 & 0.0874 & 454 & Winter & ovx & Autumn & 3 \\
\hline 32 & 2 & 0.0878 & 418 & Winter & ovx & Autumn & 3 \\
\hline 32 & 2 & 0.0881 & 417 & Winter & ovx & Autumn & 3 \\
\hline 32 & 2 & 0.0885 & 357 & Winter & ovx & Autumn & 3 \\
\hline 32 & 2 & 0.0888 & 358 & Winter & ovx & Autumn & 3 \\
\hline 32 & 2 & 0.0892 & 349 & Winter & ovx & Autumn & 3 \\
\hline
\end{tabular}




\begin{tabular}{|c|c|c|c|c|c|c|c|}
\hline $\begin{array}{l}\text { Sheep } \\
\text { Eartag }\end{array}$ & Sector & $\begin{array}{l}\text { ETA } \\
(\mathrm{mm})\end{array}$ & $\begin{array}{l}\text { Bone } \\
\text { Pixels }\end{array}$ & $\begin{array}{l}\text { Sacrifice } \\
\text { Season }\end{array}$ & Treatment & $\begin{array}{l}\text { Season of } \\
\text { surgery }\end{array}$ & $\begin{array}{l}\text { Time } \\
\text { (months) }\end{array}$ \\
\hline 32 & 2 & 0.0895 & 310 & Winter & ovx & Autumn & 3 \\
\hline 32 & 2 & 0.0899 & 281 & Winter & ovx & Autumn & 3 \\
\hline 32 & 2 & 0.0902 & 267 & Winter & ovx & Autumn & 3 \\
\hline 32 & 2 & 0.0906 & 226 & Winter & ovx & Autumn & 3 \\
\hline 32 & 2 & 0.0909 & 230 & Winter & ovx & Autumn & 3 \\
\hline 32 & 2 & 0.0913 & 234 & Winter & ovx & Autumn & 3 \\
\hline 32 & 2 & 0.0916 & 211 & Winter & ovx & Autumn & 3 \\
\hline 32 & 2 & 0.0919 & 187 & Winter & ovx & Autumn & 3 \\
\hline 32 & 2 & 0.0923 & 153 & Winter & ovx & Autumn & 3 \\
\hline 32 & 2 & 0.0926 & 150 & Winter & ovx & Autumn & 3 \\
\hline 32 & 2 & 0.0930 & 183 & Winter & ovx & Autumn & 3 \\
\hline 32 & 2 & 0.0933 & 131 & Winter & ovx & Autumn & 3 \\
\hline 32 & 2 & 0.0936 & 141 & Winter & ovx & Autumn & 3 \\
\hline 32 & 2 & 0.0939 & 122 & Winter & ovx & Autumn & 3 \\
\hline 32 & 2 & 0.0943 & 102 & Winter & ovx & Autumn & 3 \\
\hline 32 & 2 & 0.0946 & 98 & Winter & ovx & Autumn & 3 \\
\hline 32 & 2 & 0.0949 & 93 & Winter & ovx & Autumn & 3 \\
\hline 32 & 2 & 0.0953 & 89 & Winter & ovx & Autumn & 3 \\
\hline 32 & 2 & 0.0956 & 77 & Winter & ovx & Autumn & 3 \\
\hline 32 & 2 & 0.0959 & 92 & Winter & ovx & Autumn & 3 \\
\hline 32 & 2 & 0.0962 & 69 & Winter & ovx & Autumn & 3 \\
\hline 32 & 2 & 0.0965 & 63 & Winter & ovx & Autumn & 3 \\
\hline 32 & 2 & 0.0969 & 83 & Winter & ovx & Autumn & 3 \\
\hline 32 & 2 & 0.0972 & 55 & Winter & ovx & Autumn & 3 \\
\hline 32 & 2 & 0.0975 & 56 & Winter & ovx & Autumn & 3 \\
\hline 32 & 2 & 0.0978 & 37 & Winter & ovx & Autumn & 3 \\
\hline 32 & 2 & 0.0981 & 49 & Winter & ovx & Autumn & 3 \\
\hline 32 & 2 & 0.0984 & 55 & Winter & ovx & Autumn & 3 \\
\hline 32 & 2 & 0.0988 & 39 & Winter & ovx & Autumn & 3 \\
\hline 32 & 2 & 0.0991 & 34 & Winter & ovx & Autumn & 3 \\
\hline 32 & 2 & 0.0994 & 34 & Winter & ovx & Autumn & 3 \\
\hline 32 & 2 & 0.0997 & 27 & Winter & ovx & Autumn & 3 \\
\hline 32 & 2 & 0.1000 & 24 & Winter & ovx & Autumn & 3 \\
\hline 32 & 2 & 0.1003 & 32 & Winter & ovx & Autumn & 3 \\
\hline 32 & 2 & 0.1006 & 24 & Winter & ovx & Autumn & 3 \\
\hline 32 & 2 & 0.1009 & 14 & Winter & ovx & Autumn & 3 \\
\hline 32 & 2 & 0.1012 & 15 & Winter & ovx & Autumn & 3 \\
\hline 32 & 2 & 0.1015 & 19 & Winter & ovx & Autumn & 3 \\
\hline 32 & 2 & 0.1018 & 20 & Winter & ovx & Autumn & 3 \\
\hline 32 & 2 & 0.1022 & 16 & Winter & ovx & Autumn & 3 \\
\hline
\end{tabular}




\begin{tabular}{|c|c|c|c|c|c|c|c|}
\hline $\begin{array}{l}\text { Sheep } \\
\text { Eartag }\end{array}$ & Sector & $\begin{array}{l}\text { ETA } \\
(\mathbf{m m})\end{array}$ & $\begin{array}{l}\text { Bone } \\
\text { Pixels }\end{array}$ & $\begin{array}{l}\text { Sacrifice } \\
\text { Season }\end{array}$ & Treatment & $\begin{array}{l}\text { Season of } \\
\text { surgery }\end{array}$ & $\begin{array}{l}\text { Time } \\
\text { (months) }\end{array}$ \\
\hline 32 & 2 & 0.1025 & 13 & Winter & ovx & Autumn & 3 \\
\hline 32 & 2 & 0.1028 & 10 & Winter & ovx & Autumn & 3 \\
\hline 32 & 2 & 0.1031 & 7 & Winter & ovx & Autumn & 3 \\
\hline 32 & 2 & 0.1034 & 11 & Winter & ovx & Autumn & 3 \\
\hline 32 & 2 & 0.1037 & 11 & Winter & ovx & Autumn & 3 \\
\hline 32 & 2 & 0.1040 & 5 & Winter & ovx & Autumn & 3 \\
\hline 32 & 2 & 0.1043 & 6 & Winter & ovx & Autumn & 3 \\
\hline 32 & 2 & 0.1046 & 2 & Winter & ovx & Autumn & 3 \\
\hline 32 & 2 & 0.1049 & 1 & Winter & ovx & Autumn & 3 \\
\hline 32 & 2 & 0.1052 & 1 & Winter & ovx & Autumn & 3 \\
\hline 32 & 2 & 0.1055 & 0 & Winter & ovx & Autumn & 3 \\
\hline 32 & 2 & 0.1058 & 0 & Winter & ovx & Autumn & 3 \\
\hline 32 & 2 & 0.1061 & 0 & Winter & ovx & Autumn & 3 \\
\hline 32 & 2 & 0.1064 & 0 & Winter & ovx & Autumn & 3 \\
\hline 32 & 2 & 0.1067 & 0 & Winter & ovx & Autumn & 3 \\
\hline 32 & 2 & 0.1070 & 0 & Winter & ovx & Autumn & 3 \\
\hline 32 & 2 & 0.1073 & 0 & Winter & ovx & Autumn & 3 \\
\hline 32 & 2 & 0.1076 & 0 & Winter & ovx & Autumn & 3 \\
\hline 32 & 2 & 0.1079 & 0 & Winter & ovx & Autumn & 3 \\
\hline 32 & 2 & 0.1082 & 0 & Winter & ovx & Autumn & 3 \\
\hline 32 & 2 & 0.1085 & 0 & Winter & ovx & Autumn & 3 \\
\hline 32 & 2 & 0.1088 & 0 & Winter & ovx & Autumn & 3 \\
\hline 32 & 2 & 0.1091 & 0 & Winter & ovx & Autumn & 3 \\
\hline 32 & 2 & 0.1094 & 0 & Winter & ovx & Autumn & 3 \\
\hline 32 & 2 & 0.1097 & 0 & Winter & ovx & Autumn & 3 \\
\hline 32 & 2 & 0.1100 & 0 & Winter & ovx & Autumn & 3 \\
\hline 32 & 2 & 0.1103 & 0 & Winter & ovx & Autumn & 3 \\
\hline 32 & 2 & 0.1106 & 0 & Winter & ovx & Autumn & 3 \\
\hline 32 & 2 & 0.1109 & 0 & Winter & ovx & Autumn & 3 \\
\hline 32 & 2 & 0.1112 & 0 & Winter & ovx & Autumn & 3 \\
\hline 32 & 2 & 0.1115 & 0 & Winter & ovx & Autumn & 3 \\
\hline 32 & 2 & 0.1118 & 0 & Winter & ovx & Autumn & 3 \\
\hline 32 & 2 & 0.1122 & 0 & Winter & ovx & Autumn & 3 \\
\hline 32 & 2 & 0.1125 & 0 & Winter & ovx & Autumn & 3 \\
\hline 32 & 2 & 0.1128 & 0 & Winter & ovx & Autumn & 3 \\
\hline 32 & 2 & 0.1131 & 0 & Winter & ovx & Autumn & 3 \\
\hline 32 & 2 & 0.1134 & 0 & Winter & ovx & Autumn & 3 \\
\hline 32 & 2 & 0.1137 & 0 & Winter & ovx & Autumn & 3 \\
\hline 32 & 2 & 0.1140 & 0 & Winter & ovx & Autumn & 3 \\
\hline 32 & 2 & 0.1143 & 0 & Winter & ovx & Autumn & 3 \\
\hline
\end{tabular}




\begin{tabular}{|c|c|c|c|c|c|c|c|}
\hline $\begin{array}{l}\text { Sheep } \\
\text { Eartag }\end{array}$ & Sector & $\begin{array}{l}\text { ETA } \\
(\mathbf{m m})\end{array}$ & $\begin{array}{l}\text { Bone } \\
\text { Pixels }\end{array}$ & $\begin{array}{l}\text { Sacrifice } \\
\text { Season }\end{array}$ & Treatment & $\begin{array}{l}\text { Season of } \\
\text { surgery }\end{array}$ & $\begin{array}{l}\text { Time } \\
\text { (months) }\end{array}$ \\
\hline 32 & 2 & 0.1146 & 0 & Winter & ovx & Autumn & 3 \\
\hline 32 & 2 & 0.1149 & 0 & Winter & ovx & Autumn & 3 \\
\hline 32 & 2 & 0.1152 & 0 & Winter & ovx & Autumn & 3 \\
\hline 32 & 2 & 0.1155 & 0 & Winter & ovx & Autumn & 3 \\
\hline 32 & 2 & 0.1158 & 0 & Winter & ovx & Autumn & 3 \\
\hline 32 & 2 & 0.1161 & 0 & Winter & ovx & Autumn & 3 \\
\hline 32 & 2 & 0.1165 & 0 & Winter & ovx & Autumn & 3 \\
\hline 32 & 2 & 0.1168 & 0 & Winter & ovx & Autumn & 3 \\
\hline 32 & 2 & 0.1171 & 0 & Winter & ovx & Autumn & 3 \\
\hline 32 & 2 & 0.1174 & 0 & Winter & ovx & Autumn & 3 \\
\hline 32 & 2 & 0.1177 & 0 & Winter & ovx & Autumn & 3 \\
\hline 32 & 2 & 0.1180 & 0 & Winter & ovx & Autumn & 3 \\
\hline 32 & 2 & 0.1183 & 0 & Winter & ovx & Autumn & 3 \\
\hline 32 & 2 & 0.1187 & 0 & Winter & ovx & Autumn & 3 \\
\hline 32 & 2 & 0.1190 & 0 & Winter & ovx & Autumn & 3 \\
\hline 32 & 2 & 0.1193 & 0 & Winter & ovx & Autumn & 3 \\
\hline 32 & 2 & 0.1196 & 0 & Winter & ovx & Autumn & 3 \\
\hline 32 & 2 & 0.1199 & 0 & Winter & ovx & Autumn & 3 \\
\hline 32 & 2 & 0.1203 & 0 & Winter & ovx & Autumn & 3 \\
\hline 32 & 2 & 0.1206 & 0 & Winter & ovx & Autumn & 3 \\
\hline 32 & 2 & 0.1209 & 0 & Winter & ovx & Autumn & 3 \\
\hline 32 & 2 & 0.1212 & 0 & Winter & ovx & Autumn & 3 \\
\hline 32 & 2 & 0.1216 & 0 & Winter & ovx & Autumn & 3 \\
\hline 32 & 2 & 0.1219 & 0 & Winter & ovx & Autumn & 3 \\
\hline 32 & 2 & 0.1222 & 0 & Winter & ovx & Autumn & 3 \\
\hline 32 & 2 & 0.1226 & 0 & Winter & ovx & Autumn & 3 \\
\hline 32 & 2 & 0.1229 & 0 & Winter & ovx & Autumn & 3 \\
\hline 32 & 2 & 0.1232 & 0 & Winter & ovx & Autumn & 3 \\
\hline 32 & 2 & 0.1236 & 0 & Winter & ovx & Autumn & 3 \\
\hline 32 & 2 & 0.1239 & 0 & Winter & ovx & Autumn & 3 \\
\hline 32 & 2 & 0.1243 & 0 & Winter & ovx & Autumn & 3 \\
\hline 32 & 2 & 0.1246 & 0 & Winter & ovx & Autumn & 3 \\
\hline 32 & 2 & 0.1249 & 0 & Winter & ovx & Autumn & 3 \\
\hline 32 & 2 & 0.1253 & 0 & Winter & ovx & Autumn & 3 \\
\hline 32 & 2 & 0.1256 & 0 & Winter & ovx & Autumn & 3 \\
\hline 32 & 2 & 0.1260 & 0 & Winter & ovx & Autumn & 3 \\
\hline 32 & 2 & 0.1263 & 0 & Winter & ovx & Autumn & 3 \\
\hline 32 & 2 & 0.1267 & 0 & Winter & ovx & Autumn & 3 \\
\hline 32 & 2 & 0.1270 & 0 & Winter & ovx & Autumn & 3 \\
\hline 32 & 2 & 0.1274 & 0 & Winter & ovx & Autumn & 3 \\
\hline
\end{tabular}




\begin{tabular}{|c|c|c|c|c|c|c|c|}
\hline $\begin{array}{l}\text { Sheep } \\
\text { Eartag }\end{array}$ & Sector & $\begin{array}{l}\text { ETA } \\
(\mathbf{m m})\end{array}$ & $\begin{array}{l}\text { Bone } \\
\text { Pixels } \\
\end{array}$ & $\begin{array}{l}\text { Sacrifice } \\
\text { Season }\end{array}$ & Treatment & $\begin{array}{l}\text { Season of } \\
\text { surgery }\end{array}$ & $\begin{array}{l}\text { Time } \\
\text { (months) }\end{array}$ \\
\hline 32 & 2 & 0.1278 & 0 & Winter & ovx & Autumn & 3 \\
\hline 32 & 2 & 0.1281 & 0 & Winter & ovx & Autumn & 3 \\
\hline 32 & 2 & 0.1285 & 0 & Winter & ovx & Autumn & 3 \\
\hline 32 & 2 & 0.1288 & 0 & Winter & ovx & Autumn & 3 \\
\hline 32 & 2 & 0.1292 & 0 & Winter & ovx & Autumn & 3 \\
\hline 32 & 2 & 0.1296 & 0 & Winter & ovx & Autumn & 3 \\
\hline 32 & 2 & 0.1300 & 0 & Winter & ovx & Autumn & 3 \\
\hline 32 & 2 & 0.1303 & 0 & Winter & ovx & Autumn & 3 \\
\hline 32 & 2 & 0.1307 & 0 & Winter & ovx & Autumn & 3 \\
\hline 32 & 2 & 0.1311 & 0 & Winter & ovx & Autumn & 3 \\
\hline 32 & 2 & 0.1315 & 0 & Winter & ovx & Autumn & 3 \\
\hline 32 & 2 & 0.1319 & 0 & Winter & ovx & Autumn & 3 \\
\hline 32 & 2 & 0.1323 & 0 & Winter & ovx & Autumn & 3 \\
\hline 32 & 2 & 0.1327 & 0 & Winter & ovx & Autumn & 3 \\
\hline 32 & 2 & 0.1331 & 0 & Winter & ovx & Autumn & 3 \\
\hline 32 & 2 & 0.1335 & 0 & Winter & ovx & Autumn & 3 \\
\hline 32 & 2 & 0.1339 & 0 & Winter & ovx & Autumn & 3 \\
\hline 32 & 2 & 0.1343 & 0 & Winter & ovx & Autumn & 3 \\
\hline 32 & 2 & 0.1347 & 0 & Winter & ovx & Autumn & 3 \\
\hline 32 & 2 & 0.1351 & 0 & Winter & ovx & Autumn & 3 \\
\hline 32 & 2 & 0.1355 & 0 & Winter & ovx & Autumn & 3 \\
\hline 32 & 2 & 0.1359 & 0 & Winter & ovx & Autumn & 3 \\
\hline 32 & 2 & 0.1364 & 0 & Winter & ovx & Autumn & 3 \\
\hline 32 & 2 & 0.1368 & 0 & Winter & ovx & Autumn & 3 \\
\hline 32 & 2 & 0.1372 & 0 & Winter & ovx & Autumn & 3 \\
\hline 32 & 2 & 0.1377 & 0 & Winter & ovx & Autumn & 3 \\
\hline 32 & 2 & 0.1381 & 0 & Winter & ovx & Autumn & 3 \\
\hline 32 & 2 & 0.1386 & 0 & Winter & ovx & Autumn & 3 \\
\hline 32 & 2 & 0.1390 & 0 & Winter & ovx & Autumn & 3 \\
\hline 32 & 2 & 0.1395 & 0 & Winter & ovx & Autumn & 3 \\
\hline 32 & 2 & 0.1400 & 0 & Winter & ovx & Autumn & 3 \\
\hline 32 & 2 & 0.1404 & 0 & Winter & ovx & Autumn & 3 \\
\hline 32 & 2 & 0.1409 & 0 & Winter & ovx & Autumn & 3 \\
\hline 32 & 2 & 0.1414 & 0 & Winter & ovx & Autumn & 3 \\
\hline 32 & 2 & 0.1419 & 0 & Winter & ovx & Autumn & 3 \\
\hline 32 & 2 & 0.1424 & 0 & Winter & ovx & Autumn & 3 \\
\hline 32 & 2 & 0.1429 & 0 & Winter & ovx & Autumn & 3 \\
\hline 32 & 2 & 0.1434 & 0 & Winter & ovx & Autumn & 3 \\
\hline 32 & 2 & 0.1439 & 0 & Winter & ovx & Autumn & 3 \\
\hline 32 & 2 & 0.1444 & 0 & Winter & ovx & Autumn & 3 \\
\hline
\end{tabular}




\begin{tabular}{|c|c|c|c|c|c|c|c|}
\hline $\begin{array}{l}\text { Sheep } \\
\text { Eartag }\end{array}$ & Sector & $\begin{array}{l}\text { ETA } \\
(\mathbf{m m})\end{array}$ & $\begin{array}{l}\text { Bone } \\
\text { Pixels } \\
\end{array}$ & $\begin{array}{l}\text { Sacrifice } \\
\text { Season }\end{array}$ & Treatment & $\begin{array}{l}\text { Season of } \\
\text { surgery }\end{array}$ & $\begin{array}{l}\text { Time } \\
\text { (months) }\end{array}$ \\
\hline 32 & 2 & 0.1450 & 0 & Winter & ovx & Autumn & 3 \\
\hline 32 & 2 & 0.1455 & 0 & Winter & ovx & Autumn & 3 \\
\hline 32 & 2 & 0.1461 & 0 & Winter & ovx & Autumn & 3 \\
\hline 32 & 3 & 0.0059 & 0 & Winter & ovx & Autumn & 3 \\
\hline 32 & 3 & 0.0114 & 452760 & Winter & ovx & Autumn & 3 \\
\hline 32 & 3 & 0.0158 & 14674 & Winter & ovx & Autumn & 3 \\
\hline 32 & 3 & 0.0196 & 12209 & Winter & ovx & Autumn & 3 \\
\hline 32 & 3 & 0.0228 & 12630 & Winter & ovx & Autumn & 3 \\
\hline 32 & 3 & 0.0257 & 12927 & Winter & ovx & Autumn & 3 \\
\hline 32 & 3 & 0.0283 & 11087 & Winter & ovx & Autumn & 3 \\
\hline 32 & 3 & 0.0306 & 13033 & Winter & ovx & Autumn & 3 \\
\hline 32 & 3 & 0.0327 & 11096 & Winter & ovx & Autumn & 3 \\
\hline 32 & 3 & 0.0347 & 13614 & Winter & ovx & Autumn & 3 \\
\hline 32 & 3 & 0.0365 & 13938 & Winter & ovx & Autumn & 3 \\
\hline 32 & 3 & 0.0382 & 15044 & Winter & ovx & Autumn & 3 \\
\hline 32 & 3 & 0.0398 & 21780 & Winter & ovx & Autumn & 3 \\
\hline 32 & 3 & 0.0413 & 19260 & Winter & ovx & Autumn & 3 \\
\hline 32 & 3 & 0.0427 & 27899 & Winter & ovx & Autumn & 3 \\
\hline 32 & 3 & 0.0441 & 30041 & Winter & ovx & Autumn & 3 \\
\hline 32 & 3 & 0.0454 & 32228 & Winter & ovx & Autumn & 3 \\
\hline 32 & 3 & 0.0466 & 44485 & Winter & ovx & Autumn & 3 \\
\hline 32 & 3 & 0.0478 & 51411 & Winter & ovx & Autumn & 3 \\
\hline 32 & 3 & 0.0489 & 63319 & Winter & ovx & Autumn & 3 \\
\hline 32 & 3 & 0.0500 & 81397 & Winter & ovx & Autumn & 3 \\
\hline 32 & 3 & 0.0510 & 78841 & Winter & ovx & Autumn & 3 \\
\hline 32 & 3 & 0.0520 & 90573 & Winter & ovx & Autumn & 3 \\
\hline 32 & 3 & 0.0530 & 90169 & Winter & ovx & Autumn & 3 \\
\hline 32 & 3 & 0.0539 & 101201 & Winter & ovx & Autumn & 3 \\
\hline 32 & 3 & 0.0548 & 109898 & Winter & ovx & Autumn & 3 \\
\hline 32 & 3 & 0.0557 & 115411 & Winter & ovx & Autumn & 3 \\
\hline 32 & 3 & 0.0566 & 128194 & Winter & ovx & Autumn & 3 \\
\hline 32 & 3 & 0.0574 & 127861 & Winter & ovx & Autumn & 3 \\
\hline 32 & 3 & 0.0582 & 132219 & Winter & ovx & Autumn & 3 \\
\hline 32 & 3 & 0.0590 & 132984 & Winter & ovx & Autumn & 3 \\
\hline 32 & 3 & 0.0597 & 129261 & Winter & ovx & Autumn & 3 \\
\hline 32 & 3 & 0.0605 & 133525 & Winter & ovx & Autumn & 3 \\
\hline 32 & 3 & 0.0612 & 130482 & Winter & ovx & Autumn & 3 \\
\hline 32 & 3 & 0.0619 & 136048 & Winter & ovx & Autumn & 3 \\
\hline 32 & 3 & 0.0626 & 140601 & Winter & ovx & Autumn & 3 \\
\hline 32 & 3 & 0.0633 & 139787 & Winter & ovx & Autumn & 3 \\
\hline
\end{tabular}




\begin{tabular}{|c|c|c|c|c|c|c|c|}
\hline $\begin{array}{l}\text { Sheep } \\
\text { Eartag }\end{array}$ & Sector & $\begin{array}{l}\text { ETA } \\
(\mathbf{m m})\end{array}$ & $\begin{array}{l}\text { Bone } \\
\text { Pixels } \\
\end{array}$ & $\begin{array}{l}\text { Sacrifice } \\
\text { Season }\end{array}$ & Treatment & $\begin{array}{l}\text { Season of } \\
\text { surgery }\end{array}$ & $\begin{array}{l}\text { Time } \\
\text { (months) }\end{array}$ \\
\hline 32 & 3 & 0.0640 & 150794 & Winter & ovx & Autumn & 3 \\
\hline 32 & 3 & 0.0646 & 151530 & Winter & ovx & Autumn & 3 \\
\hline 32 & 3 & 0.0652 & 154010 & Winter & ovx & Autumn & 3 \\
\hline 32 & 3 & 0.0659 & 158098 & Winter & ovx & Autumn & 3 \\
\hline 32 & 3 & 0.0665 & 159328 & Winter & ovx & Autumn & 3 \\
\hline 32 & 3 & 0.0671 & 160796 & Winter & ovx & Autumn & 3 \\
\hline 32 & 3 & 0.0677 & 157681 & Winter & ovx & Autumn & 3 \\
\hline 32 & 3 & 0.0683 & 154898 & Winter & ovx & Autumn & 3 \\
\hline 32 & 3 & 0.0688 & 150394 & Winter & ovx & Autumn & 3 \\
\hline 32 & 3 & 0.0694 & 145550 & Winter & ovx & Autumn & 3 \\
\hline 32 & 3 & 0.0699 & 140550 & Winter & ovx & Autumn & 3 \\
\hline 32 & 3 & 0.0705 & 133360 & Winter & ovx & Autumn & 3 \\
\hline 32 & 3 & 0.0710 & 125758 & Winter & ovx & Autumn & 3 \\
\hline 32 & 3 & 0.0716 & 117660 & Winter & ovx & Autumn & 3 \\
\hline 32 & 3 & 0.0721 & 108018 & Winter & ovx & Autumn & 3 \\
\hline 32 & 3 & 0.0726 & 100050 & Winter & ovx & Autumn & 3 \\
\hline 32 & 3 & 0.0731 & 89816 & Winter & ovx & Autumn & 3 \\
\hline 32 & 3 & 0.0736 & 81138 & Winter & ovx & Autumn & 3 \\
\hline 32 & 3 & 0.0741 & 71786 & Winter & ovx & Autumn & 3 \\
\hline 32 & 3 & 0.0746 & 63671 & Winter & ovx & Autumn & 3 \\
\hline 32 & 3 & 0.0751 & 55064 & Winter & ovx & Autumn & 3 \\
\hline 32 & 3 & 0.0755 & 47969 & Winter & ovx & Autumn & 3 \\
\hline 32 & 3 & 0.0760 & 40838 & Winter & ovx & Autumn & 3 \\
\hline 32 & 3 & 0.0765 & 34645 & Winter & ovx & Autumn & 3 \\
\hline 32 & 3 & 0.0769 & 28843 & Winter & ovx & Autumn & 3 \\
\hline 32 & 3 & 0.0774 & 24231 & Winter & ovx & Autumn & 3 \\
\hline 32 & 3 & 0.0778 & 19916 & Winter & ovx & Autumn & 3 \\
\hline 32 & 3 & 0.0783 & 16719 & Winter & ovx & Autumn & 3 \\
\hline 32 & 3 & 0.0787 & 13462 & Winter & ovx & Autumn & 3 \\
\hline 32 & 3 & 0.0791 & 11104 & Winter & ovx & Autumn & 3 \\
\hline 32 & 3 & 0.0796 & 8971 & Winter & ovx & Autumn & 3 \\
\hline 32 & 3 & 0.0800 & 7309 & Winter & ovx & Autumn & 3 \\
\hline 32 & 3 & 0.0804 & 6024 & Winter & ovx & Autumn & 3 \\
\hline 32 & 3 & 0.0808 & 4903 & Winter & ovx & Autumn & 3 \\
\hline 32 & 3 & 0.0812 & 4030 & Winter & ovx & Autumn & 3 \\
\hline 32 & 3 & 0.0816 & 3260 & Winter & ovx & Autumn & 3 \\
\hline 32 & 3 & 0.0820 & 2715 & Winter & ovx & Autumn & 3 \\
\hline 32 & 3 & 0.0824 & 2184 & Winter & ovx & Autumn & 3 \\
\hline 32 & 3 & 0.0828 & 1871 & Winter & ovx & Autumn & 3 \\
\hline 32 & 3 & 0.0832 & 1531 & Winter & ovx & Autumn & 3 \\
\hline
\end{tabular}




\begin{tabular}{|c|c|c|c|c|c|c|c|}
\hline $\begin{array}{l}\text { Sheep } \\
\text { Eartag }\end{array}$ & Sector & $\begin{array}{l}\text { ETA } \\
(\mathbf{m m})\end{array}$ & $\begin{array}{l}\text { Bone } \\
\text { Pixels } \\
\end{array}$ & $\begin{array}{l}\text { Sacrifice } \\
\text { Season }\end{array}$ & Treatment & $\begin{array}{l}\text { Season of } \\
\text { surgery }\end{array}$ & $\begin{array}{l}\text { Time } \\
\text { (months) }\end{array}$ \\
\hline 32 & 3 & 0.0836 & 1331 & Winter & ovx & Autumn & 3 \\
\hline 32 & 3 & 0.0840 & 1051 & Winter & ovx & Autumn & 3 \\
\hline 32 & 3 & 0.0844 & 845 & Winter & ovx & Autumn & 3 \\
\hline 32 & 3 & 0.0848 & 667 & Winter & ovx & Autumn & 3 \\
\hline 32 & 3 & 0.0852 & 582 & Winter & ovx & Autumn & 3 \\
\hline 32 & 3 & 0.0855 & 482 & Winter & ovx & Autumn & 3 \\
\hline 32 & 3 & 0.0859 & 386 & Winter & ovx & Autumn & 3 \\
\hline 32 & 3 & 0.0863 & 338 & Winter & ovx & Autumn & 3 \\
\hline 32 & 3 & 0.0867 & 233 & Winter & ovx & Autumn & 3 \\
\hline 32 & 3 & 0.0870 & 209 & Winter & ovx & Autumn & 3 \\
\hline 32 & 3 & 0.0874 & 163 & Winter & ovx & Autumn & 3 \\
\hline 32 & 3 & 0.0878 & 143 & Winter & ovx & Autumn & 3 \\
\hline 32 & 3 & 0.0881 & 94 & Winter & ovx & Autumn & 3 \\
\hline 32 & 3 & 0.0885 & 88 & Winter & ovx & Autumn & 3 \\
\hline 32 & 3 & 0.0888 & 53 & Winter & ovx & Autumn & 3 \\
\hline 32 & 3 & 0.0892 & 49 & Winter & ovx & Autumn & 3 \\
\hline 32 & 3 & 0.0895 & 40 & Winter & ovx & Autumn & 3 \\
\hline 32 & 3 & 0.0899 & 45 & Winter & ovx & Autumn & 3 \\
\hline 32 & 3 & 0.0902 & 35 & Winter & ovx & Autumn & 3 \\
\hline 32 & 3 & 0.0906 & 25 & Winter & ovx & Autumn & 3 \\
\hline 32 & 3 & 0.0909 & 16 & Winter & ovx & Autumn & 3 \\
\hline 32 & 3 & 0.0913 & 9 & Winter & ovx & Autumn & 3 \\
\hline 32 & 3 & 0.0916 & 11 & Winter & ovx & Autumn & 3 \\
\hline 32 & 3 & 0.0919 & 10 & Winter & ovx & Autumn & 3 \\
\hline 32 & 3 & 0.0923 & 6 & Winter & ovx & Autumn & 3 \\
\hline 32 & 3 & 0.0926 & 6 & Winter & ovx & Autumn & 3 \\
\hline 32 & 3 & 0.0930 & 6 & Winter & ovx & Autumn & 3 \\
\hline 32 & 3 & 0.0933 & 5 & Winter & ovx & Autumn & 3 \\
\hline 32 & 3 & 0.0936 & 7 & Winter & ovx & Autumn & 3 \\
\hline 32 & 3 & 0.0939 & 2 & Winter & ovx & Autumn & 3 \\
\hline 32 & 3 & 0.0943 & 3 & Winter & ovx & Autumn & 3 \\
\hline 32 & 3 & 0.0946 & 2 & Winter & ovx & Autumn & 3 \\
\hline 32 & 3 & 0.0949 & 6 & Winter & ovx & Autumn & 3 \\
\hline 32 & 3 & 0.0953 & 4 & Winter & ovx & Autumn & 3 \\
\hline 32 & 3 & 0.0956 & 2 & Winter & ovx & Autumn & 3 \\
\hline 32 & 3 & 0.0959 & 1 & Winter & ovx & Autumn & 3 \\
\hline 32 & 3 & 0.0962 & 0 & Winter & ovx & Autumn & 3 \\
\hline 32 & 3 & 0.0965 & 3 & Winter & ovx & Autumn & 3 \\
\hline 32 & 3 & 0.0969 & 0 & Winter & ovx & Autumn & 3 \\
\hline 32 & 3 & 0.0972 & 4 & Winter & ovx & Autumn & 3 \\
\hline
\end{tabular}




\begin{tabular}{|c|c|c|c|c|c|c|c|}
\hline $\begin{array}{l}\text { Sheep } \\
\text { Eartag }\end{array}$ & Sector & $\begin{array}{l}\text { ETA } \\
(\mathbf{m m})\end{array}$ & $\begin{array}{l}\text { Bone } \\
\text { Pixels }\end{array}$ & $\begin{array}{l}\text { Sacrifice } \\
\text { Season }\end{array}$ & Treatment & $\begin{array}{l}\text { Season of } \\
\text { surgery }\end{array}$ & $\begin{array}{l}\text { Time } \\
\text { (months) }\end{array}$ \\
\hline 32 & 3 & 0.0975 & 2 & Winter & ovx & Autumn & 3 \\
\hline 32 & 3 & 0.0978 & 4 & Winter & ovx & Autumn & 3 \\
\hline 32 & 3 & 0.0981 & 0 & Winter & ovx & Autumn & 3 \\
\hline 32 & 3 & 0.0984 & 0 & Winter & ovx & Autumn & 3 \\
\hline 32 & 3 & 0.0988 & 2 & Winter & ovx & Autumn & 3 \\
\hline 32 & 3 & 0.0991 & 2 & Winter & ovx & Autumn & 3 \\
\hline 32 & 3 & 0.0994 & 2 & Winter & ovx & Autumn & 3 \\
\hline 32 & 3 & 0.0997 & 0 & Winter & ovx & Autumn & 3 \\
\hline 32 & 3 & 0.1000 & 5 & Winter & ovx & Autumn & 3 \\
\hline 32 & 3 & 0.1003 & 0 & Winter & ovx & Autumn & 3 \\
\hline 32 & 3 & 0.1006 & 1 & Winter & ovx & Autumn & 3 \\
\hline 32 & 3 & 0.1009 & 1 & Winter & ovx & Autumn & 3 \\
\hline 32 & 3 & 0.1012 & 1 & Winter & ovx & Autumn & 3 \\
\hline 32 & 3 & 0.1015 & 0 & Winter & ovx & Autumn & 3 \\
\hline 32 & 3 & 0.1018 & 1 & Winter & ovx & Autumn & 3 \\
\hline 32 & 3 & 0.1022 & 1 & Winter & ovx & Autumn & 3 \\
\hline 32 & 3 & 0.1025 & 1 & Winter & ovx & Autumn & 3 \\
\hline 32 & 3 & 0.1028 & 2 & Winter & ovx & Autumn & 3 \\
\hline 32 & 3 & 0.1031 & 1 & Winter & ovx & Autumn & 3 \\
\hline 32 & 3 & 0.1034 & 0 & Winter & ovx & Autumn & 3 \\
\hline 32 & 3 & 0.1037 & 0 & Winter & ovx & Autumn & 3 \\
\hline 32 & 3 & 0.1040 & 2 & Winter & ovx & Autumn & 3 \\
\hline 32 & 3 & 0.1043 & 1 & Winter & ovx & Autumn & 3 \\
\hline 32 & 3 & 0.1046 & 1 & Winter & ovx & Autumn & 3 \\
\hline 32 & 3 & 0.1049 & 0 & Winter & ovx & Autumn & 3 \\
\hline 32 & 3 & 0.1052 & 0 & Winter & ovx & Autumn & 3 \\
\hline 32 & 3 & 0.1055 & 1 & Winter & ovx & Autumn & 3 \\
\hline 32 & 3 & 0.1058 & 0 & Winter & ovx & Autumn & 3 \\
\hline 32 & 3 & 0.1061 & 1 & Winter & ovx & Autumn & 3 \\
\hline 32 & 3 & 0.1064 & 0 & Winter & ovx & Autumn & 3 \\
\hline 32 & 3 & 0.1067 & 0 & Winter & ovx & Autumn & 3 \\
\hline 32 & 3 & 0.1070 & 0 & Winter & ovx & Autumn & 3 \\
\hline 32 & 3 & 0.1073 & 0 & Winter & ovx & Autumn & 3 \\
\hline 32 & 3 & 0.1076 & 1 & Winter & ovx & Autumn & 3 \\
\hline 32 & 3 & 0.1079 & 0 & Winter & ovx & Autumn & 3 \\
\hline 32 & 3 & 0.1082 & 2 & Winter & ovx & Autumn & 3 \\
\hline 32 & 3 & 0.1085 & 0 & Winter & ovx & Autumn & 3 \\
\hline 32 & 3 & 0.1088 & 0 & Winter & ovx & Autumn & 3 \\
\hline 32 & 3 & 0.1091 & 2 & Winter & ovx & Autumn & 3 \\
\hline 32 & 3 & 0.1094 & 1 & Winter & ovx & Autumn & 3 \\
\hline
\end{tabular}




\begin{tabular}{|c|c|c|c|c|c|c|c|}
\hline $\begin{array}{l}\text { Sheep } \\
\text { Eartag }\end{array}$ & Sector & $\begin{array}{l}\text { ETA } \\
(\mathbf{m m})\end{array}$ & $\begin{array}{l}\text { Bone } \\
\text { Pixels } \\
\end{array}$ & $\begin{array}{l}\text { Sacrifice } \\
\text { Season }\end{array}$ & Treatment & $\begin{array}{l}\text { Season of } \\
\text { surgery }\end{array}$ & $\begin{array}{l}\text { Time } \\
\text { (months) }\end{array}$ \\
\hline 32 & 3 & 0.1097 & 1 & Winter & ovx & Autumn & 3 \\
\hline 32 & 3 & 0.1100 & 0 & Winter & ovx & Autumn & 3 \\
\hline 32 & 3 & 0.1103 & 2 & Winter & ovx & Autumn & 3 \\
\hline 32 & 3 & 0.1106 & 2 & Winter & ovx & Autumn & 3 \\
\hline 32 & 3 & 0.1109 & 0 & Winter & ovx & Autumn & 3 \\
\hline 32 & 3 & 0.1112 & 3 & Winter & ovx & Autumn & 3 \\
\hline 32 & 3 & 0.1115 & 0 & Winter & ovx & Autumn & 3 \\
\hline 32 & 3 & 0.1118 & 1 & Winter & ovx & Autumn & 3 \\
\hline 32 & 3 & 0.1122 & 1 & Winter & ovx & Autumn & 3 \\
\hline 32 & 3 & 0.1125 & 0 & Winter & ovx & Autumn & 3 \\
\hline 32 & 3 & 0.1128 & 0 & Winter & ovx & Autumn & 3 \\
\hline 32 & 3 & 0.1131 & 0 & Winter & ovx & Autumn & 3 \\
\hline 32 & 3 & 0.1134 & 0 & Winter & ovx & Autumn & 3 \\
\hline 32 & 3 & 0.1137 & 2 & Winter & ovx & Autumn & 3 \\
\hline 32 & 3 & 0.1140 & 0 & Winter & ovx & Autumn & 3 \\
\hline 32 & 3 & 0.1143 & 2 & Winter & ovx & Autumn & 3 \\
\hline 32 & 3 & 0.1146 & 1 & Winter & ovx & Autumn & 3 \\
\hline 32 & 3 & 0.1149 & 0 & Winter & ovx & Autumn & 3 \\
\hline 32 & 3 & 0.1152 & 0 & Winter & ovx & Autumn & 3 \\
\hline 32 & 3 & 0.1155 & 1 & Winter & ovx & Autumn & 3 \\
\hline 32 & 3 & 0.1158 & 0 & Winter & ovx & Autumn & 3 \\
\hline 32 & 3 & 0.1161 & 1 & Winter & ovx & Autumn & 3 \\
\hline 32 & 3 & 0.1165 & 1 & Winter & ovx & Autumn & 3 \\
\hline 32 & 3 & 0.1168 & 1 & Winter & ovx & Autumn & 3 \\
\hline 32 & 3 & 0.1171 & 0 & Winter & ovx & Autumn & 3 \\
\hline 32 & 3 & 0.1174 & 0 & Winter & ovx & Autumn & 3 \\
\hline 32 & 3 & 0.1177 & 0 & Winter & ovx & Autumn & 3 \\
\hline 32 & 3 & 0.1180 & 0 & Winter & ovx & Autumn & 3 \\
\hline 32 & 3 & 0.1183 & 0 & Winter & ovx & Autumn & 3 \\
\hline 32 & 3 & 0.1187 & 0 & Winter & ovx & Autumn & 3 \\
\hline 32 & 3 & 0.1190 & 0 & Winter & ovx & Autumn & 3 \\
\hline 32 & 3 & 0.1193 & 0 & Winter & ovx & Autumn & 3 \\
\hline 32 & 3 & 0.1196 & 0 & Winter & ovx & Autumn & 3 \\
\hline 32 & 3 & 0.1199 & 0 & Winter & ovx & Autumn & 3 \\
\hline 32 & 3 & 0.1203 & 0 & Winter & ovx & Autumn & 3 \\
\hline 32 & 3 & 0.1206 & 0 & Winter & ovx & Autumn & 3 \\
\hline 32 & 3 & 0.1209 & 0 & Winter & ovx & Autumn & 3 \\
\hline 32 & 3 & 0.1212 & 0 & Winter & ovx & Autumn & 3 \\
\hline 32 & 3 & 0.1216 & 0 & Winter & ovx & Autumn & 3 \\
\hline 32 & 3 & 0.1219 & 0 & Winter & ovx & Autumn & 3 \\
\hline
\end{tabular}




\begin{tabular}{|c|c|c|c|c|c|c|c|}
\hline $\begin{array}{l}\text { Sheep } \\
\text { Eartag }\end{array}$ & Sector & $\begin{array}{l}\text { ETA } \\
(\mathbf{m m})\end{array}$ & $\begin{array}{l}\text { Bone } \\
\text { Pixels } \\
\end{array}$ & $\begin{array}{l}\text { Sacrifice } \\
\text { Season }\end{array}$ & Treatment & $\begin{array}{l}\text { Season of } \\
\text { surgery }\end{array}$ & $\begin{array}{l}\text { Time } \\
\text { (months) }\end{array}$ \\
\hline 32 & 3 & 0.1222 & 0 & Winter & ovx & Autumn & 3 \\
\hline 32 & 3 & 0.1226 & 0 & Winter & ovx & Autumn & 3 \\
\hline 32 & 3 & 0.1229 & 0 & Winter & ovx & Autumn & 3 \\
\hline 32 & 3 & 0.1232 & 0 & Winter & ovx & Autumn & 3 \\
\hline 32 & 3 & 0.1236 & 0 & Winter & ovx & Autumn & 3 \\
\hline 32 & 3 & 0.1239 & 0 & Winter & ovx & Autumn & 3 \\
\hline 32 & 3 & 0.1243 & 0 & Winter & ovx & Autumn & 3 \\
\hline 32 & 3 & 0.1246 & 0 & Winter & ovx & Autumn & 3 \\
\hline 32 & 3 & 0.1249 & 0 & Winter & ovx & Autumn & 3 \\
\hline 32 & 3 & 0.1253 & 0 & Winter & ovx & Autumn & 3 \\
\hline 32 & 3 & 0.1256 & 0 & Winter & ovx & Autumn & 3 \\
\hline 32 & 3 & 0.1260 & 0 & Winter & ovx & Autumn & 3 \\
\hline 32 & 3 & 0.1263 & 0 & Winter & ovx & Autumn & 3 \\
\hline 32 & 3 & 0.1267 & 0 & Winter & ovx & Autumn & 3 \\
\hline 32 & 3 & 0.1270 & 0 & Winter & ovx & Autumn & 3 \\
\hline 32 & 3 & 0.1274 & 0 & Winter & ovx & Autumn & 3 \\
\hline 32 & 3 & 0.1278 & 0 & Winter & ovx & Autumn & 3 \\
\hline 32 & 3 & 0.1281 & 0 & Winter & ovx & Autumn & 3 \\
\hline 32 & 3 & 0.1285 & 0 & Winter & ovx & Autumn & 3 \\
\hline 32 & 3 & 0.1288 & 0 & Winter & ovx & Autumn & 3 \\
\hline 32 & 3 & 0.1292 & 0 & Winter & ovx & Autumn & 3 \\
\hline 32 & 3 & 0.1296 & 0 & Winter & ovx & Autumn & 3 \\
\hline 32 & 3 & 0.1300 & 0 & Winter & ovx & Autumn & 3 \\
\hline 32 & 3 & 0.1303 & 0 & Winter & ovx & Autumn & 3 \\
\hline 32 & 3 & 0.1307 & 0 & Winter & ovx & Autumn & 3 \\
\hline 32 & 3 & 0.1311 & 0 & Winter & ovx & Autumn & 3 \\
\hline 32 & 3 & 0.1315 & 0 & Winter & ovx & Autumn & 3 \\
\hline 32 & 3 & 0.1319 & 0 & Winter & ovx & Autumn & 3 \\
\hline 32 & 3 & 0.1323 & 0 & Winter & ovx & Autumn & 3 \\
\hline 32 & 3 & 0.1327 & 0 & Winter & ovx & Autumn & 3 \\
\hline 32 & 3 & 0.1331 & 0 & Winter & ovx & Autumn & 3 \\
\hline 32 & 3 & 0.1335 & 0 & Winter & ovx & Autumn & 3 \\
\hline 32 & 3 & 0.1339 & 0 & Winter & ovx & Autumn & 3 \\
\hline 32 & 3 & 0.1343 & 0 & Winter & ovx & Autumn & 3 \\
\hline 32 & 3 & 0.1347 & 0 & Winter & ovx & Autumn & 3 \\
\hline 32 & 3 & 0.1351 & 0 & Winter & ovx & Autumn & 3 \\
\hline 32 & 3 & 0.1355 & 0 & Winter & ovx & Autumn & 3 \\
\hline 32 & 3 & 0.1359 & 0 & Winter & ovx & Autumn & 3 \\
\hline 32 & 3 & 0.1364 & 0 & Winter & ovx & Autumn & 3 \\
\hline 32 & 3 & 0.1368 & 0 & Winter & ovx & Autumn & 3 \\
\hline
\end{tabular}




\begin{tabular}{|c|c|c|c|c|c|c|c|}
\hline $\begin{array}{l}\text { Sheep } \\
\text { Eartag }\end{array}$ & Sector & $\begin{array}{l}\text { ETA } \\
(\mathbf{m m})\end{array}$ & $\begin{array}{l}\text { Bone } \\
\text { Pixels }\end{array}$ & $\begin{array}{l}\text { Sacrifice } \\
\text { Season }\end{array}$ & Treatment & $\begin{array}{l}\text { Season of } \\
\text { surgery }\end{array}$ & $\begin{array}{l}\text { Time } \\
\text { (months) }\end{array}$ \\
\hline 32 & 3 & 0.1372 & 0 & Winter & ovx & Autumn & 3 \\
\hline 32 & 3 & 0.1377 & 0 & Winter & ovx & Autumn & 3 \\
\hline 32 & 3 & 0.1381 & 0 & Winter & ovx & Autumn & 3 \\
\hline 32 & 3 & 0.1386 & 0 & Winter & ovx & Autumn & 3 \\
\hline 32 & 3 & 0.1390 & 0 & Winter & ovx & Autumn & 3 \\
\hline 32 & 3 & 0.1395 & 0 & Winter & ovx & Autumn & 3 \\
\hline 32 & 3 & 0.1400 & 0 & Winter & ovx & Autumn & 3 \\
\hline 32 & 3 & 0.1404 & 0 & Winter & ovx & Autumn & 3 \\
\hline 32 & 3 & 0.1409 & 0 & Winter & ovx & Autumn & 3 \\
\hline 32 & 3 & 0.1414 & 0 & Winter & ovx & Autumn & 3 \\
\hline 32 & 3 & 0.1419 & 0 & Winter & ovx & Autumn & 3 \\
\hline 32 & 3 & 0.1424 & 0 & Winter & ovx & Autumn & 3 \\
\hline 32 & 3 & 0.1429 & 0 & Winter & ovx & Autumn & 3 \\
\hline 32 & 3 & 0.1434 & 0 & Winter & ovx & Autumn & 3 \\
\hline 32 & 3 & 0.1439 & 0 & Winter & ovx & Autumn & 3 \\
\hline 32 & 3 & 0.1444 & 0 & Winter & ovx & Autumn & 3 \\
\hline 32 & 3 & 0.1450 & 0 & Winter & ovx & Autumn & 3 \\
\hline 32 & 3 & 0.1455 & 0 & Winter & ovx & Autumn & 3 \\
\hline 32 & 3 & 0.1461 & 0 & Winter & ovx & Autumn & 3 \\
\hline 32 & 4 & 0.0059 & 0 & Winter & ovx & Autumn & 3 \\
\hline 32 & 4 & 0.0114 & 0 & Winter & ovx & Autumn & 3 \\
\hline 32 & 4 & 0.0158 & 0 & Winter & ovx & Autumn & 3 \\
\hline 32 & 4 & 0.0196 & 0 & Winter & ovx & Autumn & 3 \\
\hline 32 & 4 & 0.0228 & 0 & Winter & ovx & Autumn & 3 \\
\hline 32 & 4 & 0.0257 & 0 & Winter & ovx & Autumn & 3 \\
\hline 32 & 4 & 0.0283 & 0 & Winter & ovx & Autumn & 3 \\
\hline 32 & 4 & 0.0306 & 0 & Winter & ovx & Autumn & 3 \\
\hline 32 & 4 & 0.0327 & 0 & Winter & ovx & Autumn & 3 \\
\hline 32 & 4 & 0.0347 & 0 & Winter & ovx & Autumn & 3 \\
\hline 32 & 4 & 0.0365 & 0 & Winter & ovx & Autumn & 3 \\
\hline 32 & 4 & 0.0382 & 0 & Winter & ovx & Autumn & 3 \\
\hline 32 & 4 & 0.0398 & 0 & Winter & ovx & Autumn & 3 \\
\hline 32 & 4 & 0.0413 & 0 & Winter & ovx & Autumn & 3 \\
\hline 32 & 4 & 0.0427 & 0 & Winter & ovx & Autumn & 3 \\
\hline 32 & 4 & 0.0441 & 0 & Winter & ovx & Autumn & 3 \\
\hline 32 & 4 & 0.0454 & 0 & Winter & ovx & Autumn & 3 \\
\hline 32 & 4 & 0.0466 & 0 & Winter & ovx & Autumn & 3 \\
\hline 32 & 4 & 0.0478 & 0 & Winter & ovx & Autumn & 3 \\
\hline 32 & 4 & 0.0489 & 11144 & Winter & ovx & Autumn & 3 \\
\hline 32 & 4 & 0.0500 & 13814 & Winter & ovx & Autumn & 3 \\
\hline
\end{tabular}




\begin{tabular}{|c|c|c|c|c|c|c|c|}
\hline $\begin{array}{l}\text { Sheep } \\
\text { Eartag }\end{array}$ & Sector & $\begin{array}{l}\text { ETA } \\
(\mathbf{m m})\end{array}$ & $\begin{array}{l}\text { Bone } \\
\text { Pixels }\end{array}$ & $\begin{array}{l}\text { Sacrifice } \\
\text { Season }\end{array}$ & Treatment & $\begin{array}{l}\text { Season of } \\
\text { surgery }\end{array}$ & $\begin{array}{l}\text { Time } \\
\text { (months) }\end{array}$ \\
\hline 32 & 4 & 0.0510 & 14646 & Winter & ovx & Autumn & 3 \\
\hline 32 & 4 & 0.0520 & 17945 & Winter & ovx & Autumn & 3 \\
\hline 32 & 4 & 0.0530 & 19078 & Winter & ovx & Autumn & 3 \\
\hline 32 & 4 & 0.0539 & 21935 & Winter & ovx & Autumn & 3 \\
\hline 32 & 4 & 0.0548 & 24766 & Winter & ovx & Autumn & 3 \\
\hline 32 & 4 & 0.0557 & 26562 & Winter & ovx & Autumn & 3 \\
\hline 32 & 4 & 0.0566 & 30628 & Winter & ovx & Autumn & 3 \\
\hline 32 & 4 & 0.0574 & 32616 & Winter & ovx & Autumn & 3 \\
\hline 32 & 4 & 0.0582 & 35371 & Winter & ovx & Autumn & 3 \\
\hline 32 & 4 & 0.0590 & 38245 & Winter & ovx & Autumn & 3 \\
\hline 32 & 4 & 0.0597 & 40036 & Winter & ovx & Autumn & 3 \\
\hline 32 & 4 & 0.0605 & 44511 & Winter & ovx & Autumn & 3 \\
\hline 32 & 4 & 0.0612 & 47132 & Winter & ovx & Autumn & 3 \\
\hline 32 & 4 & 0.0619 & 52152 & Winter & ovx & Autumn & 3 \\
\hline 32 & 4 & 0.0626 & 58111 & Winter & ovx & Autumn & 3 \\
\hline 32 & 4 & 0.0633 & 60684 & Winter & ovx & Autumn & 3 \\
\hline 32 & 4 & 0.0640 & 68966 & Winter & ovx & Autumn & 3 \\
\hline 32 & 4 & 0.0646 & 72198 & Winter & ovx & Autumn & 3 \\
\hline 32 & 4 & 0.0652 & 76608 & Winter & ovx & Autumn & 3 \\
\hline 32 & 4 & 0.0659 & 82691 & Winter & ovx & Autumn & 3 \\
\hline 32 & 4 & 0.0665 & 85611 & Winter & ovx & Autumn & 3 \\
\hline 32 & 4 & 0.0671 & 90364 & Winter & ovx & Autumn & 3 \\
\hline 32 & 4 & 0.0677 & 93316 & Winter & ovx & Autumn & 3 \\
\hline 32 & 4 & 0.0683 & 97079 & Winter & ovx & Autumn & 3 \\
\hline 32 & 4 & 0.0688 & 101647 & Winter & ovx & Autumn & 3 \\
\hline 32 & 4 & 0.0694 & 103892 & Winter & ovx & Autumn & 3 \\
\hline 32 & 4 & 0.0699 & 109718 & Winter & ovx & Autumn & 3 \\
\hline 32 & 4 & 0.0705 & 114454 & Winter & ovx & Autumn & 3 \\
\hline 32 & 4 & 0.0710 & 120238 & Winter & ovx & Autumn & 3 \\
\hline 32 & 4 & 0.0716 & 127381 & Winter & ovx & Autumn & 3 \\
\hline 32 & 4 & 0.0721 & 132316 & Winter & ovx & Autumn & 3 \\
\hline 32 & 4 & 0.0726 & 138104 & Winter & ovx & Autumn & 3 \\
\hline 32 & 4 & 0.0731 & 144987 & Winter & ovx & Autumn & 3 \\
\hline 32 & 4 & 0.0736 & 150877 & Winter & ovx & Autumn & 3 \\
\hline 32 & 4 & 0.0741 & 159154 & Winter & ovx & Autumn & 3 \\
\hline 32 & 4 & 0.0746 & 163927 & Winter & ovx & Autumn & 3 \\
\hline 32 & 4 & 0.0751 & 168968 & Winter & ovx & Autumn & 3 \\
\hline 32 & 4 & 0.0755 & 173279 & Winter & ovx & Autumn & 3 \\
\hline 32 & 4 & 0.0760 & 175241 & Winter & ovx & Autumn & 3 \\
\hline 32 & 4 & 0.0765 & 176295 & Winter & ovx & Autumn & 3 \\
\hline
\end{tabular}




\begin{tabular}{|c|c|c|c|c|c|c|c|}
\hline $\begin{array}{l}\text { Sheep } \\
\text { Eartag }\end{array}$ & Sector & $\begin{array}{l}\text { ETA } \\
(\mathrm{mm})\end{array}$ & $\begin{array}{l}\text { Bone } \\
\text { Pixels } \\
\end{array}$ & $\begin{array}{l}\text { Sacrifice } \\
\text { Season }\end{array}$ & Treatment & $\begin{array}{l}\text { Season of } \\
\text { surgery }\end{array}$ & $\begin{array}{l}\text { Time } \\
\text { (months) }\end{array}$ \\
\hline 32 & 4 & 0.0769 & 176818 & Winter & ovx & Autumn & 3 \\
\hline 32 & 4 & 0.0774 & 174052 & Winter & ovx & Autumn & 3 \\
\hline 32 & 4 & 0.0778 & 170906 & Winter & ovx & Autumn & 3 \\
\hline 32 & 4 & 0.0783 & 165575 & Winter & ovx & Autumn & 3 \\
\hline 32 & 4 & 0.0787 & 155699 & Winter & ovx & Autumn & 3 \\
\hline 32 & 4 & 0.0791 & 146204 & Winter & ovx & Autumn & 3 \\
\hline 32 & 4 & 0.0796 & 135272 & Winter & ovx & Autumn & 3 \\
\hline 32 & 4 & 0.0800 & 123282 & Winter & ovx & Autumn & 3 \\
\hline 32 & 4 & 0.0804 & 111163 & Winter & ovx & Autumn & 3 \\
\hline 32 & 4 & 0.0808 & 100067 & Winter & ovx & Autumn & 3 \\
\hline 32 & 4 & 0.0812 & 89294 & Winter & ovx & Autumn & 3 \\
\hline 32 & 4 & 0.0816 & 78344 & Winter & ovx & Autumn & 3 \\
\hline 32 & 4 & 0.0820 & 68939 & Winter & ovx & Autumn & 3 \\
\hline 32 & 4 & 0.0824 & 59728 & Winter & ovx & Autumn & 3 \\
\hline 32 & 4 & 0.0828 & 51766 & Winter & ovx & Autumn & 3 \\
\hline 32 & 4 & 0.0832 & 44429 & Winter & ovx & Autumn & 3 \\
\hline 32 & 4 & 0.0836 & 37560 & Winter & ovx & Autumn & 3 \\
\hline 32 & 4 & 0.0840 & 31517 & Winter & ovx & Autumn & 3 \\
\hline 32 & 4 & 0.0844 & 26599 & Winter & ovx & Autumn & 3 \\
\hline 32 & 4 & 0.0848 & 21974 & Winter & ovx & Autumn & 3 \\
\hline 32 & 4 & 0.0852 & 18696 & Winter & ovx & Autumn & 3 \\
\hline 32 & 4 & 0.0855 & 15335 & Winter & ovx & Autumn & 3 \\
\hline 32 & 4 & 0.0859 & 13007 & Winter & ovx & Autumn & 3 \\
\hline 32 & 4 & 0.0863 & 10658 & Winter & ovx & Autumn & 3 \\
\hline 32 & 4 & 0.0867 & 9035 & Winter & ovx & Autumn & 3 \\
\hline 32 & 4 & 0.0870 & 7519 & Winter & ovx & Autumn & 3 \\
\hline 32 & 4 & 0.0874 & 6233 & Winter & ovx & Autumn & 3 \\
\hline 32 & 4 & 0.0878 & 5109 & Winter & ovx & Autumn & 3 \\
\hline 32 & 4 & 0.0881 & 4226 & Winter & ovx & Autumn & 3 \\
\hline 32 & 4 & 0.0885 & 3646 & Winter & ovx & Autumn & 3 \\
\hline 32 & 4 & 0.0888 & 2866 & Winter & ovx & Autumn & 3 \\
\hline 32 & 4 & 0.0892 & 2356 & Winter & ovx & Autumn & 3 \\
\hline 32 & 4 & 0.0895 & 2017 & Winter & ovx & Autumn & 3 \\
\hline 32 & 4 & 0.0899 & 1666 & Winter & ovx & Autumn & 3 \\
\hline 32 & 4 & 0.0902 & 1348 & Winter & ovx & Autumn & 3 \\
\hline 32 & 4 & 0.0906 & 1123 & Winter & ovx & Autumn & 3 \\
\hline 32 & 4 & 0.0909 & 902 & Winter & ovx & Autumn & 3 \\
\hline 32 & 4 & 0.0913 & 692 & Winter & ovx & Autumn & 3 \\
\hline 32 & 4 & 0.0916 & 561 & Winter & ovx & Autumn & 3 \\
\hline 32 & 4 & 0.0919 & 477 & Winter & ovx & Autumn & 3 \\
\hline
\end{tabular}




\begin{tabular}{|c|c|c|c|c|c|c|c|}
\hline $\begin{array}{l}\text { Sheep } \\
\text { Eartag }\end{array}$ & Sector & $\begin{array}{l}\text { ETA } \\
(\mathbf{m m})\end{array}$ & $\begin{array}{l}\text { Bone } \\
\text { Pixels } \\
\end{array}$ & $\begin{array}{l}\text { Sacrifice } \\
\text { Season }\end{array}$ & Treatment & $\begin{array}{l}\text { Season of } \\
\text { surgery }\end{array}$ & $\begin{array}{l}\text { Time } \\
\text { (months) }\end{array}$ \\
\hline 32 & 4 & 0.0923 & 399 & Winter & ovx & Autumn & 3 \\
\hline 32 & 4 & 0.0926 & 314 & Winter & ovx & Autumn & 3 \\
\hline 32 & 4 & 0.0930 & 240 & Winter & ovx & Autumn & 3 \\
\hline 32 & 4 & 0.0933 & 192 & Winter & ovx & Autumn & 3 \\
\hline 32 & 4 & 0.0936 & 167 & Winter & ovx & Autumn & 3 \\
\hline 32 & 4 & 0.0939 & 114 & Winter & ovx & Autumn & 3 \\
\hline 32 & 4 & 0.0943 & 97 & Winter & ovx & Autumn & 3 \\
\hline 32 & 4 & 0.0946 & 65 & Winter & ovx & Autumn & 3 \\
\hline 32 & 4 & 0.0949 & 69 & Winter & ovx & Autumn & 3 \\
\hline 32 & 4 & 0.0953 & 65 & Winter & ovx & Autumn & 3 \\
\hline 32 & 4 & 0.0956 & 34 & Winter & ovx & Autumn & 3 \\
\hline 32 & 4 & 0.0959 & 35 & Winter & ovx & Autumn & 3 \\
\hline 32 & 4 & 0.0962 & 33 & Winter & ovx & Autumn & 3 \\
\hline 32 & 4 & 0.0965 & 26 & Winter & ovx & Autumn & 3 \\
\hline 32 & 4 & 0.0969 & 22 & Winter & ovx & Autumn & 3 \\
\hline 32 & 4 & 0.0972 & 15 & Winter & ovx & Autumn & 3 \\
\hline 32 & 4 & 0.0975 & 21 & Winter & ovx & Autumn & 3 \\
\hline 32 & 4 & 0.0978 & 10 & Winter & ovx & Autumn & 3 \\
\hline 32 & 4 & 0.0981 & 8 & Winter & ovx & Autumn & 3 \\
\hline 32 & 4 & 0.0984 & 7 & Winter & ovx & Autumn & 3 \\
\hline 32 & 4 & 0.0988 & 12 & Winter & ovx & Autumn & 3 \\
\hline 32 & 4 & 0.0991 & 10 & Winter & ovx & Autumn & 3 \\
\hline 32 & 4 & 0.0994 & 10 & Winter & ovx & Autumn & 3 \\
\hline 32 & 4 & 0.0997 & 10 & Winter & ovx & Autumn & 3 \\
\hline 32 & 4 & 0.1000 & 4 & Winter & ovx & Autumn & 3 \\
\hline 32 & 4 & 0.1003 & 9 & Winter & ovx & Autumn & 3 \\
\hline 32 & 4 & 0.1006 & 3 & Winter & ovx & Autumn & 3 \\
\hline 32 & 4 & 0.1009 & 10 & Winter & ovx & Autumn & 3 \\
\hline 32 & 4 & 0.1012 & 4 & Winter & ovx & Autumn & 3 \\
\hline 32 & 4 & 0.1015 & 7 & Winter & ovx & Autumn & 3 \\
\hline 32 & 4 & 0.1018 & 3 & Winter & ovx & Autumn & 3 \\
\hline 32 & 4 & 0.1022 & 2 & Winter & ovx & Autumn & 3 \\
\hline 32 & 4 & 0.1025 & 4 & Winter & ovx & Autumn & 3 \\
\hline 32 & 4 & 0.1028 & 7 & Winter & ovx & Autumn & 3 \\
\hline 32 & 4 & 0.1031 & 2 & Winter & ovx & Autumn & 3 \\
\hline 32 & 4 & 0.1034 & 4 & Winter & ovx & Autumn & 3 \\
\hline 32 & 4 & 0.1037 & 4 & Winter & ovx & Autumn & 3 \\
\hline 32 & 4 & 0.1040 & 2 & Winter & ovx & Autumn & 3 \\
\hline 32 & 4 & 0.1043 & 0 & Winter & ovx & Autumn & 3 \\
\hline 32 & 4 & 0.1046 & 0 & Winter & ovx & Autumn & 3 \\
\hline
\end{tabular}




\begin{tabular}{|c|c|c|c|c|c|c|c|}
\hline $\begin{array}{l}\text { Sheep } \\
\text { Eartag }\end{array}$ & Sector & $\begin{array}{l}\text { ETA } \\
(\mathbf{m m})\end{array}$ & $\begin{array}{l}\text { Bone } \\
\text { Pixels }\end{array}$ & $\begin{array}{l}\text { Sacrifice } \\
\text { Season }\end{array}$ & Treatment & $\begin{array}{l}\text { Season of } \\
\text { surgery }\end{array}$ & $\begin{array}{l}\text { Time } \\
\text { (months) }\end{array}$ \\
\hline 32 & 4 & 0.1049 & 3 & Winter & ovx & Autumn & 3 \\
\hline 32 & 4 & 0.1052 & 1 & Winter & ovx & Autumn & 3 \\
\hline 32 & 4 & 0.1055 & 0 & Winter & ovx & Autumn & 3 \\
\hline 32 & 4 & 0.1058 & 0 & Winter & ovx & Autumn & 3 \\
\hline 32 & 4 & 0.1061 & 2 & Winter & ovx & Autumn & 3 \\
\hline 32 & 4 & 0.1064 & 0 & Winter & ovx & Autumn & 3 \\
\hline 32 & 4 & 0.1067 & 1 & Winter & ovx & Autumn & 3 \\
\hline 32 & 4 & 0.1070 & 0 & Winter & ovx & Autumn & 3 \\
\hline 32 & 4 & 0.1073 & 0 & Winter & ovx & Autumn & 3 \\
\hline 32 & 4 & 0.1076 & 0 & Winter & ovx & Autumn & 3 \\
\hline 32 & 4 & 0.1079 & 1 & Winter & ovx & Autumn & 3 \\
\hline 32 & 4 & 0.1082 & 0 & Winter & ovx & Autumn & 3 \\
\hline 32 & 4 & 0.1085 & 3 & Winter & ovx & Autumn & 3 \\
\hline 32 & 4 & 0.1088 & 0 & Winter & ovx & Autumn & 3 \\
\hline 32 & 4 & 0.1091 & 1 & Winter & ovx & Autumn & 3 \\
\hline 32 & 4 & 0.1094 & 0 & Winter & ovx & Autumn & 3 \\
\hline 32 & 4 & 0.1097 & 0 & Winter & ovx & Autumn & 3 \\
\hline 32 & 4 & 0.1100 & 1 & Winter & ovx & Autumn & 3 \\
\hline 32 & 4 & 0.1103 & 0 & Winter & ovx & Autumn & 3 \\
\hline 32 & 4 & 0.1106 & 1 & Winter & ovx & Autumn & 3 \\
\hline 32 & 4 & 0.1109 & 0 & Winter & ovx & Autumn & 3 \\
\hline 32 & 4 & 0.1112 & 0 & Winter & ovx & Autumn & 3 \\
\hline 32 & 4 & 0.1115 & 0 & Winter & ovx & Autumn & 3 \\
\hline 32 & 4 & 0.1118 & 1 & Winter & ovx & Autumn & 3 \\
\hline 32 & 4 & 0.1122 & 0 & Winter & ovx & Autumn & 3 \\
\hline 32 & 4 & 0.1125 & 0 & Winter & ovx & Autumn & 3 \\
\hline 32 & 4 & 0.1128 & 1 & Winter & ovx & Autumn & 3 \\
\hline 32 & 4 & 0.1131 & 0 & Winter & ovx & Autumn & 3 \\
\hline 32 & 4 & 0.1134 & 0 & Winter & ovx & Autumn & 3 \\
\hline 32 & 4 & 0.1137 & 0 & Winter & ovx & Autumn & 3 \\
\hline 32 & 4 & 0.1140 & 0 & Winter & ovx & Autumn & 3 \\
\hline 32 & 4 & 0.1143 & 1 & Winter & ovx & Autumn & 3 \\
\hline 32 & 4 & 0.1146 & 0 & Winter & ovx & Autumn & 3 \\
\hline 32 & 4 & 0.1149 & 0 & Winter & ovx & Autumn & 3 \\
\hline 32 & 4 & 0.1152 & 0 & Winter & ovx & Autumn & 3 \\
\hline 32 & 4 & 0.1155 & 1 & Winter & ovx & Autumn & 3 \\
\hline 32 & 4 & 0.1158 & 0 & Winter & ovx & Autumn & 3 \\
\hline 32 & 4 & 0.1161 & 1 & Winter & ovx & Autumn & 3 \\
\hline 32 & 4 & 0.1165 & 0 & Winter & ovx & Autumn & 3 \\
\hline 32 & 4 & 0.1168 & 0 & Winter & ovx & Autumn & 3 \\
\hline
\end{tabular}




\begin{tabular}{|c|c|c|c|c|c|c|c|}
\hline $\begin{array}{l}\text { Sheep } \\
\text { Eartag }\end{array}$ & Sector & $\begin{array}{l}\text { ETA } \\
(\mathbf{m m})\end{array}$ & $\begin{array}{l}\text { Bone } \\
\text { Pixels }\end{array}$ & $\begin{array}{l}\text { Sacrifice } \\
\text { Season }\end{array}$ & Treatment & $\begin{array}{l}\text { Season of } \\
\text { surgery }\end{array}$ & $\begin{array}{l}\text { Time } \\
\text { (months) }\end{array}$ \\
\hline 32 & 4 & 0.1171 & 0 & Winter & ovx & Autumn & 3 \\
\hline 32 & 4 & 0.1174 & 0 & Winter & ovx & Autumn & 3 \\
\hline 32 & 4 & 0.1177 & 1 & Winter & ovx & Autumn & 3 \\
\hline 32 & 4 & 0.1180 & 0 & Winter & ovx & Autumn & 3 \\
\hline 32 & 4 & 0.1183 & 0 & Winter & ovx & Autumn & 3 \\
\hline 32 & 4 & 0.1187 & 1 & Winter & ovx & Autumn & 3 \\
\hline 32 & 4 & 0.1190 & 0 & Winter & ovx & Autumn & 3 \\
\hline 32 & 4 & 0.1193 & 0 & Winter & ovx & Autumn & 3 \\
\hline 32 & 4 & 0.1196 & 0 & Winter & ovx & Autumn & 3 \\
\hline 32 & 4 & 0.1199 & 0 & Winter & ovx & Autumn & 3 \\
\hline 32 & 4 & 0.1203 & 0 & Winter & ovx & Autumn & 3 \\
\hline 32 & 4 & 0.1206 & 0 & Winter & ovx & Autumn & 3 \\
\hline 32 & 4 & 0.1209 & 0 & Winter & ovx & Autumn & 3 \\
\hline 32 & 4 & 0.1212 & 0 & Winter & ovx & Autumn & 3 \\
\hline 32 & 4 & 0.1216 & 0 & Winter & ovx & Autumn & 3 \\
\hline 32 & 4 & 0.1219 & 0 & Winter & ovx & Autumn & 3 \\
\hline 32 & 4 & 0.1222 & 0 & Winter & ovx & Autumn & 3 \\
\hline 32 & 4 & 0.1226 & 0 & Winter & ovx & Autumn & 3 \\
\hline 32 & 4 & 0.1229 & 0 & Winter & ovx & Autumn & 3 \\
\hline 32 & 4 & 0.1232 & 0 & Winter & ovx & Autumn & 3 \\
\hline 32 & 4 & 0.1236 & 0 & Winter & ovx & Autumn & 3 \\
\hline 32 & 4 & 0.1239 & 0 & Winter & ovx & Autumn & 3 \\
\hline 32 & 4 & 0.1243 & 0 & Winter & ovx & Autumn & 3 \\
\hline 32 & 4 & 0.1246 & 0 & Winter & ovx & Autumn & 3 \\
\hline 32 & 4 & 0.1249 & 0 & Winter & ovx & Autumn & 3 \\
\hline 32 & 4 & 0.1253 & 0 & Winter & ovx & Autumn & 3 \\
\hline 32 & 4 & 0.1256 & 0 & Winter & ovx & Autumn & 3 \\
\hline 32 & 4 & 0.1260 & 0 & Winter & ovx & Autumn & 3 \\
\hline 32 & 4 & 0.1263 & 0 & Winter & ovx & Autumn & 3 \\
\hline 32 & 4 & 0.1267 & 0 & Winter & ovx & Autumn & 3 \\
\hline 32 & 4 & 0.1270 & 0 & Winter & ovx & Autumn & 3 \\
\hline 32 & 4 & 0.1274 & 0 & Winter & ovx & Autumn & 3 \\
\hline 32 & 4 & 0.1278 & 0 & Winter & ovx & Autumn & 3 \\
\hline 32 & 4 & 0.1281 & 0 & Winter & ovx & Autumn & 3 \\
\hline 32 & 4 & 0.1285 & 0 & Winter & ovx & Autumn & 3 \\
\hline 32 & 4 & 0.1288 & 0 & Winter & ovx & Autumn & 3 \\
\hline 32 & 4 & 0.1292 & 0 & Winter & ovx & Autumn & 3 \\
\hline 32 & 4 & 0.1296 & 0 & Winter & ovx & Autumn & 3 \\
\hline 32 & 4 & 0.1300 & 0 & Winter & ovx & Autumn & 3 \\
\hline 32 & 4 & 0.1303 & 0 & Winter & ovx & Autumn & 3 \\
\hline
\end{tabular}




\begin{tabular}{|c|c|c|c|c|c|c|c|}
\hline $\begin{array}{l}\text { Sheep } \\
\text { Eartag }\end{array}$ & Sector & $\begin{array}{l}\text { ETA } \\
(\mathbf{m m})\end{array}$ & $\begin{array}{l}\text { Bone } \\
\text { Pixels } \\
\end{array}$ & $\begin{array}{l}\text { Sacrifice } \\
\text { Season }\end{array}$ & Treatment & $\begin{array}{l}\text { Season of } \\
\text { surgery }\end{array}$ & $\begin{array}{l}\text { Time } \\
\text { (months) }\end{array}$ \\
\hline 32 & 4 & 0.1307 & 0 & Winter & ovx & Autumn & 3 \\
\hline 32 & 4 & 0.1311 & 0 & Winter & ovx & Autumn & 3 \\
\hline 32 & 4 & 0.1315 & 0 & Winter & ovx & Autumn & 3 \\
\hline 32 & 4 & 0.1319 & 0 & Winter & ovx & Autumn & 3 \\
\hline 32 & 4 & 0.1323 & 0 & Winter & ovx & Autumn & 3 \\
\hline 32 & 4 & 0.1327 & 0 & Winter & ovx & Autumn & 3 \\
\hline 32 & 4 & 0.1331 & 0 & Winter & ovx & Autumn & 3 \\
\hline 32 & 4 & 0.1335 & 0 & Winter & ovx & Autumn & 3 \\
\hline 32 & 4 & 0.1339 & 0 & Winter & ovx & Autumn & 3 \\
\hline 32 & 4 & 0.1343 & 0 & Winter & ovx & Autumn & 3 \\
\hline 32 & 4 & 0.1347 & 0 & Winter & ovx & Autumn & 3 \\
\hline 32 & 4 & 0.1351 & 0 & Winter & ovx & Autumn & 3 \\
\hline 32 & 4 & 0.1355 & 0 & Winter & ovx & Autumn & 3 \\
\hline 32 & 4 & 0.1359 & 0 & Winter & ovx & Autumn & 3 \\
\hline 32 & 4 & 0.1364 & 0 & Winter & ovx & Autumn & 3 \\
\hline 32 & 4 & 0.1368 & 0 & Winter & ovx & Autumn & 3 \\
\hline 32 & 4 & 0.1372 & 0 & Winter & ovx & Autumn & 3 \\
\hline 32 & 4 & 0.1377 & 0 & Winter & ovx & Autumn & 3 \\
\hline 32 & 4 & 0.1381 & 0 & Winter & ovx & Autumn & 3 \\
\hline 32 & 4 & 0.1386 & 0 & Winter & ovx & Autumn & 3 \\
\hline 32 & 4 & 0.1390 & 0 & Winter & ovx & Autumn & 3 \\
\hline 32 & 4 & 0.1395 & 0 & Winter & ovx & Autumn & 3 \\
\hline 32 & 4 & 0.1400 & 0 & Winter & ovx & Autumn & 3 \\
\hline 32 & 4 & 0.1404 & 0 & Winter & ovx & Autumn & 3 \\
\hline 32 & 4 & 0.1409 & 0 & Winter & ovx & Autumn & 3 \\
\hline 32 & 4 & 0.1414 & 0 & Winter & ovx & Autumn & 3 \\
\hline 32 & 4 & 0.1419 & 0 & Winter & ovx & Autumn & 3 \\
\hline 32 & 4 & 0.1424 & 0 & Winter & ovx & Autumn & 3 \\
\hline 32 & 4 & 0.1429 & 0 & Winter & ovx & Autumn & 3 \\
\hline 32 & 4 & 0.1434 & 0 & Winter & ovx & Autumn & 3 \\
\hline 32 & 4 & 0.1439 & 0 & Winter & ovx & Autumn & 3 \\
\hline 32 & 4 & 0.1444 & 0 & Winter & ovx & Autumn & 3 \\
\hline 32 & 4 & 0.1450 & 0 & Winter & ovx & Autumn & 3 \\
\hline 32 & 4 & 0.1455 & 0 & Winter & ovx & Autumn & 3 \\
\hline 32 & 4 & 0.1461 & 0 & Winter & ovx & Autumn & 3 \\
\hline 32 & 5 & 0.0059 & 0 & Winter & ovx & Autumn & 3 \\
\hline 32 & 5 & 0.0114 & 0 & Winter & ovx & Autumn & 3 \\
\hline 32 & 5 & 0.0158 & 0 & Winter & ovx & Autumn & 3 \\
\hline 32 & 5 & 0.0196 & 0 & Winter & ovx & Autumn & 3 \\
\hline 32 & 5 & 0.0228 & 0 & Winter & ovx & Autumn & 3 \\
\hline
\end{tabular}




\begin{tabular}{|c|c|c|c|c|c|c|c|}
\hline $\begin{array}{l}\text { Sheep } \\
\text { Eartag }\end{array}$ & Sector & $\begin{array}{l}\text { ETA } \\
(\mathbf{m m})\end{array}$ & $\begin{array}{l}\text { Bone } \\
\text { Pixels } \\
\end{array}$ & $\begin{array}{l}\text { Sacrifice } \\
\text { Season }\end{array}$ & Treatment & $\begin{array}{l}\text { Season of } \\
\text { surgery }\end{array}$ & $\begin{array}{l}\text { Time } \\
\text { (months) }\end{array}$ \\
\hline 32 & 5 & 0.0257 & 0 & Winter & ovx & Autumn & 3 \\
\hline 32 & 5 & 0.0283 & 0 & Winter & ovx & Autumn & 3 \\
\hline 32 & 5 & 0.0306 & 0 & Winter & ovx & Autumn & 3 \\
\hline 32 & 5 & 0.0327 & 0 & Winter & ovx & Autumn & 3 \\
\hline 32 & 5 & 0.0347 & 0 & Winter & ovx & Autumn & 3 \\
\hline 32 & 5 & 0.0365 & 0 & Winter & ovx & Autumn & 3 \\
\hline 32 & 5 & 0.0382 & 0 & Winter & ovx & Autumn & 3 \\
\hline 32 & 5 & 0.0398 & 0 & Winter & ovx & Autumn & 3 \\
\hline 32 & 5 & 0.0413 & 0 & Winter & ovx & Autumn & 3 \\
\hline 32 & 5 & 0.0427 & 0 & Winter & ovx & Autumn & 3 \\
\hline 32 & 5 & 0.0441 & 0 & Winter & ovx & Autumn & 3 \\
\hline 32 & 5 & 0.0454 & 0 & Winter & ovx & Autumn & 3 \\
\hline 32 & 5 & 0.0466 & 27203 & Winter & ovx & Autumn & 3 \\
\hline 32 & 5 & 0.0478 & 31484 & Winter & ovx & Autumn & 3 \\
\hline 32 & 5 & 0.0489 & 40753 & Winter & ovx & Autumn & 3 \\
\hline 32 & 5 & 0.0500 & 53612 & Winter & ovx & Autumn & 3 \\
\hline 32 & 5 & 0.0510 & 54038 & Winter & ovx & Autumn & 3 \\
\hline 32 & 5 & 0.0520 & 61251 & Winter & ovx & Autumn & 3 \\
\hline 32 & 5 & 0.0530 & 65976 & Winter & ovx & Autumn & 3 \\
\hline 32 & 5 & 0.0539 & 72619 & Winter & ovx & Autumn & 3 \\
\hline 32 & 5 & 0.0548 & 80420 & Winter & ovx & Autumn & 3 \\
\hline 32 & 5 & 0.0557 & 85184 & Winter & ovx & Autumn & 3 \\
\hline 32 & 5 & 0.0566 & 95544 & Winter & ovx & Autumn & 3 \\
\hline 32 & 5 & 0.0574 & 99971 & Winter & ovx & Autumn & 3 \\
\hline 32 & 5 & 0.0582 & 103350 & Winter & ovx & Autumn & 3 \\
\hline 32 & 5 & 0.0590 & 110691 & Winter & ovx & Autumn & 3 \\
\hline 32 & 5 & 0.0597 & 110540 & Winter & ovx & Autumn & 3 \\
\hline 32 & 5 & 0.0605 & 116731 & Winter & ovx & Autumn & 3 \\
\hline 32 & 5 & 0.0612 & 120268 & Winter & ovx & Autumn & 3 \\
\hline 32 & 5 & 0.0619 & 125089 & Winter & ovx & Autumn & 3 \\
\hline 32 & 5 & 0.0626 & 131077 & Winter & ovx & Autumn & 3 \\
\hline 32 & 5 & 0.0633 & 133029 & Winter & ovx & Autumn & 3 \\
\hline 32 & 5 & 0.0640 & 140974 & Winter & ovx & Autumn & 3 \\
\hline 32 & 5 & 0.0646 & 142326 & Winter & ovx & Autumn & 3 \\
\hline 32 & 5 & 0.0652 & 143638 & Winter & ovx & Autumn & 3 \\
\hline 32 & 5 & 0.0659 & 146087 & Winter & ovx & Autumn & 3 \\
\hline 32 & 5 & 0.0665 & 147095 & Winter & ovx & Autumn & 3 \\
\hline 32 & 5 & 0.0671 & 148052 & Winter & ovx & Autumn & 3 \\
\hline 32 & 5 & 0.0677 & 148465 & Winter & ovx & Autumn & 3 \\
\hline 32 & 5 & 0.0683 & 148663 & Winter & ovx & Autumn & 3 \\
\hline
\end{tabular}




\begin{tabular}{|c|c|c|c|c|c|c|c|}
\hline $\begin{array}{l}\text { Sheep } \\
\text { Eartag }\end{array}$ & Sector & $\begin{array}{l}\text { ETA } \\
(\mathbf{m m})\end{array}$ & $\begin{array}{l}\text { Bone } \\
\text { Pixels }\end{array}$ & $\begin{array}{l}\text { Sacrifice } \\
\text { Season }\end{array}$ & Treatment & $\begin{array}{l}\text { Season of } \\
\text { surgery }\end{array}$ & $\begin{array}{l}\text { Time } \\
\text { (months) }\end{array}$ \\
\hline 32 & 5 & 0.0688 & 147738 & Winter & ovx & Autumn & 3 \\
\hline 32 & 5 & 0.0694 & 147632 & Winter & ovx & Autumn & 3 \\
\hline 32 & 5 & 0.0699 & 149549 & Winter & ovx & Autumn & 3 \\
\hline 32 & 5 & 0.0705 & 149547 & Winter & ovx & Autumn & 3 \\
\hline 32 & 5 & 0.0710 & 149169 & Winter & ovx & Autumn & 3 \\
\hline 32 & 5 & 0.0716 & 149509 & Winter & ovx & Autumn & 3 \\
\hline 32 & 5 & 0.0721 & 147535 & Winter & ovx & Autumn & 3 \\
\hline 32 & 5 & 0.0726 & 144579 & Winter & ovx & Autumn & 3 \\
\hline 32 & 5 & 0.0731 & 140308 & Winter & ovx & Autumn & 3 \\
\hline 32 & 5 & 0.0736 & 135194 & Winter & ovx & Autumn & 3 \\
\hline 32 & 5 & 0.0741 & 128853 & Winter & ovx & Autumn & 3 \\
\hline 32 & 5 & 0.0746 & 121522 & Winter & ovx & Autumn & 3 \\
\hline 32 & 5 & 0.0751 & 112021 & Winter & ovx & Autumn & 3 \\
\hline 32 & 5 & 0.0755 & 103278 & Winter & ovx & Autumn & 3 \\
\hline 32 & 5 & 0.0760 & 93125 & Winter & ovx & Autumn & 3 \\
\hline 32 & 5 & 0.0765 & 83381 & Winter & ovx & Autumn & 3 \\
\hline 32 & 5 & 0.0769 & 73285 & Winter & ovx & Autumn & 3 \\
\hline 32 & 5 & 0.0774 & 65129 & Winter & ovx & Autumn & 3 \\
\hline 32 & 5 & 0.0778 & 56163 & Winter & ovx & Autumn & 3 \\
\hline 32 & 5 & 0.0783 & 48352 & Winter & ovx & Autumn & 3 \\
\hline 32 & 5 & 0.0787 & 40881 & Winter & ovx & Autumn & 3 \\
\hline 32 & 5 & 0.0791 & 34300 & Winter & ovx & Autumn & 3 \\
\hline 32 & 5 & 0.0796 & 28248 & Winter & ovx & Autumn & 3 \\
\hline 32 & 5 & 0.0800 & 23307 & Winter & ovx & Autumn & 3 \\
\hline 32 & 5 & 0.0804 & 18478 & Winter & ovx & Autumn & 3 \\
\hline 32 & 5 & 0.0808 & 15190 & Winter & ovx & Autumn & 3 \\
\hline 32 & 5 & 0.0812 & 12261 & Winter & ovx & Autumn & 3 \\
\hline 32 & 5 & 0.0816 & 9721 & Winter & ovx & Autumn & 3 \\
\hline 32 & 5 & 0.0820 & 7868 & Winter & ovx & Autumn & 3 \\
\hline 32 & 5 & 0.0824 & 6140 & Winter & ovx & Autumn & 3 \\
\hline 32 & 5 & 0.0828 & 4784 & Winter & ovx & Autumn & 3 \\
\hline 32 & 5 & 0.0832 & 3800 & Winter & ovx & Autumn & 3 \\
\hline 32 & 5 & 0.0836 & 3074 & Winter & ovx & Autumn & 3 \\
\hline 32 & 5 & 0.0840 & 2467 & Winter & ovx & Autumn & 3 \\
\hline 32 & 5 & 0.0844 & 1929 & Winter & ovx & Autumn & 3 \\
\hline 32 & 5 & 0.0848 & 1483 & Winter & ovx & Autumn & 3 \\
\hline 32 & 5 & 0.0852 & 1143 & Winter & ovx & Autumn & 3 \\
\hline 32 & 5 & 0.0855 & 897 & Winter & ovx & Autumn & 3 \\
\hline 32 & 5 & 0.0859 & 724 & Winter & ovx & Autumn & 3 \\
\hline 32 & 5 & 0.0863 & 571 & Winter & ovx & Autumn & 3 \\
\hline
\end{tabular}




\begin{tabular}{|c|c|c|c|c|c|c|c|}
\hline $\begin{array}{l}\text { Sheep } \\
\text { Eartag }\end{array}$ & Sector & $\begin{array}{l}\text { ETA } \\
(\mathrm{mm})\end{array}$ & $\begin{array}{l}\text { Bone } \\
\text { Pixels } \\
\end{array}$ & $\begin{array}{l}\text { Sacrifice } \\
\text { Season }\end{array}$ & Treatment & $\begin{array}{l}\text { Season of } \\
\text { surgery }\end{array}$ & $\begin{array}{l}\text { Time } \\
\text { (months) }\end{array}$ \\
\hline 32 & 5 & 0.0867 & 463 & Winter & ovx & Autumn & 3 \\
\hline 32 & 5 & 0.0870 & 379 & Winter & ovx & Autumn & 3 \\
\hline 32 & 5 & 0.0874 & 311 & Winter & ovx & Autumn & 3 \\
\hline 32 & 5 & 0.0878 & 206 & Winter & ovx & Autumn & 3 \\
\hline 32 & 5 & 0.0881 & 211 & Winter & ovx & Autumn & 3 \\
\hline 32 & 5 & 0.0885 & 178 & Winter & ovx & Autumn & 3 \\
\hline 32 & 5 & 0.0888 & 126 & Winter & ovx & Autumn & 3 \\
\hline 32 & 5 & 0.0892 & 101 & Winter & ovx & Autumn & 3 \\
\hline 32 & 5 & 0.0895 & 98 & Winter & ovx & Autumn & 3 \\
\hline 32 & 5 & 0.0899 & 70 & Winter & ovx & Autumn & 3 \\
\hline 32 & 5 & 0.0902 & 62 & Winter & ovx & Autumn & 3 \\
\hline 32 & 5 & 0.0906 & 41 & Winter & ovx & Autumn & 3 \\
\hline 32 & 5 & 0.0909 & 36 & Winter & ovx & Autumn & 3 \\
\hline 32 & 5 & 0.0913 & 34 & Winter & ovx & Autumn & 3 \\
\hline 32 & 5 & 0.0916 & 24 & Winter & ovx & Autumn & 3 \\
\hline 32 & 5 & 0.0919 & 29 & Winter & ovx & Autumn & 3 \\
\hline 32 & 5 & 0.0923 & 22 & Winter & ovx & Autumn & 3 \\
\hline 32 & 5 & 0.0926 & 25 & Winter & ovx & Autumn & 3 \\
\hline 32 & 5 & 0.0930 & 20 & Winter & ovx & Autumn & 3 \\
\hline 32 & 5 & 0.0933 & 16 & Winter & ovx & Autumn & 3 \\
\hline 32 & 5 & 0.0936 & 20 & Winter & ovx & Autumn & 3 \\
\hline 32 & 5 & 0.0939 & 19 & Winter & ovx & Autumn & 3 \\
\hline 32 & 5 & 0.0943 & 12 & Winter & ovx & Autumn & 3 \\
\hline 32 & 5 & 0.0946 & 13 & Winter & ovx & Autumn & 3 \\
\hline 32 & 5 & 0.0949 & 10 & Winter & ovx & Autumn & 3 \\
\hline 32 & 5 & 0.0953 & 9 & Winter & ovx & Autumn & 3 \\
\hline 32 & 5 & 0.0956 & 9 & Winter & ovx & Autumn & 3 \\
\hline 32 & 5 & 0.0959 & 10 & Winter & ovx & Autumn & 3 \\
\hline 32 & 5 & 0.0962 & 7 & Winter & ovx & Autumn & 3 \\
\hline 32 & 5 & 0.0965 & 19 & Winter & ovx & Autumn & 3 \\
\hline 32 & 5 & 0.0969 & 12 & Winter & ovx & Autumn & 3 \\
\hline 32 & 5 & 0.0972 & 8 & Winter & ovx & Autumn & 3 \\
\hline 32 & 5 & 0.0975 & 10 & Winter & ovx & Autumn & 3 \\
\hline 32 & 5 & 0.0978 & 11 & Winter & ovx & Autumn & 3 \\
\hline 32 & 5 & 0.0981 & 8 & Winter & ovx & Autumn & 3 \\
\hline 32 & 5 & 0.0984 & 10 & Winter & ovx & Autumn & 3 \\
\hline 32 & 5 & 0.0988 & 3 & Winter & ovx & Autumn & 3 \\
\hline 32 & 5 & 0.0991 & 10 & Winter & ovx & Autumn & 3 \\
\hline 32 & 5 & 0.0994 & 4 & Winter & ovx & Autumn & 3 \\
\hline 32 & 5 & 0.0997 & 6 & Winter & ovx & Autumn & 3 \\
\hline
\end{tabular}




\begin{tabular}{|c|c|c|c|c|c|c|c|}
\hline $\begin{array}{l}\text { Sheep } \\
\text { Eartag }\end{array}$ & Sector & $\begin{array}{l}\text { ETA } \\
(\mathbf{m m})\end{array}$ & $\begin{array}{l}\text { Bone } \\
\text { Pixels }\end{array}$ & $\begin{array}{l}\text { Sacrifice } \\
\text { Season }\end{array}$ & Treatment & $\begin{array}{l}\text { Season of } \\
\text { surgery }\end{array}$ & $\begin{array}{l}\text { Time } \\
\text { (months) }\end{array}$ \\
\hline 32 & 5 & 0.1000 & 5 & Winter & ovx & Autumn & 3 \\
\hline 32 & 5 & 0.1003 & 7 & Winter & ovx & Autumn & 3 \\
\hline 32 & 5 & 0.1006 & 8 & Winter & ovx & Autumn & 3 \\
\hline 32 & 5 & 0.1009 & 2 & Winter & ovx & Autumn & 3 \\
\hline 32 & 5 & 0.1012 & 5 & Winter & ovx & Autumn & 3 \\
\hline 32 & 5 & 0.1015 & 1 & Winter & ovx & Autumn & 3 \\
\hline 32 & 5 & 0.1018 & 5 & Winter & ovx & Autumn & 3 \\
\hline 32 & 5 & 0.1022 & 4 & Winter & ovx & Autumn & 3 \\
\hline 32 & 5 & 0.1025 & 7 & Winter & ovx & Autumn & 3 \\
\hline 32 & 5 & 0.1028 & 7 & Winter & ovx & Autumn & 3 \\
\hline 32 & 5 & 0.1031 & 6 & Winter & ovx & Autumn & 3 \\
\hline 32 & 5 & 0.1034 & 4 & Winter & ovx & Autumn & 3 \\
\hline 32 & 5 & 0.1037 & 3 & Winter & ovx & Autumn & 3 \\
\hline 32 & 5 & 0.1040 & 3 & Winter & ovx & Autumn & 3 \\
\hline 32 & 5 & 0.1043 & 2 & Winter & ovx & Autumn & 3 \\
\hline 32 & 5 & 0.1046 & 3 & Winter & ovx & Autumn & 3 \\
\hline 32 & 5 & 0.1049 & 1 & Winter & ovx & Autumn & 3 \\
\hline 32 & 5 & 0.1052 & 1 & Winter & ovx & Autumn & 3 \\
\hline 32 & 5 & 0.1055 & 4 & Winter & ovx & Autumn & 3 \\
\hline 32 & 5 & 0.1058 & 3 & Winter & ovx & Autumn & 3 \\
\hline 32 & 5 & 0.1061 & 2 & Winter & ovx & Autumn & 3 \\
\hline 32 & 5 & 0.1064 & 3 & Winter & ovx & Autumn & 3 \\
\hline 32 & 5 & 0.1067 & 1 & Winter & ovx & Autumn & 3 \\
\hline 32 & 5 & 0.1070 & 4 & Winter & ovx & Autumn & 3 \\
\hline 32 & 5 & 0.1073 & 0 & Winter & ovx & Autumn & 3 \\
\hline 32 & 5 & 0.1076 & 1 & Winter & ovx & Autumn & 3 \\
\hline 32 & 5 & 0.1079 & 4 & Winter & ovx & Autumn & 3 \\
\hline 32 & 5 & 0.1082 & 0 & Winter & ovx & Autumn & 3 \\
\hline 32 & 5 & 0.1085 & 6 & Winter & ovx & Autumn & 3 \\
\hline 32 & 5 & 0.1088 & 4 & Winter & ovx & Autumn & 3 \\
\hline 32 & 5 & 0.1091 & 1 & Winter & ovx & Autumn & 3 \\
\hline 32 & 5 & 0.1094 & 1 & Winter & ovx & Autumn & 3 \\
\hline 32 & 5 & 0.1097 & 1 & Winter & ovx & Autumn & 3 \\
\hline 32 & 5 & 0.1100 & 2 & Winter & ovx & Autumn & 3 \\
\hline 32 & 5 & 0.1103 & 0 & Winter & ovx & Autumn & 3 \\
\hline 32 & 5 & 0.1106 & 1 & Winter & ovx & Autumn & 3 \\
\hline 32 & 5 & 0.1109 & 2 & Winter & ovx & Autumn & 3 \\
\hline 32 & 5 & 0.1112 & 1 & Winter & ovx & Autumn & 3 \\
\hline 32 & 5 & 0.1115 & 2 & Winter & ovx & Autumn & 3 \\
\hline 32 & 5 & 0.1118 & 3 & Winter & ovx & Autumn & 3 \\
\hline
\end{tabular}




\begin{tabular}{|c|c|c|c|c|c|c|c|}
\hline $\begin{array}{l}\text { Sheep } \\
\text { Eartag }\end{array}$ & Sector & $\begin{array}{l}\text { ETA } \\
(\mathbf{m m})\end{array}$ & $\begin{array}{l}\text { Bone } \\
\text { Pixels }\end{array}$ & $\begin{array}{l}\text { Sacrifice } \\
\text { Season }\end{array}$ & Treatment & $\begin{array}{l}\text { Season of } \\
\text { surgery }\end{array}$ & $\begin{array}{l}\text { Time } \\
\text { (months) }\end{array}$ \\
\hline 32 & 5 & 0.1122 & 2 & Winter & ovx & Autumn & 3 \\
\hline 32 & 5 & 0.1125 & 0 & Winter & ovx & Autumn & 3 \\
\hline 32 & 5 & 0.1128 & 0 & Winter & ovx & Autumn & 3 \\
\hline 32 & 5 & 0.1131 & 0 & Winter & ovx & Autumn & 3 \\
\hline 32 & 5 & 0.1134 & 1 & Winter & ovx & Autumn & 3 \\
\hline 32 & 5 & 0.1137 & 0 & Winter & ovx & Autumn & 3 \\
\hline 32 & 5 & 0.1140 & 0 & Winter & ovx & Autumn & 3 \\
\hline 32 & 5 & 0.1143 & 0 & Winter & ovx & Autumn & 3 \\
\hline 32 & 5 & 0.1146 & 2 & Winter & ovx & Autumn & 3 \\
\hline 32 & 5 & 0.1149 & 1 & Winter & ovx & Autumn & 3 \\
\hline 32 & 5 & 0.1152 & 1 & Winter & ovx & Autumn & 3 \\
\hline 32 & 5 & 0.1155 & 0 & Winter & ovx & Autumn & 3 \\
\hline 32 & 5 & 0.1158 & 0 & Winter & ovx & Autumn & 3 \\
\hline 32 & 5 & 0.1161 & 0 & Winter & ovx & Autumn & 3 \\
\hline 32 & 5 & 0.1165 & 0 & Winter & ovx & Autumn & 3 \\
\hline 32 & 5 & 0.1168 & 0 & Winter & ovx & Autumn & 3 \\
\hline 32 & 5 & 0.1171 & 0 & Winter & ovx & Autumn & 3 \\
\hline 32 & 5 & 0.1174 & 0 & Winter & ovx & Autumn & 3 \\
\hline 32 & 5 & 0.1177 & 1 & Winter & ovx & Autumn & 3 \\
\hline 32 & 5 & 0.1180 & 0 & Winter & ovx & Autumn & 3 \\
\hline 32 & 5 & 0.1183 & 1 & Winter & ovx & Autumn & 3 \\
\hline 32 & 5 & 0.1187 & 1 & Winter & ovx & Autumn & 3 \\
\hline 32 & 5 & 0.1190 & 0 & Winter & ovx & Autumn & 3 \\
\hline 32 & 5 & 0.1193 & 0 & Winter & ovx & Autumn & 3 \\
\hline 32 & 5 & 0.1196 & 0 & Winter & ovx & Autumn & 3 \\
\hline 32 & 5 & 0.1199 & 0 & Winter & ovx & Autumn & 3 \\
\hline 32 & 5 & 0.1203 & 0 & Winter & ovx & Autumn & 3 \\
\hline 32 & 5 & 0.1206 & 0 & Winter & ovx & Autumn & 3 \\
\hline 32 & 5 & 0.1209 & 0 & Winter & ovx & Autumn & 3 \\
\hline 32 & 5 & 0.1212 & 1 & Winter & ovx & Autumn & 3 \\
\hline 32 & 5 & 0.1216 & 0 & Winter & ovx & Autumn & 3 \\
\hline 32 & 5 & 0.1219 & 0 & Winter & ovx & Autumn & 3 \\
\hline 32 & 5 & 0.1222 & 0 & Winter & ovx & Autumn & 3 \\
\hline 32 & 5 & 0.1226 & 0 & Winter & ovx & Autumn & 3 \\
\hline 32 & 5 & 0.1229 & 0 & Winter & ovx & Autumn & 3 \\
\hline 32 & 5 & 0.1232 & 0 & Winter & ovx & Autumn & 3 \\
\hline 32 & 5 & 0.1236 & 0 & Winter & ovx & Autumn & 3 \\
\hline 32 & 5 & 0.1239 & 0 & Winter & ovx & Autumn & 3 \\
\hline 32 & 5 & 0.1243 & 0 & Winter & ovx & Autumn & 3 \\
\hline 32 & 5 & 0.1246 & 0 & Winter & ovx & Autumn & 3 \\
\hline
\end{tabular}




\begin{tabular}{|c|c|c|c|c|c|c|c|}
\hline $\begin{array}{l}\text { Sheep } \\
\text { Eartag }\end{array}$ & Sector & $\begin{array}{l}\text { ETA } \\
(\mathbf{m m})\end{array}$ & $\begin{array}{l}\text { Bone } \\
\text { Pixels }\end{array}$ & $\begin{array}{l}\text { Sacrifice } \\
\text { Season }\end{array}$ & Treatment & $\begin{array}{l}\text { Season of } \\
\text { surgery }\end{array}$ & $\begin{array}{l}\text { Time } \\
\text { (months) }\end{array}$ \\
\hline 32 & 5 & 0.1249 & 0 & Winter & ovx & Autumn & 3 \\
\hline 32 & 5 & 0.1253 & 0 & Winter & ovx & Autumn & 3 \\
\hline 32 & 5 & 0.1256 & 0 & Winter & ovx & Autumn & 3 \\
\hline 32 & 5 & 0.1260 & 0 & Winter & ovx & Autumn & 3 \\
\hline 32 & 5 & 0.1263 & 0 & Winter & ovx & Autumn & 3 \\
\hline 32 & 5 & 0.1267 & 0 & Winter & ovx & Autumn & 3 \\
\hline 32 & 5 & 0.1270 & 0 & Winter & ovx & Autumn & 3 \\
\hline 32 & 5 & 0.1274 & 0 & Winter & ovx & Autumn & 3 \\
\hline 32 & 5 & 0.1278 & 0 & Winter & ovx & Autumn & 3 \\
\hline 32 & 5 & 0.1281 & 0 & Winter & ovx & Autumn & 3 \\
\hline 32 & 5 & 0.1285 & 0 & Winter & ovx & Autumn & 3 \\
\hline 32 & 5 & 0.1288 & 0 & Winter & ovx & Autumn & 3 \\
\hline 32 & 5 & 0.1292 & 0 & Winter & ovx & Autumn & 3 \\
\hline 32 & 5 & 0.1296 & 0 & Winter & ovx & Autumn & 3 \\
\hline 32 & 5 & 0.1300 & 0 & Winter & ovx & Autumn & 3 \\
\hline 32 & 5 & 0.1303 & 0 & Winter & ovx & Autumn & 3 \\
\hline 32 & 5 & 0.1307 & 0 & Winter & ovx & Autumn & 3 \\
\hline 32 & 5 & 0.1311 & 0 & Winter & ovx & Autumn & 3 \\
\hline 32 & 5 & 0.1315 & 0 & Winter & ovx & Autumn & 3 \\
\hline 32 & 5 & 0.1319 & 0 & Winter & ovx & Autumn & 3 \\
\hline 32 & 5 & 0.1323 & 0 & Winter & ovx & Autumn & 3 \\
\hline 32 & 5 & 0.1327 & 0 & Winter & ovx & Autumn & 3 \\
\hline 32 & 5 & 0.1331 & 0 & Winter & ovx & Autumn & 3 \\
\hline 32 & 5 & 0.1335 & 0 & Winter & ovx & Autumn & 3 \\
\hline 32 & 5 & 0.1339 & 0 & Winter & ovx & Autumn & 3 \\
\hline 32 & 5 & 0.1343 & 0 & Winter & ovx & Autumn & 3 \\
\hline 32 & 5 & 0.1347 & 0 & Winter & ovx & Autumn & 3 \\
\hline 32 & 5 & 0.1351 & 0 & Winter & ovx & Autumn & 3 \\
\hline 32 & 5 & 0.1355 & 0 & Winter & ovx & Autumn & 3 \\
\hline 32 & 5 & 0.1359 & 0 & Winter & ovx & Autumn & 3 \\
\hline 32 & 5 & 0.1364 & 0 & Winter & ovx & Autumn & 3 \\
\hline 32 & 5 & 0.1368 & 0 & Winter & ovx & Autumn & 3 \\
\hline 32 & 5 & 0.1372 & 0 & Winter & ovx & Autumn & 3 \\
\hline 32 & 5 & 0.1377 & 0 & Winter & ovx & Autumn & 3 \\
\hline 32 & 5 & 0.1381 & 0 & Winter & ovx & Autumn & 3 \\
\hline 32 & 5 & 0.1386 & 0 & Winter & ovx & Autumn & 3 \\
\hline 32 & 5 & 0.1390 & 0 & Winter & ovx & Autumn & 3 \\
\hline 32 & 5 & 0.1395 & 0 & Winter & ovx & Autumn & 3 \\
\hline 32 & 5 & 0.1400 & 0 & Winter & ovx & Autumn & 3 \\
\hline 32 & 5 & 0.1404 & 0 & Winter & ovx & Autumn & 3 \\
\hline
\end{tabular}




\begin{tabular}{|c|c|c|c|c|c|c|c|}
\hline $\begin{array}{l}\text { Sheep } \\
\text { Eartag }\end{array}$ & Sector & $\begin{array}{l}\text { ETA } \\
(\mathbf{m m})\end{array}$ & $\begin{array}{l}\text { Bone } \\
\text { Pixels } \\
\end{array}$ & $\begin{array}{l}\text { Sacrifice } \\
\text { Season }\end{array}$ & Treatment & $\begin{array}{l}\text { Season of } \\
\text { surgery }\end{array}$ & $\begin{array}{l}\text { Time } \\
\text { (months) }\end{array}$ \\
\hline 32 & 5 & 0.1409 & 0 & Winter & ovx & Autumn & 3 \\
\hline 32 & 5 & 0.1414 & 0 & Winter & ovx & Autumn & 3 \\
\hline 32 & 5 & 0.1419 & 0 & Winter & ovx & Autumn & 3 \\
\hline 32 & 5 & 0.1424 & 0 & Winter & ovx & Autumn & 3 \\
\hline 32 & 5 & 0.1429 & 0 & Winter & ovx & Autumn & 3 \\
\hline 32 & 5 & 0.1434 & 0 & Winter & ovx & Autumn & 3 \\
\hline 32 & 5 & 0.1439 & 0 & Winter & ovx & Autumn & 3 \\
\hline 32 & 5 & 0.1444 & 0 & Winter & ovx & Autumn & 3 \\
\hline 32 & 5 & 0.1450 & 0 & Winter & ovx & Autumn & 3 \\
\hline 32 & 5 & 0.1455 & 0 & Winter & ovx & Autumn & 3 \\
\hline 32 & 5 & 0.1461 & 0 & Winter & ovx & Autumn & 3 \\
\hline 32 & 6 & 0.0059 & 0 & Winter & ovx & Autumn & 3 \\
\hline 32 & 6 & 0.0114 & 0 & Winter & ovx & Autumn & 3 \\
\hline 32 & 6 & 0.0158 & 0 & Winter & ovx & Autumn & 3 \\
\hline 32 & 6 & 0.0196 & 0 & Winter & ovx & Autumn & 3 \\
\hline 32 & 6 & 0.0228 & 0 & Winter & ovx & Autumn & 3 \\
\hline 32 & 6 & 0.0257 & 0 & Winter & ovx & Autumn & 3 \\
\hline 32 & 6 & 0.0283 & 0 & Winter & ovx & Autumn & 3 \\
\hline 32 & 6 & 0.0306 & 0 & Winter & ovx & Autumn & 3 \\
\hline 32 & 6 & 0.0327 & 0 & Winter & ovx & Autumn & 3 \\
\hline 32 & 6 & 0.0347 & 0 & Winter & ovx & Autumn & 3 \\
\hline 32 & 6 & 0.0365 & 0 & Winter & ovx & Autumn & 3 \\
\hline 32 & 6 & 0.0382 & 0 & Winter & ovx & Autumn & 3 \\
\hline 32 & 6 & 0.0398 & 0 & Winter & ovx & Autumn & 3 \\
\hline 32 & 6 & 0.0413 & 0 & Winter & ovx & Autumn & 3 \\
\hline 32 & 6 & 0.0427 & 0 & Winter & ovx & Autumn & 3 \\
\hline 32 & 6 & 0.0441 & 0 & Winter & ovx & Autumn & 3 \\
\hline 32 & 6 & 0.0454 & 0 & Winter & ovx & Autumn & 3 \\
\hline 32 & 6 & 0.0466 & 0 & Winter & ovx & Autumn & 3 \\
\hline 32 & 6 & 0.0478 & 0 & Winter & ovx & Autumn & 3 \\
\hline 32 & 6 & 0.0489 & 22519 & Winter & ovx & Autumn & 3 \\
\hline 32 & 6 & 0.0500 & 30978 & Winter & ovx & Autumn & 3 \\
\hline 32 & 6 & 0.0510 & 32352 & Winter & ovx & Autumn & 3 \\
\hline 32 & 6 & 0.0520 & 40115 & Winter & ovx & Autumn & 3 \\
\hline 32 & 6 & 0.0530 & 47263 & Winter & ovx & Autumn & 3 \\
\hline 32 & 6 & 0.0539 & 52226 & Winter & ovx & Autumn & 3 \\
\hline 32 & 6 & 0.0548 & 59316 & Winter & ovx & Autumn & 3 \\
\hline 32 & 6 & 0.0557 & 64123 & Winter & ovx & Autumn & 3 \\
\hline 32 & 6 & 0.0566 & 73234 & Winter & ovx & Autumn & 3 \\
\hline 32 & 6 & 0.0574 & 79068 & Winter & ovx & Autumn & 3 \\
\hline
\end{tabular}




\begin{tabular}{|c|c|c|c|c|c|c|c|}
\hline $\begin{array}{l}\text { Sheep } \\
\text { Eartag }\end{array}$ & Sector & $\begin{array}{l}\text { ETA } \\
(\mathbf{m m})\end{array}$ & $\begin{array}{l}\text { Bone } \\
\text { Pixels }\end{array}$ & $\begin{array}{l}\text { Sacrifice } \\
\text { Season }\end{array}$ & Treatment & $\begin{array}{l}\text { Season of } \\
\text { surgery }\end{array}$ & $\begin{array}{l}\text { Time } \\
\text { (months) }\end{array}$ \\
\hline 32 & 6 & 0.0582 & 83601 & Winter & ovx & Autumn & 3 \\
\hline 32 & 6 & 0.0590 & 93879 & Winter & ovx & Autumn & 3 \\
\hline 32 & 6 & 0.0597 & 98451 & Winter & ovx & Autumn & 3 \\
\hline 32 & 6 & 0.0605 & 106472 & Winter & ovx & Autumn & 3 \\
\hline 32 & 6 & 0.0612 & 115486 & Winter & ovx & Autumn & 3 \\
\hline 32 & 6 & 0.0619 & 123694 & Winter & ovx & Autumn & 3 \\
\hline 32 & 6 & 0.0626 & 133469 & Winter & ovx & Autumn & 3 \\
\hline 32 & 6 & 0.0633 & 139098 & Winter & ovx & Autumn & 3 \\
\hline 32 & 6 & 0.0640 & 148124 & Winter & ovx & Autumn & 3 \\
\hline 32 & 6 & 0.0646 & 151895 & Winter & ovx & Autumn & 3 \\
\hline 32 & 6 & 0.0652 & 155370 & Winter & ovx & Autumn & 3 \\
\hline 32 & 6 & 0.0659 & 160935 & Winter & ovx & Autumn & 3 \\
\hline 32 & 6 & 0.0665 & 164414 & Winter & ovx & Autumn & 3 \\
\hline 32 & 6 & 0.0671 & 169388 & Winter & ovx & Autumn & 3 \\
\hline 32 & 6 & 0.0677 & 173599 & Winter & ovx & Autumn & 3 \\
\hline 32 & 6 & 0.0683 & 176183 & Winter & ovx & Autumn & 3 \\
\hline 32 & 6 & 0.0688 & 179365 & Winter & ovx & Autumn & 3 \\
\hline 32 & 6 & 0.0694 & 182691 & Winter & ovx & Autumn & 3 \\
\hline 32 & 6 & 0.0699 & 186967 & Winter & ovx & Autumn & 3 \\
\hline 32 & 6 & 0.0705 & 190430 & Winter & ovx & Autumn & 3 \\
\hline 32 & 6 & 0.0710 & 194267 & Winter & ovx & Autumn & 3 \\
\hline 32 & 6 & 0.0716 & 194927 & Winter & ovx & Autumn & 3 \\
\hline 32 & 6 & 0.0721 & 192921 & Winter & ovx & Autumn & 3 \\
\hline 32 & 6 & 0.0726 & 186718 & Winter & ovx & Autumn & 3 \\
\hline 32 & 6 & 0.0731 & 178421 & Winter & ovx & Autumn & 3 \\
\hline 32 & 6 & 0.0736 & 167897 & Winter & ovx & Autumn & 3 \\
\hline 32 & 6 & 0.0741 & 154661 & Winter & ovx & Autumn & 3 \\
\hline 32 & 6 & 0.0746 & 140582 & Winter & ovx & Autumn & 3 \\
\hline 32 & 6 & 0.0751 & 125073 & Winter & ovx & Autumn & 3 \\
\hline 32 & 6 & 0.0755 & 108662 & Winter & ovx & Autumn & 3 \\
\hline 32 & 6 & 0.0760 & 94193 & Winter & ovx & Autumn & 3 \\
\hline 32 & 6 & 0.0765 & 79274 & Winter & ovx & Autumn & 3 \\
\hline 32 & 6 & 0.0769 & 66323 & Winter & ovx & Autumn & 3 \\
\hline 32 & 6 & 0.0774 & 55382 & Winter & ovx & Autumn & 3 \\
\hline 32 & 6 & 0.0778 & 45194 & Winter & ovx & Autumn & 3 \\
\hline 32 & 6 & 0.0783 & 36594 & Winter & ovx & Autumn & 3 \\
\hline 32 & 6 & 0.0787 & 29331 & Winter & ovx & Autumn & 3 \\
\hline 32 & 6 & 0.0791 & 23491 & Winter & ovx & Autumn & 3 \\
\hline 32 & 6 & 0.0796 & 18520 & Winter & ovx & Autumn & 3 \\
\hline 32 & 6 & 0.0800 & 14572 & Winter & ovx & Autumn & 3 \\
\hline
\end{tabular}




\begin{tabular}{|c|c|c|c|c|c|c|c|}
\hline $\begin{array}{l}\text { Sheep } \\
\text { Eartag }\end{array}$ & Sector & $\begin{array}{l}\text { ETA } \\
(\mathbf{m m})\end{array}$ & $\begin{array}{l}\text { Bone } \\
\text { Pixels } \\
\end{array}$ & $\begin{array}{l}\text { Sacrifice } \\
\text { Season }\end{array}$ & Treatment & $\begin{array}{l}\text { Season of } \\
\text { surgery }\end{array}$ & $\begin{array}{l}\text { Time } \\
\text { (months) }\end{array}$ \\
\hline 32 & 6 & 0.0804 & 11419 & Winter & ovx & Autumn & 3 \\
\hline 32 & 6 & 0.0808 & 9019 & Winter & ovx & Autumn & 3 \\
\hline 32 & 6 & 0.0812 & 6937 & Winter & ovx & Autumn & 3 \\
\hline 32 & 6 & 0.0816 & 5413 & Winter & ovx & Autumn & 3 \\
\hline 32 & 6 & 0.0820 & 4328 & Winter & ovx & Autumn & 3 \\
\hline 32 & 6 & 0.0824 & 3250 & Winter & ovx & Autumn & 3 \\
\hline 32 & 6 & 0.0828 & 2611 & Winter & ovx & Autumn & 3 \\
\hline 32 & 6 & 0.0832 & 2038 & Winter & ovx & Autumn & 3 \\
\hline 32 & 6 & 0.0836 & 1573 & Winter & ovx & Autumn & 3 \\
\hline 32 & 6 & 0.0840 & 1213 & Winter & ovx & Autumn & 3 \\
\hline 32 & 6 & 0.0844 & 959 & Winter & ovx & Autumn & 3 \\
\hline 32 & 6 & 0.0848 & 706 & Winter & ovx & Autumn & 3 \\
\hline 32 & 6 & 0.0852 & 552 & Winter & ovx & Autumn & 3 \\
\hline 32 & 6 & 0.0855 & 472 & Winter & ovx & Autumn & 3 \\
\hline 32 & 6 & 0.0859 & 326 & Winter & ovx & Autumn & 3 \\
\hline 32 & 6 & 0.0863 & 224 & Winter & ovx & Autumn & 3 \\
\hline 32 & 6 & 0.0867 & 176 & Winter & ovx & Autumn & 3 \\
\hline 32 & 6 & 0.0870 & 143 & Winter & ovx & Autumn & 3 \\
\hline 32 & 6 & 0.0874 & 111 & Winter & ovx & Autumn & 3 \\
\hline 32 & 6 & 0.0878 & 71 & Winter & ovx & Autumn & 3 \\
\hline 32 & 6 & 0.0881 & 81 & Winter & ovx & Autumn & 3 \\
\hline 32 & 6 & 0.0885 & 51 & Winter & ovx & Autumn & 3 \\
\hline 32 & 6 & 0.0888 & 33 & Winter & ovx & Autumn & 3 \\
\hline 32 & 6 & 0.0892 & 18 & Winter & ovx & Autumn & 3 \\
\hline 32 & 6 & 0.0895 & 20 & Winter & ovx & Autumn & 3 \\
\hline 32 & 6 & 0.0899 & 10 & Winter & ovx & Autumn & 3 \\
\hline 32 & 6 & 0.0902 & 10 & Winter & ovx & Autumn & 3 \\
\hline 32 & 6 & 0.0906 & 8 & Winter & ovx & Autumn & 3 \\
\hline 32 & 6 & 0.0909 & 7 & Winter & ovx & Autumn & 3 \\
\hline 32 & 6 & 0.0913 & 11 & Winter & ovx & Autumn & 3 \\
\hline 32 & 6 & 0.0916 & 2 & Winter & ovx & Autumn & 3 \\
\hline 32 & 6 & 0.0919 & 6 & Winter & ovx & Autumn & 3 \\
\hline 32 & 6 & 0.0923 & 8 & Winter & ovx & Autumn & 3 \\
\hline 32 & 6 & 0.0926 & 6 & Winter & ovx & Autumn & 3 \\
\hline 32 & 6 & 0.0930 & 2 & Winter & ovx & Autumn & 3 \\
\hline 32 & 6 & 0.0933 & 5 & Winter & ovx & Autumn & 3 \\
\hline 32 & 6 & 0.0936 & 3 & Winter & ovx & Autumn & 3 \\
\hline 32 & 6 & 0.0939 & 2 & Winter & ovx & Autumn & 3 \\
\hline 32 & 6 & 0.0943 & 1 & Winter & ovx & Autumn & 3 \\
\hline 32 & 6 & 0.0946 & 2 & Winter & ovx & Autumn & 3 \\
\hline
\end{tabular}




\begin{tabular}{|c|c|c|c|c|c|c|c|}
\hline $\begin{array}{l}\text { Sheep } \\
\text { Eartag }\end{array}$ & Sector & $\begin{array}{l}\text { ETA } \\
(\mathbf{m m})\end{array}$ & $\begin{array}{l}\text { Bone } \\
\text { Pixels }\end{array}$ & $\begin{array}{l}\text { Sacrifice } \\
\text { Season }\end{array}$ & Treatment & $\begin{array}{l}\text { Season of } \\
\text { surgery }\end{array}$ & $\begin{array}{l}\text { Time } \\
\text { (months) }\end{array}$ \\
\hline 32 & 6 & 0.0949 & 4 & Winter & ovx & Autumn & 3 \\
\hline 32 & 6 & 0.0953 & 2 & Winter & ovx & Autumn & 3 \\
\hline 32 & 6 & 0.0956 & 3 & Winter & ovx & Autumn & 3 \\
\hline 32 & 6 & 0.0959 & 2 & Winter & ovx & Autumn & 3 \\
\hline 32 & 6 & 0.0962 & 4 & Winter & ovx & Autumn & 3 \\
\hline 32 & 6 & 0.0965 & 1 & Winter & ovx & Autumn & 3 \\
\hline 32 & 6 & 0.0969 & 1 & Winter & ovx & Autumn & 3 \\
\hline 32 & 6 & 0.0972 & 2 & Winter & ovx & Autumn & 3 \\
\hline 32 & 6 & 0.0975 & 4 & Winter & ovx & Autumn & 3 \\
\hline 32 & 6 & 0.0978 & 3 & Winter & ovx & Autumn & 3 \\
\hline 32 & 6 & 0.0981 & 4 & Winter & ovx & Autumn & 3 \\
\hline 32 & 6 & 0.0984 & 2 & Winter & ovx & Autumn & 3 \\
\hline 32 & 6 & 0.0988 & 5 & Winter & ovx & Autumn & 3 \\
\hline 32 & 6 & 0.0991 & 1 & Winter & ovx & Autumn & 3 \\
\hline 32 & 6 & 0.0994 & 1 & Winter & ovx & Autumn & 3 \\
\hline 32 & 6 & 0.0997 & 5 & Winter & ovx & Autumn & 3 \\
\hline 32 & 6 & 0.1000 & 0 & Winter & ovx & Autumn & 3 \\
\hline 32 & 6 & 0.1003 & 1 & Winter & ovx & Autumn & 3 \\
\hline 32 & 6 & 0.1006 & 3 & Winter & ovx & Autumn & 3 \\
\hline 32 & 6 & 0.1009 & 1 & Winter & ovx & Autumn & 3 \\
\hline 32 & 6 & 0.1012 & 0 & Winter & ovx & Autumn & 3 \\
\hline 32 & 6 & 0.1015 & 3 & Winter & ovx & Autumn & 3 \\
\hline 32 & 6 & 0.1018 & 1 & Winter & ovx & Autumn & 3 \\
\hline 32 & 6 & 0.1022 & 2 & Winter & ovx & Autumn & 3 \\
\hline 32 & 6 & 0.1025 & 0 & Winter & ovx & Autumn & 3 \\
\hline 32 & 6 & 0.1028 & 4 & Winter & ovx & Autumn & 3 \\
\hline 32 & 6 & 0.1031 & 5 & Winter & ovx & Autumn & 3 \\
\hline 32 & 6 & 0.1034 & 4 & Winter & ovx & Autumn & 3 \\
\hline 32 & 6 & 0.1037 & 1 & Winter & ovx & Autumn & 3 \\
\hline 32 & 6 & 0.1040 & 1 & Winter & ovx & Autumn & 3 \\
\hline 32 & 6 & 0.1043 & 2 & Winter & ovx & Autumn & 3 \\
\hline 32 & 6 & 0.1046 & 0 & Winter & ovx & Autumn & 3 \\
\hline 32 & 6 & 0.1049 & 2 & Winter & ovx & Autumn & 3 \\
\hline 32 & 6 & 0.1052 & 0 & Winter & ovx & Autumn & 3 \\
\hline 32 & 6 & 0.1055 & 4 & Winter & ovx & Autumn & 3 \\
\hline 32 & 6 & 0.1058 & 1 & Winter & ovx & Autumn & 3 \\
\hline 32 & 6 & 0.1061 & 3 & Winter & ovx & Autumn & 3 \\
\hline 32 & 6 & 0.1064 & 0 & Winter & ovx & Autumn & 3 \\
\hline 32 & 6 & 0.1067 & 2 & Winter & ovx & Autumn & 3 \\
\hline 32 & 6 & 0.1070 & 1 & Winter & ovx & Autumn & 3 \\
\hline
\end{tabular}




\begin{tabular}{|c|c|c|c|c|c|c|c|}
\hline $\begin{array}{l}\text { Sheep } \\
\text { Eartag }\end{array}$ & Sector & $\begin{array}{l}\text { ETA } \\
(\mathbf{m m})\end{array}$ & $\begin{array}{l}\text { Bone } \\
\text { Pixels } \\
\end{array}$ & $\begin{array}{l}\text { Sacrifice } \\
\text { Season }\end{array}$ & Treatment & $\begin{array}{l}\text { Season of } \\
\text { surgery }\end{array}$ & $\begin{array}{l}\text { Time } \\
\text { (months) }\end{array}$ \\
\hline 32 & 6 & 0.1073 & 1 & Winter & ovx & Autumn & 3 \\
\hline 32 & 6 & 0.1076 & 2 & Winter & ovx & Autumn & 3 \\
\hline 32 & 6 & 0.1079 & 2 & Winter & ovx & Autumn & 3 \\
\hline 32 & 6 & 0.1082 & 1 & Winter & ovx & Autumn & 3 \\
\hline 32 & 6 & 0.1085 & 1 & Winter & ovx & Autumn & 3 \\
\hline 32 & 6 & 0.1088 & 3 & Winter & ovx & Autumn & 3 \\
\hline 32 & 6 & 0.1091 & 0 & Winter & ovx & Autumn & 3 \\
\hline 32 & 6 & 0.1094 & 0 & Winter & ovx & Autumn & 3 \\
\hline 32 & 6 & 0.1097 & 1 & Winter & ovx & Autumn & 3 \\
\hline 32 & 6 & 0.1100 & 2 & Winter & ovx & Autumn & 3 \\
\hline 32 & 6 & 0.1103 & 2 & Winter & ovx & Autumn & 3 \\
\hline 32 & 6 & 0.1106 & 3 & Winter & ovx & Autumn & 3 \\
\hline 32 & 6 & 0.1109 & 0 & Winter & ovx & Autumn & 3 \\
\hline 32 & 6 & 0.1112 & 2 & Winter & ovx & Autumn & 3 \\
\hline 32 & 6 & 0.1115 & 1 & Winter & ovx & Autumn & 3 \\
\hline 32 & 6 & 0.1118 & 2 & Winter & ovx & Autumn & 3 \\
\hline 32 & 6 & 0.1122 & 2 & Winter & ovx & Autumn & 3 \\
\hline 32 & 6 & 0.1125 & 2 & Winter & ovx & Autumn & 3 \\
\hline 32 & 6 & 0.1128 & 0 & Winter & ovx & Autumn & 3 \\
\hline 32 & 6 & 0.1131 & 0 & Winter & ovx & Autumn & 3 \\
\hline 32 & 6 & 0.1134 & 2 & Winter & ovx & Autumn & 3 \\
\hline 32 & 6 & 0.1137 & 1 & Winter & ovx & Autumn & 3 \\
\hline 32 & 6 & 0.1140 & 0 & Winter & ovx & Autumn & 3 \\
\hline 32 & 6 & 0.1143 & 1 & Winter & ovx & Autumn & 3 \\
\hline 32 & 6 & 0.1146 & 2 & Winter & ovx & Autumn & 3 \\
\hline 32 & 6 & 0.1149 & 0 & Winter & ovx & Autumn & 3 \\
\hline 32 & 6 & 0.1152 & 1 & Winter & ovx & Autumn & 3 \\
\hline 32 & 6 & 0.1155 & 0 & Winter & ovx & Autumn & 3 \\
\hline 32 & 6 & 0.1158 & 1 & Winter & ovx & Autumn & 3 \\
\hline 32 & 6 & 0.1161 & 2 & Winter & ovx & Autumn & 3 \\
\hline 32 & 6 & 0.1165 & 1 & Winter & ovx & Autumn & 3 \\
\hline 32 & 6 & 0.1168 & 0 & Winter & ovx & Autumn & 3 \\
\hline 32 & 6 & 0.1171 & 1 & Winter & ovx & Autumn & 3 \\
\hline 32 & 6 & 0.1174 & 0 & Winter & ovx & Autumn & 3 \\
\hline 32 & 6 & 0.1177 & 2 & Winter & ovx & Autumn & 3 \\
\hline 32 & 6 & 0.1180 & 1 & Winter & ovx & Autumn & 3 \\
\hline 32 & 6 & 0.1183 & 0 & Winter & ovx & Autumn & 3 \\
\hline 32 & 6 & 0.1187 & 2 & Winter & ovx & Autumn & 3 \\
\hline 32 & 6 & 0.1190 & 1 & Winter & ovx & Autumn & 3 \\
\hline 32 & 6 & 0.1193 & 0 & Winter & ovx & Autumn & 3 \\
\hline
\end{tabular}




\begin{tabular}{|c|c|c|c|c|c|c|c|}
\hline $\begin{array}{l}\text { Sheep } \\
\text { Eartag }\end{array}$ & Sector & $\begin{array}{l}\text { ETA } \\
(\mathbf{m m})\end{array}$ & $\begin{array}{l}\text { Bone } \\
\text { Pixels } \\
\end{array}$ & $\begin{array}{l}\text { Sacrifice } \\
\text { Season }\end{array}$ & Treatment & $\begin{array}{l}\text { Season of } \\
\text { surgery }\end{array}$ & $\begin{array}{l}\text { Time } \\
\text { (months) }\end{array}$ \\
\hline 32 & 6 & 0.1196 & 0 & Winter & ovx & Autumn & 3 \\
\hline 32 & 6 & 0.1199 & 1 & Winter & ovx & Autumn & 3 \\
\hline 32 & 6 & 0.1203 & 1 & Winter & ovx & Autumn & 3 \\
\hline 32 & 6 & 0.1206 & 1 & Winter & ovx & Autumn & 3 \\
\hline 32 & 6 & 0.1209 & 1 & Winter & ovx & Autumn & 3 \\
\hline 32 & 6 & 0.1212 & 1 & Winter & ovx & Autumn & 3 \\
\hline 32 & 6 & 0.1216 & 1 & Winter & ovx & Autumn & 3 \\
\hline 32 & 6 & 0.1219 & 0 & Winter & ovx & Autumn & 3 \\
\hline 32 & 6 & 0.1222 & 2 & Winter & ovx & Autumn & 3 \\
\hline 32 & 6 & 0.1226 & 1 & Winter & ovx & Autumn & 3 \\
\hline 32 & 6 & 0.1229 & 0 & Winter & ovx & Autumn & 3 \\
\hline 32 & 6 & 0.1232 & 1 & Winter & ovx & Autumn & 3 \\
\hline 32 & 6 & 0.1236 & 2 & Winter & ovx & Autumn & 3 \\
\hline 32 & 6 & 0.1239 & 0 & Winter & ovx & Autumn & 3 \\
\hline 32 & 6 & 0.1243 & 0 & Winter & ovx & Autumn & 3 \\
\hline 32 & 6 & 0.1246 & 0 & Winter & ovx & Autumn & 3 \\
\hline 32 & 6 & 0.1249 & 1 & Winter & ovx & Autumn & 3 \\
\hline 32 & 6 & 0.1253 & 0 & Winter & ovx & Autumn & 3 \\
\hline 32 & 6 & 0.1256 & 0 & Winter & ovx & Autumn & 3 \\
\hline 32 & 6 & 0.1260 & 0 & Winter & ovx & Autumn & 3 \\
\hline 32 & 6 & 0.1263 & 0 & Winter & ovx & Autumn & 3 \\
\hline 32 & 6 & 0.1267 & 0 & Winter & ovx & Autumn & 3 \\
\hline 32 & 6 & 0.1270 & 0 & Winter & ovx & Autumn & 3 \\
\hline 32 & 6 & 0.1274 & 0 & Winter & ovx & Autumn & 3 \\
\hline 32 & 6 & 0.1278 & 0 & Winter & ovx & Autumn & 3 \\
\hline 32 & 6 & 0.1281 & 0 & Winter & ovx & Autumn & 3 \\
\hline 32 & 6 & 0.1285 & 0 & Winter & ovx & Autumn & 3 \\
\hline 32 & 6 & 0.1288 & 0 & Winter & ovx & Autumn & 3 \\
\hline 32 & 6 & 0.1292 & 0 & Winter & ovx & Autumn & 3 \\
\hline 32 & 6 & 0.1296 & 0 & Winter & ovx & Autumn & 3 \\
\hline 32 & 6 & 0.1300 & 0 & Winter & ovx & Autumn & 3 \\
\hline 32 & 6 & 0.1303 & 0 & Winter & ovx & Autumn & 3 \\
\hline 32 & 6 & 0.1307 & 0 & Winter & ovx & Autumn & 3 \\
\hline 32 & 6 & 0.1311 & 0 & Winter & ovx & Autumn & 3 \\
\hline 32 & 6 & 0.1315 & 0 & Winter & ovx & Autumn & 3 \\
\hline 32 & 6 & 0.1319 & 0 & Winter & ovx & Autumn & 3 \\
\hline 32 & 6 & 0.1323 & 0 & Winter & ovx & Autumn & 3 \\
\hline 32 & 6 & 0.1327 & 0 & Winter & ovx & Autumn & 3 \\
\hline 32 & 6 & 0.1331 & 0 & Winter & ovx & Autumn & 3 \\
\hline 32 & 6 & 0.1335 & 0 & Winter & ovx & Autumn & 3 \\
\hline
\end{tabular}




\begin{tabular}{|c|c|c|c|c|c|c|c|}
\hline $\begin{array}{l}\text { Sheep } \\
\text { Eartag }\end{array}$ & Sector & $\begin{array}{l}\text { ETA } \\
(\mathbf{m m})\end{array}$ & $\begin{array}{l}\text { Bone } \\
\text { Pixels }\end{array}$ & $\begin{array}{l}\text { Sacrifice } \\
\text { Season }\end{array}$ & Treatment & $\begin{array}{l}\text { Season of } \\
\text { surgery }\end{array}$ & $\begin{array}{l}\text { Time } \\
\text { (months) }\end{array}$ \\
\hline 32 & 6 & 0.1339 & 0 & Winter & ovx & Autumn & 3 \\
\hline 32 & 6 & 0.1343 & 0 & Winter & ovx & Autumn & 3 \\
\hline 32 & 6 & 0.1347 & 0 & Winter & ovx & Autumn & 3 \\
\hline 32 & 6 & 0.1351 & 0 & Winter & ovx & Autumn & 3 \\
\hline 32 & 6 & 0.1355 & 0 & Winter & ovx & Autumn & 3 \\
\hline 32 & 6 & 0.1359 & 0 & Winter & ovx & Autumn & 3 \\
\hline 32 & 6 & 0.1364 & 0 & Winter & ovx & Autumn & 3 \\
\hline 32 & 6 & 0.1368 & 0 & Winter & ovx & Autumn & 3 \\
\hline 32 & 6 & 0.1372 & 0 & Winter & ovx & Autumn & 3 \\
\hline 32 & 6 & 0.1377 & 0 & Winter & ovx & Autumn & 3 \\
\hline 32 & 6 & 0.1381 & 0 & Winter & ovx & Autumn & 3 \\
\hline 32 & 6 & 0.1386 & 0 & Winter & ovx & Autumn & 3 \\
\hline 32 & 6 & 0.1390 & 0 & Winter & ovx & Autumn & 3 \\
\hline 32 & 6 & 0.1395 & 0 & Winter & ovx & Autumn & 3 \\
\hline 32 & 6 & 0.1400 & 0 & Winter & ovx & Autumn & 3 \\
\hline 32 & 6 & 0.1404 & 0 & Winter & ovx & Autumn & 3 \\
\hline 32 & 6 & 0.1409 & 0 & Winter & ovx & Autumn & 3 \\
\hline 32 & 6 & 0.1414 & 0 & Winter & ovx & Autumn & 3 \\
\hline 32 & 6 & 0.1419 & 0 & Winter & ovx & Autumn & 3 \\
\hline 32 & 6 & 0.1424 & 0 & Winter & ovx & Autumn & 3 \\
\hline 32 & 6 & 0.1429 & 0 & Winter & ovx & Autumn & 3 \\
\hline 32 & 6 & 0.1434 & 0 & Winter & ovx & Autumn & 3 \\
\hline 32 & 6 & 0.1439 & 0 & Winter & ovx & Autumn & 3 \\
\hline 32 & 6 & 0.1444 & 0 & Winter & ovx & Autumn & 3 \\
\hline 32 & 6 & 0.1450 & 0 & Winter & ovx & Autumn & 3 \\
\hline 32 & 6 & 0.1455 & 0 & Winter & ovx & Autumn & 3 \\
\hline 32 & 6 & 0.1461 & 0 & Winter & ovx & Autumn & 3 \\
\hline
\end{tabular}




\section{APPENDIX C: SUMMARY OF RAW DATA AVERAGES}

\begin{tabular}{|c|c|c|c|c|c|c|c|c|}
\hline $\begin{array}{l}\text { Sheep } \\
\text { Ear } \\
\text { Tag } \\
\end{array}$ & Plate & Specimen & $\begin{array}{l}\text { Mean } \\
\text { ETA }\end{array}$ & $\begin{array}{l}\text { SD } \\
\text { ETA } \\
\end{array}$ & Treatment & $\begin{array}{l}\text { Season of } \\
\text { surgery }\end{array}$ & $\begin{array}{l}\text { Time } \\
\text { (months) }\end{array}$ & $\begin{array}{l}\text { Season of } \\
\text { Sacrifice }\end{array}$ \\
\hline $\mathrm{C} 01$ & 1 & 1 & 0.0836 & 0.0189 & control & Summer & 12 & \\
\hline $\mathrm{C} 01$ & 1 & 2 & 0.1012 & 0.0132 & control & Summer & 12 & \\
\hline $\mathrm{C} 01$ & 1 & 3 & 0.1042 & 0.0080 & control & Summer & 12 & \\
\hline $\mathrm{C} 01$ & 1 & 4 & 0.0638 & 0.0122 & control & Summer & 12 & \\
\hline $\mathrm{C} 01$ & 1 & 5 & 0.0726 & 0.0138 & control & Summer & 12 & \\
\hline $\mathrm{C} 01$ & 1 & 6 & 0.0893 & 0.0116 & control & Summer & 12 & \\
\hline $\mathrm{C} 02$ & 2 & 1 & 0.0308 & 0.0329 & ovx & Summer & 3 & Fall \\
\hline $\mathrm{C} 02$ & 2 & 2 & 0.0493 & 0.0323 & ovx & Summer & 3 & Fall \\
\hline $\mathrm{C} 02$ & 2 & 3 & 0.0571 & 0.0285 & ovx & Summer & 3 & Fall \\
\hline $\mathrm{C} 02$ & 2 & 4 & 0.0244 & 0.0305 & ovx & Summer & 3 & Fall \\
\hline $\mathrm{C} 02$ & 2 & 5 & 0.0002 & 0.0036 & ovx & Summer & 3 & Fall \\
\hline $\mathrm{C} 02$ & 2 & 6 & 0.0245 & 0.0306 & ovx & Summer & 3 & Fall \\
\hline $\mathrm{C} 03$ & 3 & 1 & 0.0418 & 0.0092 & control & Summer & 12 & \\
\hline $\mathrm{C} 03$ & 3 & 2 & 0.0602 & 0.0094 & control & Summer & 12 & \\
\hline $\mathrm{C} 03$ & 3 & 3 & 0.0523 & 0.0101 & control & Summer & 12 & \\
\hline $\mathrm{C} 03$ & 3 & 4 & 0.0238 & 0.0120 & control & Summer & 12 & \\
\hline $\mathrm{C} 03$ & 3 & 5 & 0.0283 & 0.0127 & control & Summer & 12 & \\
\hline $\mathrm{C} 03$ & 3 & 6 & 0.0427 & 0.0051 & control & Summer & 12 & \\
\hline $\mathrm{C} 04$ & 4 & 1 & 0.0656 & & ovx & Summer & 12 & \\
\hline $\mathrm{C} 04$ & 4 & 2 & 0.0431 & & ovx & Summer & 12 & \\
\hline $\mathrm{C} 04$ & 4 & 3 & 0.0445 & & ovx & Summer & 12 & \\
\hline $\mathrm{C} 04$ & 4 & 4 & 0.0376 & & ovx & Summer & 12 & \\
\hline $\mathrm{C} 04$ & 4 & 5 & 0.0461 & & ovx & Summer & 12 & \\
\hline C04 & 4 & 6 & 0.0648 & & ovx & Summer & 12 & \\
\hline $\mathrm{C} 05$ & 5 & 1 & 0.0793 & & ovx & Summer & 12 & \\
\hline $\mathrm{C} 05$ & 5 & 2 & 0.0633 & & ovx & Summer & 12 & \\
\hline $\mathrm{C} 05$ & 5 & 3 & 0.0817 & & ovx & Summer & 12 & \\
\hline $\mathrm{C} 05$ & 5 & 4 & 0.0586 & & ovx & Summer & 12 & \\
\hline $\mathrm{C} 05$ & 5 & 5 & 0.0613 & & ovx & Summer & 12 & \\
\hline $\mathrm{C} 05$ & 5 & 6 & 0.0546 & & ovx & Summer & 12 & \\
\hline C06 & 6 & 1 & 0.0582 & 0.0054 & control & Summer & 12 & \\
\hline C06 & 6 & 2 & 0.0572 & 0.0062 & control & Summer & 12 & \\
\hline $\mathrm{C} 06$ & 6 & 3 & 0.0613 & 0.0071 & control & Summer & 12 & \\
\hline $\mathrm{C} 06$ & 6 & 4 & 0.0497 & 0.0068 & control & Summer & 12 & \\
\hline $\mathrm{C} 06$ & 6 & 5 & 0.0360 & 0.0052 & control & Summer & 12 & \\
\hline C06 & 6 & 6 & 0.0471 & 0.0081 & control & Summer & 12 & \\
\hline
\end{tabular}




\begin{tabular}{|c|c|c|c|c|c|c|c|c|}
\hline $\begin{array}{l}\text { Sheep } \\
\text { Ear } \\
\text { Tag }\end{array}$ & Plate & Specimen & $\begin{array}{l}\text { Mean } \\
\text { ETA }\end{array}$ & $\begin{array}{l}\text { SD } \\
\text { ETA }\end{array}$ & Treatment & $\begin{array}{l}\text { Season of } \\
\text { surgery }\end{array}$ & $\begin{array}{l}\text { Time } \\
\text { (months) }\end{array}$ & $\begin{array}{l}\text { Season of } \\
\text { Sacrifice }\end{array}$ \\
\hline $\mathrm{C} 07$ & 7 & 1 & 0.0355 & 0.0085 & control & Summer & 12 & \\
\hline $\mathrm{C} 07$ & 7 & 2 & 0.0338 & 0.0052 & control & Summer & 12 & \\
\hline $\mathrm{C} 07$ & 7 & 3 & 0.0453 & 0.0067 & control & Summer & 12 & \\
\hline $\mathrm{C} 07$ & 7 & 4 & 0.0365 & 0.0072 & control & Summer & 12 & \\
\hline $\mathrm{C} 07$ & 7 & 5 & 0.0420 & 0.0065 & control & Summer & 12 & \\
\hline $\mathrm{C} 07$ & 7 & 6 & 0.0320 & 0.0060 & control & Summer & 12 & \\
\hline $\mathrm{C} 08$ & 8 & 1 & 0.0440 & & ovx & Summer & 12 & \\
\hline $\mathrm{C} 08$ & 8 & 2 & 0.0407 & & ovx & Summer & 12 & \\
\hline $\mathrm{C} 08$ & 8 & 3 & 0.0258 & & ovx & Summer & 12 & \\
\hline $\mathrm{C} 08$ & 8 & 4 & 0.0390 & & ovx & Summer & 12 & \\
\hline $\mathrm{C} 08$ & 8 & 5 & 0.0266 & & ovx & Summer & 12 & \\
\hline $\mathrm{C} 08$ & 8 & 6 & 0.0346 & & ovx & Summer & 12 & \\
\hline $\mathrm{C} 09$ & 9 & 1 & 0.0631 & 0.0253 & ovx & Summer & 3 & Fall \\
\hline C09 & 9 & 2 & 0.0784 & 0.0152 & ovx & Summer & 3 & Fall \\
\hline $\mathrm{C} 09$ & 9 & 3 & 0.0075 & 0.0194 & ovx & Summer & 3 & Fall \\
\hline C09 & 9 & 4 & 0.0452 & 0.0323 & ovx & Summer & 3 & Fall \\
\hline C09 & 9 & 5 & 0.0687 & 0.0241 & ovx & Summer & 3 & Fall \\
\hline $\mathrm{C} 09$ & 9 & 6 & 0.0004 & 0.0044 & ovx & Summer & 3 & Fall \\
\hline $\mathrm{C} 11$ & 11 & 1 & 0.0533 & 0.0057 & control & Summer & 12 & \\
\hline $\mathrm{C} 11$ & 11 & 2 & 0.0463 & 0.0069 & control & Summer & 12 & \\
\hline C11 & 11 & 3 & 0.0542 & 0.0062 & control & Summer & 12 & \\
\hline $\mathrm{C} 11$ & 11 & 4 & 0.0609 & 0.0055 & control & Summer & 12 & \\
\hline $\mathrm{C} 11$ & 11 & 5 & 0.0478 & 0.0074 & control & Summer & 12 & \\
\hline $\mathrm{C} 11$ & 11 & 6 & 0.0351 & 0.0087 & control & Summer & 12 & \\
\hline $\mathrm{C} 12$ & 12 & 1 & 0.0586 & 0.0035 & ovx & Summer & 3 & Fall \\
\hline $\mathrm{C} 12$ & 12 & 2 & 0.0336 & 0.0058 & ovx & Summer & 3 & Fall \\
\hline $\mathrm{C} 12$ & 12 & 3 & 0.0512 & 0.0053 & ovx & Summer & 3 & Fall \\
\hline $\mathrm{C} 12$ & 12 & 4 & 0.0464 & 0.0043 & ovx & Summer & 3 & Fall \\
\hline $\mathrm{C} 12$ & 12 & 5 & 0.0470 & 0.0055 & ovx & Summer & 3 & Fall \\
\hline $\mathrm{C} 12$ & 12 & 6 & 0.0515 & 0.0048 & ovx & Summer & 3 & Fall \\
\hline $\mathrm{C} 13$ & 13 & 1 & 0.0481 & & ovx & Summer & 12 & \\
\hline $\mathrm{C} 13$ & 13 & 2 & 0.0646 & & ovx & Summer & 12 & \\
\hline $\mathrm{C} 13$ & 13 & 3 & 0.0765 & & ovx & Summer & 12 & \\
\hline $\mathrm{C} 13$ & 13 & 4 & 0.0632 & & ovx & Summer & 12 & \\
\hline $\mathrm{C} 13$ & 13 & 6 & 0.0494 & & ovx & Summer & 12 & \\
\hline $\mathrm{C} 14$ & 14 & 1 & 0.0000 & 0.0000 & ovx & Summer & 3 & Fall \\
\hline $\mathrm{C} 14$ & 14 & 2 & 0.0000 & 0.0000 & ovx & Summer & 3 & Fall \\
\hline $\mathrm{C} 14$ & 14 & 3 & 0.0000 & 0.0000 & ovx & Summer & 3 & Fall \\
\hline $\mathrm{C} 14$ & 14 & 4 & 0.0000 & 0.0000 & ovx & Summer & 3 & Fall \\
\hline
\end{tabular}




\begin{tabular}{|c|c|c|c|c|c|c|c|c|}
\hline $\begin{array}{l}\text { Sheep } \\
\text { Ear } \\
\text { Tag }\end{array}$ & Plate & Specimen & $\begin{array}{l}\text { Mean } \\
\text { ETA }\end{array}$ & $\begin{array}{l}\text { SD } \\
\text { ETA }\end{array}$ & Treatment & $\begin{array}{l}\text { Season of } \\
\text { surgery }\end{array}$ & $\begin{array}{l}\text { Time } \\
\text { (months) }\end{array}$ & $\begin{array}{l}\text { Season of } \\
\text { Sacrifice }\end{array}$ \\
\hline $\mathrm{C} 14$ & 14 & 5 & 0.0000 & 0.0000 & ovx & Summer & 3 & Fall \\
\hline $\mathrm{C} 14$ & 14 & 6 & 0.0000 & 0.0000 & ovx & Summer & 3 & Fall \\
\hline $\mathrm{C} 15$ & 15 & 1 & 0.0727 & 0.0070 & control & Summer & 3 & Fall \\
\hline $\mathrm{C} 15$ & 15 & 2 & 0.0696 & 0.0048 & control & Summer & 3 & Fall \\
\hline $\mathrm{C} 15$ & 15 & 3 & 0.0695 & 0.0051 & control & Summer & 3 & Fall \\
\hline $\mathrm{C} 15$ & 15 & 4 & 0.0753 & 0.0062 & control & Summer & 3 & Fall \\
\hline $\mathrm{C} 15$ & 15 & 5 & 0.0736 & 0.0062 & control & Summer & 3 & Fall \\
\hline $\mathrm{C} 15$ & 15 & 6 & 0.0760 & 0.0053 & control & Summer & 3 & Fall \\
\hline $\mathrm{C} 16$ & 16 & 1 & 0.0582 & 0.0062 & control & Summer & 3 & Fall \\
\hline $\mathrm{C} 16$ & 16 & 2 & 0.0484 & 0.0100 & control & Summer & 3 & Fall \\
\hline $\mathrm{C} 16$ & 16 & 3 & 0.0572 & 0.0053 & control & Summer & 3 & Fall \\
\hline $\mathrm{C} 16$ & 16 & 4 & 0.0513 & 0.0069 & control & Summer & 3 & Fall \\
\hline $\mathrm{C} 16$ & 16 & 5 & 0.0382 & 0.0156 & control & Summer & 3 & Fall \\
\hline $\mathrm{C} 16$ & 16 & 6 & 0.0638 & 0.0067 & control & Summer & 3 & Fall \\
\hline $\mathrm{C} 17$ & 17 & 1 & 0.0618 & 0.0161 & control & Summer & 3 & Fall \\
\hline $\mathrm{C} 17$ & 17 & 2 & 0.0618 & 0.0137 & control & Summer & 3 & Fall \\
\hline $\mathrm{C} 17$ & 17 & 3 & 0.0632 & 0.0090 & control & Summer & 3 & Fall \\
\hline $\mathrm{C} 17$ & 17 & 4 & 0.0621 & 0.0122 & control & Summer & 3 & Fall \\
\hline $\mathrm{C} 17$ & 17 & 5 & 0.0506 & 0.0221 & control & Summer & 3 & Fall \\
\hline $\mathrm{C} 17$ & 17 & 6 & 0.0704 & 0.0067 & control & Summer & 3 & Fall \\
\hline $\mathrm{C} 18$ & 18 & 1 & 0.0776 & & ovx & Summer & 12 & \\
\hline $\mathrm{C} 18$ & 18 & 2 & 0.0710 & & ovx & Summer & 12 & \\
\hline $\mathrm{C} 18$ & 18 & 3 & 0.0684 & & ovx & Summer & 12 & \\
\hline $\mathrm{C} 18$ & 18 & 4 & 0.0665 & & ovx & Summer & 12 & \\
\hline $\mathrm{C} 18$ & 18 & 5 & 0.0608 & & ovx & Summer & 12 & \\
\hline $\mathrm{C} 18$ & 18 & 6 & 0.0740 & & ovx & Summer & 12 & \\
\hline $\mathrm{C} 19$ & 19 & 1 & 0.0431 & 0.0049 & ovx & Summer & 3 & Fall \\
\hline C19 & 19 & 2 & 0.0502 & 0.0042 & ovx & Summer & 3 & Fall \\
\hline $\mathrm{C} 19$ & 19 & 3 & 0.0529 & 0.0051 & ovx & Summer & 3 & Fall \\
\hline C19 & 19 & 4 & 0.0578 & 0.0052 & ovx & Summer & 3 & Fall \\
\hline $\mathrm{C} 19$ & 19 & 5 & 0.0621 & 0.0044 & ovx & Summer & 3 & Fall \\
\hline C19 & 19 & 6 & 0.0496 & 0.0083 & ovx & Summer & 3 & Fall \\
\hline $\mathrm{C} 20$ & 20 & 1 & 0.0400 & 0.0329 & ovx & Summer & 3 & Fall \\
\hline $\mathrm{C} 20$ & 20 & 2 & 0.0402 & 0.0339 & ovx & Summer & 3 & Fall \\
\hline $\mathrm{C} 20$ & 20 & 3 & 0.0151 & 0.0259 & ovx & Summer & 3 & Fall \\
\hline $\mathrm{C} 20$ & 20 & 4 & 0.0151 & 0.0265 & ovx & Summer & 3 & Fall \\
\hline $\mathrm{C} 20$ & 20 & 5 & 0.0109 & 0.0231 & ovx & Summer & 3 & Fall \\
\hline $\mathrm{C} 20$ & 20 & 6 & 0.0125 & 0.0241 & ovx & Summer & 3 & Fall \\
\hline $\mathrm{C} 21$ & 21 & 2 & 0.0534 & 0.0051 & ovx & Summer & 3 & Fall \\
\hline
\end{tabular}




\begin{tabular}{|c|c|c|c|c|c|c|c|c|}
\hline $\begin{array}{l}\text { Sheep } \\
\text { Ear } \\
\text { Tag } \\
\end{array}$ & Plate & Specimen & $\begin{array}{l}\text { Mean } \\
\text { ETA }\end{array}$ & $\begin{array}{l}\text { SD } \\
\text { ETA }\end{array}$ & Treatment & $\begin{array}{l}\text { Season of } \\
\text { surgery }\end{array}$ & $\begin{array}{l}\text { Time } \\
\text { (months) }\end{array}$ & $\begin{array}{l}\text { Season of } \\
\text { Sacrifice }\end{array}$ \\
\hline $\mathrm{C} 22$ & 22 & 1 & 0.0469 & 0.0098 & control & Summer & 12 & \\
\hline $\mathrm{C} 22$ & 22 & 2 & 0.0569 & 0.0058 & control & Summer & 12 & \\
\hline $\mathrm{C} 22$ & 22 & 3 & 0.0495 & 0.0073 & control & Summer & 12 & \\
\hline $\mathrm{C} 22$ & 22 & 4 & 0.0548 & 0.0079 & control & Summer & 12 & \\
\hline $\mathrm{C} 22$ & 22 & 5 & 0.0604 & 0.0079 & control & Summer & 12 & \\
\hline $\mathrm{C} 22$ & 22 & 6 & 0.0379 & 0.0055 & control & Summer & 12 & \\
\hline $\mathrm{C} 23$ & 23 & 1 & 0.0613 & 0.0052 & control & Summer & 3 & Fall \\
\hline $\mathrm{C} 23$ & 23 & 2 & 0.0587 & 0.0040 & control & Summer & 3 & Fall \\
\hline $\mathrm{C} 23$ & 23 & 3 & 0.0695 & 0.0051 & control & Summer & 3 & Fall \\
\hline $\mathrm{C} 23$ & 23 & 4 & 0.0580 & 0.0057 & control & Summer & 3 & Fall \\
\hline $\mathrm{C} 23$ & 23 & 5 & 0.0683 & 0.0034 & control & Summer & 3 & Fall \\
\hline $\mathrm{C} 23$ & 23 & 6 & 0.0587 & 0.0066 & control & Summer & 3 & Fall \\
\hline $\mathrm{C} 24$ & 24 & 1 & 0.0610 & 0.0086 & control & Summer & 3 & Fall \\
\hline $\mathrm{C} 24$ & 24 & 2 & 0.0333 & 0.0129 & control & Summer & 3 & Fall \\
\hline $\mathrm{C} 24$ & 24 & 3 & 0.0374 & 0.0170 & control & Summer & 3 & Fall \\
\hline $\mathrm{C} 24$ & 24 & 4 & 0.0652 & 0.0067 & control & Summer & 3 & Fall \\
\hline $\mathrm{C} 24$ & 24 & 5 & 0.0426 & 0.0217 & control & Summer & 3 & Fall \\
\hline $\mathrm{C} 24$ & 24 & 6 & 0.0389 & 0.0175 & control & Summer & 3 & Fall \\
\hline $\mathrm{C} 25$ & 25 & 1 & 0.0591 & 0.0271 & ovx & Summer & 3 & Fall \\
\hline $\mathrm{C} 25$ & 25 & 2 & 0.0010 & 0.0074 & ovx & Summer & 3 & Fall \\
\hline $\mathrm{C} 25$ & 25 & 3 & 0.0521 & 0.0297 & ovx & Summer & 3 & Fall \\
\hline $\mathrm{C} 25$ & 25 & 4 & 0.0008 & 0.0066 & ovx & Summer & 3 & Fall \\
\hline $\mathrm{C} 25$ & 25 & 5 & 0.0421 & 0.0321 & ovx & Summer & 3 & Fall \\
\hline $\mathrm{C} 25$ & 25 & 6 & 0.0004 & 0.0045 & ovx & Summer & 3 & Fall \\
\hline $\mathrm{C} 26$ & 26 & 1 & 0.0285 & 0.0052 & control & Summer & 12 & \\
\hline $\mathrm{C} 26$ & 26 & 2 & 0.0137 & 0.0049 & control & Summer & 12 & \\
\hline $\mathrm{C} 26$ & 26 & 3 & 0.0253 & 0.0044 & control & Summer & 12 & \\
\hline $\mathrm{C} 26$ & 26 & 4 & 0.0146 & 0.0047 & control & Summer & 12 & \\
\hline $\mathrm{C} 26$ & 26 & 5 & 0.0151 & 0.0046 & control & Summer & 12 & \\
\hline $\mathrm{C} 26$ & 26 & 6 & 0.0203 & 0.0063 & control & Summer & 12 & \\
\hline $\mathrm{C} 27$ & 27 & 1 & 0.0643 & 0.0040 & control & Summer & 3 & Fall \\
\hline $\mathrm{C} 27$ & 27 & 2 & 0.0538 & 0.0053 & control & Summer & 3 & Fall \\
\hline $\mathrm{C} 27$ & 27 & 3 & 0.0620 & 0.0053 & control & Summer & 3 & Fall \\
\hline $\mathrm{C} 27$ & 27 & 4 & 0.0597 & 0.0039 & control & Summer & 3 & Fall \\
\hline $\mathrm{C} 27$ & 27 & 5 & 0.0482 & 0.0058 & control & Summer & 3 & Fall \\
\hline $\mathrm{C} 27$ & 27 & 6 & 0.0518 & 0.0075 & control & Summer & 3 & Fall \\
\hline $\mathrm{C} 28$ & 28 & 1 & 0.0504 & 0.0052 & control & Summer & 3 & Fall \\
\hline $\mathrm{C} 28$ & 28 & 2 & 0.0497 & 0.0052 & control & Summer & 3 & Fall \\
\hline
\end{tabular}




\begin{tabular}{|c|c|c|c|c|c|c|c|c|}
\hline $\begin{array}{l}\text { Sheep } \\
\text { Ear } \\
\text { Tag }\end{array}$ & Plate & Specimen & $\begin{array}{l}\text { Mean } \\
\text { ETA }\end{array}$ & $\begin{array}{l}\text { SD } \\
\text { ETA }\end{array}$ & Treatment & $\begin{array}{l}\text { Season of } \\
\text { surgery }\end{array}$ & $\begin{array}{l}\text { Time } \\
\text { (months) }\end{array}$ & $\begin{array}{l}\text { Season of } \\
\text { Sacrifice }\end{array}$ \\
\hline $\mathrm{C} 28$ & 28 & 3 & 0.0314 & 0.0059 & control & Summer & 3 & Fall \\
\hline $\mathrm{C} 28$ & 28 & 4 & 0.0236 & 0.0073 & control & Summer & 3 & Fall \\
\hline $\mathrm{C} 28$ & 28 & 5 & 0.0346 & 0.0046 & control & Summer & 3 & Fall \\
\hline $\mathrm{C} 28$ & 28 & 6 & 0.0664 & 0.0043 & control & Summer & 3 & Fall \\
\hline $\mathrm{C} 29$ & 29 & 1 & 0.0938 & & control & Summer & 12 & Fall \\
\hline $\mathrm{C} 29$ & 29 & 2 & 0.0862 & & control & Summer & 12 & Fall \\
\hline $\mathrm{C} 29$ & 29 & 4 & 0.0828 & & control & Summer & 12 & Fall \\
\hline $\mathrm{C} 29$ & 29 & 5 & 0.0720 & & control & Summer & 12 & Fall \\
\hline $\mathrm{C} 29$ & 29 & 6 & 0.0889 & & control & Summer & 12 & Fall \\
\hline $\mathrm{C} 30$ & 30 & 1 & 0.0584 & & ovx & Fall & 12 & \\
\hline $\mathrm{C} 30$ & 30 & 2 & 0.0543 & & ovx & Fall & 12 & \\
\hline $\mathrm{C} 30$ & 30 & 4 & 0.0653 & & ovx & Fall & 12 & \\
\hline $\mathrm{C} 30$ & 30 & 5 & 0.0598 & & ovx & Fall & 12 & \\
\hline $\mathrm{C} 31$ & 31 & 1 & 0.0353 & 0.0042 & ovx & Autumn & 3 & Winter \\
\hline $\mathrm{C} 31$ & 31 & 2 & 0.0358 & 0.0038 & ovx & Autumn & 3 & Winter \\
\hline $\mathrm{C} 31$ & 31 & 3 & 0.0369 & 0.0045 & ovx & Autumn & 3 & Winter \\
\hline $\mathrm{C} 31$ & 31 & 4 & 0.0338 & 0.0053 & ovx & Autumn & 3 & Winter \\
\hline $\mathrm{C} 31$ & 31 & 5 & 0.0325 & 0.0048 & ovx & Autumn & 3 & Winter \\
\hline $\mathrm{C} 31$ & 31 & 6 & 0.0400 & 0.0048 & ovx & Autumn & 3 & Winter \\
\hline $\mathrm{C} 32$ & 32 & 1 & 0.0757 & 0.0069 & ovx & Autumn & 3 & Winter \\
\hline $\mathrm{C} 32$ & 32 & 2 & 0.0729 & 0.0067 & ovx & Autumn & 3 & Winter \\
\hline $\mathrm{C} 32$ & 32 & 3 & 0.0627 & 0.0168 & ovx & Autumn & 3 & Winter \\
\hline $\mathrm{C} 32$ & 32 & 4 & 0.0788 & 0.0072 & ovx & Autumn & 3 & Winter \\
\hline $\mathrm{C} 32$ & 32 & 5 & 0.0715 & 0.0078 & ovx & Autumn & 3 & Winter \\
\hline C32 & 32 & 6 & 0.0725 & 0.0067 & ovx & Autumn & 3 & Winter \\
\hline $\mathrm{C} 33$ & 33 & 1 & 0.0712 & & ovx & Fall & 12 & \\
\hline $\mathrm{C} 33$ & 33 & 2 & 0.0681 & & ovx & Fall & 12 & \\
\hline $\mathrm{C} 33$ & 33 & 3 & 0.0592 & & ovx & Fall & 12 & \\
\hline C33 & 33 & 4 & 0.0774 & & ovx & Fall & 12 & \\
\hline $\mathrm{C} 33$ & 33 & 5 & 0.0637 & & ovx & Fall & 12 & \\
\hline $\mathrm{C} 33$ & 33 & 6 & 0.0689 & & ovx & Fall & 12 & \\
\hline C34 & 34 & 1 & 0.0783 & 0.0105 & ovx & Autumn & 3 & Winter \\
\hline C34 & 34 & 2 & 0.0557 & 0.0109 & ovx & Autumn & 3 & Winter \\
\hline C34 & 34 & 3 & 0.0868 & 0.0063 & ovx & Autumn & 3 & Winter \\
\hline $\mathrm{C} 34$ & 34 & 4 & 0.0750 & 0.0083 & ovx & Autumn & 3 & Winter \\
\hline $\mathrm{C} 34$ & 34 & 5 & 0.0827 & 0.0054 & ovx & Autumn & 3 & Winter \\
\hline C34 & 34 & 6 & 0.0702 & 0.0047 & ovx & Autumn & 3 & Winter \\
\hline $\mathrm{C} 35$ & 35 & 1 & 0.0835 & 0.0055 & ovx & Autumn & 3 & Winter \\
\hline $\mathrm{C} 35$ & 35 & 2 & 0.0683 & 0.0091 & ovx & Autumn & 3 & Winter \\
\hline
\end{tabular}




\begin{tabular}{|c|c|c|c|c|c|c|c|c|}
\hline $\begin{array}{l}\text { Sheep } \\
\text { Ear } \\
\text { Tag }\end{array}$ & Plate & Specimen & $\begin{array}{l}\text { Mean } \\
\text { ETA }\end{array}$ & $\begin{array}{l}\text { SD } \\
\text { ETA }\end{array}$ & Treatment & $\begin{array}{l}\text { Season of } \\
\text { surgery }\end{array}$ & $\begin{array}{l}\text { Time } \\
\text { (months) }\end{array}$ & $\begin{array}{l}\text { Season of } \\
\text { Sacrifice }\end{array}$ \\
\hline $\mathrm{C} 35$ & 35 & 3 & 0.0840 & 0.0043 & ovx & Autumn & 3 & Winter \\
\hline $\mathrm{C} 35$ & 35 & 4 & 0.0710 & 0.0053 & ovx & Autumn & 3 & Winter \\
\hline $\mathrm{C} 35$ & 35 & 5 & 0.0697 & 0.0086 & ovx & Autumn & 3 & Winter \\
\hline $\mathrm{C} 35$ & 35 & 6 & 0.0738 & 0.0145 & ovx & Autumn & 3 & Winter \\
\hline $\mathrm{C} 36$ & 36 & 1 & 0.0546 & 0.0076 & ovx & Autumn & 3 & Winter \\
\hline $\mathrm{C} 36$ & 36 & 2 & 0.0430 & 0.0098 & ovx & Autumn & 3 & Winter \\
\hline $\mathrm{C} 36$ & 36 & 3 & 0.0554 & 0.0098 & ovx & Autumn & 3 & Winter \\
\hline $\mathrm{C} 36$ & 36 & 4 & 0.0498 & 0.0079 & ovx & Autumn & 3 & Winter \\
\hline $\mathrm{C} 36$ & 36 & 5 & 0.0558 & 0.0070 & ovx & Autumn & 3 & Winter \\
\hline $\mathrm{C} 36$ & 36 & 6 & 0.0510 & 0.0224 & ovx & Autumn & 3 & Winter \\
\hline $\mathrm{C} 37$ & 37 & 1 & 0.0498 & 0.0116 & ovx & Autumn & 3 & Winter \\
\hline $\mathrm{C} 37$ & 37 & 2 & 0.0648 & 0.0058 & ovx & Autumn & 3 & Winter \\
\hline $\mathrm{C} 37$ & 37 & 3 & 0.0629 & 0.0063 & ovx & Autumn & 3 & Winter \\
\hline $\mathrm{C} 37$ & 37 & 4 & 0.0563 & 0.0063 & ovx & Autumn & 3 & Winter \\
\hline $\mathrm{C} 37$ & 37 & 5 & 0.0552 & 0.0069 & ovx & Autumn & 3 & Winter \\
\hline C37 & 37 & 6 & 0.0530 & 0.0054 & ovx & Autumn & 3 & Winter \\
\hline $\mathrm{C} 38$ & 38 & 1 & 0.0699 & 0.0080 & ovx & Autumn & 3 & Winter \\
\hline $\mathrm{C} 38$ & 38 & 2 & 0.0625 & 0.0145 & ovx & Autumn & 3 & Winter \\
\hline $\mathrm{C} 38$ & 38 & 3 & 0.0638 & 0.0073 & ovx & Autumn & 3 & Winter \\
\hline $\mathrm{C} 38$ & 38 & 4 & 0.0649 & 0.0088 & ovx & Autumn & 3 & Winter \\
\hline C38 & 38 & 5 & 0.0577 & 0.0122 & ovx & Autumn & 3 & Winter \\
\hline $\mathrm{C} 38$ & 38 & 6 & 0.0773 & 0.0092 & ovx & Autumn & 3 & Winter \\
\hline C39 & 39 & 1 & 0.0585 & & ovx & Fall & 12 & \\
\hline C39 & 39 & 2 & 0.0570 & & ovx & Fall & 12 & \\
\hline C39 & 39 & 3 & 0.0526 & & ovx & Fall & 12 & \\
\hline C39 & 39 & 4 & 0.0427 & & ovx & Fall & 12 & \\
\hline C39 & 39 & 5 & 0.0490 & & ovx & Fall & 12 & \\
\hline C39 & 39 & 6 & 0.0560 & & ovx & Fall & 12 & \\
\hline $\mathrm{C} 40$ & 40 & 1 & 0.0721 & & ovx & Fall & 12 & \\
\hline $\mathrm{C} 40$ & 40 & 2 & 0.0728 & & ovx & Fall & 12 & \\
\hline $\mathrm{C} 40$ & 40 & 3 & 0.0773 & & ovx & Fall & 12 & \\
\hline $\mathrm{C} 40$ & 40 & 4 & 0.0570 & & ovx & Fall & 12 & \\
\hline $\mathrm{C} 40$ & 40 & 5 & 0.0765 & & ovx & Fall & 12 & \\
\hline $\mathrm{C} 40$ & 40 & 6 & 0.0788 & & ovx & Fall & 12 & \\
\hline $\mathrm{C} 42$ & 42 & 1 & 0.0372 & & ovx & Fall & 12 & \\
\hline $\mathrm{C} 42$ & 42 & 2 & 0.0637 & & ovx & Fall & 12 & \\
\hline $\mathrm{C} 42$ & 42 & 3 & 0.0685 & & ovx & Fall & 12 & \\
\hline $\mathrm{C} 42$ & 42 & 4 & 0.0597 & & ovx & Fall & 12 & \\
\hline $\mathrm{C} 42$ & 42 & 5 & 0.0550 & & ovx & Fall & 12 & \\
\hline
\end{tabular}




\begin{tabular}{|c|c|c|c|c|c|c|c|c|}
\hline $\begin{array}{l}\text { Sheep } \\
\text { Ear } \\
\text { Tag }\end{array}$ & Plate & Specimen & $\begin{array}{l}\text { Mean } \\
\text { ETA }\end{array}$ & $\begin{array}{l}\text { SD } \\
\text { ETA }\end{array}$ & Treatment & $\begin{array}{l}\text { Season of } \\
\text { surgery }\end{array}$ & $\begin{array}{l}\text { Time } \\
\text { (months) }\end{array}$ & $\begin{array}{l}\text { Season of } \\
\text { Sacrifice }\end{array}$ \\
\hline $\mathrm{C} 42$ & 42 & 6 & 0.0666 & & ovx & Fall & 12 & \\
\hline $\mathrm{C} 43$ & 43 & 1 & 0.0705 & 0.0072 & control & Autumn & 3 & Winter \\
\hline $\mathrm{C} 43$ & 43 & 2 & 0.0508 & 0.0069 & control & Autumn & 3 & Winter \\
\hline $\mathrm{C} 43$ & 43 & 3 & 0.0601 & 0.0059 & control & Autumn & 3 & Winter \\
\hline $\mathrm{C} 43$ & 43 & 4 & 0.0525 & 0.0075 & control & Autumn & 3 & Winter \\
\hline $\mathrm{C} 43$ & 43 & 5 & 0.0543 & 0.0046 & control & Autumn & 3 & Winter \\
\hline $\mathrm{C} 43$ & 43 & 6 & 0.0466 & 0.0055 & control & Autumn & 3 & Winter \\
\hline $\mathrm{C} 44$ & 44 & 1 & 0.0559 & 0.0079 & control & Fall & 12 & \\
\hline $\mathrm{C} 44$ & 44 & 2 & 0.0607 & 0.0087 & control & Fall & 12 & \\
\hline $\mathrm{C} 44$ & 44 & 3 & 0.0524 & 0.0118 & control & Fall & 12 & \\
\hline $\mathrm{C} 44$ & 44 & 4 & 0.0432 & 0.0110 & control & Fall & 12 & \\
\hline $\mathrm{C} 44$ & 44 & 5 & 0.0500 & 0.0087 & control & Fall & 12 & \\
\hline $\mathrm{C} 44$ & 44 & 6 & 0.0337 & 0.0092 & control & Fall & 12 & \\
\hline $\mathrm{C} 45$ & 45 & 1 & 0.0903 & 0.0075 & control & Autumn & 3 & Winter \\
\hline $\mathrm{C} 45$ & 45 & 2 & 0.0822 & 0.0064 & control & Autumn & 3 & Winter \\
\hline $\mathrm{C} 45$ & 45 & 3 & 0.0778 & 0.0083 & control & Autumn & 3 & Winter \\
\hline $\mathrm{C} 45$ & 45 & 4 & 0.0906 & 0.0044 & control & Autumn & 3 & Winter \\
\hline $\mathrm{C} 45$ & 45 & 5 & 0.0811 & 0.0048 & control & Autumn & 3 & Winter \\
\hline $\mathrm{C} 45$ & 45 & 6 & 0.0736 & 0.0094 & control & Autumn & 3 & Winter \\
\hline $\mathrm{C} 46$ & 46 & 1 & 0.0574 & 0.0150 & control & Fall & 12 & \\
\hline $\mathrm{C} 46$ & 46 & 2 & 0.0535 & 0.0125 & control & Fall & 12 & \\
\hline $\mathrm{C} 46$ & 46 & 3 & 0.0754 & 0.0104 & control & Fall & 12 & \\
\hline $\mathrm{C} 46$ & 46 & 4 & 0.0690 & 0.0082 & control & Fall & 12 & \\
\hline $\mathrm{C} 46$ & 46 & 5 & 0.0632 & 0.0110 & control & Fall & 12 & \\
\hline $\mathrm{C} 46$ & 46 & 6 & 0.0642 & 0.0091 & control & Fall & 12 & \\
\hline $\mathrm{C} 47$ & 47 & 1 & 0.0576 & 0.0099 & control & Fall & 12 & \\
\hline $\mathrm{C} 47$ & 47 & 2 & 0.0586 & 0.0081 & control & Fall & 12 & \\
\hline $\mathrm{C} 47$ & 47 & 3 & 0.0426 & 0.0102 & control & Fall & 12 & \\
\hline C47 & 47 & 4 & 0.0591 & 0.0044 & control & Fall & 12 & \\
\hline C47 & 47 & 5 & 0.0559 & 0.0082 & control & Fall & 12 & \\
\hline $\mathrm{C} 47$ & 47 & 6 & 0.0480 & 0.0074 & control & Fall & 12 & \\
\hline C49 & 49 & 1 & 0.0750 & 0.0084 & control & Autumn & 3 & Winter \\
\hline C49 & 49 & 2 & 0.0431 & 0.0050 & control & Autumn & 3 & Winter \\
\hline C49 & 49 & 3 & 0.0714 & 0.0080 & control & Autumn & 3 & Winter \\
\hline C49 & 49 & 4 & 0.0784 & 0.0089 & control & Autumn & 3 & Winter \\
\hline C49 & 49 & 5 & 0.0664 & 0.0055 & control & Autumn & 3 & Winter \\
\hline C49 & 49 & 6 & 0.0773 & 0.0079 & control & Autumn & 3 & Winter \\
\hline C50 & 50 & 1 & 0.0695 & 0.0099 & control & Fall & 12 & \\
\hline C50 & 50 & 2 & 0.0728 & 0.0088 & control & Fall & 12 & \\
\hline
\end{tabular}




\begin{tabular}{|c|c|c|c|c|c|c|c|c|}
\hline $\begin{array}{l}\text { Sheep } \\
\text { Ear } \\
\text { Tag }\end{array}$ & Plate & Specimen & $\begin{array}{l}\text { Mean } \\
\text { ETA }\end{array}$ & $\begin{array}{l}\text { SD } \\
\text { ETA }\end{array}$ & Treatment & $\begin{array}{l}\text { Season of } \\
\text { surgery }\end{array}$ & $\begin{array}{l}\text { Time } \\
\text { (months) }\end{array}$ & $\begin{array}{l}\text { Season of } \\
\text { Sacrifice }\end{array}$ \\
\hline C50 & 50 & 3 & 0.0672 & 0.0098 & control & Fall & 12 & \\
\hline $\mathrm{C} 50$ & 50 & 4 & 0.0682 & 0.0110 & control & Fall & 12 & \\
\hline $\mathrm{C} 50$ & 50 & 6 & 0.0731 & 0.0076 & control & Fall & 12 & \\
\hline C51 & 51 & 1 & 0.0806 & 0.0185 & control & Autumn & 3 & Winter \\
\hline $\mathrm{C} 51$ & 51 & 2 & 0.0741 & 0.0152 & control & Autumn & 3 & Winter \\
\hline C51 & 51 & 3 & 0.0563 & 0.0187 & control & Autumn & 3 & Winter \\
\hline C51 & 51 & 4 & 0.0723 & 0.0110 & control & Autumn & 3 & Winter \\
\hline C51 & 51 & 5 & 0.0738 & 0.0165 & control & Autumn & 3 & Winter \\
\hline C51 & 51 & 6 & 0.0894 & 0.0117 & control & Autumn & 3 & Winter \\
\hline $\mathrm{C} 52$ & 52 & 1 & 0.1209 & 0.0105 & control & Autumn & 3 & Winter \\
\hline $\mathrm{C} 52$ & 52 & 2 & 0.1210 & 0.0106 & control & Autumn & 3 & Winter \\
\hline $\mathrm{C} 52$ & 52 & 3 & 0.1145 & 0.0162 & control & Autumn & 3 & Winter \\
\hline $\mathrm{C} 52$ & 52 & 4 & 0.1019 & 0.0115 & control & Autumn & 3 & Winter \\
\hline $\mathrm{C} 52$ & 52 & 5 & 0.0973 & 0.0107 & control & Autumn & 3 & Winter \\
\hline $\mathrm{C} 52$ & 52 & 6 & 0.1312 & 0.0079 & control & Autumn & 3 & Winter \\
\hline $\mathrm{C} 53$ & 53 & 1 & 0.1438 & 0.0159 & control & Autumn & 3 & Winter \\
\hline C53 & 53 & 2 & 0.1337 & 0.0085 & control & Autumn & 3 & Winter \\
\hline $\mathrm{C} 53$ & 53 & 3 & 0.1451 & 0.0084 & control & Autumn & 3 & Winter \\
\hline $\mathrm{C} 53$ & 53 & 4 & 0.1192 & 0.0123 & control & Autumn & 3 & Winter \\
\hline C53 & 53 & 5 & 0.0937 & 0.0256 & control & Autumn & 3 & Winter \\
\hline C53 & 53 & 6 & 0.1088 & 0.0103 & control & Autumn & 3 & Winter \\
\hline C54 & 54 & 1 & 1.1629 & 0.0065 & control & Fall & 12 & \\
\hline C54 & 54 & 2 & 1.2382 & 0.0072 & control & Fall & 12 & \\
\hline C54 & 54 & 3 & 1.2036 & 0.0087 & control & Fall & 12 & \\
\hline C54 & 54 & 4 & 1.1804 & 0.0091 & control & Fall & 12 & \\
\hline C54 & 54 & 5 & 1.1876 & 0.0118 & control & Fall & 12 & \\
\hline C54 & 54 & 6 & 1.1807 & 0.0082 & control & Fall & 12 & \\
\hline C55 & 55 & 1 & 0.0332 & 0.0076 & control & Fall & 12 & \\
\hline C55 & 55 & 2 & 0.0431 & 0.0093 & control & Fall & 12 & \\
\hline C55 & 55 & 3 & 0.0429 & 0.0111 & control & Fall & 12 & \\
\hline C55 & 55 & 4 & 0.0469 & 0.0076 & control & Fall & 12 & \\
\hline C55 & 55 & 5 & 0.0251 & 0.0065 & control & Fall & 12 & \\
\hline C55 & 55 & 6 & 0.0326 & 0.0069 & control & Fall & 12 & \\
\hline C56 & 56 & 1 & 0.1177 & 0.0053 & control & Autumn & 3 & Winter \\
\hline C56 & 56 & 2 & 0.1120 & 0.0074 & control & Autumn & 3 & Winter \\
\hline C56 & 56 & 3 & 0.1250 & 0.0091 & control & Autumn & 3 & Winter \\
\hline C56 & 56 & 4 & 0.1078 & 0.0164 & control & Autumn & 3 & Winter \\
\hline C56 & 56 & 5 & 0.1203 & 0.0070 & control & Autumn & 3 & Winter \\
\hline C56 & 56 & 6 & 0.1201 & 0.0065 & control & Autumn & 3 & Winter \\
\hline
\end{tabular}




\begin{tabular}{|c|c|c|c|c|c|c|c|c|}
\hline $\begin{array}{l}\text { Sheep } \\
\text { Ear } \\
\text { Tag }\end{array}$ & Plate & Specimen & $\begin{array}{l}\text { Mean } \\
\text { ETA }\end{array}$ & $\begin{array}{l}\text { SD } \\
\text { ETA }\end{array}$ & Treatment & $\begin{array}{l}\text { Season of } \\
\text { surgery }\end{array}$ & $\begin{array}{l}\text { Time } \\
\text { (months) }\end{array}$ & $\begin{array}{l}\text { Season of } \\
\text { Sacrifice }\end{array}$ \\
\hline $\mathrm{C} 58$ & 58 & 1 & 0.0662 & & ovx & Winter & 12 & \\
\hline C58 & 58 & 2 & 0.0727 & & ovx & Winter & 12 & \\
\hline $\mathrm{C} 58$ & 58 & 3 & 0.0736 & & ovx & Winter & 12 & \\
\hline C58 & 58 & 4 & 0.0724 & & ovx & Winter & 12 & \\
\hline C58 & 58 & 6 & 0.0751 & & ovx & Winter & 12 & \\
\hline C59 & 59 & 1 & 0.0657 & 0.0066 & control & Winter & 12 & \\
\hline C59 & 59 & 2 & 0.0552 & 0.0048 & control & Winter & 12 & \\
\hline C59 & 59 & 3 & 0.0716 & 0.0077 & control & Winter & 12 & \\
\hline C59 & 59 & 4 & 0.0636 & 0.0084 & control & Winter & 12 & \\
\hline C59 & 59 & 5 & 0.0577 & 0.0052 & control & Winter & 12 & \\
\hline C59 & 59 & 6 & 0.0575 & 0.0064 & control & Winter & 12 & \\
\hline C60 & 60 & 1 & 0.0469 & 0.0054 & ovx & Winter & 3 & Spring \\
\hline $\mathrm{C} 60$ & 60 & 2 & 0.0508 & 0.0034 & ovx & Winter & 3 & Spring \\
\hline C60 & 60 & 3 & 0.0481 & 0.0090 & ovx & Winter & 3 & Spring \\
\hline C60 & 60 & 4 & 0.0540 & 0.0047 & ovx & Winter & 3 & Spring \\
\hline C60 & 60 & 5 & 0.0537 & 0.0038 & ovx & Winter & 3 & Spring \\
\hline C60 & 60 & 6 & 0.0498 & 0.0058 & ovx & Winter & 3 & Spring \\
\hline C61 & 61 & 1 & 0.0746 & 0.0031 & ovx & Winter & 3 & Spring \\
\hline C61 & 61 & 2 & 0.0760 & 0.0027 & ovx & Winter & 3 & Spring \\
\hline C61 & 61 & 3 & 0.0715 & 0.0036 & ovx & Winter & 3 & Spring \\
\hline C61 & 61 & 4 & 0.0705 & 0.0032 & ovx & Winter & 3 & Spring \\
\hline C61 & 61 & 5 & 0.0705 & 0.0024 & ovx & Winter & 3 & Spring \\
\hline C61 & 61 & 6 & 0.0726 & 0.0027 & ovx & Winter & 3 & Spring \\
\hline C62 & 62 & 1 & 0.0650 & & ovx & Winter & 12 & \\
\hline C62 & 62 & 2 & 0.0649 & & ovx & Winter & 12 & \\
\hline C62 & 62 & 3 & 0.0754 & & ovx & Winter & 12 & \\
\hline C62 & 62 & 4 & 0.0703 & & ovx & Winter & 12 & \\
\hline C62 & 62 & 5 & 0.0646 & & ovx & Winter & 12 & \\
\hline C62 & 62 & 6 & 0.0692 & & ovx & Winter & 12 & \\
\hline C63 & 63 & 1 & 0.0636 & 0.0001 & control & Winter & 3 & Spring \\
\hline C63 & 63 & 2 & 0.0635 & 0.0001 & control & Winter & 3 & Spring \\
\hline C63 & 63 & 3 & 0.0634 & 0.0001 & control & Winter & 3 & Spring \\
\hline C63 & 63 & 4 & 0.0635 & 0.0001 & control & Winter & 3 & Spring \\
\hline C63 & 63 & 5 & 0.0637 & 0.0001 & control & Winter & 3 & Spring \\
\hline C63 & 63 & 6 & 0.0638 & 0.0001 & control & Winter & 3 & Spring \\
\hline $\mathrm{C} 65$ & 65 & 1 & 0.0395 & 0.0045 & ovx & Winter & 3 & Spring \\
\hline C65 & 65 & 2 & 0.0738 & 0.0052 & ovx & Winter & 3 & Spring \\
\hline C65 & 65 & 3 & 0.0735 & 0.0054 & ovx & Winter & 3 & Spring \\
\hline C65 & 65 & 4 & 0.0825 & 0.0074 & ovx & Winter & 3 & Spring \\
\hline
\end{tabular}




\begin{tabular}{|c|c|c|c|c|c|c|c|c|}
\hline $\begin{array}{l}\text { Sheep } \\
\text { Ear } \\
\text { Tag }\end{array}$ & Plate & Specimen & $\begin{array}{l}\text { Mean } \\
\text { ETA }\end{array}$ & $\begin{array}{l}\text { SD } \\
\text { ETA }\end{array}$ & Treatment & $\begin{array}{l}\text { Season of } \\
\text { surgery }\end{array}$ & $\begin{array}{l}\text { Time } \\
\text { (months) }\end{array}$ & $\begin{array}{l}\text { Season of } \\
\text { Sacrifice }\end{array}$ \\
\hline C65 & 65 & 5 & 0.0859 & 0.0060 & ovx & Winter & 3 & Spring \\
\hline C65 & 65 & 6 & 0.0829 & 0.0090 & ovx & Winter & 3 & Spring \\
\hline C66 & 66 & 1 & 0.0120 & 0.0052 & control & Winter & 3 & Spring \\
\hline C66 & 66 & 2 & 0.0149 & 0.0047 & control & Winter & 3 & Spring \\
\hline C66 & 66 & 3 & 0.0131 & 0.0071 & control & Winter & 3 & Spring \\
\hline C66 & 66 & 4 & 0.0164 & 0.0057 & control & Winter & 3 & Spring \\
\hline C66 & 66 & 5 & 0.0037 & 0.0047 & control & Winter & 3 & Spring \\
\hline C66 & 66 & 6 & 0.0163 & 0.0055 & control & Winter & 3 & Spring \\
\hline C67 & 67 & 1 & 0.0768 & & ovx & Winter & 12 & \\
\hline C67 & 67 & 2 & 0.0644 & & ovx & Winter & 12 & \\
\hline C67 & 67 & 3 & 0.0677 & & ovx & Winter & 12 & \\
\hline C67 & 67 & 4 & 0.0814 & & ovx & Winter & 12 & \\
\hline C67 & 67 & 5 & 0.0709 & & ovx & Winter & 12 & \\
\hline C67 & 67 & 6 & 0.0741 & & ovx & Winter & 12 & \\
\hline C68 & 68 & 1 & 0.0745 & & ovx & Winter & 12 & \\
\hline C68 & 68 & 2 & 0.0663 & & ovx & Winter & 12 & \\
\hline C68 & 68 & 3 & 0.0742 & & ovx & Winter & 12 & \\
\hline C68 & 68 & 4 & 0.0584 & & ovx & Winter & 12 & \\
\hline C68 & 68 & 5 & 0.0564 & & ovx & Winter & 12 & \\
\hline C68 & 68 & 6 & 0.0725 & & ovx & Winter & 12 & \\
\hline C69 & 69 & 1 & 0.0557 & 0.0075 & ovx & Winter & 3 & Spring \\
\hline C69 & 69 & 2 & 0.0439 & 0.0095 & ovx & Winter & 3 & Spring \\
\hline C69 & 69 & 3 & 0.0291 & 0.0146 & ovx & Winter & 3 & Spring \\
\hline C69 & 69 & 4 & 0.0533 & 0.0072 & ovx & Winter & 3 & Spring \\
\hline C69 & 69 & 5 & 0.0517 & 0.0087 & ovx & Winter & 3 & Spring \\
\hline C69 & 69 & 6 & 0.0567 & 0.0086 & ovx & Winter & 3 & Spring \\
\hline $\mathrm{C} 70$ & 70 & 1 & 0.0486 & & ovx & Winter & 12 & \\
\hline $\mathrm{C} 70$ & 70 & 2 & 0.0324 & & ovx & Winter & 12 & \\
\hline $\mathrm{C} 70$ & 70 & 3 & 0.0389 & & ovx & Winter & 12 & \\
\hline $\mathrm{C} 70$ & 70 & 5 & 0.0315 & & ovx & Winter & 12 & \\
\hline $\mathrm{C} 70$ & 70 & 6 & 0.0448 & & ovx & Winter & 12 & \\
\hline C71 & 71 & 1 & 0.0521 & & ovx & Winter & 12 & \\
\hline C71 & 71 & 2 & 0.0436 & & ovx & Winter & 12 & \\
\hline C71 & 71 & 3 & 0.0475 & & ovx & Winter & 12 & \\
\hline $\mathrm{C} 71$ & 71 & 4 & 0.0503 & & ovx & Winter & 12 & \\
\hline C71 & 71 & 5 & 0.0430 & & ovx & Winter & 12 & \\
\hline C71 & 71 & 6 & 0.0414 & & ovx & Winter & 12 & \\
\hline C72 & 72 & 1 & 0.0379 & 0.0112 & control & Winter & 3 & Spring \\
\hline $\mathrm{C} 72$ & 72 & 2 & 0.0611 & 0.0064 & control & Winter & 3 & Spring \\
\hline
\end{tabular}




\begin{tabular}{|c|c|c|c|c|c|c|c|c|}
\hline $\begin{array}{l}\text { Sheep } \\
\text { Ear } \\
\text { Tag }\end{array}$ & Plate & Specimen & $\begin{array}{l}\text { Mean } \\
\text { ETA }\end{array}$ & $\begin{array}{l}\text { SD } \\
\text { ETA }\end{array}$ & Treatment & $\begin{array}{l}\text { Season of } \\
\text { surgery }\end{array}$ & $\begin{array}{l}\text { Time } \\
\text { (months) }\end{array}$ & $\begin{array}{l}\text { Season of } \\
\text { Sacrifice }\end{array}$ \\
\hline C72 & 72 & 3 & 0.0717 & 0.0069 & control & Winter & 3 & Spring \\
\hline $\mathrm{C} 72$ & 72 & 4 & 0.0646 & 0.0086 & control & Winter & 3 & Spring \\
\hline $\mathrm{C} 72$ & 72 & 5 & 0.0328 & 0.0135 & control & Winter & 3 & Spring \\
\hline $\mathrm{C} 72$ & 72 & 6 & 0.0771 & 0.0047 & control & Winter & 3 & Spring \\
\hline $\mathrm{C} 73$ & 73 & 1 & 0.0789 & 0.0048 & control & Winter & 3 & Spring \\
\hline $\mathrm{C} 73$ & 73 & 2 & 0.0738 & 0.0059 & control & Winter & 3 & Spring \\
\hline $\mathrm{C} 73$ & 73 & 3 & 0.0645 & 0.0106 & control & Winter & 3 & Spring \\
\hline $\mathrm{C} 73$ & 73 & 4 & 0.0819 & 0.0044 & control & Winter & 3 & Spring \\
\hline $\mathrm{C} 73$ & 73 & 5 & 0.0621 & 0.0064 & control & Winter & 3 & Spring \\
\hline $\mathrm{C} 73$ & 73 & 6 & 0.0632 & 0.0080 & control & Winter & 3 & Spring \\
\hline $\mathrm{C} 74$ & 74 & 1 & 0.0373 & 0.0098 & ovx & Winter & 3 & Spring \\
\hline $\mathrm{C} 74$ & 74 & 2 & 0.0481 & 0.0048 & ovx & Winter & 3 & Spring \\
\hline $\mathrm{C} 74$ & 74 & 3 & 0.0637 & 0.0094 & ovx & Winter & 3 & Spring \\
\hline $\mathrm{C} 74$ & 74 & 4 & 0.0498 & 0.0049 & ovx & Winter & 3 & Spring \\
\hline $\mathrm{C} 74$ & 74 & 5 & 0.0491 & 0.0051 & ovx & Winter & 3 & Spring \\
\hline C74 & 74 & 6 & 0.0385 & 0.0074 & ovx & Winter & 3 & Spring \\
\hline $\mathrm{C} 75$ & 75 & 1 & 0.0249 & 0.0084 & control & Winter & 12 & \\
\hline $\mathrm{C} 75$ & 75 & 2 & 0.0330 & 0.0042 & control & Winter & 12 & \\
\hline $\mathrm{C} 75$ & 75 & 3 & 0.0267 & 0.0055 & control & Winter & 12 & \\
\hline $\mathrm{C} 75$ & 75 & 4 & 0.0343 & 0.0048 & control & Winter & 12 & \\
\hline C75 & 75 & 5 & 0.0277 & 0.0041 & control & Winter & 12 & \\
\hline $\mathrm{C} 75$ & 75 & 6 & 0.0390 & 0.0050 & control & Winter & 12 & \\
\hline C76 & 76 & 1 & 0.0371 & 0.0020 & ovx & Winter & 3 & Spring \\
\hline $\mathrm{C} 76$ & 76 & 2 & 0.0354 & 0.0034 & ovx & Winter & 3 & Spring \\
\hline C76 & 76 & 3 & 0.0357 & 0.0028 & ovx & Winter & 3 & Spring \\
\hline $\mathrm{C} 76$ & 76 & 4 & 0.0360 & 0.0024 & ovx & Winter & 3 & Spring \\
\hline C76 & 76 & 5 & 0.0343 & 0.0021 & ovx & Winter & 3 & Spring \\
\hline C76 & 76 & 6 & 0.0309 & 0.0026 & ovx & Winter & 3 & Spring \\
\hline C77 & 77 & 1 & 0.0428 & 0.0051 & control & Winter & 12 & \\
\hline C77 & 77 & 2 & 0.0374 & 0.0045 & control & Winter & 12 & \\
\hline $\mathrm{C} 77$ & 77 & 3 & 0.0403 & 0.0070 & control & Winter & 12 & \\
\hline C77 & 77 & 4 & 0.0352 & 0.0052 & control & Winter & 12 & \\
\hline C77 & 77 & 5 & 0.0361 & 0.0050 & control & Winter & 12 & \\
\hline $\mathrm{C} 77$ & 77 & 6 & 0.0288 & 0.0049 & control & Winter & 12 & \\
\hline $\mathrm{C} 78$ & 78 & 1 & 0.0797 & 0.0055 & ovx & Winter & 3 & Spring \\
\hline $\mathrm{C} 78$ & 78 & 2 & 0.0803 & 0.0061 & ovx & Winter & 3 & Spring \\
\hline C78 & 78 & 3 & 0.0802 & 0.0046 & ovx & Winter & 3 & Spring \\
\hline C78 & 78 & 4 & 0.0817 & 0.0056 & ovx & Winter & 3 & Spring \\
\hline $\mathrm{C} 78$ & 78 & 5 & 0.0712 & 0.0067 & ovx & Winter & 3 & Spring \\
\hline
\end{tabular}




\begin{tabular}{|c|c|c|c|c|c|c|c|c|}
\hline $\begin{array}{l}\text { Sheep } \\
\text { Ear } \\
\text { Tag }\end{array}$ & Plate & Specimen & $\begin{array}{l}\text { Mean } \\
\text { ETA }\end{array}$ & $\begin{array}{l}\text { SD } \\
\text { ETA }\end{array}$ & Treatment & $\begin{array}{l}\text { Season of } \\
\text { surgery }\end{array}$ & $\begin{array}{l}\text { Time } \\
\text { (months) }\end{array}$ & $\begin{array}{l}\text { Season of } \\
\text { Sacrifice }\end{array}$ \\
\hline C78 & 78 & 6 & 0.0787 & 0.0054 & ovx & Winter & 3 & Spring \\
\hline C79 & 79 & 1 & 0.0257 & 0.0052 & control & Winter & 3 & Spring \\
\hline $\mathrm{C} 79$ & 79 & 2 & 0.0213 & 0.0085 & control & Winter & 3 & Spring \\
\hline C79 & 79 & 3 & 0.0194 & 0.0043 & control & Winter & 3 & Spring \\
\hline $\mathrm{C} 79$ & 79 & 4 & 0.0272 & 0.0034 & control & Winter & 3 & Spring \\
\hline C79 & 79 & 5 & 0.0761 & 0.0047 & control & Winter & 3 & Spring \\
\hline C79 & 79 & 6 & 0.0768 & 0.0082 & control & Winter & 3 & Spring \\
\hline $\mathrm{C} 80$ & 80 & 1 & 0.0629 & 0.0079 & control & Winter & 12 & \\
\hline $\mathrm{C} 80$ & 80 & 2 & 0.0396 & 0.0043 & control & Winter & 12 & \\
\hline $\mathrm{C} 81$ & 81 & 1 & 0.0580 & 0.0119 & control & Winter & 3 & Spring \\
\hline $\mathrm{C} 81$ & 81 & 2 & 0.0663 & 0.0080 & control & Winter & 3 & Spring \\
\hline C81 & 81 & 3 & 0.0646 & 0.0078 & control & Winter & 3 & Spring \\
\hline $\mathrm{C} 81$ & 81 & 4 & 0.0637 & 0.0081 & control & Winter & 3 & Spring \\
\hline $\mathrm{C} 81$ & 81 & 5 & 0.0632 & 0.0144 & control & Winter & 3 & Spring \\
\hline $\mathrm{C} 81$ & 81 & 6 & 0.0722 & 0.0103 & control & Winter & 3 & Spring \\
\hline $\mathrm{C} 82$ & 82 & 1 & 0.1036 & 0.0089 & control & Winter & 12 & \\
\hline $\mathrm{C} 82$ & 82 & 2 & 0.0478 & 0.0048 & control & Winter & 12 & \\
\hline $\mathrm{C} 82$ & 82 & 3 & 0.0591 & 0.0085 & control & Winter & 12 & \\
\hline $\mathrm{C} 82$ & 82 & 4 & 0.0295 & 0.0125 & control & Winter & 12 & \\
\hline $\mathrm{C} 82$ & 82 & 5 & 0.0516 & 0.0076 & control & Winter & 12 & \\
\hline C82 & 82 & 6 & 0.0487 & 0.0068 & control & Winter & 12 & \\
\hline $\mathrm{C} 83$ & 83 & 1 & 0.0342 & 0.0042 & control & Winter & 12 & \\
\hline $\mathrm{C} 83$ & 83 & 2 & 0.0431 & 0.0033 & control & Winter & 12 & \\
\hline $\mathrm{C} 83$ & 83 & 3 & 0.0394 & 0.0041 & control & Winter & 12 & \\
\hline $\mathrm{C} 83$ & 83 & 4 & 0.0299 & 0.0038 & control & Winter & 12 & \\
\hline $\mathrm{C} 83$ & 83 & 5 & 0.0367 & 0.0055 & control & Winter & 12 & \\
\hline $\mathrm{C} 83$ & 83 & 6 & 0.0299 & 0.0038 & control & Winter & 12 & \\
\hline $\mathrm{C} 84$ & 84 & 1 & 0.0629 & 0.0079 & control & Winter & 12 & \\
\hline C84 & 84 & 2 & 0.0495 & 0.0059 & control & Winter & 12 & \\
\hline $\mathrm{C} 84$ & 84 & 3 & 0.0483 & 0.0060 & control & Winter & 12 & \\
\hline $\mathrm{C} 84$ & 84 & 4 & 0.0614 & 0.0087 & control & Winter & 12 & \\
\hline $\mathrm{C} 84$ & 84 & 5 & 0.0513 & 0.0089 & control & Winter & 12 & \\
\hline C84 & 84 & 6 & 0.0365 & 0.0217 & control & Winter & 12 & \\
\hline $\mathrm{C} 85$ & 85 & 1 & 0.0799 & 0.0062 & ovx & Spring & 3 & Summer \\
\hline $\mathrm{C} 85$ & 85 & 2 & 0.0607 & 0.0074 & ovx & Spring & 3 & Summer \\
\hline $\mathrm{C} 85$ & 85 & 3 & 0.0710 & 0.0078 & ovx & Spring & 3 & Summer \\
\hline $\mathrm{C} 85$ & 85 & 4 & 0.0531 & 0.0076 & ovx & Spring & 3 & Summer \\
\hline $\mathrm{C} 85$ & 85 & 5 & 0.0402 & 0.0080 & ovx & Spring & 3 & Summer \\
\hline $\mathrm{C} 85$ & 85 & 6 & 0.0577 & 0.0095 & ovx & Spring & 3 & Summer \\
\hline
\end{tabular}




\begin{tabular}{|c|c|c|c|c|c|c|c|c|}
\hline $\begin{array}{l}\text { Sheep } \\
\text { Ear } \\
\text { Tag }\end{array}$ & Plate & Specimen & $\begin{array}{l}\text { Mean } \\
\text { ETA }\end{array}$ & $\begin{array}{l}\text { SD } \\
\text { ETA }\end{array}$ & Treatment & $\begin{array}{l}\text { Season of } \\
\text { surgery }\end{array}$ & $\begin{array}{l}\text { Time } \\
\text { (months) }\end{array}$ & $\begin{array}{l}\text { Season of } \\
\text { Sacrifice }\end{array}$ \\
\hline $\mathrm{C} 86$ & 86 & 1 & 0.0923 & 0.0048 & control & Spring & 3 & Summer \\
\hline $\mathrm{C} 86$ & 86 & 2 & 0.0884 & 0.0061 & control & Spring & 3 & Summer \\
\hline $\mathrm{C} 86$ & 86 & 3 & 0.0882 & 0.0064 & control & Spring & 3 & Summer \\
\hline $\mathrm{C} 86$ & 86 & 4 & 0.0924 & 0.0069 & control & Spring & 3 & Summer \\
\hline $\mathrm{C} 86$ & 86 & 5 & 0.0792 & 0.0066 & control & Spring & 3 & Summer \\
\hline $\mathrm{C} 86$ & 86 & 6 & 0.0999 & 0.0051 & control & Spring & 3 & Summer \\
\hline $\mathrm{C} 87$ & 87 & 1 & 0.0655 & 0.0063 & ovx & Spring & 3 & Summer \\
\hline $\mathrm{C} 87$ & 87 & 2 & 0.0534 & 0.0080 & ovx & Spring & 3 & Summer \\
\hline $\mathrm{C} 87$ & 87 & 3 & 0.0603 & 0.0067 & ovx & Spring & 3 & Summer \\
\hline $\mathrm{C} 87$ & 87 & 4 & 0.0564 & 0.0064 & ovx & Spring & 3 & Summer \\
\hline $\mathrm{C} 87$ & 87 & 5 & 0.0506 & 0.0070 & ovx & Spring & 3 & Summer \\
\hline $\mathrm{C} 87$ & 87 & 6 & 0.0575 & 0.0078 & ovx & Spring & 3 & Summer \\
\hline $\mathrm{C} 88$ & 88 & 1 & 0.0728 & 0.0062 & control & Spring & 3 & Summer \\
\hline $\mathrm{C} 88$ & 88 & 2 & 0.0732 & 0.0052 & control & Spring & 3 & Summer \\
\hline $\mathrm{C} 88$ & 88 & 3 & 0.0845 & 0.0046 & control & Spring & 3 & Summer \\
\hline C88 & 88 & 4 & 0.0765 & 0.0049 & control & Spring & 3 & Summer \\
\hline $\mathrm{C} 88$ & 88 & 5 & 0.0749 & 0.0055 & control & Spring & 3 & Summer \\
\hline $\mathrm{C} 88$ & 88 & 6 & 0.0773 & 0.0063 & control & Spring & 3 & Summer \\
\hline C89 & 89 & 1 & 0.0652 & & ovx & Spring & 12 & \\
\hline $\mathrm{C} 89$ & 89 & 2 & 0.0499 & & ovx & Spring & 12 & \\
\hline C89 & 89 & 3 & 0.0637 & & ovx & Spring & 12 & \\
\hline C89 & 89 & 4 & 0.0574 & & ovx & Spring & 12 & \\
\hline C89 & 89 & 5 & 0.0712 & & ovx & Spring & 12 & \\
\hline C89 & 89 & 6 & 0.0505 & & ovx & Spring & 12 & \\
\hline C90 & 90 & 1 & 0.0787 & 0.0023 & ovx & Spring & 3 & Summer \\
\hline $\mathrm{C} 90$ & 90 & 2 & 0.0675 & 0.0055 & ovx & Spring & 3 & Summer \\
\hline $\mathrm{C} 90$ & 90 & 3 & 0.0641 & 0.0058 & ovx & Spring & 3 & Summer \\
\hline $\mathrm{C} 90$ & 90 & 4 & 0.0721 & 0.0064 & ovx & Spring & 3 & Summer \\
\hline C90 & 90 & 5 & 0.0674 & 0.0051 & ovx & Spring & 3 & Summer \\
\hline $\mathrm{C} 90$ & 90 & 6 & 0.0645 & 0.0054 & ovx & Spring & 3 & Summer \\
\hline $\mathrm{C} 92$ & 92 & 1 & 0.0880 & 0.0067 & control & Spring & 3 & Summer \\
\hline $\mathrm{C} 92$ & 92 & 2 & 0.0883 & 0.0056 & control & Spring & 3 & Summer \\
\hline C92 & 92 & 3 & 0.0741 & 0.0159 & control & Spring & 3 & Summer \\
\hline C92 & 92 & 4 & 0.0731 & 0.0062 & control & Spring & 3 & Summer \\
\hline C92 & 92 & 5 & 0.0731 & 0.0062 & control & Spring & 3 & Summer \\
\hline C92 & 92 & 5 & 0.0624 & 0.0108 & control & Spring & 3 & Summer \\
\hline C92 & 92 & 6 & 0.0708 & 0.0077 & control & Spring & 3 & Summer \\
\hline C93 & 93 & 1 & 0.0783 & 0.0039 & ovx & Spring & 3 & Summer \\
\hline $\mathrm{C} 93$ & 93 & 2 & 0.0868 & 0.0068 & ovx & Spring & 3 & Summer \\
\hline
\end{tabular}




\begin{tabular}{|c|c|c|c|c|c|c|c|c|}
\hline $\begin{array}{l}\text { Sheep } \\
\text { Ear } \\
\text { Tag }\end{array}$ & Plate & Specimen & $\begin{array}{l}\text { Mean } \\
\text { ETA }\end{array}$ & $\begin{array}{l}\text { SD } \\
\text { ETA }\end{array}$ & Treatment & $\begin{array}{l}\text { Season of } \\
\text { surgery }\end{array}$ & $\begin{array}{l}\text { Time } \\
\text { (months) }\end{array}$ & $\begin{array}{l}\text { Season of } \\
\text { Sacrifice }\end{array}$ \\
\hline $\mathrm{C} 93$ & 93 & 3 & 0.0849 & 0.0060 & ovx & Spring & 3 & Summer \\
\hline $\mathrm{C} 93$ & 93 & 4 & 0.0754 & 0.0059 & ovx & Spring & 3 & Summer \\
\hline $\mathrm{C} 93$ & 93 & 5 & 0.0601 & 0.0069 & ovx & Spring & 3 & Summer \\
\hline $\mathrm{C} 93$ & 93 & 6 & 0.0736 & 0.0074 & ovx & Spring & 3 & Summer \\
\hline C94 & 94 & 1 & 0.0874 & 0.0063 & control & Spring & 3 & Summer \\
\hline C94 & 94 & 2 & 0.0738 & 0.0061 & control & Spring & 3 & Summer \\
\hline C94 & 94 & 3 & 0.0826 & 0.0068 & control & Spring & 3 & Summer \\
\hline C94 & 94 & 4 & 0.0866 & 0.0071 & control & Spring & 3 & Summer \\
\hline C94 & 94 & 5 & 0.0845 & 0.0079 & control & Spring & 3 & Summer \\
\hline C94 & 94 & 6 & 0.0985 & 0.0067 & control & Spring & 3 & Summer \\
\hline $\mathrm{C} 95$ & 95 & 1 & 0.0778 & 0.0041 & control & Spring & 3 & Summer \\
\hline C95 & 95 & 2 & 0.0683 & 0.0055 & control & Spring & 3 & Summer \\
\hline $\mathrm{C} 95$ & 95 & 3 & 0.0667 & 0.0059 & control & Spring & 3 & Summer \\
\hline $\mathrm{C} 95$ & 95 & 4 & 0.0720 & 0.0044 & control & Spring & 3 & Summer \\
\hline $\mathrm{C} 95$ & 95 & 5 & 0.0693 & 0.0054 & control & Spring & 3 & Summer \\
\hline C95 & 95 & 6 & 0.0636 & 0.0062 & control & Spring & 3 & Summer \\
\hline C96 & 96 & 1 & 0.0517 & 0.0072 & control & Spring & 12 & \\
\hline C96 & 96 & 2 & 0.0580 & 0.0051 & control & Spring & 12 & \\
\hline C96 & 96 & 3 & 0.0572 & 0.0069 & control & Spring & 12 & \\
\hline C96 & 96 & 4 & 0.0578 & 0.0043 & control & Spring & 12 & \\
\hline C96 & 96 & 5 & 0.0387 & 0.0067 & control & Spring & 12 & \\
\hline C96 & 96 & 6 & 0.0496 & 0.0035 & control & Spring & 12 & \\
\hline C97 & 97 & 1 & 0.0744 & 0.0076 & control & Spring & 12 & \\
\hline C97 & 97 & 2 & 0.0637 & 0.0083 & control & Spring & 12 & \\
\hline C97 & 97 & 3 & 0.0602 & 0.0106 & control & Spring & 12 & \\
\hline $\mathrm{C} 97$ & 97 & 4 & 0.0577 & 0.0086 & control & Spring & 12 & \\
\hline $\mathrm{C} 97$ & 97 & 5 & 0.0554 & 0.0078 & control & Spring & 12 & \\
\hline C97 & 97 & 6 & 0.0545 & 0.0078 & control & Spring & 12 & \\
\hline C98 & 98 & 1 & 0.0656 & & ovx & Spring & 12 & \\
\hline C98 & 98 & 2 & 0.0407 & & ovx & Spring & 12 & \\
\hline C98 & 98 & 4 & 0.0555 & & ovx & Spring & 12 & \\
\hline $\mathrm{C} 98$ & 98 & 5 & 0.0415 & & ovx & Spring & 12 & \\
\hline C98 & 98 & 6 & 0.0511 & & ovx & Spring & 12 & \\
\hline C99 & 99 & 1 & 0.0324 & 0.0074 & control & Spring & 12 & \\
\hline C99 & 99 & 2 & 0.0293 & 0.0065 & control & Spring & 12 & \\
\hline C99 & 99 & 3 & 0.0458 & 0.0106 & control & Spring & 12 & \\
\hline C99 & 99 & 4 & 0.0513 & 0.0092 & control & Spring & 12 & \\
\hline C99 & 99 & 5 & 0.0406 & 0.0080 & control & Spring & 12 & \\
\hline C99 & 99 & 6 & 0.0538 & 0.0082 & control & Spring & 12 & \\
\hline
\end{tabular}




\begin{tabular}{|c|c|c|c|c|c|c|c|c|}
\hline $\begin{array}{l}\text { Sheep } \\
\text { Ear } \\
\text { Tag }\end{array}$ & Plate & Specimen & $\begin{array}{l}\text { Mean } \\
\text { ETA }\end{array}$ & $\begin{array}{l}\text { SD } \\
\text { ETA }\end{array}$ & Treatment & $\begin{array}{l}\text { Season of } \\
\text { surgery }\end{array}$ & $\begin{array}{l}\text { Time } \\
\text { (months) }\end{array}$ & $\begin{array}{l}\text { Season of } \\
\text { Sacrifice }\end{array}$ \\
\hline C100 & 100 & 1 & 0.0646 & 0.0138 & control & Spring & 3 & Summer \\
\hline $\mathrm{C} 100$ & 100 & 3 & 0.0748 & 0.0105 & control & Spring & 3 & Summer \\
\hline $\mathrm{C} 100$ & 100 & 4 & 0.0767 & 0.0084 & control & Spring & 3 & Summer \\
\hline $\mathrm{C} 100$ & 100 & 5 & 0.0741 & 0.0056 & control & Spring & 3 & Summer \\
\hline $\mathrm{C} 100$ & 100 & 5 & 0.0519 & 0.0086 & control & Spring & 3 & Summer \\
\hline $\mathrm{C} 100$ & 100 & 6 & 0.0807 & 0.0056 & control & Spring & 3 & Summer \\
\hline C101 & 101 & 1 & 0.0682 & & ovx & Spring & 12 & \\
\hline C101 & 101 & 2 & 0.0639 & & ovx & Spring & 12 & \\
\hline C101 & 101 & 3 & 0.0644 & & ovx & Spring & 12 & \\
\hline C101 & 101 & 4 & 0.0781 & & ovx & Spring & 12 & \\
\hline $\mathrm{C} 101$ & 101 & 5 & 0.0577 & & ovx & Spring & 12 & \\
\hline C101 & 101 & 6 & 0.0582 & & ovx & Spring & 12 & \\
\hline $\mathrm{C} 102$ & 102 & 1 & 0.0585 & & ovx & Spring & 12 & \\
\hline $\mathrm{C} 102$ & 102 & 2 & 0.0600 & & ovx & Spring & 12 & \\
\hline $\mathrm{C} 102$ & 102 & 3 & 0.0798 & & ovx & Spring & 12 & \\
\hline $\mathrm{C} 102$ & 102 & 4 & 0.0677 & & ovx & Spring & 12 & \\
\hline $\mathrm{C} 102$ & 102 & 5 & 0.0663 & & ovx & Spring & 12 & \\
\hline $\mathrm{C} 102$ & 102 & 6 & 0.0725 & & ovx & Spring & 12 & \\
\hline $\mathrm{C} 103$ & 103 & 1 & 0.0448 & 0.0098 & control & Spring & 12 & \\
\hline $\mathrm{C} 103$ & 103 & 2 & 0.0415 & 0.0092 & control & Spring & 12 & \\
\hline $\mathrm{C} 103$ & 103 & 3 & 0.0514 & 0.0054 & control & Spring & 12 & \\
\hline C103 & 103 & 4 & 0.0491 & 0.0057 & control & Spring & 12 & \\
\hline $\mathrm{C} 103$ & 103 & 5 & 0.0152 & 0.0066 & control & Spring & 12 & \\
\hline $\mathrm{C} 103$ & 103 & 6 & 0.0515 & 0.0066 & control & Spring & 12 & \\
\hline C104 & 104 & 1 & 0.0640 & & ovx & Spring & 12 & \\
\hline C104 & 104 & 2 & 0.0665 & & ovx & Spring & 12 & \\
\hline C104 & 104 & 3 & 0.0765 & & ovx & Spring & 12 & \\
\hline C104 & 104 & 4 & 0.0865 & & ovx & Spring & 12 & \\
\hline C104 & 104 & 5 & 0.0679 & & ovx & Spring & 12 & \\
\hline C104 & 104 & 6 & 0.0738 & & ovx & Spring & 12 & \\
\hline $\mathrm{C} 105$ & 105 & 1 & 0.0648 & 0.0083 & ovx & Spring & 3 & Summer \\
\hline C105 & 105 & 2 & 0.0609 & 0.0059 & ovx & Spring & 3 & Summer \\
\hline $\mathrm{C} 105$ & 105 & 3 & 0.0586 & 0.0070 & ovx & Spring & 3 & Summer \\
\hline $\mathrm{C} 105$ & 105 & 4 & 0.0490 & 0.0122 & ovx & Spring & 3 & Summer \\
\hline C105 & 105 & 5 & 0.0519 & 0.0086 & ovx & Spring & 3 & Summer \\
\hline $\mathrm{C} 105$ & 105 & 6 & 0.0588 & 0.0053 & ovx & Spring & 3 & Summer \\
\hline C106 & 106 & 1 & 0.1018 & 0.0056 & control & Spring & 3 & Summer \\
\hline C106 & 106 & 2 & 0.1055 & 0.0061 & control & Spring & 3 & Summer \\
\hline C106 & 106 & 3 & 0.1007 & 0.0045 & control & Spring & 3 & Summer \\
\hline
\end{tabular}




\begin{tabular}{|c|c|c|c|c|c|c|c|c|}
\hline $\begin{array}{l}\text { Sheep } \\
\text { Ear } \\
\text { Tag } \\
\end{array}$ & Plate & Specimen & $\begin{array}{l}\text { Mean } \\
\text { ETA }\end{array}$ & $\begin{array}{l}\text { SD } \\
\text { ETA }\end{array}$ & Treatment & $\begin{array}{l}\text { Season of } \\
\text { surgery }\end{array}$ & $\begin{array}{l}\text { Time } \\
\text { (months) }\end{array}$ & $\begin{array}{l}\text { Season of } \\
\text { Sacrifice }\end{array}$ \\
\hline $\mathrm{C} 106$ & 106 & 4 & 0.1029 & 0.0092 & control & Spring & 3 & Summer \\
\hline C106 & 106 & 5 & 0.0985 & 0.0067 & control & Spring & 3 & Summer \\
\hline $\mathrm{C} 106$ & 106 & 6 & 0.0889 & 0.0075 & control & Spring & 3 & Summer \\
\hline C107 & 107 & 1 & 0.0847 & 0.0129 & ovx & Spring & 3 & Summer \\
\hline $\mathrm{C} 107$ & 107 & 2 & 0.0708 & 0.0084 & ovx & Spring & 3 & Summer \\
\hline C107 & 107 & 3 & 0.0605 & 0.0100 & ovx & Spring & 3 & Summer \\
\hline $\mathrm{C} 107$ & 107 & 4 & 0.0663 & 0.0079 & ovx & Spring & 3 & Summer \\
\hline C107 & 107 & 5 & 0.0601 & 0.0069 & ovx & Spring & 3 & Summer \\
\hline C107 & 107 & 6 & 0.0553 & 0.0093 & ovx & Spring & 3 & Summer \\
\hline $\mathrm{C} 108$ & 108 & 1 & 0.0505 & 0.0032 & control & Spring & 12 & \\
\hline $\mathrm{C} 108$ & 108 & 2 & 0.0664 & 0.0033 & control & Spring & 12 & \\
\hline C108 & 108 & 3 & 0.0437 & 0.0120 & control & Spring & 12 & \\
\hline $\mathrm{C} 108$ & 108 & 4 & 0.0449 & 0.0135 & control & Spring & 12 & \\
\hline $\mathrm{C} 108$ & 108 & 5 & 0.0505 & 0.0109 & control & Spring & 12 & \\
\hline $\mathrm{C} 108$ & 108 & 6 & 0.0552 & 0.0041 & control & Spring & 12 & \\
\hline C109 & 109 & 1 & 0.0642 & 0.0107 & control & Spring & 12 & \\
\hline C109 & 109 & 2 & 0.0572 & 0.0125 & control & Spring & 12 & \\
\hline C109 & 109 & 3 & 0.0445 & 0.0101 & control & Spring & 12 & \\
\hline C109 & 109 & 4 & 0.0439 & 0.0073 & control & Spring & 12 & \\
\hline C109 & 109 & 5 & 0.0406 & 0.0104 & control & Spring & 12 & \\
\hline C109 & 109 & 6 & 0.0446 & 0.0150 & control & Spring & 12 & \\
\hline C110 & 110 & 1 & 0.0822 & 0.0060 & ovx & Spring & 3 & Summer \\
\hline C110 & 110 & 2 & 0.0798 & 0.0052 & ovx & Spring & 3 & Summer \\
\hline C110 & 110 & 3 & 0.0789 & 0.0083 & ovx & Spring & 3 & Summer \\
\hline C110 & 110 & 4 & 0.0732 & 0.0096 & ovx & Spring & 3 & Summer \\
\hline C110 & 110 & 5 & 0.0624 & 0.0108 & ovx & Spring & 3 & Summer \\
\hline $\mathrm{C} 110$ & 110 & 6 & 0.0687 & 0.0058 & ovx & Spring & 3 & Summer \\
\hline C111 & 111 & 1 & 0.0752 & & ovx & Spring & 12 & \\
\hline C111 & 111 & 2 & 0.0504 & & ovx & Spring & 12 & \\
\hline C111 & 111 & 3 & 0.0547 & & ovx & Spring & 12 & \\
\hline C111 & 111 & 4 & 0.0762 & & ovx & Spring & 12 & \\
\hline C111 & 111 & 5 & 0.0623 & & ovx & Spring & 12 & \\
\hline C111 & 111 & 6 & 0.0587 & & ovx & Spring & 12 & \\
\hline C112 & 112 & 1 & 0.0808 & & ovx & Spring & 12 & \\
\hline C112 & 112 & 2 & 0.0750 & & ovx & Spring & 12 & \\
\hline C112 & 112 & 3 & 0.0777 & & ovx & Spring & 12 & \\
\hline C112 & 112 & 4 & 0.0775 & & ovx & Spring & 12 & \\
\hline C112 & 112 & 5 & 0.0776 & & ovx & Spring & 12 & \\
\hline C112 & 112 & 6 & 0.0846 & & ovx & Spring & 12 & \\
\hline
\end{tabular}


